\title{
"Ni un español sin pan" \\ La Red Nacional de Silos y Graneros
}

\section{Carlos Barciela}

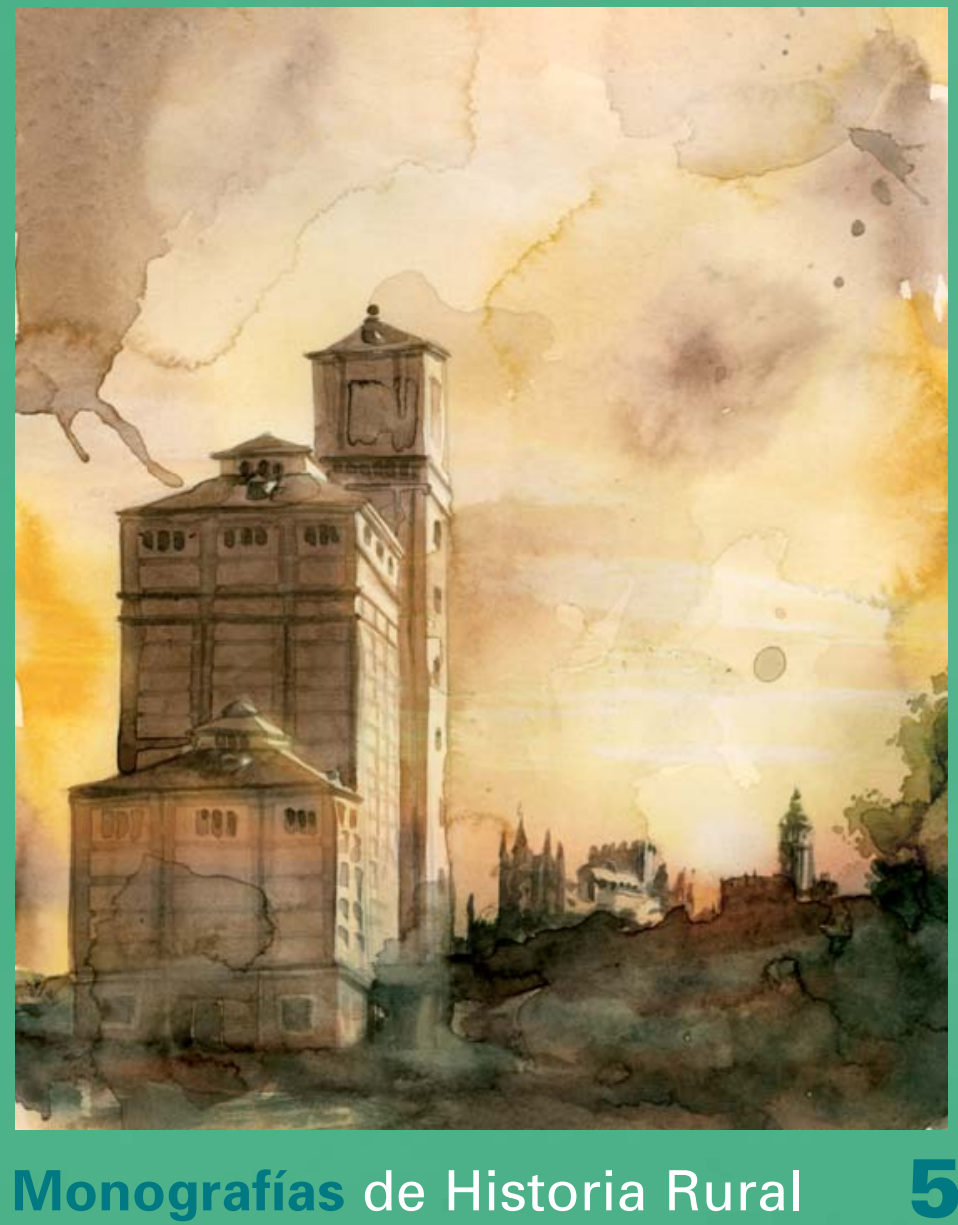

5 E H A

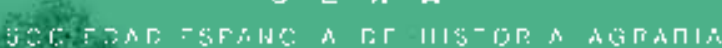

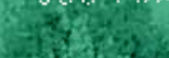



«NI UN ESPAÑOL SIN PAN»

La Red Nacional de Silos y Graneros 



\section{"NI UN ESPAÑOL SIN PAN» La Red Nacional de Silos y Graneros}

Carlos Barciela

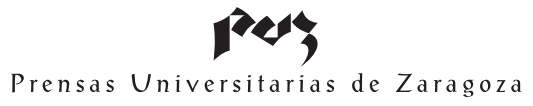




\section{FICHA CATALOGRÁFICA}

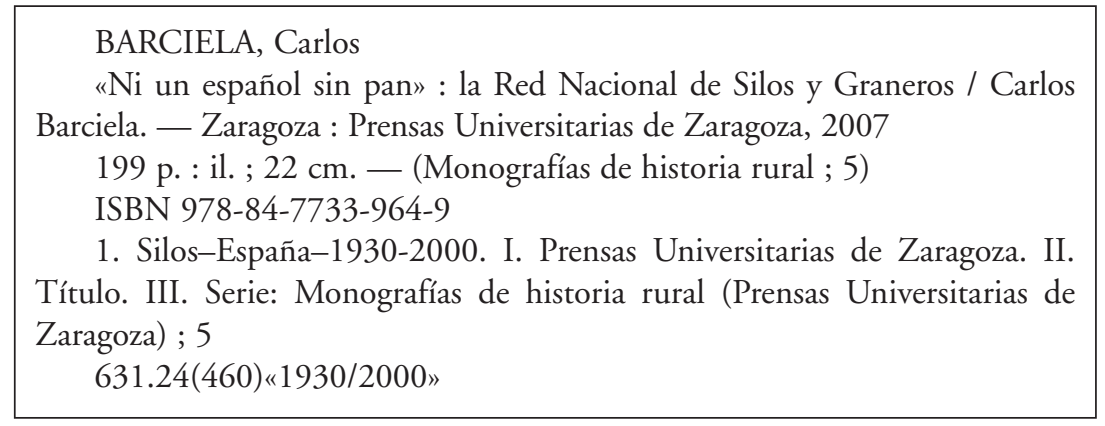

No está permitida la reproducción total o parcial de este libro, ni su tratamiento informático, ni la transmisión de ninguna forma o por cualquier medio, ya sea electrónico, mecánico, por fotocopia, por registro u otros métodos, ni su préstamo, alquiler o cualquier forma de cesión de uso del ejemplar, sin el permiso previo y por escrito de los titulares del Copyright.

(C) Carlos Barciela

(C) De la presente edición, Prensas Universitarias de Zaragoza

$1 .^{a}$ edición, 2007

Colección: Monografías de Historia Rural, n. ${ }^{\circ} 5$

Seminario de Historia Agraria (SEHA)

Diseño de la cubierta: David Guirao

Prensas Universitarias de Zaragoza. Edificio de Ciencias Geológicas, c/ Pedro Cerbuna, 12. 50009 Zaragoza, España. Tel.: 976761 330. Fax: 976761063

puz@unizar.es http://puz.unizar.es

Prensas Universitarias de Zaragoza es la editorial de la Universidad de Zaragoza, que edita e imprime libros desde su fundación en 1542.

Impreso en España

Imprime: INO Reproducciones, S. A.

D.L.: Z-3960-2007 


\section{PRÓLOGO}

En la fase final de redacción del presente trabajo tuve la oportunidad de poder presentarlo en tres seminarios de investigación celebrados en los departamentos de Historia Económica de las universidades de Murcia, Zaragoza y Pablo de Olavide. En todos los casos, la acogida fue muy positiva -espero que no solo por la amistad que me une a todos los colegas de estos centros-y dio origen a debates y preguntas de gran utilidad para mí. En general, he intentado incorporar al texto todas las sugerencias que se me han hecho. Así, por ejemplo, he añadido, a raíz del interés mostrado por los compañeros de Zaragoza por los silos aragoneses, un apéndice con la relación nominal por provincias de todas las instalaciones que configuraron la Red Nacional.

Sin embargo, y no puedo dejar de lamentarlo, he optado por no incluir algunas de las muy interesantes cuestiones que se me plantearon. María Teresa Pérez Picazo me indicó la conveniencia de aportar información relativa a la actividad crediticia llevada a cabo por el organismo regulador triguero. En Zaragoza, Eloy Fernández Clemente y otros compañeros, me animaron a que añadiese un análisis de las pautas y evolución del consumo de pan, y, en Sevilla, Antonio Miguel Bernal destacó la conveniencia de considerar algunos elementos fundamentales del sistema de comercialización cerealista, estrechamente relacionados con el problema del almacenamiento.

No me cabe ninguna duda de que todas estas sugerencias son del máximo interés y su inclusión hubiera enriquecido notablemente el trabajo. Por lo demás, y cosa nada extraña dada mi dedicación durante décadas a los problemas de la agricultura española contemporánea, dispongo de una abundante y completa información sobre todas ellas. La decisión, 
no sé si acertada o no —el lector lo juzgará-, de dejar el trabajo como lo presento responde a la idea, más concreta, con la que abordé esta investigación: proporcionar una historia de la Red de Silos. Entrar en el análisis del consumo, del crédito o de los sistemas de comercialización hubiera mejorado el resultado, hubiera dado una explicación más completa y coherente de los factores que impulsaron la construcción de la Red, pero me habría conducido a un trabajo diferente, mucho más amplio, pero en el que mi objetivo central habría quedado más desdibujado. Si el tiempo me lo permite, abordaré estas cuestiones en futuros trabajos.

Alfredo Ramón, profesor de Geografía de la Universidad de Alicante y buen amigo, me ha prestado su generosa ayuda con la realización de los mapas. Al Ministerio de Agricultura, y particularmente a Juan Manuel García Bartolomé, debo agradecerles las facilidades concedidas para poder incluir en el libro las interesantísimas fotos de los diversos silos, graneros e instalaciones.

Entre la versión inicial que envié a la SEHA para que consideraran la oportunidad de su publicación y el texto que finalmente se publica hay diferencias muy notables. Debo agradecer muy sinceramente a los dos evaluadores la atención con la que leyeron mi texto y las numerosas y acertadas sugerencias que me hicieron.

Aunque el libro se publique en este momento, mi interés por la construcción de la Red de Silos data de bastantes años atrás. En aquellos primeros momentos fue Pedro Tedde de Lorca quien me animó a escribir una historia completa de la Red desde sus orígenes hasta la actualidad. Seguramente sin su amistosa persuasión nunca me habría animado a concluir este trabajo. 


\section{La Red Nacional de Silos y Graneros $(1930-2000)^{1}$}

Silos. Silos.

El problema cerealista de España reside aquí. Sobre todo en su aspecto comercial. Esa angustia de la anarquía en el precio, siempre en baja cuando la cosecha llega, únicamente se dominará cuando el proceso comercial del trigo se racionalice.

Silos. Silos.

Y con ellos el crédito. Sin ellos es difícil que pueda hacerse nada práctico. Sin ellos no es posible hacer nada en ese camino de perfección económica hacia el que deseamos caminar, elevando a la vez la moral de nuestros campesinos.

Silos. Silos.

Es inútil que queramos soslayarlos. Vendrán. Este año, el que viene. Pero vendrán. El problema triguero estriba aquí. Primero almacenar, después pignorar. Luego la cadena del precio sujetará todos sus eslabones ${ }^{2}$.

\section{INTRODUCCIÓN}

Una de las realizaciones más espectaculares del Servicio Nacional del Trigo (SNT), y de sus sucesores el Servicio Nacional de Cereales (SNC) y el Servicio Nacional de Productos Agrarios (SENPA), por su

1 Esta investigación se ha beneficiado de la ayuda del Ministerio de Educación y Ciencia SEJ 2004-08224/ECON.

2 Citado por García González y Sánchez-Altomuro Vera (1962: 402). Los autores no indican ni el autor del texto ni la fecha en que fue escrito. Por su contenido es muy probable que sea del periodo 1932-1934. 
dimensión, por los recursos empleados, por sus repercusiones en el sector e, incluso, por su impacto visual en el paisaje español, fue la denominada Red Nacional de Silos y Graneros ${ }^{3}$.

Entre 1945 y 1984 se levantaron por todas las regiones españolas cientos de silos y almacenes de diverso tamaño y funcionalidad, que transformaron las prácticas comercializadoras de los agricultores y la propia imagen de muchas localidades. La torre del silo pasó a perfilar la silueta de los pueblos, con la de las iglesias y los castillos y, aún más, las grandes construcciones, los denominados «macrosilos», rivalizaron en dimensiones, aunque no en estética, lamentablemente, con las antiguas catedrales. En Castilla la Vieja se rehabilitaron y acondicionaron para servir como graneros algunos castillos, como los de Arévalo, Torrelobatón, Montealegre y Encinas de Esgueva, en una fusión cargada de intencionalidad y simbolismo. Los dos primeros los compró el SNT «precisamente en el año del quinto centenario de los Reyes Católicos». Los dirigentes del Servicio recordaban con satisfacción que el castillo de Arévalo había sido residencia de Isabel I y que el de Torrelobatón había pertenecido a los Enríquez, Almirantes de Castilla ${ }^{4}$.

El propósito de este trabajo es explicar el origen, el desarrollo, el declive y el desmantelamiento de la Red Nacional de Silos, uno de los proyectos más emblemáticos del franquismo, así como proporcionar una serie de datos básicos sobre los costes que este proyecto tuvo para nuestro país.

La necesidad de contar con almacenes que permitiesen conservar el grano para su administración hasta la próxima cosecha y, en la medida de lo posible, para formar reservas y conservarlas en las mejores condiciones posibles para afrontar los años malos, fue sentida muy pronto por las sociedades agrarias.

En nuestro país, y ya en épocas más recientes, los Pósitos intentaron desarrollar, con desigual fortuna, una labor de creación de reservas y de crédito agrícola ${ }^{5}$. Fue, sin embargo, durante el primer tercio del siglo xx

3 En 1968 se creó, a partir del SNT, el Servicio Nacional de Cereales que, a su vez, fue transformado en 1971 en el SENPA. En lo que concierne a este trabajo, hay que señalar que los tres organismos citados asumieron sucesivamente las competencias relativas a la Red Nacional de Silos.

4 SNT (1958: 233).

5 Sobre la labor de los Pósitos puede consultarse Anes (1968) y, más recientemente, Martínez Soto (en proceso de publicación). 
cuando se planteó con especial intensidad lo que dio en llamarse el «problema triguero". La Primera Guerra Mundial, con sus importantes repercusiones inflacionistas, provocó la intervención del Estado en el sector y el desarrollo de una serie de iniciativas, como las leyes de subsistencias, la creación de la Comisaría de Abastecimientos y Transportes (CAT), la aplicación de sistemas de precios de tasa o la creación obligatoria de depósitos, con el objetivo de regular los mercados y estabilizar los precios y las rentas $^{6}$.

En 1932, como es bien conocido, se produjo, dentro de una tendencia creciente, una excelente cosecha de trigo, la mejor de toda la historia de nuestro país hasta ese momento, que provocó una situación de sobreoferta, un grave efecto depresivo sobre los precios y una delicada situación económica para la mayor parte de los pequeños productores trigueros, con espectaculares repercusiones políticas ${ }^{7}$.

El problema triguero se convirtió en un instrumento más, por parte de la derecha y de la extrema derecha de carácter fascista, para combatir a la República y a sus proyectos de reforma. Los gobernantes, en un contexto económico internacional muy desfavorable y con una hacienda en no muy brillante situación, tuvieron que hacer frente a un nuevo problema para el que se carecía de experiencia histórica y de medios materiales.

Las iniciativas para la solución del problema se multiplicaron y a las medidas gubernamentales se fueron sumando propuestas realizadas por partidos políticos, empresas privadas, economistas y agraristas. La mayor parte de ellas intentaban proporcionar soluciones que abordaban distintos

6 Sobre el contenido y alcance de las medidas adoptadas, Barciela (1981a). En 1948, la FAO publicó un libro titulado Politiques relatives aux réserves nacionales de produits alimentaires dans les pays sous-developpés, en el que se analizan las funciones reguladoras de las instalaciones de almacenaje.

7 Muchos economistas agrarios han destacado los efectos perjudiciales para los agricultores que se derivan de la existencia de estructuras monopsónicas en los mercados agrarios y que parte de su solución radica en ampliar las instalaciones de almacenamiento a disposición de los agricultores. Al respecto el gran economista agrario italiano Arrigo Serpieri señalaba: «Questi ammassi, costituiti generalmente presso gli acquirenti (commercianti, industriali) —non presso gli agricoltori che, per mancanza di mezzi tecnici di ammasso o per urgenza finanziaria, sono costretti a vendere a raccolta (e talora prima)-, pongono facilmente gli acquirenti in condizione de imporre prezzi anormalmente bassi». Serpieri (1946: 439). 
aspectos del problema y, las más elaboradas, llegaron a proponer una total regulación del mercado triguero. En otros trabajos me he ocupado de estos proyectos y en el presente me centraré exclusivamente en las propuestas cuyo eje central se situaba en resolver la cuestión crucial de los almacenamientos ${ }^{8}$.

La primera reacción al respecto fue el Decreto de 15 de septiembre de 1932 que anunciaba la futura creación, aunque sin plazo, de los primeros silos cooperativos oficiales. Este sistema de silos permitiría conocer en todo momento las existencias de trigo, ordenando su gradual salida al mercado. De manera más inmediata se disponía la obligación, por parte de los fabricantes de harina, de mantener un stock de trigo equivalente a su capacidad molturadora de sesenta días.

En 1933, Rafael del Caño, a la sazón secretario general del Instituto de Reforma Agraria, publicaba un libro en el que abordaba de manera general el problema triguero reconociendo «la necesidad de arbitrar [...] un aparato técnico, burocrático, comprador y conservador», así como la de contar con «una serie de grandes almacenes, silos o paneras reguladoras», aunque advertía de que el Estado «no podía crearlas o construirlas de manera súbita» 9 .

En febrero de 1934, el gobernador del Banco de España elevaba al Gobierno de la nación un «Informe sobre la importación y comercio de trigo, en su relación con la producción nacional», en el que proponía que

el Servicio de Crédito Agrícola [...] estableciese una red de silos debidamente equipados en los centros de comunicación de las regiones productoras hasta completar la capacidad bastante para toda la cosecha nacional. En esos silos se recibiría para su almacenamiento gratuito la producción obtenida por los cultivadores $^{10}$.

8 Las propuestas de regulación del mercado triguero durante la II República pueden verse en Barciela (1981a).

9 Del Caño (1933: 79). Este autor se mostraba partidario de fomentar un sistema de préstamos con garantía prendaria, pero sin desplazamiento de la prenda, como ya hacía el Servicio Nacional de Crédito Agrícola, de manera que «el Estado no tendría necesidad de crear y montar todo un aparato técnico-burocrático, edificar o adquirir múltiples almacenes, cosas ambas costosas y difíciles, por no decir que imposibles de improvisar» (ib.: 80).

10 Citado por Larraz (1935: 83). También de 1934 era el proyecto de Manuel de Torres relativo a la creación de mercados reguladores de trigo. 
Cuando todavía estaban sin resolver los problemas originados por la gran cosecha de 1932, la de 1934 volvió a ser excepcional. A finales de dicho año, la minoría agraria presentó en el Congreso una proposición de ley sobre depósitos reguladores del comercio de trigo que obligaría al Gobierno, caso de ser aprobada, a comprar forzosamente grano a precio de tasa. Para ello se preveía que el Estado dispusiera de una red de almacenes o depósitos en los que poder retener el trigo hasta el momento de su venta a los fabricantes de harina. La construcción de esta red se financiaría mediante la emisión de deuda pública, que se amortizaría con los ingresos procedentes de un canon del $5 \%$ sobre las ventas de trigo ${ }^{11}$.

En marzo de 1935, Antonio Rodríguez Pérez, diputado en el Congreso por el Partido Nacional Republicano, pronunciaba una conferencia con el título «El problema del trigo», en la que exponía un detallado plan para una ordenación total del mercado. La piedra maestra del sistema, en opinión del diputado, no podía ser más que una política de silos. El Estado, o un organismo dependiente, establecería silos en las comarcas de producción triguera. Cada silo sería el único comprador y vendedor de trigo de su respectiva zona y tendría que estar equipado con todo tipo de instalaciones auxiliares para proceder a la limpieza, pesaje, análisis de pesos específicos y calidad del gluten, así como de un aparato administrativo para el control de las entregas. La financiación de la red se haría con cargo a un canon sobre las compraventas de trigo y a los beneficios del monopolio de las importaciones. Rodríguez Pérez rechazaba con clarividencia, en unos momentos en los que predominaban en todo el mundo las tendencias intervencionistas en la economía, la idea de que la red fuese estatal: "Yo no creo que deba serlo el mismo Estado; las organizaciones meramente estatales degeneran con facilidad en nidos de burocracia». Lo mejor, en su opinión, era crear una compañía semiestatal parecida a CAMPSA o a la Compañía Arrendataria de Tabacos ${ }^{12}$.

Poco después, el 23 de julio de 1935, se presentaba en el Congreso un nuevo proyecto de ley para la creación de un «Consorcio Regulador del Mercado Triguero", que preveía, igualmente, la existencia de una red de depósitos ${ }^{13}$.

\footnotetext{
11 Larraz (1935: 71) y Montojo (1945: 42).

12 Rodríguez Pérez (1935: 29).

13 Montojo (1945: 44).
} 
Mención especial merece, por ser una iniciativa de carácter privado, el proyecto de la Sociedad Silos Españoles, tras el que estaba la poderosa casa Bühler, que pretendía obtener una concesión administrativa para la organización, desarrollo y explotación de un servicio de silos reguladores. La propuesta implicaba una concesión otorgada a título precario y el Estado aprobaría anualmente las tarifas correspondientes. Se trataba, en mi opinión, de una propuesta original, fácilmente aplicable, sin costes para el Estado, aunque poco acorde con el espíritu intervencionista y estatalista de la época ${ }^{14}$.

En 1935, José Larraz publicaba su libro El ordenamiento del mercado triguero en España, obra fundamental en la materia, en el que proponía la creación de una Corporación Nacional Triguera y una Compañía Concesionaria de la Administración de la Corporación del Trigo. En este proyecto, Larraz defendía, como parte sustancial de este, «la creación de una red de silos y almacenes o paneras en el territorio nacional» ${ }^{15}$.

Curiosamente, el triunfo electoral del Frente Popular no supuso una modificación de los planteamientos dominantes sobre la «necesidad» de crear una red de silos. El Decreto de 8 de abril de 1936 ordenaba la libertad de contratación del trigo (ante las malas perspectivas de la inminente cosecha) y anunciaba la organización de una red nacional de silos y paneras mecanizados para almacenar el grano ${ }^{16}$.

En la misma línea de defensa de la creación de una red de silos, se manifestaron, obviamente, las minoritarias y extremistas organizaciones representativas del fascismo agrario castellano. El I Consejo Nacional de Falange Española de las JONS, celebrado en noviembre de 1935, emitía un dictamen sobre el problema triguero en el que se señalaba: «se impone la necesidad de la sindicación de los agricultores y la implantación en España de grandes silos que regulen el mercado, como, por ejemplo, el Canadá y hoy en la Argentina» ${ }^{17 .}$

\footnotetext{
14 Larraz (1935: 64-65).

15 Larraz (1935: 45).

16 Montojo (1945: 45).

17 Citado en el II Consejo Sindical (1941: 335-336). No deja de ser sorprendente que los países citados como ejemplo fuesen dos grandes naciones exportadoras que nada tenían en común con los problemas del mercado triguero español.
} 
En enero de 1936, el dirigente falangista Ruiz de Alda reclamaba, en un discurso en el Teatro Calderón de Madrid, la construcción de una red de silos $^{18}$. El propio Onésimo Redondo, uno de los líderes más destacados del fascismo agrario castellano, candidato en las elecciones de febrero de 1936, presentó en su programa electoral un plan triguero en el que defendía la «inmediata construcción de silos y almacenes para llegar al comprador único» ${ }^{19}$.

En marzo de 1936, Rafael Cavestany, Antonio Bartual y Miguel Cavero redactaban un proyecto titulado: "Organización del mercado triguero nacional y creación de la Red Nacional de Silos", en el que insistían en la necesidad de crear dicha Red como instrumento indispensable para una política eficaz en la resolución del problema triguero ${ }^{20}$.

En el mes de julio de 1936, Dionisio Martín Sanz, ingeniero agrónomo, falangista y gran propietario triguero vallisoletano, publicaba un artículo en la revista Economía y Técnica Agrícola titulado «Bases para el emplazamiento de una Red Nacional de Silos para el trigo", en el que anticipaba algunas de las líneas básicas que inspiraron, poco después, la actuación del Servicio Nacional del Trigo ${ }^{21}$. Concretamente, Martín Sanz propugnaba la construcción de una Red Nacional que sirviera de base para una futura intervención estatal para alcanzar la «total ordenación» del mercado triguero y como instrumento para lograr la autarquía e «impedir las importaciones». La construcción de la Red se realizaría conforme a un Plan Nacional, con una «dirección única que fije, con arreglo a un plan previo, emplazamiento y capacidad de los silos que deben construirse e impedir la construcción de los que no estén comprendidos en dicho plan»22.

La sublevación militar en julio de 1936 y el posterior curso de los acontecimientos concedieron un destacado protagonismo, en materia triguera, a Dionisio Martín Sanz. El 20 de junio de 1937, Martín Sanz y

18 Ruiz de Alda (1936). Acto público en el que participó, también, J. A. Primo de Rivera.

19 www.falange.info... (2005: 16).

20 Como es bien conocido, Rafael Cavestany fue nombrado ministro de Agricultura en 1951, quien, a su vez, nombró a Miguel Cavero, delegado nacional del SNT. A partir de ese momento, ambos tuvieron, finalmente, la ocasión de emprender su ansiado proyecto.

21 El lector interesado puede consultar la biografía de Dionisio Martín Sanz en el Diccionario Biográfico Español de la Real Academia de la Historia.

Martín Sanz (1936: 193-194). 
Mariano Rodríguez de Torres presentaron una ponencia sobre la ordenación del sector triguero en la Asamblea de Entidades Agrícolas, recogida, con otros textos, en el libro El problema triguero y el nacionalsindicalismo.

Finalmente, el 23 de agosto de 1937, se promulgaba en Burgos el Decreto-Ley de Ordenación Triguera, que creaba el Servicio Nacional del Trigo. En lo que concierne al tema objeto de estudio de este trabajo, hay que señalar que el proyecto de intervención «totalitaria» del SNT exigía, a juicio de sus creadores, la construcción de una red de almacenes y silos que permitiesen la recogida del trigo, la retirada de los excedentes en los años de sobreproducción, la importación en los años deficitarios y el abastecimiento de las fábricas de harina. Se culminaba, de esta forma, el proceso iniciado en 1932 y se daba vía libre a la construcción de una Red Nacional de Silos.

Si bien es cierto que durante los años treinta se asiste en todo el mundo a un proceso de intervención estatal en la agricultura, y de manera muy especial en los países totalitarios, la intervención en España presenta rasgos muy específicos. El más destacado, a mi juicio, es el carácter extremado de la intervención. Ni en Italia ni en Alemania se promulgaron normas interventoras de un alcance similar, ni se limitaron de modo tan drástico las iniciativas individuales de agricultores y comerciantes. En concreto, en Italia, donde se planteó un problema similar de falta de almacenamiento durante los últimos años veinte y primeros treinta, conforme fue aumentando la producción triguera, la respuesta del Gobierno italiano fue la de organizar una política de almacenamientos voluntarios, e impulsar la construcción de silos por consorcios, también voluntarios, de agricultores ${ }^{23}$. En 1933 la producción comenzó a superar al consumo, situación que agravó la tendencia bajista de los precios y el problema de los almacenamientos ${ }^{24}$. Para Italia, el problema de los exceden-

23 La «Federazione Italiana dei Consorzi Agrari (Federconsorzi)», organización privada nacida en 1892, comenzó a organizar ventas colectivas de trigo entre 1927 y 1929, aunque en cantidades modestas, y a potenciar la construcción de almacenes y silos privados. Sobre el importante papel de la Federconsorzi en la agricultura italiana debe verse Staderini (1978). Una breve reseña de su labor en Bandini (1959: 142).

24 Segre (1988: 18). Serpieri (1946: 440), destaca también el papel de las ayudas estatales en forma de créditos subvencionados para el fomento de la construcción de almacenes privados. 
tes, del almacenamiento y de la caída de los precios se resolvió, tristemente, cuando en 1935 las sanciones de la Sociedad de Naciones, por la agresión fascista a Etiopía, cambiaron las expectativas del mercado sobre la garantía futura de los abastecimientos ${ }^{25}$.

Tampoco en la Alemania nazi la intervención alcanzó el carácter «totalitario» de la España franquista. Según Richard Walter Darré, teórico del nazismo, ministro de agricultura y principal inspirador de las líneas maestras nacionalsocialistas para el campo alemán, "la "Marktordnung" (ordenación del mercado) no supone una cortapisa a la iniciativa privada, sino que ordena esta iniciativa privada en favor del bien común», la Marktordnung «no es una economía estatal. El Estado no debe reglamentar la economía, tan sólo debe darle los impulsos necesarios „26.

En 1933 se creaba el Reichsnährstand ${ }^{27}$ y, dentro de su organigrama, el «Reichsstellen» (una corporación de derecho público) de los cereales. Este organismo, a diferencia del SNT, no pretendía imponer un control total del mercado, ni tampoco la eliminación del comercio exterior. De hecho, entre sus funciones estaba la de regular el equilibrio interno, mediante compras y ventas en el mercado internacional. En 1934 y frente a una situación de sobreproducción interior, Darré no se planteó la construcción de silos estatales. Impuso la creación de un cártel obligatorio de las industrias harineras y molineras para que se hiciesen cargo de

25 Segre (1988: 19). El autoabastecimiento triguero presentado por Mussolini como el éxito de la «battaglia del grano», fue una victoria pírrica lograda a costa de un fracaso general de la agricultura italiana. En esta valoración coinciden, prácticamente, todos los historiadores italianos. Así, Bandini (1959: 425-426), afirma que el ensayo autárquico triguero italiano fue un rotundo fracaso y que a cambio del autoabastecimiento de trigo y de otros cereales menores, se provocó la crisis y el estancamiento de la mayor parte de las producciones hortícolas y frutícolas en las que Italia tenía grandes ventajas competitivas. De la misma opinión son Profumieri (1971), Preti (1973) y (1982) y D'Attorre (1982).

27 El Reichsnährstand ('Corporación de la alimentación del Reich'), era un organismo que agrupaba, obligatoriamente, a todos los agentes individuales y colectivos que estuviesen relacionados con la producción, comercialización y transformación de todos los productos agrarios y alimentarios. Se trató de una organización muy poderosa que coexistió con el Ministerio de Agricultura y que tenía un cúmulo espectacular de funciones encaminadas a desarrollar los planteamientos de los nazis al campo alemán. Bornás et alii (1941: 21-42). 
la gestión de los excedentes, y desarrolló una amplia labor de fomento de la construcción de silos privados, mediante la concesión de subvenciones $^{28}$.

En concreto, Alemania disponía en 1934 de silos para forrajes con una capacidad de 2 millones de metros cúbicos, que subió a 5 millones en 1936 y a 8 millones en 1940. Toda esta red era de propiedad privada, si bien es cierto que su construcción se había realizado con ayudas y bajo criterios constructivos estatales ${ }^{29}$.

Todas estas soluciones, evidentemente autoritarias, pero menos estatalistas que las que se adoptaron en la España franquista, respondían también a una realidad económica muy distinta y, en concreto, al diverso grado de desarrollo agrario e industrial y a la distinta dotación de medios de almacenamiento modernos en cada uno de los países ${ }^{30}$. La experiencia francesa resulta especialmente interesante. En 1936 se creó la ONIB (Office National Interprofessionel du Blé) que en 1940 se transformó en un organismo implicado en toda la economía cerealista (no solo triguera), evitando de esta forma las distorsiones de todo tipo que provocó en España la política del SNT, centrada en el trigo. En Francia la autoritaria intervención inicial evolucionó, rápidamente, en una línea de mayor flexibilidad. La ONIB, concebida en sus comienzos como un organismo comprador único, nunca se propuso la tarea de construir una red de almacenamiento, sino que coordinó un servicio de almacenadores compuesto por industriales y por los servicios agrícolas de las cooperativas ${ }^{31}$.

En conclusión, ni en Alemania ni en Italia ni en Francia encontramos nada parecido a lo que se planteó en España. La Red Nacional de Silos y Graneros fue una respuesta muy autóctona y también arriesgada, por la

El atraso de España en lo concerniente a instalaciones modernas de almace namiento era muy llamativo. La lectura del excelente libro de Dodlinger (1908), permite conocer los enormes avances que, en esta materia, habían tenido lugar en los EE. UU. y en los países desarrollados. Rusia, país exportador, pero atrasado, levantó almacenes dotados con elevadores a partir de 1888 y en 1895 disponía ya de 55 de estas instalaciones que igualaban en capacidad a las 221 sin elevadores (1908: 228-229). En España, según el SNT, la construcción de silos se inició solo en 1930, con la edificación de dos unidades por entidades particulares, una de ellas proyectada por Miguel Cavero. SNT (1958). 
falta de elementos de comparación y de experiencias previas. Además, y como tendremos ocasión de comprobar, la Red se puso en marcha y se desarrolló durante décadas, bajo planteamientos autárquicos que configuraron un sistema estatal de almacenamiento que resultó completamente inadecuado cuando, finalmente, en 1984 se abolió en España el monopolio triguero creado en $1937^{32}$.

\section{LAS LÍNEAS BÁSICAS DE LA POLÍTICA CEREALISTA EN ESPAÑA ENTRE 1937 Y 1984}

En el presente apartado intento ofrecer al lector una síntesis —que sirva como marco de referencia- de la evolución de la política cerealista desarrollada en España entre 1937 y 1984, fechas en las que se aprobó, primero, y derogó, después, el Decreto-Ley de Ordenación Triguera de 23 de agosto de 1937, norma fundamental que reguló durante todos estos años el sector. Aunque es cierto que durante este largo periodo, y como veremos a continuación, se produjeron diversos cambios, no deja de ser llamativa la inusitadamente larga vigencia temporal de una norma aprobada en las circunstancias excepcionalísimas de una guerra civil.

El proyecto de Dionisio Martín Sanz que, como he señalado anteriormente, constituye el origen del Servicio Nacional del Trigo, se publicó en Valladolid en 1937 con el título de El problema triguero y el NacionalSindicalismo ${ }^{33}$. Según este destacado falangista, el campo estaba sufriendo un proceso de pauperización como consecuencia de los «privilegios de la ciudad y de la rapiña del capitalismo liberal». Para resolver esta situación era imprescindible la «intervención totalitaria» del Estado en la economía, y particularmente en el sector agrario, mediante sindicatos verticales de producción, inspirados en el modelo del fascismo italiano.

32 Leandro Castro Rodríguez, de la subdirección de mercadeo de la FAO, insistía, años más tarde, en la necesidad de crear «instalaciones de mercadeo en zonas rurales, en particular centros de recogida, almacenes y subastas», como forma de estabilizar los precios. En este trabajo no se debate sobre esta necesidad, se analiza el resultado de la solución monopolista y estatalista que representó el SNT.

El libro contiene, además, la «Ponencia sobre bases para la solución del problema triguero», presentada en la Asamblea de Entidades Agrícolas, celebrada el día 20 de junio de 1937, por D. Mariano Rodríguez de Torres y D. Dionisio Martín Sanz, delegado y vocal del Servicio Técnico Nacional de Agricultura de FET y de las JONS. 
El objetivo final de la intervención, en el orden productivo, era el de alcanzar la autarquía triguera «imprescindible para garantizar nuestra independencia económica» ${ }^{34}$. Para ello el Estado debía quedar legalmente capacitado para fijar los precios, clasificar comercialmente los trigos, comarcalizar las zonas productoras, ordenar las entregas del grano por parte de los agricultores, controlar el cumplimiento de adquisición del trigo por parte de las industrias harineras exclusivamente en los silos estatales, realizar en régimen de monopolio las operaciones de comercio exterior y organizar un registro de productores. En resumen, un control prácticamente total de todas las facetas de la producción, comercialización y consumo de trigo.

Lo esencial de los planteamientos de Martín Sanz quedó recogido, evidentemente, en el Decreto-Ley de Ordenación Triguera publicado el 23 de agosto de 1937, por el que se creaba el Servicio Nacional del Trigo. Este organismo nacía con una estructura interna y unos medios capaces, al menos en teoría, de regular hasta en sus más mínimos detalles la economía triguera. En la exposición de motivos de la norma, se partía de la idea de que la situación de la mayor parte de los agricultores trigueros era desesperada, ya que se encontraban «inermes ante la empresa poderosa y los acaparadores desaprensivos». La raíz de esta situación se encontraba en el propio sistema económico, el capitalismo liberal, que sacrificaba a los agricultores privilegiando a la urbe y a los obreros industriales. Los efectos negativos intrínsecos del sistema se veían reforzados por la política de abandono del campo llevada a cabo por los gobiernos burgueses republicanos. Para colmo de males se pensaba que se había alcanzado "una situación clara de superproducción» que agravaba aún más la difícil situación de los cultivadores trigueros.

34 La cuestión de la autarquía exige todavía, al parecer, alguna aclaración. Los apologistas del franquismo en su momento y los neofranquistas actuales han sostenido que la autarquía vino impuesta desde el exterior y, por consiguiente, el régimen no fue responsable de sus secuelas de estancamiento económico, hambre y miseria. Esta postura resulta a todas luces insostenible. La autarquía, como objetivo de la política económica del Nuevo Estado, fue claramente expuesta muchas veces por responsables políticos del más alto nivel, incluido el propio general Franco. En lo concerniente al trigo, Dionisio Martín Sanz lo expresó de manera inequívoca en diversas ocasiones. Puede verse al respecto Barciela (1981a: 53). 
Tras el catastrófico diagnóstico venía la solución: el Nuevo Estado «sensible al clamor campesino y fiel a su decidido propósito de elevar a todo trance el nivel de vida del campo, vivero permanente de España», asumiría la tarea de resolver de manera definitiva estos problemas ${ }^{35}$. Para ello era necesario, en primer lugar, sustituir el modelo económico capitalista-liberal por un nuevo sistema «nacional-sindicalista». A corto plazo, en tanto no se llevara a cabo la anunciada revolución nacionalsindicalista, el Servicio Nacional del Trigo procedería a realizar una reforma económica basada en la revalorización de la producción «asegurando al trigo los precios mínimos remuneradores, ordenando la producción y distribución del mismo y sus principales derivados y regulando su adquisición y movilización». En definitiva, un control total del sector. Esta reforma económica sería solo el primer paso, pues se completaría «en su día» con otra de carácter social, que no se concretaba y que, evidentemente, nunca se llevó a cabo.

Los responsables franquistas en materia agraria auguraban que la nueva intervención totalitaria habría de tener resultados casi milagrosos al señalar que en el futuro y al tener el trigo un precio más elevado "desaparecerán los jornales mínimos, renacerá la prosperidad en las aldeas y comenzaremos a devolver al campo, para dotarlo suficientemente, gran parte de lo que hoy absorbe la ciudad en pago de sus servicios intelectuales y comerciales» ${ }^{36}$. Es evidente que los creadores del SNT ignoraban o despreciaban las consecuencias que podía tener una subida de los precios del trigo sobre la economía española y sobre su capacidad de competir internacionalmente.

El articulado del Decreto-Ley concretaba la forma en la que se procedería a intervenir en el sector. Además de fijar los precios, el Estado podría establecer, en lo sucesivo, las superficies que se dedicarían obligatoriamente al cultivo triguero, quedando la iniciativa del agricultor "subordinada a las órdenes que en atención al interés nacional dicte el Departamento de Agricultura». Los agricultores quedaban también obligados a formular una declaración anual de la superficie cultivada y de la producción obtenida «en la forma y plazo que el SNT exija».

35 Preámbulo del Decreto-Ley de Ordenación Triguera de 23 de agosto de 1937, BOE, de 23 de agosto de 1937.

36 Preámbulo del Decreto-Ley de Ordenación Triguera. 
El sector triguero quedaba, en definitiva, totalmente sometido, desde el cultivo hasta el consumo, a una absoluta regulación estatal. Tan solo quedaba un pequeño grado de libertad de mercado, ya que los tenedores de trigo no tenían, en principio, la obligación de vender todo su grano al SNT, sino tan solo las cantidades que este exigiese para atender a las necesidades del consumo nacional, aunque muy pronto y dadas las dificultades de abastecimiento, los agricultores se vieron obligados a entregar toda su producción al Servicio.

Los industriales harineros, sin embargo, sí quedaban obligados a adquirir el trigo en los silos y almacenes estatales al precio fijado por el Gobierno. En lo que concierne al sector exterior, quedaba sometido al régimen de comercio de estado.

La decidida vocación intervencionista de las nuevas autoridades se manifestó en una larga sucesión de normas reguladoras. En febrero de 1938 quedaba en manos del Servicio la regulación del mercado del maíz, en septiembre de 1939 se intervenía el mercado del centeno, y en octubre de 1939 se ampliaba la intervención del Estado a todos los cereales y leguminosas, y a todos los productos de la molinería.

Según el Gobierno, la ampliación de los productos objeto de intervención era aconsejable «ante las irregularidades advertidas en el mercado de estos productos, íntimamente ligados a los ya intervenidos por este Servicio y [...] como medio de dar efectividad a una armonía en el consumo de los mismos y lograr sensiblemente el equilibrio de precios necesario para su más ordenada producción» ${ }^{37}$. El Gobierno venía a reconocer que el intento de controlar la producción y los precios del trigo había provocado una reacción contraria entre los productores que les había llevado a dedicar sus tierras y su trabajo a otros aprovechamientos con precio libre y más remunerador. En esta situación, la disyuntiva que se planteaba era la de restaurar la libertad del mercado triguero o la de intentar controlar también los productos alternativos. El Gobierno optó por la segunda de las opciones, confiando en que sería capaz de lograr a golpe de decreto el equilibrio de precios necesario para una ordenada producción de los diversos artículos y en armonía con las necesidades del consumo. El proyecto, no es necesario insistir mucho en ello, era absurdo e irrealizable.

37 Decreto de 27 de octubre de 1939, BOE de 30 de octubre de 1939. 
Además de ampliar la intervención a nuevos productos, el Gobierno procedió también a su intensificación. Así, en octubre de 1938, se declaraban de interés nacional y obligatorias las labores de sementera, quedando en manos de las Juntas Agrícolas Locales la responsabilidad de formular «un plan de sementera que concrete las extensiones aproximadas a sembrar de cada especie de planta, sus periodos de siembra, extensiones a barbechar, necesidades de semillas, brazos, ganado de labor, maquinaria y útiles, etc. ${ }^{38}$.

El 5 de noviembre de 1940 se declaraba de interés nacional la realización de las labores de siembra y barbechera; el 15 de junio de 1944 se declaraba obligatoria la labor de respigueo —mostrando la dificilísima situación que atravesaban los suministros de trigo-, y el 4 de enero de 1946 se declaraba obligatoria la escarda ${ }^{39}$.

A todo ello hay que añadir los decretos ordenadores de campañas, las numerosas circulares y otras muchas disposiciones que terminaron por dar al SNT un control absoluto, por supuesto meramente teórico, sobre la economía cerealista.

En julio de 1951 se produjo, como es bien sabido, un importante cambio ministerial. El nuevo gobierno protagonizó un sensible giro liberalizador en la política económica. Como ministro de Agricultura fue nombrado Rafael Cavestany y de Anduaga, en mi opinión la primera persona verdaderamente capacitada para el cargo desde el comienzo de la dictadura franquista. En un discurso ante el Pleno de las Cortes, pronunciado el 18 de diciembre de 1951, Cavestany planteó las líneas generales de la «nueva política agraria». El elemento central de su programa podría sintetizarse en una frase del propio discurso: «Hay que hacer principalmente que los productos de primera necesidad sean remuneradores para que nunca escaseen ${ }^{40}$. Era, si no estoy equivocado, la primera vez que un ministro de Franco reconocía públicamente que la causa esencial de los problemas de escasez de trigo durante los años cuarenta había sido la política de bajos precios de tasa.

38 Decreto de 20 de octubre de 1938, BOE de 23 de octubre de 1938.

39 Se llegaron a fijar hasta el número de jornadas de escarda por hectárea y el número de obreros que debían ser contratados, disposiciones absurdas e imposibles de controlar.

40 En esta idea insistió el ministro en numerosas ocasiones, especialmente en una conferencia en el Teatro San Fernando de Sevilla el 1 de marzo de 1952, titulada «Iniciativa privada y proteccionismo estatal». 
En la misma idea insistiría unos años después Miguel Cavero Blecua, delegado nacional del Servicio Nacional del Trigo y amigo personal de Rafael Cavestany, quien en un ejercicio de autocrítica inusual en aquellos tiempos reconocía que el mercado triguero había estado sumido en un auténtico caos durante los años cuarenta «a causa de la política de precios»; y añadía: «Para salir de esta situación sólo cabía fijar para el trigo un precio medio igual para todos, de acuerdo con su calidad, equiparando a todos los agricultores en el precio de todas las partidas vendibles, forma única ésta para ir logrando la normalización del mercado y llevar la tranquilidad a todos los agricultores ${ }^{41}$.

A partir de 1951 se asiste, pues, a un proceso de restauración de los mecanismos del mercado y a un intento de aproximar los precios de tasa a los que se habrían alcanzado en un mercado libre. El equipo formado por Rafael Cavestany y Miguel Cavero era plenamente consciente de que no podían conseguirse altos niveles de producción triguera manteniendo artificialmente bajos los precios oficiales, por muchas medidas coercitivas que se tomasen. Su «nueva política» consistió en cosas tan elementales, pero tan fundamentales, como adecuar los precios de compra a los costes de producción, suprimir muchas de las medidas de intervención, particularmente las más dañinas y las más ineficaces, y en emprender medidas positivas para los agricultores como el Plan de Intensificación y la construcción de la Red de Silos y Graneros.

En 1953 Cavestany, en otro importante discurso, dejaba ya constancia del cambio operado ante las nuevas medidas:

Buena prueba de ello la tenéis en el volumen de las entregas de trigo al Servicio Nacional durante los meses que van de esta campaña, que arroja cifras superiores a las de otros años, pese a la existencia de una cosecha que en el mejor de los casos podemos quitarle la palabra «muy» a la calificación de mala. Y se ha aumentado la superficie sembrada sin necesidad de imponer sanciones. Todo esto porque los agricultores han sabido darse cuenta de la protección que se les ha dispensado al mejorar el precio del trigo y han querido responder a la protección con la confianza ${ }^{42}$.

Pero, además de elevar los precios, se adoptaron, como ya he señalado, otras líneas de actuación. En primer lugar, se procedió a suprimir

41 SNT (1958: 127).

42 Rafael Cavestany, «Cataluña labradora», discurso pronunciado el 9 de noviembre de 1953 en Granollers, en Cavestany (1958). 
algunas de las medidas de intervención que habían resultado especialmente ineficaces y enojosas. En el decreto ordenador de la campaña 1952-1953 se afirmaba que era necesario «relevar al agricultor de ciertas obligaciones extremas de difícil aplicación que en anteriores campañas, por adversas circunstancias e insuficientes cosechas, hubieron de imponerse ${ }^{43}$. De esta forma se fueron suprimiendo las obligaciones de realizar labores de respigueo y de escarda, y cayeron en desuso las normas de fijación de superficies obligatorias de siembra y barbechera. Asimismo, se fue liberalizando el mercado de multitud de productos intervenidos, quedando tan solo la compraventa del trigo en régimen de monopolio estatal.

Estos cambios plantearon al Servicio dos importantes problemas: el de los recursos financieros necesarios para la adquisición de las cosechas y el de disponer de la capacidad de almacenamiento suficiente para su recogida y posterior distribución. Desde el momento mismo de su creación, el Servicio obtuvo créditos de la banca privada, aunque estos se mantuvieron en unos niveles modestos, ya que el bajo nivel de compras de trigo no hacía necesario disponer de más fondos. Un consorcio de bancos privados, cuarenta y cuatro en total, concedieron al SNT créditos anuales que pasaron de 250 millones de pesetas en 1938 a 500 millones en 1950, cifras modestas que revelan bien a las claras el débil papel jugado por el Servicio en la comercialización de las cosechas durante los años cuarenta, los años en los que reinó el estraperlo ${ }^{44}$.

A partir de 1952 el Servicio dispuso de una nueva fuente de financiación procedente directamente del Banco de España. El organismo triguero pasó de disponer de unos créditos de 1500 millones de pesetas en 1951 a 11900 millones en 1959 de los que 7400 provenían del Banco de España al módico interés del 2,75\%. Este espectacular incremento de las disponibilidades financieras permitió la compra fluida de las cosechas trigueras por parte del Servicio ${ }^{45}$.

En lo que concierne a las disponibilidades de almacenamiento, fue en este periodo cuando se emprendió definitivamente, como se verá más adelante con detalle, la construcción de la Red Nacional de Silos y Graneros.

43 Decreto de 14 de junio de 1952, BOE de 18 de junio de 1952.

44 Barciela (1981b).

45 El lector interesado en el sistema de financiación del SNT puede ver un análisis detallado de este en Barciela (1981b). 
En esta fase se emprendieron también una serie de medidas de fomento de la producción como el ya citado Plan de Intensificación que buscaba el aumento del uso de semillas selectas y abonos, concediendo para ello ayudas directas a los agricultores. El Servicio concedió semillas seleccionadas hasta cubrir el $30 \%$ del total consumido a finales de la década de los cincuenta. En lo que concierne a los abonos, el SNT concedió préstamos en metálico que permitieron a los cultivadores pasar de comprar 109000 t en la campaña 1953-1954 a 711400 t en la correspondiente a 1960-1961. Además, subvencionó la construcción de estercoleros, de almacenes, de graneros y silos, y de secaderos de maíz ${ }^{46}$. El resultado de todas estas medidas fue un aumento muy importante de la producción triguera, superándose los niveles alcanzados durante la República (eso sí, tras veinte años de penalidades).

En lo que concierne al consumo de pan, principal forma de consumo del trigo, durante los años cincuenta se asiste a un proceso de plena satisfacción de la demanda que, sin embargo, no alcanzó el consumo per cápita anterior a la guerra. La causa de este menor nivel de consumo no se debe, evidentemente, a ningún tipo de dificultad en el abastecimiento, sino al cambio de los gustos de los consumidores, paralelos a la paulatina recuperación del nivel de renta.

Finalmente, y en lo que respecta al sector exterior, en este periodo se alcanzó un equilibrio entre la producción y el consumo, aunque conviene insistir en que dicho equilibrio se alcanzó en el marco de una agricultura aún atrasada y con unas pautas de consumo tradicionales.

Se consiguió, después de tantas penalidades, el tan anhelado autoabastecimiento triguero y, dados los bajos niveles de consumo de proteínas de origen animal, no se planteó aún el problema de la escasez de cereales pienso y las correspondientes importaciones. La balanza exterior cerealista entre 1955 y 1960 se cerró con saldos prácticamente equilibrados $^{47}$.

En 1959, como es sobradamente conocido, las autoridades españolas pusieron en marcha un conjunto de medidas de política económica que han pasado a la historia con el nombre de Plan de Estabilización. En esencia, este plan pretendía liberalizar el comercio interior y las relaciones

46 Para más detalles Barciela (1981a, capítulos III y IV).

47 Barciela (1981a, capítulo IX). 
exteriores, suprimir intervenciones y organismos reguladores, y sanear los sistemas financiero y fiscal. Existe una unánime valoración favorable del plan y sus efectos, y si se han planteado críticas han sido, más bien, a la falta de continuidad y valentía de las medidas liberalizadoras. En este sentido, considero que el mejor ejemplo lo constituye el Servicio Nacional del Trigo. El movimiento liberalizador de 1959 careció de la fuerza suficiente para tocar los privilegios del monopolio triguero y, en definitiva, de los grandes propietarios que se escudaban en él. El Servicio no fue suprimido, como ocurrió con otros organismos de intervención nacidos al calor de las ideas autárquicas; ni siquiera fue reformado para facilitar los cambios que, inevitablemente, se tendrían que producir en la composición de la oferta de los cereales en un contexto de crecimiento económico y de cambios en el consumo alimenticio ${ }^{48}$.

Incluso en algunas cuestiones en las que las medidas estabilizadoras incidieron de forma especial, como el saneamiento del crédito, el Servicio salió indemne. Así, se mantuvieron intactas sus privilegiadas relaciones de crédito con el Banco de España, a pesar de las protestas del instituto emisor y de las propias recomendaciones realizadas en este sentido por las autoridades. Concretamente, parte de las medidas estabilizadoras pretendían operar sobre la evolución de la oferta monetaria, estableciendo elementos de control y eliminando ciertas prácticas claramente inflacionistas. Estas medidas afectaban, teóricamente, de manera directa al SNT, ya que se decretó el aumento del tipo de interés y de descuento del Banco de España y la congelación y el cambio de sistema de los créditos al organismo triguero. Pues bien, hay que señalar que ni la banca privada restringió sus créditos al Servicio, ni se aumentaron los tipos de descuento y redescuento que se le aplicaban, ni se cumplieron las recomendaciones para cambiar el inflacionista sistema de crédito, ni, por supuesto, se congelaron sus límites.

El Banco de España planteó una fuerte ofensiva para restringir los créditos que obligatoriamente tenía que conceder al Servicio y para aumen-

48 El propio Rafael Cavestany en una fecha tan temprana como 1951 afirmaba la necesidad de conseguir una dieta alimenticia de calidad «sobre todo en los productos básicos como la leche y la carne, en los que estamos muy por debajo de los índices de consumo de los países occidentales de Europa». R. Cavestany, discurso ante el Pleno de las Cortes en diciembre de 1951, en Cavestany (1958). 
tar los tipos de interés, aunque estas iniciativas fracasaron radicalmente. En un alarde no sé si de ingenuidad o de prepotencia, el SNT llegó a solicitar al Banco de España la concesión de créditos ilimitados y sin interés.

A partir de 1962 la intervención del Estado en el sector cerealista entró, teóricamente, en una nueva etapa, presumiblemente más coherente, al quedar integrada dentro de un proyecto de ordenación general del sector agrario. Dentro del marco de la planificación se promulgó en 1968 un decreto por el que el Servicio Nacional del Trigo pasaba a denominarse Servicio Nacional de Cereales. El cambio de denominación, sin embargo, no afectó sustancialmente a la estructura y a las funciones que venía desempeñando el organismo triguero ${ }^{49}$.

La planificación indicativa española, como ya ha sido señalado en numerosas ocasiones, no fue, precisamente, una experiencia brillante. Los responsables de los planes, y con ellos los del SNT, afirmaron que la planificación fue un éxito porque se lograron importantes incrementos de la producción cerealista. Esto es totalmente cierto, pero no es suficiente para afirmar que la planificación fue un éxito. El aumento de la producción, contrariamente a lo prometido por las autoridades, fue muy desordenado. Aumentó en exceso la producción triguera, acumulándose importantes excedentes invendibles, y fracasó el intento de incrementar la producción de cereales pienso, soporte del necesario crecimiento de la cabaña ganadera. Y todo ello utilizando abundantes recursos públicos ${ }^{50}$.

De mayor trascendencia fue la creación por ley, también en 1968, del Fondo para la Ordenación de las Producciones y los Precios Agrarios (FORPPA $)^{51}$. Esta norma buscaba «dar unidad y coherencia a la política de ordenación de los mercados agrarios" y afectaba, como es lógico y de manera plena, al Servicio Nacional de Cereales. Las funciones del nuevo organismo eran de cuatro tipos: de propuesta al Gobierno, de fomento, de vigilancia y ejecución, y de informe. En lo que concierne a la primera de las funciones, la de propuesta al Gobierno, obligaba a diseñar:

a) Las líneas generales de la política de producciones y precios agrarios, con una doble finalidad: reestructurar la oferta y satisfacer la demanda.

49

50

51

Decreto 161/1968, de 1 de febrero (BOE de 3 de febrero de 1968).

Barciela (1985a).

Ley 26/1968, de 20 de junio (BOE de 21 de junio de 1968). 
b) Los precios indicativos o de garantía a la producción o el consumo, y los de entrada para las importaciones.

c) La ordenación del régimen de derechos arancelarios y reguladores de productos agrarios.

d) La tipificación y normalización de los productos agrarios.

e) El régimen de industrialización y comercialización.

f) La actuación en los mercados agrarios con el fin de lograr su equilibrio, transparencia y fluidez mediante la compra, almacenamiento y financiación de productos agrarios para su venta en mercados interiores o para su exportación, así como para la importación de dichos productos.

g) La política de primas y subvenciones, así como de crédito y seguro de cosecha.

h) La política de reestructuración de las explotaciones.

i) La regulación del comercio exterior.

El segundo grupo de funciones, las denominadas de fomento, consistirían en

a) Promover la constitución de entidades que pudiesen colaborar con el FORPPA.

b) Fomentar la ampliación de actividades de las entidades asociativas agrarias en la industrialización y comercialización de sus productos.

c) Orientar y promover las inversiones en el sector agrario para adecuar la producción a la demanda.

El tercer grupo lo constituían las funciones de ejecución y vigilancia de las medidas adoptadas por el Gobierno y, finalmente, el cuarto encomendaba al FORPPA la tarea de informar los proyectos o propuestas que otros organismos pudiesen elevar al Gobierno cuando afectasen a los productos o precios agrarios.

El mantenimiento de un régimen de privilegio al trigo resultaba, en un marco como el diseñado con la creación del FORPPA, cada vez más injustificado. De hecho, con la promulgación de la Ley 26/1968, de 20 de junio, que establecía un régimen general para los productos sometidos a regulación de campaña, el monopolio triguero tendría que haber desaparecido. Sin embargo, lo cierto es que el trigo siguió gozando de su estatus privilegiado. 
Durante la década de los setenta la política cerealista intentó, sin conseguirlo, una adecuación a la nueva realidad del consumo. Se impulsó la producción de cereales pienso, en particular de la cebada, y se recurrió a las importaciones de maíz y soja para conseguir un aumento de la producción ganadera. Para ello se modificaron los precios relativos de los diversos cereales, se establecieron precios mínimos de entrada para los productos de importación y se concedieron créditos y subvenciones hasta entonces exclusivas del trigo. Institucionalmente se produjeron también cambios muy importantes. En 1971 el Servicio Nacional de Cereales fue remodelado y cambió de nombre pasando a denominarse Servicio Nacional de Productos Agrarios (SENPA) ${ }^{52}$. El nuevo organismo tenía por misión la de coordinar todas las medidas de intervención en el sector agrario. De manera particular se le encomendaba la misión de ampliar, mantener y explotar la Red de Silos y Graneros, así como la colaboración con el FORPPA. Sin embargo, y como había sucedido en tantas ocasiones con anterioridad, el monopolio estatal triguero siguió en vigor.

Será solo en 1984, gracias a la Ley 26 de 20 de junio, cuando se restablezca la libertad en el mercado triguero, suprimida con el Decreto-Ley de Ordenación Triguera de 23 de agosto de 1937. Esta medida, que vino forzada por las negociaciones para el ingreso en las Comunidades Europeas, establecía que la producción y el comercio del trigo se regirían, en lo sucesivo, por los principios de libertad de producción, circulación y de precios en el marco de una economía de mercado. Una norma que según Julián Arévalo Arias, presidente del FORPPA, y Juan José Burgaz, director general del SENPA, «pertenece al reducido número de disposiciones que cabe adjetivar de históricas» $\$ 3$.

La ley descubría, después de casi cincuenta años de vigencia del monopolio, que un régimen de libertad podía beneficiar tanto a productores como a consumidores. Demasiado tiempo, sin duda, para llegar a una conclusión tan elemental. Atrás quedaban los graves y persistentes problemas de desajustes en la oferta de los diversos cereales en relación con las necesidades del consumo, provocadas por la intervención en los precios y en los sistemas de comercialización y almacenamiento, así como los problemas derivados de la acumulación de excedentes liquidables solo con graves pérdidas económicas para el Estado ( $\mathrm{y}$, en definitiva, no lo olvi-

52 Decreto-Ley 17/1971, de 28 de octubre (BOE de 4 de noviembre de 1971).

53 Arévalo y Burgaz (1985: 243). 
demos, para los contribuyentes). Finalmente, y no menos importante, se abría un futuro incierto por la existencia de un sector económico y comercial ajeno a la realidad de la economía de mercado y carente de preparación para competir en el nuevo contexto de la política agraria comunitaria $^{54}$.

\section{LA CONSTRUCCIÓN DE LA RED}

De manera muy sintética podemos señalar que, según el SNT, la construcción de la red nacional tenía que alcanzar los siguientes objetivos:

1. Posibilitar la compra de toda la cosecha de trigo a los agricultores.

2. Conservar una reserva nacional al final de cada campaña para garantizar el consumo.

3. - Permitir la recepción en puerto de los trigos de importación y la eventual exportación de excedentes.

4. ․ㅡograr la adecuada manipulación de los granos, así como su selección y tratamiento para proporcionar al agricultor semillas de mayor rendimiento.

Para conseguir estos objetivos era necesario emprender la construcción de tres tipos de unidades de almacenamiento. En primer lugar, los silos y almacenes llamados de recepción que tenían la misión de absorber la oferta de grano en los mismos lugares de producción, conservándolo hasta el momento de su venta para el consumo o para el traslado a otras zonas $^{55}$. Estos silos de recepción tenían que satisfacer en la medida de lo

54 Sobre la Ley 16/1984, de 29 de mayo, la Revista de Estudios Agro-Sociales publicó una serie de trabajos de gran interés, en el número 130, enero-marzo de 1985, de J. López de Sebastián, Juan José Burgaz, Javier García de Oteyza y Julián Briz Escribano.

55 El SNT dividió España en 150 comarcas trigueras, en función de las características de la oferta así como de la existencia de industrias molineras, de centros tradicionales de comercio de cereales y de comunicaciones ferroviarias y por carretera. Se establecieron en ellas 830 cabeceras de recepción con almacenes permanentemente abiertos, 664 subalmacenes abiertos temporalmente en las épocas de recolección y 107 centros de selección. SNT (1958: 135) y SENPA (1975 y 1976). 
posible y simultáneamente varios intereses contrapuestos. Por una parte, el de los agricultores, que deseaban tener un silo lo más cerca posible de sus tierras; por otra, el de los harineros, que los querían cerca de sus fábricas 0 , al menos, en un lugar bien comunicado y, finalmente, el del propio SNT, que con unos recursos limitados no podía emprender una política de masiva construcción de instalaciones.

En segundo lugar, eran necesarios los denominados silos de tránsito y reserva cuya función era la de constituir puntos reguladores, intermedios entre la producción y el consumo, así como mantener las reservas, y que tendrían que tener una capacidad de entre 15000 y 25000 toneladas. Su situación tenía que ser estratégica, en las zonas productoras y en lugares que contasen con excelentes vías de comunicación. Finalmente, para realizar las operaciones exteriores se precisaban los llamados silos de puerto, con capacidad de hasta 30000 toneladas.

Cada silo estaba a cargo de un jefe de almacén que validaba las operaciones y extendía los pagarés del SNT a los agricultores, que a su vez podían hacer efectivos en cualquier sucursal o agencia de los bancos concertados con el Servicio. El conjunto de los pagarés podía ser automáticamente redescontado, por estos bancos concertados, en condiciones muy favorables en el Banco de España ${ }^{56}$.

Cabría, además, señalar la existencia de otras unidades especiales como los centros de selección de semillas y los centros de secado que, aunque estrictamente no pueden ser considerados como unidades de almacenamiento, constituían un complemento funcional de gran importancia ${ }^{57}$.

Adviértase que la novedad más destacada en todos estos planteamientos era el inevitable reconocimiento de la necesidad de importar trigo. El fracaso productivo en la posguerra, el desabastecimiento y el hambre barrieron los iniciales discursos autárquicos de los teóricos y gobernantes franquistas.

56 Para más detalles sobre el sistema de financiación del SNT puede verse Barciela $(1981 b)$.

57 SNT (1958, 1959 y 1962). Existen también otras clasificaciones de los silos atendiendo a sus características técnico-constructivas que tienen escaso interés a los efectos de este trabajo. El lector interesado puede ver SNT (1958: 164-165) y SENPA (1978). 
Para que el Servicio pudiera cumplir el compromiso de adquirir toda la producción triguera y ante la inexistencia de silos estatales, el artículo 18 del Decreto-Ley de Ordenación Triguera y los artículos 3 y 145 del reglamento para su aplicación, facultaron al SNT para ocupar los terrenos y locales que pudiera necesitar y para realizar las expropiaciones forzosas correspondientes. En consecuencia, el Servicio procedió, inicialmente, a alquilar los locales necesarios para poder llevar a cabo su función, sin emprender de inmediato la construcción de unidades de almacenamiento propias.

No obstante, como hemos visto, en la mente de los gobernantes y dirigentes del SNT estaba profundamente arraigada la idea de crear una red patrimonial de almacenamiento, que se vio reforzada por la falta de adecuación de muchos de los locales arrendados, que carecían de las más mínimas condiciones para conservar el grano, lo que se traducía en graves pérdidas y en potenciales problemas para la salud de los consumidores $^{58}$.

Sin embargo, esta decidida voluntad de emprender la construcción de la red se vio condicionada por una serie de circunstancias, entre las cuales resultaba determinante la evolución de las entregas de trigo por los agricultores al SNT. Evidentemente, si los agricultores no producían o no vendían su cosecha al Servicio, la red no tenía razón de existir. En este sentido, considero de interés presentar un panorama inicial de las distintas fases que vivió la agricultura española, en lo que concierne a las necesidades potenciales de almacenamiento de cereales. Un análisis de la información contenida en el cuadro 1 y en los gráficos 1 y 1B, permite distinguir las siguientes grandes coyunturas:

58 En palabras del propio Servicio: «se venía almacenando el trigo que se compraba a los agricultores en locales que se habían podido arrendar en cada localidad, algunos de los cuales no ofrecían las condiciones debidas de resistencia y salubridad, produciéndose derrumbamientos y perdiéndose cantidades muy apreciables de trigo por humedades y el ataque de gorgojos, roedores, pájaros, etc.» SNT (1958: 172). 
CUADRO 1. COMPRAS DE TRIGO NACIONAL POR EL SNT-SNC-SENPA.

(En miles de $t$ )

\begin{tabular}{|c|c|c|}
\hline Campañas & Compras & Porcentaje sobre la cosecha \\
\hline 1937-1938 & 1143 & $?$ \\
\hline 1938-1939 & 1235 & $?$ \\
\hline $1939-1940$ & 1103 & 35,90 \\
\hline $1940-1941$ & 449 & 18,70 \\
\hline 1941-1942 & 804 & 26,10 \\
\hline $1942-1943$ & 801 & 21,90 \\
\hline 1943-1944 & 832 & 26,60 \\
\hline 1944-1945 & 1168 & 30,90 \\
\hline $1945-1946$ & 455 & 20,10 \\
\hline $1946-1947$ & 1415 & 34,20 \\
\hline 1947-1948 & 733 & 23,00 \\
\hline 1948-1949 & 730 & 22,30 \\
\hline 1949-1950 & 725 & 23,90 \\
\hline $1950-1951$ & 1289 & 38,20 \\
\hline 1951-1952 & 2214 & 51,90 \\
\hline $1952-1953$ & 1180 & 28,80 \\
\hline 1953-1954 & 923 & 30,50 \\
\hline 1954-1955 & 2504 & 52,50 \\
\hline $1955-1956$ & 2085 & 52,20 \\
\hline 1956-1957 & 2242 & 53,40 \\
\hline 1957-1958 & 3068 & 62,60 \\
\hline 1958-1959 & 2758 & 60,70 \\
\hline $1959-1960$ & 2692 & 58,10 \\
\hline $1960-1961$ & 1741 & 49,50 \\
\hline 1961-1962 & 2081 & 60,60 \\
\hline $1962-1963$ & 3377 & 70,20 \\
\hline 1963-1964 & 3787 & 77,90 \\
\hline 1964-1965 & 3044 & 76,50 \\
\hline $1965-1966$ & 3685 & 78,10 \\
\hline 1966-1967 & 3822 & 78,40 \\
\hline 1967-1968 & 4539 & 80,33 \\
\hline 1968-1969 & 4377 & 82,39 \\
\hline 1969-1970 & 3782 & 81,79 \\
\hline 1970-1971 & 3498 & 84,78 \\
\hline 1971-1972 & 4700 & 86,25 \\
\hline
\end{tabular}




\begin{tabular}{ccc}
\hline Campañas & Compras & Porcentaje sobre la cosecha \\
\hline $1972-1973$ & 3997 & 87,62 \\
$1973-1974$ & 3148 & 79,37 \\
$1974-1975$ & 3965 & 87,45 \\
$1975-1976$ & 3775 & 87,75 \\
$1976-1977$ & 3938 & 88,77 \\
\hline $1977-1978$ & 3221 & 79,26 \\
$1978-1979$ & 3874 & 80,61 \\
$1979-1980$ & 3343 & 81,90 \\
$1980-1981$ & 5294 & 87,66 \\
$1981-1982$ & 3253 & 95,45 \\
\hline $1982-1983$ & 3507 & 79,52 \\
$1983-1984$ & 2774 & 65,00 \\
$1984-1985$ & 622 & 10,28 \\
\hline
\end{tabular}

FUENTE: Elaboración propia con datos de los archivos del Banco de España y SENPA.

\section{GRÁFICO 1. COMPRAS DE TRIGO NACIONAL POR EL SNT-SNC-SENPA}

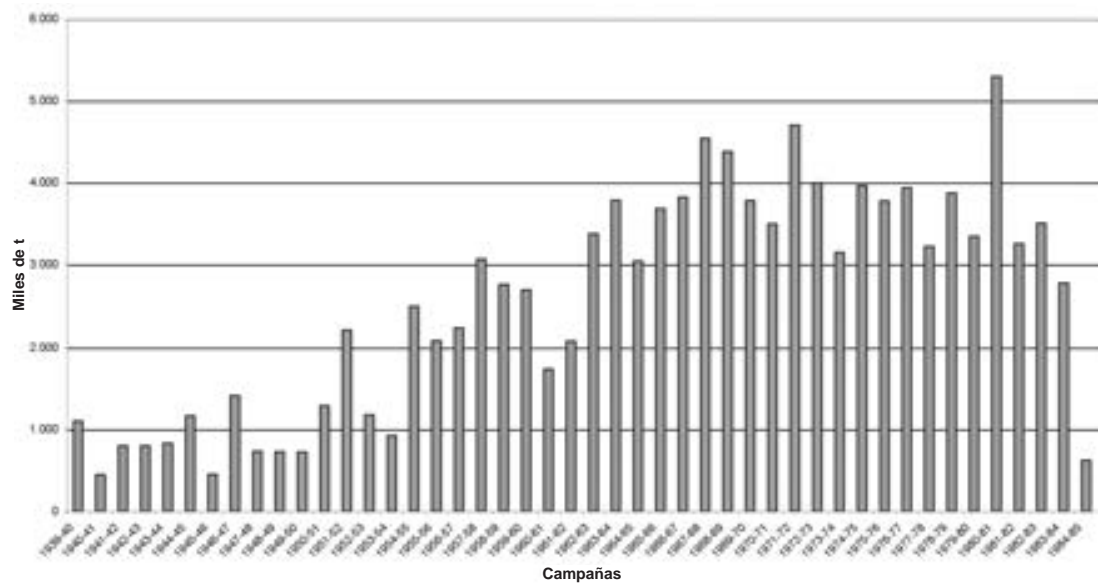

FUENTE: Cuadro 1. 


\section{GRÁFICO 1B. COMPRAS DE TRIGO NACIONAL POR EL SNT-SNC-SENPA. (Porcentaje sobre la cosecha)}

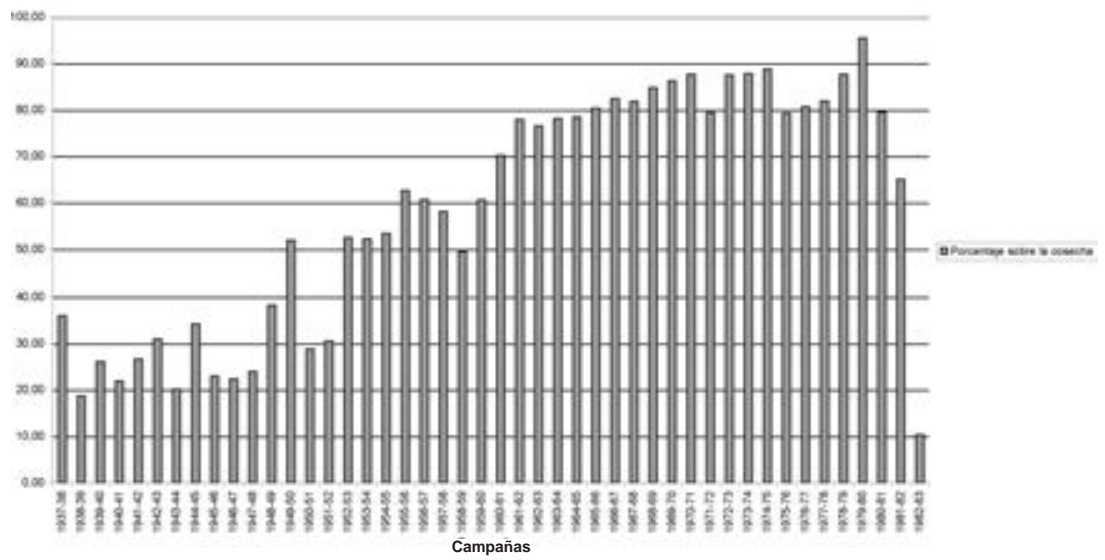

FUENTE: Cuadro 1.

a) Los años de la década de los cuarenta, hasta la campaña 19501951, que se caracterizan por la disminución de la producción triguera y porque los agricultores intentaron evitar al Servicio como intermediario. Son los años de los bajos precios de tasa, del florecimiento del mercado negro y del racionamiento ${ }^{59}$. En estas circunstancias, la necesidad de construir unidades de almacenamiento fue nula, al rechazar los agricultores el cauce oficial de comercialización. Por otra parte, los fabricantes, deseosos de obtener el mayor volumen posible de trigo al precio de tasa,

59 Resultan muy interesantes las similitudes, como no podía ser de otra forma, entre el mercado negro en España y en Italia, como puede verse en Becattini y Bellanca (1986: 14-15). Estos autores destacan como causa del mercado negro la diferencia entre los precios oficiales y los de mercado. Inciden en los altos niveles alcanzados por el mercado negro y en que los principales beneficiarios fueron «più il gerarca fascista, il vecchio o nuovo grossista e il grande proprietario terriero» (1986: 15). Las conclusiones de estos autores sobre los beneficiarios del mercado negro del trigo coinciden plenamente con las de mis investigaciones como puede comprobarse en Barciela (1981c). 
absorbían rápidamente los cupos oficiales que el SNT les concedía. En definitiva, el mercado oficial se caracterizó por la escasez de la oferta y por la gran demanda por parte de los industriales, de manera que el volumen de trigo comercializado oficialmente fue reducido y permanecía poco tiempo en manos del SNT. En consecuencia, no existió presión alguna en favor de construir la red.

b) A partir de 1951 entramos en una nueva etapa que comienza con el final del racionamiento del pan, con la revisión de la política de precios oficiales, en la que tiene lugar una rápida recuperación de la producción y en la que el SNT comercializa un porcentaje creciente de las cosechas, desapareciendo el mercado negro, aunque no el comercio ilegal directo entre agricultores y harineros ${ }^{60}$. El propio ministro de agricultura, Rafael Cavestany, en unas declaraciones públicas, reconocía la relación entre la desaparición del mercado negro, las mayores necesidades de almacenamiento y el impulso a la construcción de la red ${ }^{61}$. La gran cosecha de 1951 creó serios problemas de recepción de los trigos y se terminó el año con un stock de 5,58 millones de quintales métricos lo que, por otra parte, aseguraba plenamente el libre consumo de pan. La cosecha de 1954 resultó ser la mayor lograda hasta entonces en España y la campaña finalizó con unas reservas de 11,28 millones de quintales, lo que permitió al SNT proclamar que España estaba "en una posición de autoabastecimiento y de completa seguridad nacional en el consumo de pan»62. El aumento de las reservas originó, por otra parte, serios problemas de financiación y tensiones entre el Servicio y el Banco de España que quería

60 La razón de este comercio directo entre agricultores y harineros era soslayar la intermediación del SNT y el pago del correspondiente canon comercial. Para más detalles sobre la persistencia temporal de este tráfico y de su volumen, Barciela (1981a, 1981b y 1985b).

61 Declaraciones a la prensa el 12 de febrero de 1957. Las manifestaciones de Cavestany eran de gran calado. El ministro relacionaba la política de «precios relativamente bajos» durante los años cuarenta con las "cosechas escasas» y «las entregas reducidas al SNT»; y añadía que la elevación "de los precios oficiales del trigo», durante los cincuenta, había tenido como consecuencia «una producción suficiente» y «la desaparición del mercado negro». Todo ello había exigido la construcción de la Red. 
establecer límites a la financiación privilegiada del SNT. Dentro de esta fase hay que considerar un hecho que tuvo también importantes repercusiones, desde el punto de vista de las necesidades de almacenamiento, que fue la tipificación del trigo por calidades, que el Servicio introdujo en la campaña 1952-1953 por vez primera desde su creación ${ }^{63}$. La medida, absolutamente necesaria, provocó de modo automático una disminución efectiva de la capacidad de almacenamiento del Servicio, ya que cada calidad de trigo tuvo que almacenarse por separado. Los jefes de almacén asumieron la responsabilidad final en la clasificación comercial de las distintas partidas entregadas por los agricultores, con los correspondientes efectos sobre los precios que habrían de percibir. Existe una amplia evidencia de que no siempre esta facultad se utilizó adecuadamente y de que se produjeron, en bastantes ocasiones, tratos de favor ${ }^{64}$. No obstante, la deficiente cosecha de la campaña 1953-1954, que redujo las compras del Servicio a menos de 1 millón de toneladas, unida a la persistencia de las citadas corrientes clandestinas de trigo, paliaron momentáneamente el problema. Mediada la década, la normalización de las cosechas y de las entregas de trigo, que superaron en el caso de estas últimas los 3 millones de toneladas en la campaña 1957-1958, se convirtió en un elemento de fuerte presión para forzar la construcción de la red.

c) Desde comienzos de los años sesenta, hasta el final del monopolio triguero en 1984, la necesidad de almacenamiento fue constantemente en aumento, como consecuencia de varios factores.

63 En los planes originales del Servicio se consideraba que el trigo debía clasificarse comercialmente de acuerdo con su calidad y pagarse a precios diferentes. Sin embargo, la grave situación de escasez vivida durante los años cuarenta y la competencia ejercida por el mercado negro propiciaron una política poco exigente, además de injusta, de precio único, que tuvo efectos muy negativos sobre la calidad. Barciela (1999).

Aurelio García González, alto funcionario del SNT durante muchos años, con el que publiqué un artículo en la revista Agricultura y Sociedad y con el que mantuve largas conversaciones sobre estas cuestiones, me contaba como se elevó la consideración social de los jefes de almacén en los campos españoles. Se decía que «tenían las mejores escopetas del pueblo», gran elogio en un ámbito en el que la caza tenía connotaciones políticas, económicas y sociales incuestionables. 
CUADRO 1bis. EXISTENCIAS REALES DEL SENPA (A 31 DE MAYO DE CADA AÑO) ( $t$ )

\begin{tabular}{rrrcrr}
\hline Años & \multicolumn{1}{c}{ Trigo } & $\begin{array}{c}\text { Cereales pienso } \\
\text { Otoño-Invierno }\end{array}$ & $\begin{array}{c}\text { Cereales pienso } \\
\text { Primavera-Verano }\end{array}$ & \multicolumn{1}{c}{ Otros } & \multicolumn{1}{c}{ Total } \\
\hline 1975 & 840593 & 19892 & 208570 & 13132 & 1082187 \\
1976 & 789610 & 860937 & 357153 & 24616 & 2032316 \\
1977 & 1062776 & 80239 & 19394 & 7512 & 1169921 \\
1978 & 892142 & 42921 & 91750 & 23087 & 1049900 \\
1979 & 1421787 & 588496 & 245566 & 10714 & 2266563 \\
1980 & 964851 & 87954 & 372095 & 1698 & 1426598 \\
1981 & 1781791 & 218667 & 76838 & 2278 & 2079574 \\
1982 & 1524198 & 76509 & 268087 & 1948 & 1870742 \\
1983 & 962576 & 108201 & 120780 & 1943 & 1193742 \\
1984 & 551576 & 3601 & - & 49 & 555226 \\
1985 & 372879 & 1381371 & 36 & 1045 & 1755331 \\
\hline
\end{tabular}

FUENTE: SENPA. Memoria de actividades (años 1975 a 1984-1985).

En primer lugar, por el aumento continuado de la producción de trigo. En segundo, porque el Servicio logró, finalmente, como puede verse con claridad en el gráfico 1B, monopolizar las compraventas de trigo, eliminando casi por completo el comercio ilegal de grano. Una tercera razón fue la creciente producción de otros cereales, en particular de cebada, cuya demanda estaba aumentando notablemente, dadas las necesidades de piensos para sostener el crecimiento de la cabaña ganadera y atender, en definitiva, al aumento del consumo de carne por parte de la población española. La cebada, objeto también de la intervención del SNT, pasó a ocupar una parte creciente de la capacidad de almacenamiento de la red. Así, las existencias de cebada propiedad del Servicio eran inapreciables hasta 1967. Comenzaron a subir ligeramente en 1968, superando las 500000 t en 1969; descendieron en 1970 y 1971, y volvieron a subir en 1972 y 1973 por encima de las $500000 \mathrm{t}$, desapareciendo en 1974 y $1975^{65}$. En los últimos años de existencia del monopolio triguero, como puede comprobarse en el cuadro 1 bis, el volumen de cereales

65 SENPA (1975: 61). 
pienso almacenados ocuparon una parte significativa, aunque irregular de la Red. Finalmente, un factor que fue adquiriendo un papel creciente (y muy gravoso para la economía) fue la paulatina acumulación de excedentes de trigo, de muy difícil salida comercial en los silos del Servicio, problema al que no se supo dar solución (en realidad no se quiso, ya que la solución era sencilla) y que se intentó paliar ampliando de manera irracional la capacidad de almacenamiento propio, a la vez que aumentaba también de forma espectacular la capacidad arrendada.

d) Finalmente, a partir de 1984, con el final del monopolio estatal triguero, entramos en la etapa de desmantelamiento de la Red Nacional, una red que no dejó de crecer hasta ese mismo año, hasta el mismo momento en que se tuvo que comenzar con su liquidación de manera inexorable.

Como ya he comentado, en 1937, cuando el SNT empezó su actividad, se limitó a alquilar a los fabricantes de harinas y a los propios agricultores los locales que necesitaba. En 1941, el Servicio comenzó a considerar la posibilidad de empezar la construcción de la Red Nacional de Silos. Se llegó, incluso, a convocar un concurso de proyectos de silos y graneros, premiándose algunos proyectos, aunque no se comenzó la construcción de ninguno de ellos.

En 1942, el SNT emprendió una serie de estudios internos que culmina con los proyectos de silo de Alcalá de Henares, Córdoba y Mérida. En 1944 se sacaron a subasta y se contrataron las obras de estos silos, así como las de otros veinte pequeños silos de recepción distribuidos por toda España y las del silo del puerto de Málaga ${ }^{66}$.

En 1946 se promulgó la que fue norma fundamental relativa a la creación de la Red Nacional de Silos y Graneros, el Decreto del Ministerio de Agricultura de 12 de julio. En el preámbulo de esta disposición se señalaban los principales objetivos que debía cumplir la red:

66 SNT (1958: 148, y 1959: 6). Las peripecias del silo de Málaga, buque insignia de la red nacional, merecen un breve recordatorio. Los defectos en su cimentación obligaron a rellenar el puerto y alejaron el silo de la zona de atraque de los buques, inutilizándolo en gran medida. Con posterioridad, debido a la especialización turística de la ciudad y del puerto, Málaga se encontró con una instalación antiestética y de un enorme volumen en el centro mismo del núcleo urbano y en la mejor zona del puerto. 
La necesidad de que la nación disponga de una capacidad de almacenaje suficiente para crear en las épocas de abundancia reservas que puedan ser consumidas en las de escasez, ha sido sentida desde hace muchos años y con más intensidad tal vez en el nuestro que en la mayoría de los países que ya tienen resuelto este problema, por la variabilidad de nuestras condiciones meteorológicas, que hacen producir de un año a otro, cosechas muy desiguales. Sólo estas reservas, acondicionadas para ser conservadas indefinidamente y situadas de un modo conveniente, permitirán mediante una acción estatal mínima, una segura regulación del precio de los cereales, que, de otro modo, escapará siempre a toda intervención.

Una Red de Silos que, además de hacer posible la formación de estas reservas, cuente con centros receptores donde el grano entregado por el productor se admita rápida y fácilmente por medios mecánicos que lo pese, además, con toda exactitud; que disponga de silos de tránsito para transbordar el grano de unas vías o de unos medios de comunicación a otros, ahorrando lentas y costosas manipulaciones; que permita desecar con facilidad cosechas que, como la de maíz, se recogen húmedas en tantas regiones de España, con lo que queda imposibilitado su cultivo en grande y que, por último sirva para almacenar simientes limpias y desinfectadas después de calibrarlas exactamente por medio de una selección mecánica perfecta es de indudable interés nacional.

El artículo primero del decreto encomendaba al Servicio Nacional del Trigo el estudio, la construcción y la explotación de la Red Nacional de Silos, que constaría, conforme a los planteamientos ya expuestos del Servicio, de silos de recepción en las zonas productoras; de silos de tránsito en los principales nudos de comunicación y en los puertos que se considerase necesario, de silos de reserva colocados en función del abastecimiento de las zonas consumidoras y, finalmente, de silos destinados al almacenaje y conservación de semillas seleccionadas para siembra. El Servicio elaboraría los necesarios planes parciales para la construcción de la red que deberían ser aprobados por el Ministerio de Agricultura.

Las inversiones correspondientes se realizarían con cargo a los beneficios comerciales del SNT, es decir, con fondos propios del organismo. Finalmente, se declaraba de utilidad pública la ocupación de terrenos y edificaciones que el SNT pudiera necesitar para la construcción de la Red ${ }^{67}$.

Sin embargo, los planes chocaron con las difíciles circunstancias por las que pasaba la economía española y las obras discurrieron con una

67 El 26 de julio y el 27 de noviembre de 1947 se publicaron sendas órdenes ministeriales que aprobaban los primeros planes parciales de construcción como anticipos del Plan General. 
extraordinaria lentitud. Finalmente, tras los cambios en la política económica y la apertura exterior de la economía española en 1951, se inauguraba el silo de Córdoba y con él la Red Nacional de Silos y Graneros cuya construcción se prolongó hasta $1984^{68}$. En los cuadros 2, 3, 4 y 5, y gráfi$\cos 2,3$ y 4 , se puede observar la capacidad construida cada año, así como la capacidad total acumulada. Igualmente, pueden verse los datos desglosados entre silos y graneros, así como los relativos a la configuración funcional de la Red, distinguiendo entre unidades de recepción y unidades de tránsito y reserva. Se pueden distinguir, a la vista de estos, diversas fases en cuanto al ritmo y características de la construcción:

-Los años cuarenta. En esta década la labor fue muy limitada, llegándose a 1950 con un total de 12 unidades construidas con una capacidad de 21050 t, de las que 6500 se habían erigido en 1949. El Servicio justificó esta falta de actividad por las dificultades económicas generales de la posguerra y, en particular, por la falta de materiales de construcción y de maquinaria y la dificultad de importarla, y por la falta de medios de transporte y de vías de comunicación. En realidad, como ya hemos comentado, la construcción de la red no se presentó, en estos años, como una tarea urgente, dado el fracaso de la política triguera, la caída de la producción, el rechazo de los agricultores a las vías de comercialización oficiales y la amplitud del mercado negro.

El Servicio funcionó con almacenes arrendados y en no muy buenas condiciones técnicas. En las publicaciones oficiales se afirma que los almacenes, durante los años cuarenta, habían resultado escasos, muy deficientes y habían planteado grandes dificultades para la entrega de los trigos, sin ofrecer garantías de un pesaje exacto ni de limpieza ni de higiene ${ }^{69}$. En todo caso, y en palabras del propio SNT: «Se consumió la década en tanteos, trabajos de gabinete y obras de lento desarrollo y llenas de dificultades ${ }^{70}$.

68 El silo de Córdoba fue inaugurado por el general Franco el 6 de junio de 1951. Estaba equipado con maquinaria extranjera, de la casa Bühler, y resultaba una construcción imponente de 57,5 m de alto y $25 \mathrm{~m}$ de ancho, con una capacidad de 15000 t que se ampliaron más tarde hasta las 23 000. SNT (1958: 152). I Congreso Nacional (1950, vol. vI: 22-23).

70 SENPA (1975: 98). En el Congreso Agrario Regional del Duero, celebrado en 1945, se coincidía en esta apreciación: «En la actualidad, y por las circunstancias que atravesamos, no existe gran problema para el almacenamiento de cereales». (1945: 36). No obstante, los agricultores del Duero recordaban que era urgente la construcción de silos y la creación de la Red Nacional. 
CUADRO 2. EVOLUCIÓN ANUAL DE LA RED NACIONAL DE ALMACENAMIENTO SEGÚN TIPO DE UNIDADES

\begin{tabular}{|c|c|c|c|c|c|c|}
\hline \multirow[b]{2}{*}{ Años } & \multicolumn{2}{|c|}{ Silos } & \multicolumn{2}{|c|}{ Graneros } & \multicolumn{2}{|c|}{ Total } \\
\hline & Número & $\begin{array}{c}\text { Capacidad } \\
t\end{array}$ & Número & $\begin{array}{c}\text { Capacidad } \\
t\end{array}$ & Número & $\begin{array}{c}\text { Capacidad } \\
t\end{array}$ \\
\hline $1937-1948$ & 1 & 1500 & 8 & 13050 & 9 & 14550 \\
\hline 1949 & 3 & 6500 & 0 & 0 & 3 & 6500 \\
\hline 1950 & 10 & 56600 & 1 & 1000 & 11 & 57600 \\
\hline 1951 & 5 & 13750 & 0 & 0 & 5 & 13750 \\
\hline 1952 & 6 & 24750 & 6 & 7200 & 12 & 31950 \\
\hline 1953 & 7 & 20890 & 15 & 13200 & 22 & 34090 \\
\hline 1954 & 19 & 38790 & 16 & 13700 & 35 & 52490 \\
\hline 1955 & 38 & 92570 & 21 & 17750 & 59 & 110320 \\
\hline 1956 & 39 & 103700 & 47 & 52300 & 86 & 156000 \\
\hline 1957 & 40 & 97750 & 59 & 54100 & 99 & 151850 \\
\hline 1958 & 20 & 52400 & 13 & 13000 & 33 & 65400 \\
\hline 1959 & 6 & 11850 & 8 & 10400 & 14 & 22250 \\
\hline 1960 & 8 & 21550 & 23 & 26200 & 31 & 47750 \\
\hline 1961 & 31 & 99400 & 18 & 23800 & 49 & 123200 \\
\hline 1962 & 23 & 65900 & 8 & 11500 & 31 & 77400 \\
\hline 1963 & 17 & 39850 & 11 & 10300 & 28 & 50150 \\
\hline 1964 & 28 & 88900 & 1 & 1000 & 29 & 89900 \\
\hline 1965 & 25 & 58550 & 2 & 4000 & 27 & 62550 \\
\hline 1966 & 50 & 103400 & 2 & 1800 & 52 & 105200 \\
\hline 1967 & 69 & 204470 & 2 & 1600 & 71 & 206070 \\
\hline 1968 & 72 & 241300 & 1 & 800 & 73 & 242100 \\
\hline 1969 & 45 & 123600 & 0 & 0 & 45 & 123600 \\
\hline 1970 & 39 & 114050 & 0 & 0 & 39 & 114050 \\
\hline 1971 & 25 & 84450 & 0 & 0 & 25 & 84450 \\
\hline 1972 & 12 & 41300 & 0 & 0 & 12 & 41300 \\
\hline 1973 & 4 & 21950 & 0 & 0 & 4 & 21950 \\
\hline 1974 & 0 & 5000 & 0 & 0 & 0 & 5000 \\
\hline 1975 & 9 & 164217 & 0 & 0 & 9 & 164217 \\
\hline 1976 & 6 & 105000 & 0 & 0 & 6 & 105000 \\
\hline 1977 & -41 & -51262 & -8 & -5428 & -49 & -56690 \\
\hline 1978 & 0 & 300 & 0 & 0 & 0 & 0 \\
\hline 1979 & 0 & -300 & 0 & 6950 & 0 & 6950 \\
\hline 1980 & 10 & 77199 & 3 & 8202 & 13 & 85401 \\
\hline 1981 & 9 & 63050 & 1 & 3000 & 10 & 66050 \\
\hline 1982 & 7 & 93750 & -2 & -900 & 5 & 92850 \\
\hline 1983 & 0 & 0 & 0 & 0 & 0 & 0 \\
\hline 1984 & 1 & 31350 & 0 & -430 & 1 & 30920 \\
\hline
\end{tabular}

FUENTE: Elaboración propia. Datos primarios: SENPA, Memorias y archivo. 
CUADRO 3. RED NACIONAL DE ALMACENAMIENTO. (Datos acumulados) ( $t$ )

\begin{tabular}{|c|c|c|c|c|c|c|}
\hline \multirow[b]{2}{*}{ Años } & \multicolumn{2}{|c|}{ Silos } & \multicolumn{2}{|c|}{ Graneros } & \multicolumn{2}{|c|}{ Total } \\
\hline & Número & Capacidad & Número & Capacidad & Número & Capacidad \\
\hline $1937-1948$ & 1 & 1500 & 8 & 13050 & 9 & 14550 \\
\hline 1949 & 4 & 8000 & 8 & 13050 & 12 & 21050 \\
\hline 1950 & 12 & 64600 & 9 & 14050 & 21 & 78650 \\
\hline 1951 & 19 & 78350 & 9 & 14050 & 28 & 92400 \\
\hline 1952 & 25 & 103100 & 15 & 21250 & 40 & 124350 \\
\hline 1953 & 32 & 123990 & 30 & 34450 & 62 & 158440 \\
\hline 1954 & 51 & 162780 & 46 & 48150 & 97 & 210930 \\
\hline 1955 & 89 & 255350 & 67 & 65900 & 156 & 321250 \\
\hline 1956 & 128 & 359050 & 114 & 118200 & 242 & 477250 \\
\hline 1957 & 168 & 456800 & 173 & 172300 & 341 & 629100 \\
\hline 1958 & 188 & 509200 & 186 & 185300 & 374 & 694500 \\
\hline 1959 & 194 & 521050 & 194 & 195700 & 388 & 716750 \\
\hline 1960 & 202 & 542600 & 217 & 221900 & 419 & 764500 \\
\hline 1961 & 233 & 642000 & 235 & 245700 & 468 & 887700 \\
\hline 1962 & 256 & 707900 & 243 & 257200 & 499 & 965100 \\
\hline 1963 & 273 & 747750 & 254 & 267500 & 527 & 1015250 \\
\hline 1964 & 301 & 836650 & 255 & 268500 & 556 & 1105150 \\
\hline 1965 & 326 & 895200 & 257 & 272500 & 583 & 1167700 \\
\hline 1966 & 376 & 998600 & 259 & 274300 & 635 & 1272900 \\
\hline 1967 & 445 & 1203070 & 261 & 275900 & 706 & 1478970 \\
\hline 1968 & 517 & 1444370 & 262 & 276700 & 779 & 1721070 \\
\hline 1969 & 562 & 1567970 & 262 & 276700 & 824 & 1844670 \\
\hline 1970 & 601 & 1682020 & 262 & 276700 & 863 & 1958720 \\
\hline 1971 & 605 & 1751155 & 283 & 292015 & 888 & 2043170 \\
\hline 1972 & 607 & 1792455 & 283 & 292015 & 890 & 2084470 \\
\hline 1973 & 621 & 1814405 & 283 & 292015 & 904 & 2106420 \\
\hline 1974 & 621 & 1819405 & 283 & 292015 & 904 & 2111420 \\
\hline 1975 & 680 & 1983622 & 283 & 292015 & 963 & 2275637 \\
\hline 1976 & 686 & 2088622 & 283 & 292015 & 969 & 2380637 \\
\hline 1977 & 645 & 2037360 & 275 & 286587 & 920 & 2323947 \\
\hline 1978 & 645 & 2037660 & 275 & 286587 & 920 & 2324247 \\
\hline 1979 & 645 & 2037360 & 275 & 293537 & 920 & 2330897 \\
\hline 1980 & 655 & 2114559 & 278 & 301739 & 933 & 2416298 \\
\hline 1981 & 664 & 2177609 & 279 & 304739 & 943 & 2482348 \\
\hline 1982 & 671 & 2271359 & 277 & 303839 & 948 & 2575198 \\
\hline 1983 & 671 & 2271359 & 277 & 303839 & 948 & 2575198 \\
\hline 1984 & 672 & 2302709 & 277 & 303409 & 949 & 2606118 \\
\hline
\end{tabular}

FUENTE: Elaboración propia. Datos primarios: SENPA, Archivo y Memorias. 
CUADRO 4. EVOLUCIÓN ANUAL DE LA RED NACIONAL DE ALMACENAMIENTO

\begin{tabular}{|c|c|c|c|c|}
\hline \multirow[b]{2}{*}{ Años } & \multicolumn{2}{|c|}{ Datos anuales } & \multicolumn{2}{|c|}{ Datos acumulados } \\
\hline & Número & $\begin{array}{c}\text { Capacidad } \\
t\end{array}$ & Número & $\begin{array}{c}\text { Capacidad } \\
t\end{array}$ \\
\hline 1937-1948 & 9 & 14550 & 9 & 14550 \\
\hline 1949 & 3 & 6500 & 12 & 21050 \\
\hline 1950 & 11 & 57600 & 23 & 78650 \\
\hline 1951 & 5 & 13750 & 28 & 92400 \\
\hline 1952 & 12 & 31950 & 40 & 124350 \\
\hline 1953 & 22 & 34090 & 62 & 158440 \\
\hline 1954 & 35 & 52490 & 97 & 210930 \\
\hline 1955 & 59 & 110320 & 156 & 321250 \\
\hline 1956 & 86 & 156000 & 242 & 477250 \\
\hline 1957 & 99 & 151850 & 341 & 629100 \\
\hline 1958 & 33 & 65400 & 374 & 694500 \\
\hline 1959 & 14 & 22250 & 388 & 716750 \\
\hline 1960 & 31 & 47750 & 419 & 764500 \\
\hline 1961 & 49 & 123200 & 468 & 887700 \\
\hline 1962 & 31 & 77400 & 499 & 965100 \\
\hline 1963 & 28 & 50150 & 527 & 1015250 \\
\hline 1964 & 29 & 89900 & 556 & 1105150 \\
\hline 1965 & 27 & 62550 & 583 & 1167700 \\
\hline 1966 & 52 & 105200 & 635 & 1272900 \\
\hline 1967 & 71 & 206070 & 706 & 1478970 \\
\hline 1968 & 73 & 242100 & 779 & 1721070 \\
\hline 1969 & 45 & 123600 & 824 & 1844670 \\
\hline 1970 & 39 & 114050 & 863 & 1958720 \\
\hline 1971 & 25 & 84450 & 888 & 2043170 \\
\hline 1972 & 12 & 41300 & 900 & 2084470 \\
\hline 1973 & 4 & 21950 & 904 & 2106420 \\
\hline 1974 & 0 & 5000 & 904 & 2111420 \\
\hline 1975 & 59 & 164217 & 963 & 2275637 \\
\hline 1976 & 6 & 105000 & 969 & 2380637 \\
\hline 1977 & -49 & -56690 & 920 & 2323947 \\
\hline 1978 & 0 & 0 & 920 & 2323947 \\
\hline 1979 & 0 & 0 & 920 & 2323947 \\
\hline 1980 & 13 & 93351 & 933 & 2416298 \\
\hline 1981 & 10 & 66050 & 943 & 2482348 \\
\hline 1982 & 5 & 92850 & 948 & 2575198 \\
\hline 1983 & 0 & 0 & 948 & 2575198 \\
\hline 1984 & 1 & 30920 & 949 & 2606118 \\
\hline
\end{tabular}

FUENTE: Elaboración propia a partir de las Memorias del SENPA. 
CUADRO 5. CONFIGURACIÓN FUNCIONAL DE LA RED NACIONAL DE ALMACENAMIENTO

\begin{tabular}{|c|c|c|c|c|}
\hline \multirow[b]{2}{*}{ Años } & \multicolumn{2}{|c|}{ Unidades de recepción } & \multicolumn{2}{|c|}{ Unidades de tránsito y reserva } \\
\hline & Número & $\begin{array}{l}\text { Capacidad } \\
\text { Miles de } t\end{array}$ & Número & $\begin{array}{l}\text { Capacidad } \\
\text { Miles de } t\end{array}$ \\
\hline 1949 & 11 & 18,4 & 1 & 2,6 \\
\hline 1950 & 20 & 40,0 & 3 & 38,6 \\
\hline 1951 & 25 & 53,8 & 3 & 38,6 \\
\hline 1952 & 36 & 71,7 & 3 & 38,6 \\
\hline 1953 & 58 & 105,8 & 3 & 38,6 \\
\hline 1954 & 93 & 158,3 & 3 & 38,6 \\
\hline 1955 & 151 & 262,1 & 4 & 45,1 \\
\hline 1956 & 236 & 376,1 & 5 & 57,1 \\
\hline 1957 & 334 & 550,5 & 6 & 64,6 \\
\hline 1958 & 367 & 615,9 & 6 & 64,6 \\
\hline 1959 & 381 & 638,1 & 6 & 64,6 \\
\hline 1960 & 412 & 685,9 & 6 & 64,6 \\
\hline 1961 & 460 & 787,1 & 7 & 86,6 \\
\hline 1962 & 491 & 864,5 & 7 & 86,6 \\
\hline 1963 & 519 & 914,6 & 7 & 86,6 \\
\hline 1964 & 546 & 970,5 & 8 & 108,6 \\
\hline 1965 & 573 & 1033,1 & 8 & 108,6 \\
\hline 1966 & 625 & 1138,3 & 8 & 108,6 \\
\hline 1967 & 696 & 1344,4 & 8 & 108,6 \\
\hline 1968 & 768 & 1574,5 & 9 & 120,6 \\
\hline 1969 & 813 & 1698,1 & 9 & 120,6 \\
\hline 1970 & 852 & 1812,1 & 9 & 120,6 \\
\hline 1971 & 877 & 1896,6 & 9 & 120,6 \\
\hline 1972 & 889 & 1937,9 & 9 & 120,6 \\
\hline 1973 & 892 & 1947,8 & 10 & 132,6 \\
\hline 1974 & 892 & 1952,8 & 10 & 132,6 \\
\hline 1975 & 945 & 2037,0 & 16 & 212,6 \\
\hline 1976 & 945 & 2037,0 & 22 & 317,6 \\
\hline 1977 & 897 & 1948,9 & 21 & 349,0 \\
\hline 1978 & 897 & 1948,9 & 21 & 349,0 \\
\hline 1979 & 897 & 1955,9 & 21 & 349,0 \\
\hline 1980 & 908 & 2007,3 & 23 & 383,0 \\
\hline 1981 & 916 & 2048,3 & 25 & 408,0 \\
\hline 1982 & 920 & 2077,5 & 26 & 471,7 \\
\hline 1983 & 920 & 2077,5 & 26 & 471,7 \\
\hline
\end{tabular}

FUENTE: Elaboración propia a partir de las Memorias del SENPA. 


\section{GRÁFICO 2. EVOLUCIÓN DE LA RED NACIONAL DE ALMACENAMIENTO SEGÚN TIPO DE UNIDADES}

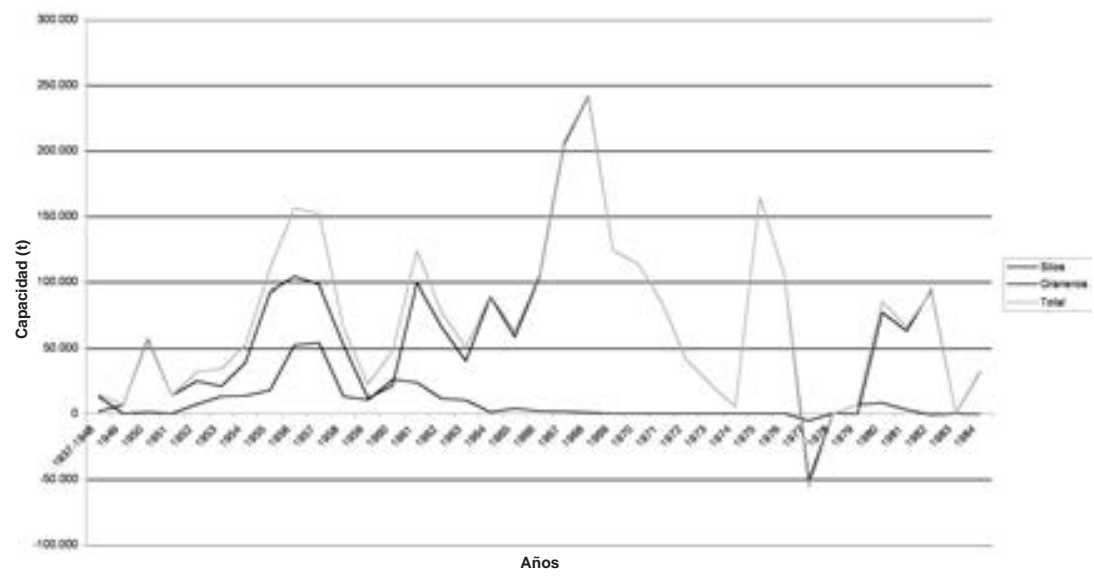

FUENTE: Cuadro 2.

GRÁFICO 3. RED NACIONAL DE ALMACENAMIENTO. (Datos acumulados)

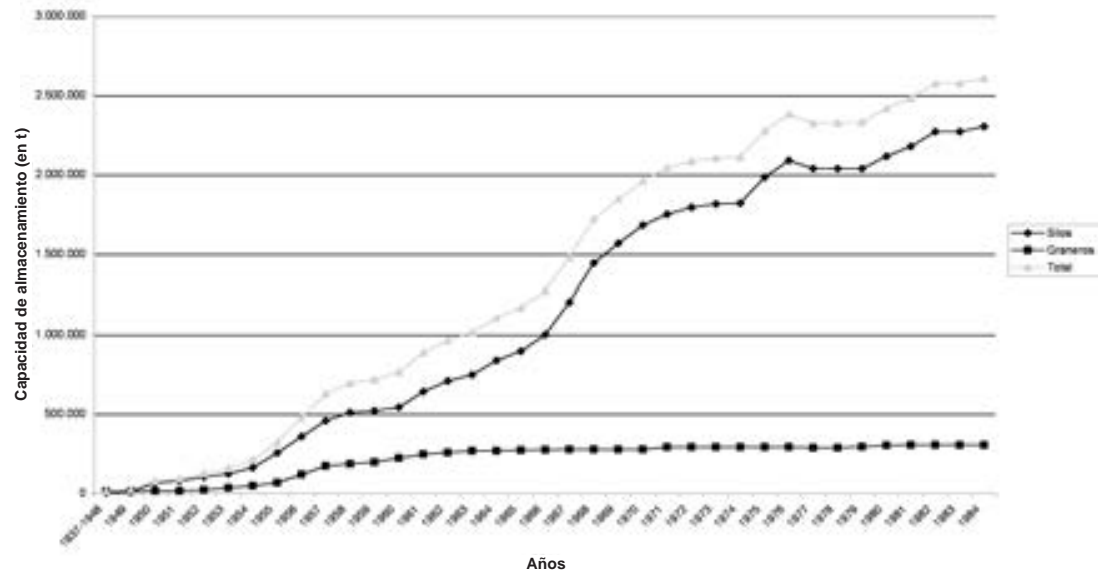

FUENTE: Cuadro 3. 


\section{GRÁFICO 4. EVOLUCIÓN DE LA RED NACIONAL DE ALMACENAMIENTO (t)}

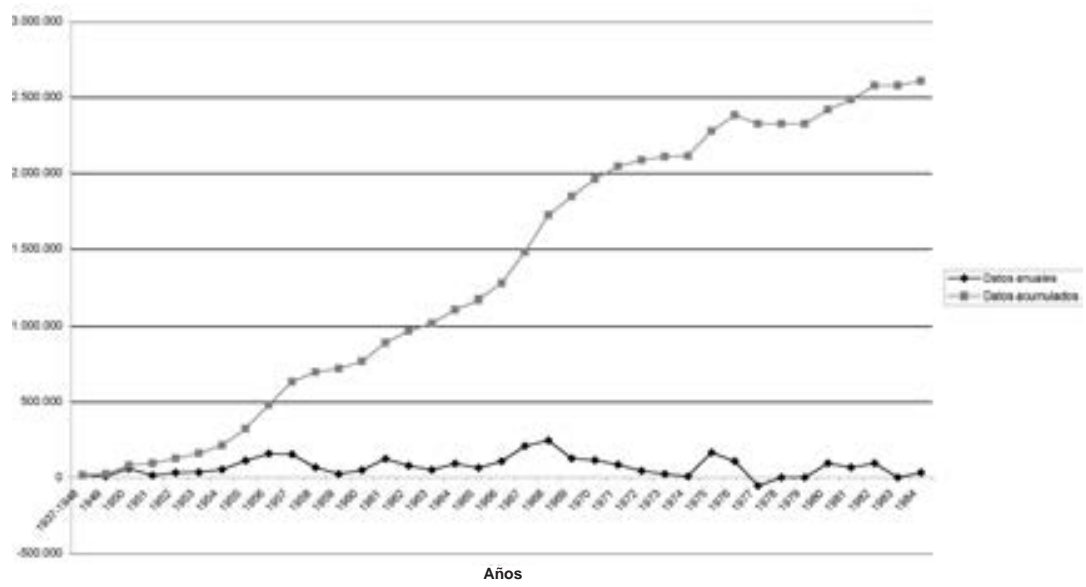

FUENTE: Cuadro 4.

- Los años cincuenta. En esta década se produce un cambio significativo en la política triguera, en un intento de normalizar los mercados, y una tímida apertura comercial exterior de España. El paulatino aumento de la producción agraria y la recuperación económica general impulsaron, en esta fase, la construcción de la red que alcanzó un ritmo muy rápido en los años 1955 a 1957, durante el ministerio de Cavestany, para experimentar un claro declive en los años 1958 a 1960, con un mínimo relativo en $1959^{71}$.

Por otra parte, el propio concepto de Red planteaba la creación de lazos de comunicación entre las diversas unidades que, en el caso de los grandes silos de tránsito y de puerto, exigían enlaces ferroviarios y medios de transporte ágiles, en concreto vagones-tolva. Las dificultades económicas y la falta de divisas impidieron la importación de este tipo de

71 Paralelamente se promulgaron diversas medidas para fomentar la capacidad privada de almacenamiento. El Decreto de 19 de octubre de 1951 regulaba la concesión de subvenciones para la construcción de graneros privados y el Decreto de 10 de octubre de 1952 hacía lo propio en relación con las construcciones de las Hermandades Sindicales de Labradores y Ganaderos. 
material rodante. A partir de 1953 se importaron 60 vagones-tolva adquiridos a la casa Etablissement Industriels $B$. Richard de París ${ }^{72}$. Con estos vagones se pudieron formar cuatro trenes de 15 vagones, capaces de transportar $300 \mathrm{t}$ de grano. Con ello se unieron los silos de Córdoba y Mérida con el silo del puerto de Málaga con lo que la Red entraba, finalmente, en funcionamiento. Este enlace ferroviario triguero permitió realizar las primeras exportaciones de trigos "ambar durum» andaluces y extremeños, muy demandados en algunos países europeos como Italia por sus características únicas para la fabricación de pastas. Igualmente, el silo de Málaga se utilizó para la «exportación» de trigos blandos, de los que empezaron a aparecer excedentes a partir de mediados de los años cincuenta, a países árabes del norte de África y del Próximo Oriente, en unas operaciones de venta cuyos resultados fueron económicamente ruinosos para España ${ }^{73}$.

A pesar de que el SNT autofinanciaba la construcción de los silos, parece claro que la coyuntura de la estabilización, las malas cosechas de 1960 y 1961 y la sustitución de Cavestany al frente del ministerio, se hicieron notar en la actividad inversora del Servicio.

En esta etapa se construyeron en especial, y en exceso, unidades de almacenamiento de escasa capacidad y horizontales, que exigían un trabajo muy duro a los agricultores a la hora de hacer sus entregas de grano al SNT. Estos graneros horizontales estaban escasamente mecanizados y el manejo de los sacos y su transporte se realizaba a hombros. Según el propio SNT: «Ante los graneros, los agricultores, cada vez van manifestando mayor resistencia a realizar trabajos pesados en sus entregas y a conducir los sacos y descargarlos subiendo a los montones de trigo, trabajo penoso que a todas luces es preciso suprimir», pero que no pudo evitarse desde el principio en muchas localidades por imposibilidad completa de mecanización en aquellos momentos o por falta de energía suficiente para mover las instalaciones ${ }^{74}$.

72 Es evidente que los trenes no formaban parte, en sentido estricto, de la Red de Silos. Sin embargo, constituían un elemento imprescindible para su funcionamiento y su coste fue sufragado por el Estado. En concreto esta operación tuvo un coste total de 14,8 millones de pesetas. SNT (1958: 281).

73 El lector interesado puede ver con detalle estas operaciones en Barciela (1981b y $1985 a)$.

74 SNT (1962: 23). 
La capacidad media de las unidades construidas en 1957 alcanzó las 1533,8 t cifra notablemente más baja, como veremos, de las que se construyeron con posterioridad. Desde un punto de vista ideológico (y propagandístico) en estos años se impone, definitivamente, la idea de la indiscutible bondad e ineludible necesidad de disponer, lo antes posible, de la Red Nacional de Silos. En todas las publicaciones oficiales, en todos los foros nacionales o internacionales donde representantes españoles tienen ocasión de exponer las líneas de la política agraria nacional, aparece siempre la construcción de la red como uno de los objetivos prioritarios. Así, en el Informe a la VII Sesión de la Conferencia de la Organización de las Naciones Unidas para la Agricultura y la Alimentación 1953-1954, se anunciaba el propósito del Gobierno español de multiplicar por cinco, en un plazo de seis años, la capacidad de almacenamiento, ampliación «indispensable para poder movilizar nuestras cosechas de trigo y almacenar las reservas indispensables que aseguren la estabilidad permanente del abastecimiento nacional» ${ }^{75}$. En idénticos términos se expresaban los planes anunciados en el libro Un siglo de progreso agrícola, publicado en 1955 con motivo del centenario de la creación de las carreras de Ingenieros Agrónomos y Peritos Agrícolas y de la fundación de la Escuela Central de Agricultura. En 1959 la FAO publicaba un importante estudio titulado Proyecto de desarrollo de la región mediterránea. En el capítulo dedicado a España se abordaban, con especial atención, los problemas relativos al sector triguero. El estudio presentaba unas previsiones de producción y consumo de trigo, por quinquenios, hasta 1979 que resultaban, sorprendentemente, totalmente coincidentes con las elaboradas por el Gobierno español, tanto en la fecha final como en las intermedias ${ }^{76}$. Se avalaba, en definitiva, por parte de la FAO una política de pleno autoabastecimiento triguero algo, como mínimo, sorprendente ${ }^{77}$. En esta línea autárquica el informe defendía la necesidad de «aumentar la capacidad de la red de silos y graneros necesarios para sentar las bases de una política de piensos y permitir el almacenamiento de las mayores producciones previs-

75 Comité nacional español para la FAO (1955: 61).

76 Al margen de los problemas que plantea una estimación a tan largo plazo, llama poderosamente la atención la pretensión de este estudio de hacer coincidir con total exactitud las previsiones del consumo con la producción nacional, cosa difícil de comprender.

77 En la página 196 del citado estudio se estimaba el consumo de trigo en 1979 en 3880 millones de toneladas, y en la página 198 se estimaba para el mismo año una producción exactamente igual al consumo. 
tas ${ }^{78}$. En consecuencia, la FAO recomendaba un programa de inversiones quinquenales en la Red de Silos entre 1960-1964 y 1975-1979 que ascendía a un total de 6796 millones de pesetas ${ }^{79}$, que venía a ratificar la política triguera y de almacenamiento en vigor en España. Esta total coincidencia entre las recomendaciones de la FAO y la política cerealista española no era, evidentemente, casual.

En realidad, el informe de la FAO, en lo que concierne a España, no estaba elaborado por técnicos propios de este organismo ni tampoco por técnicos independientes, sino que era la simple reproducción de un informe elaborado por el Instituto de Estudios Agro-Sociales y enviado a la $\mathrm{FAO}^{80}$. El informe del Instituto se mostraba muy rotundo al afirmar:

Se hace necesario asimismo intensificar el actual programa de construcción de la Red de Silos y Graneros para la regulación del mercado triguero; se calcula que el ritmo anual de construcción de silos para trigo debe ser, como mínimo de 135000 t de capacidad hasta alcanzar una capacidad total de almacenamiento de trigo de unos 13 millones de quintales ${ }^{81}$.

Entre los autores del informe español se encontraban algunos de los más destacados técnicos agronómicos implicados directamente en el diseño de la política agraria del momento lo que explica, en definitiva, la total armonía existente entre las recomendaciones de la FAO, el informe del Instituto y la política oficial ${ }^{82}$. Como es obvio, en este caso, el estudio de la FAO carecía de la objetividad y de la independencia que sí tuvieron otros estudios posteriores de este organismo.

Las organizaciones agrarias compartían, evidentemente, este objetivo. En la V Asamblea Nacional de las Hermandades Sindicales de Labradores y Ganaderos celebrada en 1953 se afirmaba:

78 FAO (1959: 200).

79 FAO (1959: 200).

80 Las diferencias entre el informe del Instituto y el de la FAO son insignificantes. Así, mientras la FAO recomendaba unas inversiones en la Red de Silos de 6796 millones de pesetas, para el periodo 1960-1979 el Instituto las evaluaba en 6856 millones.

81 Instituto (1959: 320).

82 Este estudio, no publicado, llevaba por título Proyecto de desarrollo de la región mediterránea. España, y entre sus redactores se encontraban destacados miembros del Instituto de Estudios Agro-Sociales y profesores de la Facultad de Económicas de Madrid. 
AI SNT debe corresponder la primordial y básica misión de servir de panera nacional, buscando por un lado el pleno abastecimiento del mercado, y, por otro, mantener los precios para que resulten remuneradores para el agricultor [...] para que (el SNT) pueda realizar esta función ha de imprimirse la máxima rapidez en la constitución de la Red Nacional de Silos ${ }^{83}$.

Por su parte, el Consejo Económico Sindical, en 1957 instaba al Gobierno a «acelerar la terminación de la Red Nacional de Silos y Almacenes», a la vez que criticaba, suavemente, "la excesiva lentitud» en su desarrollo ${ }^{84}$.

En el mismo año, la editorial Publicaciones Españolas, especializada en propaganda, publicaba en su colección «Temas españoles» un folleto dedicado a ensalzar y justificar la construcción de la red de silos. El autor afirmaba:

La Red Nacional de Silos es una de las empresas más interesantes acometidas hoy por el Estado. Como elemento regulador de la economía, como factor para racionalizar nuestro mercado agrícola, como instrumento puesto al servicio del labrador, la obra ingente de los silos pertenece a esa categoría de las cosas que quedan.

No imaginaba el autor del texto hasta qué punto era cierto que los silos iban a formar parte de las cosas «que quedan» y los quebraderos de cabeza y financieros que originarían. La justificación de los silos era, para el autor del folleto, evidente por sí misma: «La función de los silos es clara, y su utilidad tan patente, que se halla al margen de toda posible crítica» 85 .

83 Junta Nacional de Hermandades (1953: 88). Al margen de la defensa de planteamientos autárquicos, lógica, por lo demás, en una organización corporativa, las conclusiones de la Asamblea hacían referencia a las necesidades futuras de trigo, que estimaban, para 1965, en 5,1 millones de toneladas, es decir, $155 \mathrm{~kg}$ por persona y año, estimación, a todas luces, muy exagerada y nada fundamentada (1953: 4).

La conclusión cuarta afirmaba textualmente: «Es preciso acelerar la terminación de la Red Nacional de Silos y Almacenes, cuyo desarrollo se lleva con excesiva lentitud, sobre todo si el Servicio Nacional tuviese que ampliar su política reguladora a los piensos. La Organización Sindical puede y debe ayudar al desarrollo de esta política de almacenes». Sin embargo, este estudio no proporcionaba ningún dato concreto sobre cómo podía llevarse a cabo dicha cooperación. CES (1957: 57).

Núñez-Mayo (1957: 8-9). 
En definitiva, Gobierno y agricultores trigueros coincidían en la idea de construir la Red de forma inmediata. Sin embargo, en mi opinión, la decisión se tomó por parte del Gobierno de manera precipitada, tal vez a causa precisamente de este favorable y unánime estado de opinión, dejándose arrastrar por la inercia de unos planteamientos gestados en los años treinta y cuarenta.

En los años cincuenta las circunstancias económicas generales del país habían cambiado sustancialmente y hubiera sido necesaria una profunda reflexión por parte del Gobierno sobre la auténtica necesidad de una Red Nacional de Silos o, al menos, sobre su diseño, funciones, tamaño óptimo, así como sobre la conveniencia de ser, o no, pública.

Precisamente, en esos años, concretamente en 1956, se publicaba en castellano la obra de T. W. Schultz, La organización económica de la agricultura, cuyo estudio hubiera resultado de gran interés y provecho para los responsables de la política agraria en esta y en otras muchas cuestiones. Schultz admitía, en principio, la intervención estatal para que «el gobierno diseñe, publique y ponga en acción un programa de almacenamientos elaborado para servir a los propósitos de la seguridad nacional». Sin embargo, advertía de la necesidad de responder, antes, a una serie de preguntas básicas relativas a los criterios apropiados sobre el almacenamiento, al análisis de las experiencias y a los modelos de administración y gestión y advertía de los riesgos: «el almacenamiento presenta algunas posibilidades; pero no se ha pensado todavía en ellas lo suficiente para descubrir el criterio más apropiado respecto a este arbitrio». En el caso de nuestro país no se contribuyó, en absoluto, a resolver ese déficit de reflexión que denunciaba T. W. Schultz.

Si contemplamos con una visión amplia la situación de la economía y de la agricultura españolas a comienzos de los años cincuenta, lo cierto es que hubiera sido posible cambiar los planteamientos autárquicos que inspiraron la construcción de la Red y que se habían consolidado durante la segunda mitad de los años cuarenta.

Desde una perspectiva internacional las circunstancias habían cambiado radicalmente. La norma básica sobre la Red se había elaborado, como ya hemos visto, en 1946, tal vez en el momento más crítico de toda la historia del régimen, en el apogeo del rechazo internacional y en una dificilísima situación alimentaria mundial. Fue, precisamente en dicho año, cuando la FAO publicó su Encuesta Mundial sobre la Alimentación que 
mostraba con claridad, a pesar de la desorganización de los servicios estadísticos de muchas naciones, la gravedad de la situación alimentaria en buena parte del mundo y en particular en los países más dañados por la guerra. En este contexto, y al margen de la propia responsabilidad del régimen en su delicada situación internacional y contando con que el general Franco estaba dispuesto a asumir todo tipo de sacrificios para la población española con tal de mantenerse en el poder, era explicable el triunfo de unos planteamientos autárquicos.

Sin embargo, esta situación cambió muy pronto. Los EE. UU. proporcionaron ayuda alimentaria a España, ya durante la segunda mitad de los años cuarenta, en un contexto de diálogo y de clara aproximación entre ambos países. Por otra parte, España se incorporaba al IWA (Internacional Wheat Agreement) o Acuerdo Internacional del Trigo, con lo que se garantizaban unos cupos fijos de importaciones de grano. En 1949-1950 más de la mitad del comercio mundial de trigo se desarrollaba en el seno del IWA. La aproximación a los EE. UU. culminó con la firma de los Acuerdos de Madrid en 1953, lo que aseguraba definitivamente la posibilidad de importar todo el trigo estadounidense necesario. Finalmente, en lo que concierne al contexto internacional, la aprobación por parte del Congreso norteamericano de la Ley Federal 480, de 10 de julio de 1954 («Agricultural Trade Development and Assistence Act») y la posterior enmienda McCarran, abrían unas posibilidades prácticamente ilimitadas de importar trigo con cargo a la ayuda americana ${ }^{86}$.

En 1952, la FAO publicaba su Segunda Encuesta Mundial Alimentaria en la que, aunque se seguían apreciando dificultades en algunas regiones, se observaba una mejora sustancial en relación con la encuesta de 1946. Así, para los países de la OECE, entre los que se encontraban la mayor parte de los países más dañados por la guerra, la producción agrícola para consumo humano, que en 1947-1948 había sido tan solo el $81 \%$ de la de preguerra, alcanzaba un índice de 104 en 1949-1950 y de 111 en 1950-1951. Por su parte, América del Norte y Central alcanzaban un

86 La Ley Pública 480, como suele conocérsela, reunificaba diversos programas de ayudas y subvenciones entre ellos los programas de asistencia de productos agrícolas del Plan Marshall y los de la «Mutual Security Act», con el objetivo de «incrementar el consumo de los productos agrarios de los EE. UU. en los países extranjeros, para mejorar las relaciones exteriores de los EE. UU. y para otros fines». Barciela (1981a). 
índice medio para 1946-1947 de 143, en relación con el 100 de preguerra, también en cosechas alimenticias ${ }^{87}$. En lo que concierne específicamente a los cereales, la producción de trigo y centeno pasó de 149,7 millones de t en 1939 a 163,2 millones (promedio de 1949-1950) y la de cereales secundarios (cebada, avena, maíz y sorgo) de 196,0 a 226,2 millones. Asimismo, el comercio mundial de cereales había superado ampliamente el nivel de preguerra en 1949-1950. En concreto, el de trigo y centeno había pasado de 17,3 millones de t a 23,9, en las citadas fechas ${ }^{88}$.

En conclusión, no cabe ninguna duda de que la situación de España, desde el punto de vista de la garantía de un normal desarrollo del comercio internacional, era, a comienzos de los años cincuenta, diametralmente opuesta a la de 1946. La pregunta que surge de inmediato es: ¿por qué se insistió, entonces, en llevar a cabo la construcción de una Red de Silos concebida y diseñada durante los años cuarenta? La primera respuesta es que se insistió en dicha línea porque siguieron predominando los planteamientos autárquicos en la producción triguera, lo que a su vez puede ser explicado por varias razones. En primer lugar, el Gobierno se veía en la necesidad de intentar reparar los daños causados a cientos de miles de pequeños cultivadores trigueros durante los años cuarenta a causa de la política de cupos forzosos de entrega obligatoria a bajos precios de tasa. Con ello el régimen buscaba recuperar el apoyo político y social de un sector muy importante de la población, implicado en el «Alzamiento» y desilusionado por la evolución de los acontecimientos durante los años cuarenta.

Tampoco hay que olvidar la propia fuerza adquirida por el SNT que contó con el respaldo de políticos destacados como el ministro de Agricultura Rafael Cavestany y, lo que es más importante, con la del propio general Franco implicado directa y personalmente en la «batalla triguera».

Es evidente, en mi opinión, que tampoco era posible en aquellos momentos llevar a cabo un inmediato desmantelamiento del SNT, ni proceder a liberalizar el mercado exterior del trigo de forma súbita. A comienzos de los años cincuenta había en España un millón y medio de agricultores trigueros, la inmensa mayoría pequeños propietarios cultivadores de tierras poco aptas, con bajos rendimientos y con escasas alternativas ${ }^{89}$.

\footnotetext{
87 FAO (1952: 6).

88 FAO (1952: 11).

89 Puede verse al respecto el capítulo dedicado a la estructura de las explotaciones trigueras en Barciela (1981a).
} 
Una reforma radical del marco proteccionista habría provocado un auténtico cataclismo en el campo español y una crisis social insoportable.

Sin embargo, entre la liberalización inmediata del sector y el mantenimiento de la política autárquica, cabían soluciones intermedias y gradualistas que el Gobierno no supo o no quiso adoptar. Se perdió, de esta forma, la primera gran ocasión de reformular la política triguera y, dentro de ella, el enfoque de la solución al problema de los almacenamientos. En concreto, habría sido perfectamente posible, a mi entender, la eliminación del criterio de que los almacenamientos tenían que ser estatales y que tenían que estar dirigidos a la consecución del autoabastecimiento nacional. Considero, igualmente, que se podría haber dado más juego a la iniciativa privada en el comercio interior e internacional.

-Los años sesenta se caracterizaron por la gran fiebre constructora, en particular el periodo 1966-1970. Desde un punto de vista técnico esta etapa se caracteriza por la construcción de unidades verticales y de silos metálicos, de los que se levantaron 280 unidades con una capacidad total de $971020 \mathrm{t}$, un volumen superior al del total construido durante los años cuarenta y cincuenta. El final definitivo de las penurias energéticas permitió afrontar la elevación de los silos ${ }^{90}$. Igualmente, la paulatina sustitución de los carros por modernos remolques y camiones exigió «un reajuste en la técnica de la construcción de silos y de sus instalaciones»91. Tanto la capacidad media (2902,4 t en 1967 y 3316,4 t en 1968), como las condiciones y equipamiento técnico de los silos, fueron, lógicamente, aumentando y mejorando en esta tercera fase.

Lo más llamativo en este periodo de grandes inversiones y de alto ritmo de construcción fue la paralización de los planes relativos a la construcción de silos de puerto. En 1965 se inauguraba el de Santa Cruz de Tenerife que fue el segundo y último de los silos de puerto construidos por el SNT. Sin embargo, en 1958, estaban totalmente finalizados los proyectos de silos de Las Palmas de Gran Canaria, Cádiz y La Coruña ${ }^{92}$ y en 1962 los de Barcelona, Valencia y Santander ${ }^{93}$. Ninguno de estos seis

90 Todavía en 1958 el SNT justificaba la construcción de almacenes «cuando dificultades de cimentación o falta de energía eléctrica impidan la construcción de silos». SNT (1958: 154).

SNT (1962: 23).

SNT (1958: 223).

SNT (1962: 24). 
importantes proyectos se llevó, finalmente, a la práctica. Poco he podido averiguar en relación con las causas de la paralización de los planes de construcción de la red de silos portuarios. Es posible, por una parte, que la causa estribe en la finalidad que habrían de tener este tipo de unidades. Los dirigentes del Ministerio de Agricultura y del SNT llegaron a pensar que España podría llegar a convertirse en un país exportador de trigo y harina ${ }^{94}$. Es evidente que esta pretensión de convertir a España en un país exportador de trigo era una quimera y, en la medida en que alguno de los silos de puerto se hubiera pensado con esa finalidad, no resulta extraño que, finalmente, su construcción no se hubiera llevado a cabo. Por otra parte, tampoco parece razonable que se construyeran para realizar importaciones de trigo dada la decidida política de autoabastecimiento dominante. Es muy posible, por último, que su no construcción se debiera a los problemas que se plantearon con su financiación. De hecho, el Servicio manifestó su incapacidad de financiar la construcción de estos silos (como hacía con todas las unidades de la red), indicando que debía ser el Estado el que asumiera esta obligación. En definitiva, el conjunto de estas causas puede que explique la paralización de la construcción de esta parte de la Red.

No cabe duda de que el crecimiento económico de los años sesenta fue el factor fundamental que permitió la expansión de la Red, al eliminar multitud de obstáculos causados por la política autárquica. Como causas inmediatas de la aceleración de la construcción, hay que señalar el gran auge en la producción de trigo, de cebada y de otros cereales ${ }^{95}$, así como los crecientes excedentes de trigo que empezaron a acumularse en los silos.

Durante los años sesenta, como es bien conocido, se publicaron dos importantes informes de organismos internacionales sobre la economía

94 En SNT (1962: 27-28), se afirmaba que España había iniciado su presencia como exportadora en el mercado internacional en 1951-1952, campaña en la que «se devolvieron a Portugal 450000 qm.». Igualmente, se recordaba que entre 1954-1955 y 1962 se habían vendido 2717500 q de trigos «ambar durum» y 7 millones de q de trigos blandos a la República Árabe Unida entre 1957 y 1960, así como los trigos y harinas vendidos al Protectorado de España en Marruecos.

95 Como afirmaba el editorial del número 385 de la revista Ceres, el problema del almacenamiento se estaba agravando por la necesidad de adquirir trigo, cebada, maíz, sorgo, avena y todo ello separadamente por distintas calidades. 
española: el Informe del Banco Mundial de Reconstrucción y Fomento (BIRF) de 1962, y el del BIRF y la FAO de 1966. En ambos documentos se destacaba críticamente la pervivencia de rasgos autárquicos en la política agraria española y se abordaba, entre otros, de manera muy concreta el problema de la Red de Silos.

El primero de los informes resulta algo contradictorio. Así, tras afirmar que «deberían construirse instalaciones adicionales, a fin de almacenar las cosechas para su exportación posterior o para que sirvan de reserva [...] recomendamos que durante el período 1962-1966 se asigne anualmente la suma de 200 millones de pesetas para nuevas construcciones de instalaciones públicas de almacenaje», sostenía que «España no posee una ventaja comparativa en el cultivo de trigo que justifique la producción para la exportación con carácter regular ${ }^{96}$. No cabe duda de que los autores del Informe podrían haber sido un poco más consecuentes y haber planteado con claridad la irracionalidad de mantener una política triguera autárquica en España, aunque evidentemente se hubiera tratado de una observación no muy correcta políticamente.

El Informe del BIRF y de la FAO de 1966 era, sin embargo, mucho más clarividente en el análisis y valiente en las conclusiones. Así, recomendaba cambios radicales en la organización del mercado triguero y, específicamente, en la Red Nacional de Silos. En concreto, se proponía que los silos de puerto, incluidos los que estuviesen en construcción, se arrendasen o se vendiesen «a fabricantes de harinas o a distribuidores de cereales, ya que serán ellos quienes manejen en el futuro las importaciones, tanto de trigo como de cereales-pienso". En lo que concierne al grueso de la Red, el Informe proponía que el SNT retuviese «un núcleo estratégico para ser utilizado [...] de acuerdo con los programas de garantía de precios para todos los cereales». El resto de las instalaciones, silos y graneros debería ser «vendido o arrendado progresivamente a cooperativas y asociaciones de productores [...] así como a los fabricantes de harinas». Evidentemente, todo ello partiendo de la premisa de que el Estado tenía que abandonar de inmediato la idea de una Red Nacional de Silos ${ }^{97}$.

Las propuestas del Informe implicaban, en definitiva, la supresión de la Red Nacional de Silos, dentro de una radical reforma del SNT, y la pues-

96 Informe del BIRF (1962: 419-420).

97 Informe del BIRF y de la FAO (1966: 203). 
ta en marcha de un modelo alternativo de organización del mercado cerealista que se acercara al que se estaba construyendo en la Europa comunitaria.

El Informe no encontró eco favorable alguno, que sepamos, en ámbitos gubernamentales; más bien al contrario ${ }^{98}$. Así, los planes de desarrollo siguieron recogiendo sucesivos proyectos de expansión de la Red. En concreto, el I Plan de Desarrollo Económico preveía unas inversiones de 1261 millones y el III Plan preveía que para 1975 serían necesarios 8,16 millones de toneladas de almacenamiento ${ }^{99}$.

En 1967 la Asociación Nacional de Ingenieros Agrónomos organizó un importante seminario titulado Agricultura y desarrollo en el que intervinieron el ministro comisario del Plan de Desarrollo, Laureano López-Rodó, el ministro de Agricultura, Adolfo Díaz Ambrona, el director de Agricultura y Alimentación de la OCDE, Simantov, y representantes de la FAO, del Ministerio de Agricultura francés y de la Asociación para el Desarrollo del Mediodía Italiano. En el seminario se abordó de forma amplia el problema del sector triguero español y la cuestión de los almacenamientos. En opinión de Serrats, presidente del seminario y de la Asociación Nacional «en España, los silos desgraciadamente faltan» y esa insuficiencia de almacenamiento «ha causado daños graves, muy graves y pérdidas cuantiosas", por lo que en su opinión resultaba «indispensable» la ampliación de la Red Nacional de Silos ${ }^{100}$.

La única voz discordante con este planteamiento procedió, curiosamente, de Reus, presidente del Sindicato Nacional de Cereales, que manifestó sus «críticas a este propósito español de querer hacerlo todo, casi siempre, a base de organismos de la Administración», lo que, además de los costes para el Estado impide la formación de entidades cooperativas comerciales, y añadía de manera clarividente:

La realidad es que cuando se hace una política demasiado paternalista, se evita grandemente la formación comercial de los agricultores, y eso es lo que yo me temo que nos puede ocurrir, cuando más largo o más temprano tengamos

98 Como lo prueba el que la Ley 26/1968, de 20 de julio, que establecía un régimen general para los productos sometidos a regulación de campaña, no afectase al trigo.

99 I Plan (1964: 162 y ss.) y III Plan (1972: 286 y ss.).

100 Agricultura y desarrollo (1967: 173). 
una asociación con el Mercado Común, y tengamos que acoplarnos a sus costumbres y usos en el mercado del cereal, y es que el agricultor español va a tener un gran desconocimiento de lo que es el mercadeo agrícola [... $]^{101}$.

A pesar de las críticas y de la aparición de planteamientos reformistas, la posición oficial no varió. El propio Servicio, en una monografía publicada en 1970, titulada Red Nacional de almacenamiento del SNC, sostenía que la capacidad de almacenamiento era insuficiente y, en parte, ineficaz, por la falta de calidad de algunas construcciones, así como por la escasa dimensión media y la falta de mecanización de otras. En consecuencia, reiteraba la necesidad de ampliar y mejorar la red ${ }^{102}$.

Los agricultores trigueros consiguieron, una vez más, encastillados en el SNT, imponer sus intereses frente a los de la mayoría de la población. En 1966, como antes en 1951 y en 1959, el Gobierno optó por una defensa cerrada del sector cerealista con altos costes para el país.

En mi opinión, si bien es cierto que la total liberalización del mercado triguero en 1966 no era factible políticamente, ni aceptable socialmente, sí que hubiese sido posible y razonable un programa de reformas en la línea marcada por el Informe del BIRF y de la FAO.

Incluso el SENPA llegó a aceptar, un poco más tarde, unos nuevos planteamientos teóricos sobre la política de almacenamientos que difería de los que habían inspirado la construcción de la Red Nacional. La Memoria de actividades correspondiente a 1975 sostenía la necesidad de una política de existencias fundamentada en diez motivos:

1. Stocks disponibles, dirigidos al abastecimiento nacional y en manos de una organización legalmente comprometida a dicho fin.

2. Stocks operativos, tienen el mismo fin que el anterior, pero son propiedad de almacenistas particulares.

3. Stocks de maniobra, con la misma finalidad pero en poder de la industria transformadora.

101 Agricultura y desarrollo (1967: 178).

102 SNC (1970). En esta línea, Velarde y Campos Nordmann (1968: 402), tras señalar que el monopsonio del SNT quedaba completo con la red de almacenamiento, advertían: "Sin embargo, una red de silos y graneros supone costes importantes para su instalación, y una serie de inversiones de magnitud importante». 
4. Stocks de enlace, cuyo objetivo es garantizar el abastecimiento en el periodo de empalme de cosechas y están en manos del organismo responsable.

5. Stocks de estabilización, con la misión de limitar las oscilaciones de precios.

6. Stocks de equilibrio, que son una prolongación a más largo plazo que los de enlace.

7. Stocks preventivos de catástrofes.

8. Stocks de auxilio hacia países necesitados.

9. Stocks de solidaridad, idénticos a los anteriores, pero canalizados a través de organismos internacionales especializados.

10. Stocks de eliminación, procedentes de todos los anteriores, y que al caducar un periodo normal de conservación han de ser consumidos ${ }^{103}$.

Como puede comprobarse, esta teoría resultaba más flexible y ya no avalaba la política de almacenamiento que se estaba practicando en España, que era en esencia la organizada a comienzos de los años cincuenta ${ }^{104}$. Sin embargo, se optó por mantener el modelo y por seguir ampliando la Red. Se perdió, otra vez, la oportunidad de dar un giro racionalizador a la política de almacenamientos y, en general, a toda la política cerealista.

A partir de 1971, y hasta 1984, se vive una fase irregular y contradictoria. Tras una etapa de desaceleración constructiva en los primeros años setenta, en 1975 y 1976 se produce un fuerte repunte. Durante los últimos años de este periodo, hasta el final del monopolio, se registran datos muy irregulares con un quinquenio final de construcción de grandes unidades, los «macrosilos», así como la reestructuración y cierre de algunas viejas instalaciones. Se llegó, de este modo, en los primeros años de la década de los ochenta, en vísperas de la desaparición del Servicio, a una Red Nacional que superaba los 2,6 millones de toneladas de capacidad. Se alcanzaba, finalmente, el viejo sueño del régimen franquista de culminar la Red, aunque este «logro» se producía justo en el momento en

103 SENPA (1975: 58-60).

104 Aun aceptando esta amplia variedad de motivos para mantener reservas, no existían para defender que los almacenamientos tuvieran que ser públicos, criterio al que siguió aferrado el Servicio. 
el que España entraba en la recta final de las negociaciones para el ingreso en la CEE y, con ello, se planteaba la exigencia inmediata de comenzar con su desmantelamiento.

Paralelamente a la Red Nacional, de propiedad pública, el Servicio mantuvo la política iniciada en sus primeros momentos de vida de arrendar instalaciones de particulares, creando lo que podríamos denominar la «red arrendada» 105 . En los cuadros 6 y 7 , se recogen los principales datos relativos a este sistema paralelo de almacenamiento. Como puede comprobarse, la capacidad de la red arrendada fue superior a la de la Red Nacional hasta 1977, momento en el que se inicia un declive ininterrumpido hasta su total extinción a partir de 1984.

\section{CUADRO 6. CAPACIDAD DE ALMACENAMIENTO ARRENDADA AL SENPA. (En miles de $t$ ). (Situación a 31 de diciembre de cada año)}

\begin{tabular}{cccccc}
\hline \multirow{2}{*}{ Año } & \multicolumn{2}{c}{ Red propia } & \multicolumn{2}{c}{ Capacidad arrendada } & \\
& Miles de t & $\%$ & Miles de $\mathrm{t}$ & $\%$ & Total \\
\hline 1974 & 2111 & 42,7 & 2289 & 57,3 & 4400 \\
\hline 1975 & 2276 & 43,9 & 2913 & 56,1 & 5189 \\
1976 & 2381 & 45,6 & 2835 & 54,4 & 5216 \\
1977 & 2324 & 49,3 & 2390 & 50,7 & 4714 \\
\hline 1978 & 2324 & 51,4 & 2199 & 48,6 & 4523 \\
1979 & 2324 & 53,7 & 2006 & 46,3 & 4330 \\
1980 & 2416 & 56,0 & 1897 & 44,0 & 4313 \\
\hline 1981 & 2482 & 58,7 & 1749 & 41,3 & 4231 \\
1982 & 2575 & 61,1 & 1640 & 38,9 & 4215 \\
1983 & 2575 & 63,3 & 1492 & 36,7 & 4067 \\
\hline 1984 & 2606 & 66,2 & 1332 & 33,8 & 3938 \\
\hline
\end{tabular}

FUENTE: Elaboración propia a partir de las Memorias del SENPA (años 1975 a 1984).

105 En 1957 el número de unidades arrendadas era de 3233, frente a una red propia que contaba tan solo con 169 silos y 159 almacenes. La capacidad arrendada ascendía a 17,79 millones de q y la propia a 5,61, lo que daba una capacidad total de almacenamiento de 23,41 millones de q, a lo que habría que añadir los 2 millones de los centros de selección. SNT (1958: 136-142). 


\section{CUADRO 7. CAPACIDAD DE ALMACENAMIENTO ARRENDADA AL SENPA. (En miles de $t$ ). (Situación a 31 de diciembre de cada año)}

\begin{tabular}{cccccc}
\hline Año & $\begin{array}{c}\text { N. }{ }^{\circ} \text { de } \\
\text { locales }\end{array}$ & $\begin{array}{c}\text { Capacidad } \\
\text { total }\end{array}$ & $\begin{array}{c}\text { Capacidad } \\
\text { media }\end{array}$ & $\begin{array}{c}\text { Importe mensual } \\
\text { (miles ptas.) }\end{array}$ & $\begin{array}{c}\text { Importe medio } \\
\text { ([ptas./t/mes]) }\end{array}$ \\
\hline 1974 & 2624 & 2829 & 1078 & 14569 & 5,15 \\
\hline 1975 & 2427 & 2913 & 1200 & 16545 & 5,68 \\
1976 & 2224 & 2835 & 1275 & 16872 & 5,95 \\
1977 & 1756 & 2390 & 1361 & 14386 & 6,02 \\
\hline 1978 & 1493 & 2199 & 1473 & 13581 & 6,18 \\
1979 & 1298 & 2006 & 1546 & 12714 & 6,34 \\
1980 & 1155 & 1897 & 1642 & 12862 & 6,78 \\
\hline 1981 & 867 & 1704 & 1966 & 14661 & 8,60 \\
1982 & 776 & 1593 & 2052 & 14803 & 9,29 \\
1983 & 684 & 1430 & 2090 & 13791 & 9,64 \\
\hline 1984 & 575 & 1291 & 2246 & 14762 & 11,43 \\
\hline
\end{tabular}

FUENTE: Elaboración propia a partir de las Memorias del SENPA (años 1975 a 1984).

Conviene ser muy cautos con las cifras oficiales de capacidad arrendada, ya que, sin lugar a dudas, estas cifras oficiales son superiores a las reales. Según me transmitieron algunos altos funcionarios del SNT, y según consta en un Informe confidencial al que tuve acceso, en los contratos de arrendamiento se inflaban, sistemáticamente, las cifras de capacidad de los silos y almacenes arrendados. La razón de esta práctica fraudulenta estriba en que los precios oficiales autorizados para el arrendamiento de locales, estaban tasados por debajo del precio de mercado, de manera que mediante el aumento teórico de la capacidad se lograba la necesaria compensación que permitía, en definitiva, el ajuste de los precios oficiales a los de mercado. Como se recoge en el citado Informe: «Todos sabemos que en los contratos de arrendamiento figuran capacidades superiores a las reales para poder pagar rentas superiores a las admitidas por la Superioridad, más acordes con las que la libre oferta y demanda tenía establecidas» ${ }^{106}$. Sin embargo, no podemos valorar, al

106 El Informe lleva por título El sistema de compra-venta de trigo en España. Análisis, crítica y propuesta de nuevo sistema (copia mecanografiada), p. 42. 
menos yo no he encontrado cifra alguna, la magnitud de este fenómeno, $y$, por lo tanto, la diferencia concreta entre las cifras oficiales y las reales. Desde una perspectiva general se trata de un caso más, y muy elocuente, de la inutilidad de intentar imponer precios de tasa contrarios a la realidad de los mercados y, lo que es peor, la aparición de prácticas fraudulentas para lograr los ajustes necesarios, abriendo el camino a su generalización y justificación social.

En cualquier caso, y como puede verse en el cuadro 7, estos arrendamientos supusieron un coste para el Servicio de unos 150 millones de pesetas anuales durante el periodo 1974-1984. Coste que hay que añadir a las inversiones realizadas en la construcción de la Red Nacional, para llegar a la cifra total del coste directo de la política de almacenamiento público.

A este coste todavía habría que añadir otra partida de gastos que es la correspondiente a las subvenciones y a los préstamos que el SNT concedió para la construcción de almacenes por parte de particulares ${ }^{107}$. En el cuadro 8 he recogido las subvenciones y los préstamos a bajo interés concedidos por el Servicio para fomentar la construcción de almacenes privados. Las subvenciones alcanzaron una cifra próxima a los 500 millones de pesetas anuales en el periodo 1979-1982, y los préstamos llegaron a superar los 600 millones en 1981. En total, entre 1970 y 1983, y en pesetas constantes de 1976, el SNT repartió 2228,3 millones en subvenciones y 2609 millones en préstamos, que contribuyeron a impulsar la capacidad de almacenamiento privado ${ }^{108}$.

107 Sobre estas subvenciones y, en general, sobre la política de ayudas al sector puede verse, Barciela (1981a y 1985b). Estas ayudas, cuantitativamente muy importantes, no lograron los resultados deseados, tal vez porque como señala D. Gale Johnson (1976: 55): «siempre que los gobiernos tienen una fuerte influencia sobre los precios de los productos agrícolas el mantenimiento privado de reservas se reduce al mínimo debido a la disminución de las ganancias potenciales y a la mayor incertidumbre acerca de los precios futuros cuando estos descansan en decisiones políticas".

108 Las primeras normas legales que regularon la concesión de subvenciones para la construcción de almacenes, graneros y silos fueron el Decreto de 19 de octubre de 1951 y la Orden de 13 de noviembre de 1952, que establecían una escala que diferenciaba entre proyectos particulares, de fabricantes, de Ayuntamientos y los de las Hermandades de Labradores. En sus comienzos esta política no tuvo un gran impacto. Entre 1952 y 1957 se concedieron un total de 51,2 millones de pesetas para 1265 proyectos de los que 766 eran de las Hermandades y captaron 42,5 millones de pesetas. SNT (1958). 


\section{CUADRO 8. SUBVENCIONES Y PRÉSTAMOS DEL SENPA PARA LA CONSTRUCCIÓN DE ALMACENES PRIVADOS. (En millones de ptas.)}

\begin{tabular}{rrrrr}
\hline & \multicolumn{2}{c}{ Subvenciones } & \multicolumn{2}{c}{ Préstamos } \\
Años & ptas. & ptas. de 1976 & ptas. & ptas. de 1976 \\
\hline 1970 & 64,5 & 134,1 & 6,9 & 14,3 \\
1971 & 100,3 & 192,6 & 218,4 & 419,4 \\
1972 & 90,2 & 160,0 & 160,9 & 285,3 \\
\hline 1973 & 135,6 & 215,7 & 58,4 & 92,9 \\
1974 & 106,7 & 146,8 & 244,5 & 336,3 \\
1975 & 117,9 & 138,7 & 120,0 & 141,1 \\
\hline 1976 & 116,7 & 116,7 & 175,9 & 175,9 \\
1977 & 56,8 & 45,6 & 181,4 & 145,7 \\
1978 & 169,6 & 113,7 & 283,6 & 190,2 \\
\hline 1979 & 431,7 & 250,3 & 308,6 & 178,9 \\
1980 & 493,8 & 247,5 & 494,0 & 247,6 \\
1981 & 470,9 & 206,3 & 604,8 & 264,9 \\
\hline 1982 & 423,3 & 162,0 & 304,5 & 116,5 \\
1983 & 288,0 & 98,3 & 0,0 & 0,0 \\
\hline
\end{tabular}

FUENTE: Elaboración propia a partir de las Memorias del SENPA (años 1975 a 1983).

Finalmente, para concluir con este apartado dedicado a la dimensión de la Red he incluido los cuadros 9, 10 y 11, y el gráfico 9, en los que pueden verse algunas de sus características desde una perspectiva regional y provincial. Se puede observar también, en esta visión territorialmente desglosada, lo ya comentado sobre el claro predominio de las unidades verticales, con las molestias e inconvenientes que ello comportaba para los agricultores, según ya habíamos visto.

La distribución de unidades verticales, silos, y horizontales, graneros, por regiones presentaba importantes diferencias. Conviene dejar al margen las Comunidades Autónomas en las que la producción triguera era poco significativa, ya que presentan estructuras extremas como sucede con Galicia y Cantabria en las que toda la capacidad de almacenamiento (muy pequeña, como es lógico) estaba formada exclusivamente por graneros. De igual forma, pero en el extremo opuesto, nos 
encontramos con Canarias región en la que el $100 \%$ de la capacidad era vertical y se correspondía con el silo de puerto de Santa Cruz de Tenerife. Refiriéndonos a las regiones en las que la economía triguera tenía cierta importancia, encontramos un grupo de comunidades en las que la estructura vertical-horizontal de almacenamiento estaba situada en torno a la media nacional: $88,4 \%$ de almacenamiento vertical (silos) sobre la capacidad total. En este grupo aparecen Aragón $(90,4)$, Navarra $(90,4)$, Castilla y León $(90,4)$, Andalucía $(89,4)$, La Rioja $(86,6)$ y Extremadura $(88,3)$. Con una estructura desfavorable por la excesiva presencia de graneros destacaban Murcia $(62,1)$, País Vasco (exclusivamente la provincia de Álava) $(83,0)$ y Castilla-La Mancha $(83,4)$. Finalmente, las regiones que presentaban una estructura más favorable eran Madrid $(96,2)$ y Cataluña $(96,1)$. Lógicamente, dentro de cada una de las Comunidades Autónomas se presentaban importantes diferencias internas. Las provincias peor dotadas, entre las que tenían una importante economía triguera, eran las de Castilla-La Mancha. Si exceptuamos Ciudad Real $(88,7)$, las demás presentaban estructuras deficientes en especial Guadalajara $(78,2)$ y Albacete $(81,1)$. Sin embargo, las peores situaciones se presentaban en las provincias de Segovia $(74,4)$ y Granada $(77,5)$. En el extremo opuesto, las mejores estructuras las encontramos en Lérida $(98,7)$, Zamora $(97,0)$, Palencia $(95,1)$, Huesca $(95,0)$, Málaga $(94,7)$, Soria $(94,3)$, León $(93,1)$ y Sevilla $(93,0)$. Igualmente, se puede constatar la concentración de las unidades mayores en las zonas más productivas. Por último, en lo que concierne a la distribución regional de la Red resulta muy llamativo que la mayor capacidad de almacenamiento se situaba en las Comunidades Autónomas de Castilla y León, Castilla-La Mancha y Aragón, regiones «artificialmente» trigueras. 
CUADRO 9. RED DE ALMACENAMIENTO PROPIEDAD DEL SENPA EN 1984. (En millones de ptas.)

\begin{tabular}{lrrrrrr}
\hline & \multicolumn{2}{c}{ Silos } & \multicolumn{2}{c}{ Graneros } & \multicolumn{2}{c}{ Total } \\
Comunidades Autónomas & Número & Capacidad (t) & Número & Capacidad (t) & Número & Capacidad (t) \\
\hline GALICIA & 0 & 0 & 4 & 9160 & 4 & 9160 \\
CANTABRIA & 0 & 0 & 2 & 7100 & 2 & 7100 \\
PAÍS VASCO & 10 & 22100 & 7 & 4500 & 17 & 26600 \\
NAVARRA & 33 & 103450 & 13 & 10950 & 46 & 114400 \\
LA RIOJA & 9 & 31150 & 8 & 4800 & 17 & 35950 \\
ARAGÓN & 83 & 275350 & 29 & 29300 & 112 & 304650 \\
CATALUÑA & 29 & 99980 & 2 & 4000 & 31 & 103980 \\
CASTILLA y LEÓN & 177 & 659440 & 73 & 69650 & 250 & 729090 \\
MADRID & 8 & 30780 & 2 & 1200 & 10 & 31980 \\
CASTILLA-LA MANCHA & 125 & 378515 & 75 & 75400 & 200 & 453915 \\
C. VALENCIANA & 4 & 7460 & 1 & 1170 & 5 & 8630 \\
R. DE MURCIA & 3 & 5400 & 2 & 3300 & 5 & 8700 \\
EXTREMADURA & 66 & 202490 & 28 & 26729 & 94 & 229219 \\
ANDALUCÍA & 124 & 474594 & 31 & 56150 & 155 & 530744 \\
CANARIAS & 1 & 12000 & 0 & 0 & 1 & 12000 \\
\hline ESPAÑA & $\mathbf{6 7 2}$ & $\mathbf{2 3 0 2 7 0 9}$ & $\mathbf{2 7 7}$ & $\mathbf{3 0 3} \mathbf{4 0 9}$ & $\mathbf{9 4 9}$ & $\mathbf{2 6 0 6 1 1 8}$ \\
\hline
\end{tabular}

FUENTE: SENPA. Memoria de Actividades (1984).

\section{GRÁFICO 9. CAPACIDAD DE ALMACENAMIENTO DEL SENPA EN 1984}

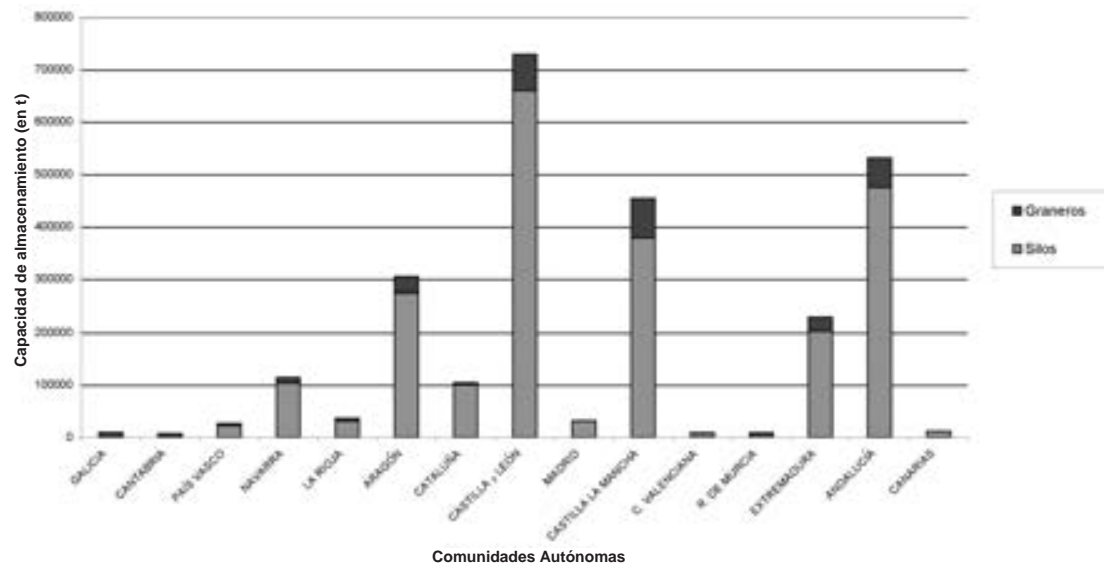

FUENTE: Cuadro 9. 


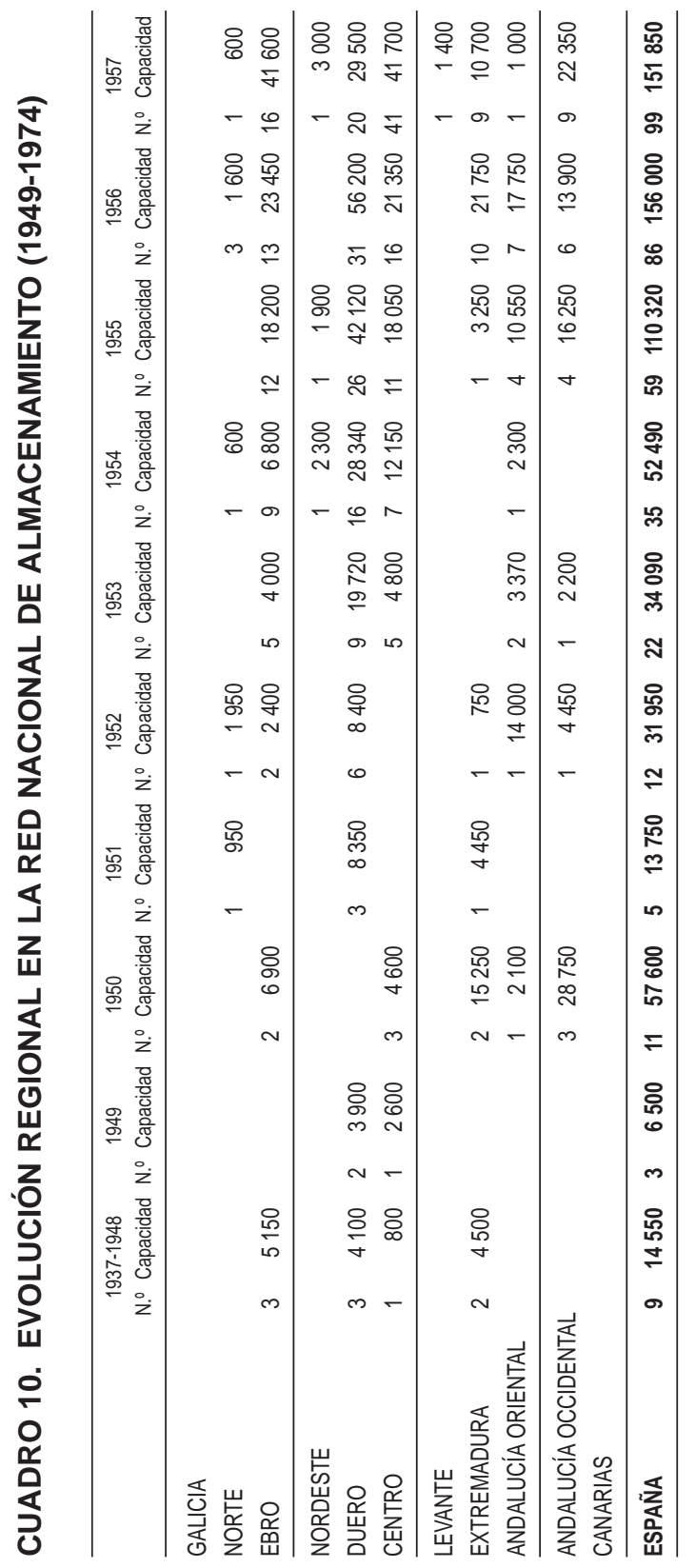




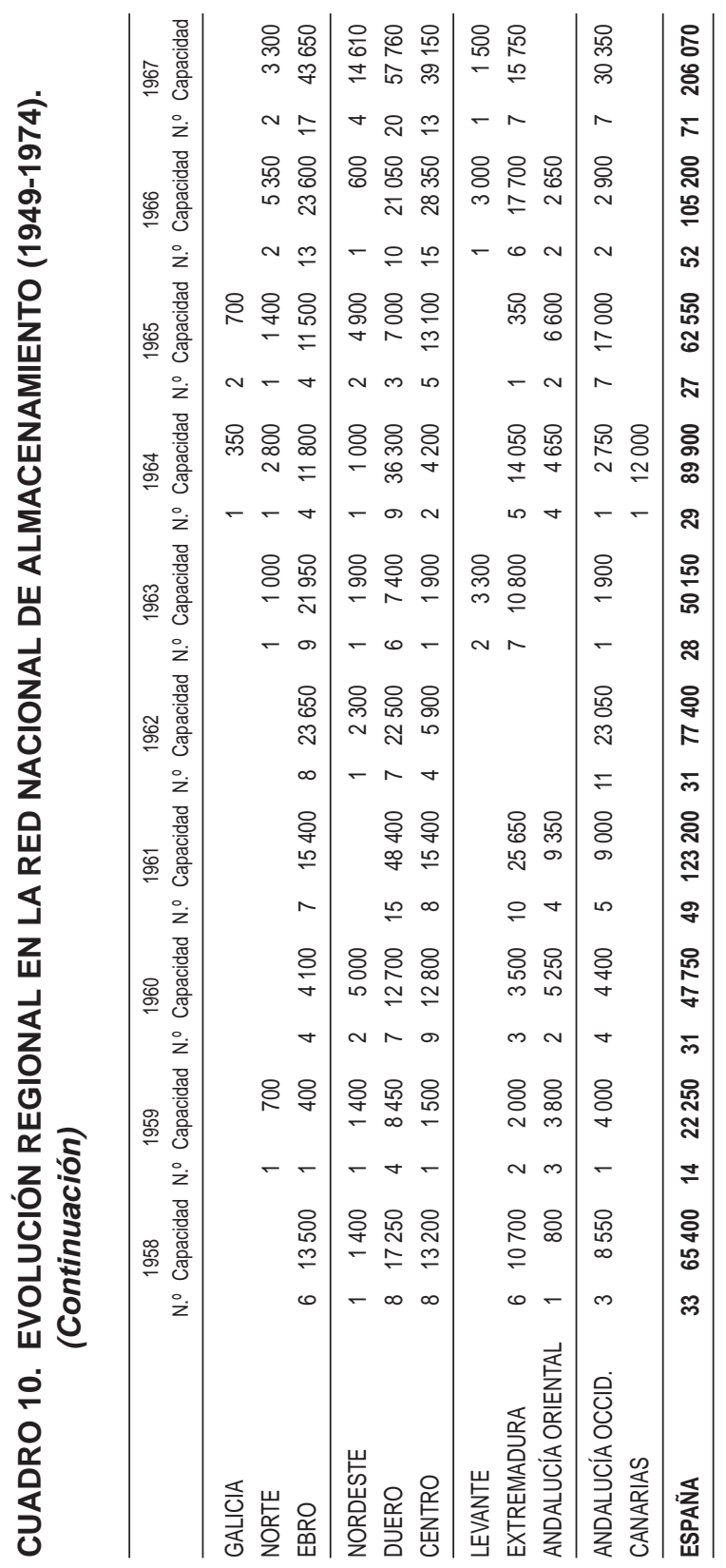




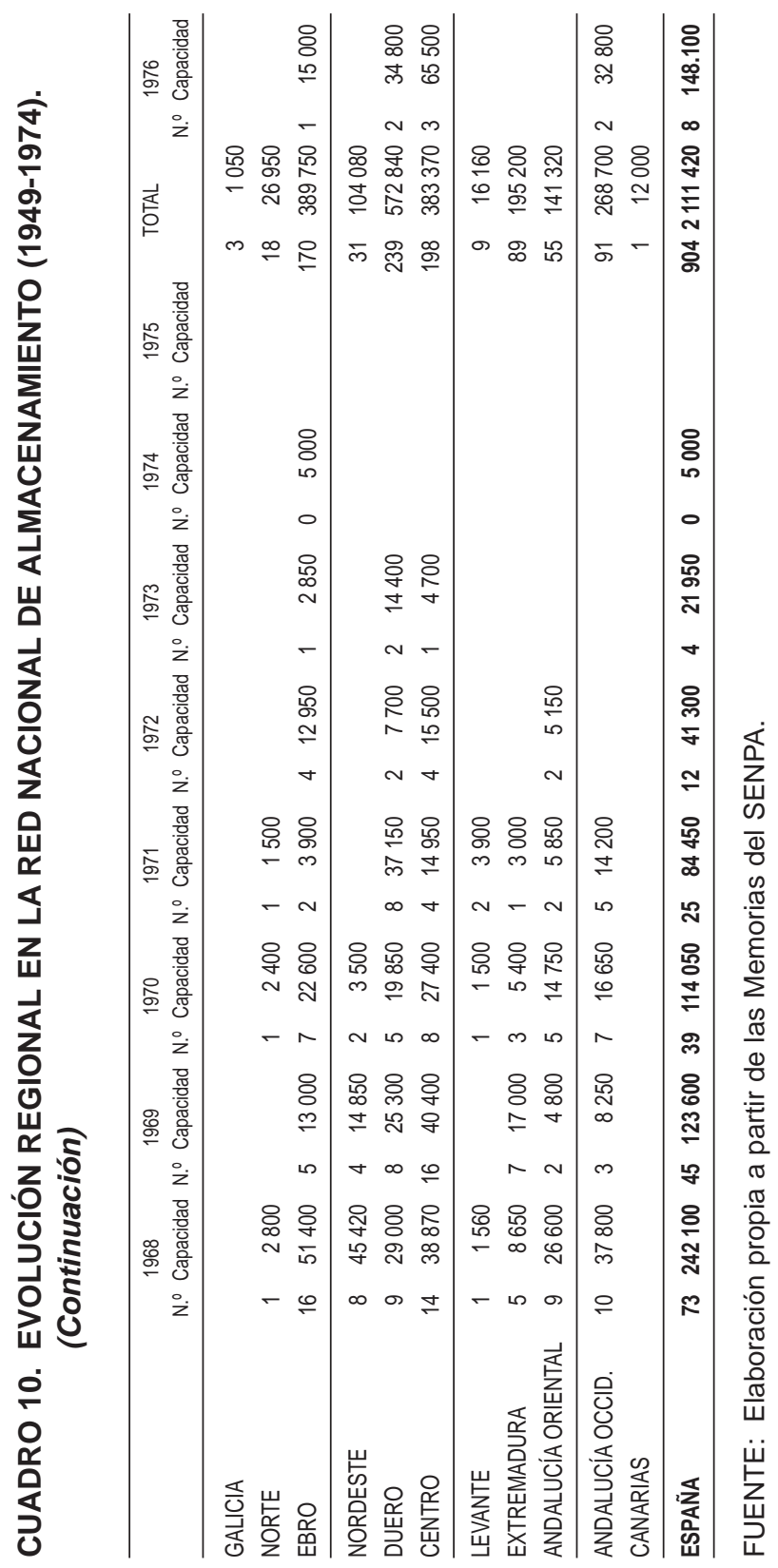


CUADRO 11. RED DE ALMACENAMIENTO PROPIEDAD DEL SENPA EN 1984

\begin{tabular}{|c|c|c|c|c|c|c|}
\hline \multirow[b]{2}{*}{ Comunidades Autónomas } & \multicolumn{2}{|r|}{ Silos } & \multicolumn{2}{|c|}{ Graneros } & \multicolumn{2}{|r|}{ Total } \\
\hline & Número & Capacidad (t) & Número & Capacidad (t) & Número & Capacidad (t) \\
\hline Coruña (La) & 0 & 0 & 1 & 720 & 1 & 720 \\
\hline Lugo & 0 & 0 & 1 & 7000 & 1 & 7000 \\
\hline Orense & 0 & 0 & 1 & 720 & 1 & 720 \\
\hline Pontevedra & 0 & 0 & 1 & 720 & 1 & 720 \\
\hline GALICIA & 0 & 0 & 4 & 9160 & 4 & 9160 \\
\hline CANTABRIA & 0 & 0 & 2 & 7100 & 2 & 7100 \\
\hline Álava & 10 & 22100 & 7 & 4500 & 17 & 26600 \\
\hline Guipúzcoa & 0 & 0 & 0 & 0 & 0 & 0 \\
\hline Vizcaya & 0 & & 0 & 0 & 0 & 0 \\
\hline PAÍS VASCO & 10 & 22100 & 7 & 4500 & 17 & 26600 \\
\hline NAVARRA & 33 & 103450 & 13 & 10950 & 46 & 114400 \\
\hline LA RIOJA & 9 & 31150 & 8 & 4800 & 17 & 35950 \\
\hline Huesca & 27 & 88900 & 5 & 4650 & 32 & 93550 \\
\hline Teruel & 19 & 54950 & 9 & 8100 & 28 & 63050 \\
\hline Zaragoza & 37 & 131500 & 15 & 16550 & 52 & 148050 \\
\hline ARAGÓN & 83 & 275350 & 29 & 29300 & 112 & 304650 \\
\hline Barcelona & 4 & 9920 & 0 & 0 & 4 & 9920 \\
\hline Gerona & 4 & 8200 & 0 & 0 & 4 & 8200 \\
\hline Lérida & 18 & 76400 & 1 & 1000 & 19 & 77400 \\
\hline Tarragona & 3 & 5460 & 1 & 3000 & 4 & 8460 \\
\hline CATALUÑA & 29 & 99980 & 2 & 4000 & 31 & 103980 \\
\hline Ávila & 12 & 33880 & 8 & 4600 & 20 & 38480 \\
\hline Burgos & 26 & 129980 & 14 & 14500 & 40 & 144480 \\
\hline León & 11 & 33700 & 2 & 2500 & 13 & 36200 \\
\hline Palencia & 24 & 79340 & 4 & 4100 & 28 & 83440 \\
\hline Salamanca & 23 & 71050 & 14 & 11600 & 37 & 82650 \\
\hline Segovia & 14 & 33000 & 13 & 11200 & 27 & 44200 \\
\hline Soria & 16 & 89320 & 4 & 5400 & 20 & 94720 \\
\hline Valladolid & 28 & 98300 & 10 & 12950 & 38 & 111250 \\
\hline Zamora & 23 & 90870 & 4 & 2800 & 27 & 93670 \\
\hline CASTILLA y LEÓN & 177 & 659440 & 73 & 69650 & 250 & 729090 \\
\hline
\end{tabular}


CUADRO 11. RED DE ALMACENAMIENTO PROPIEDAD DEL SENPA EN 1984.

(Continuación)

\begin{tabular}{|c|c|c|c|c|c|c|}
\hline \multirow[b]{2}{*}{ Comunidades Autónomas } & \multicolumn{2}{|r|}{ Silos } & \multicolumn{2}{|c|}{ Graneros } & \multicolumn{2}{|r|}{ Total } \\
\hline & Número & Capacidad (t) & Número & Capacidad (t) & Número & Capacidad (t) \\
\hline MADRID & 8 & 30780 & 2 & 1200 & 10 & 31980 \\
\hline Albacete & 15 & 63000 & 15 & 14700 & 30 & 77700 \\
\hline Ciudad Real & 26 & 74995 & 12 & 9400 & 38 & 84395 \\
\hline Cuenca & 29 & 91450 & 15 & 16600 & 44 & 108050 \\
\hline Guadalajara & 14 & 46050 & 15 & 12800 & 29 & 58850 \\
\hline Toledo & 41 & 103020 & 18 & 21900 & 59 & 124920 \\
\hline CASTILLA-LA MANCHA & 125 & 378515 & 75 & 75400 & 200 & 453915 \\
\hline Alicante & 1 & 3000 & 0 & 0 & 1 & 3000 \\
\hline Castellón & 2 & 3060 & 1 & 1170 & 3 & 4230 \\
\hline Valencia & 1 & 1400 & 0 & 0 & 1 & 1400 \\
\hline COM. VALENCIANA & 4 & 7460 & 1 & 1170 & 5 & 8630 \\
\hline R. de MURCIA & 3 & 5400 & 2 & 3300 & 5 & 8700 \\
\hline Badajoz & 42 & 133300 & 14 & 13650 & 56 & 146950 \\
\hline Cáceres & 24 & 69190 & 14 & 13079 & 38 & 82269 \\
\hline EXTREMADURA & 66 & 202490 & 28 & 26729 & 94 & 229219 \\
\hline Almería & 1 & 1500 & 0 & 0 & 1 & 1500 \\
\hline Cádiz & 17 & 63000 & 6 & 7500 & 23 & 70500 \\
\hline Córdoba & 28 & 120274 & 8 & 16250 & 36 & 136524 \\
\hline Granada & 18 & 49500 & 5 & 14350 & 23 & 63850 \\
\hline Huelva & 5 & 15450 & 1 & 600 & 6 & 16050 \\
\hline Jaén & 16 & 37800 & 5 & 3950 & 21 & 41750 \\
\hline Málaga & 8 & 32520 & 2 & 1800 & 10 & 34320 \\
\hline Sevilla & 30 & 154550 & 5 & 11700 & 35 & 166250 \\
\hline ANDALUCÍA & 123 & 474594 & 32 & 56150 & 155 & 530744 \\
\hline Palmas (Las) & 0 & 0 & 0 & 0 & 0 & 0 \\
\hline Santa Cruz de Tenerife & 1 & 12000 & 0 & 0 & 1 & 12000 \\
\hline CANARIAS & 1 & 12000 & 0 & 0 & 1 & 12000 \\
\hline ESPAÑA & 671 & 2302709 & 278 & 303409 & 949 & 2606118 \\
\hline
\end{tabular}

FUENTE: SENPA. Memoria de Actividades (1984). 


\section{LOS COSTES Y LA FINANCIACIÓN DE LA RED}

Desde que el SNT comenzó a construir la Red de Silos, a mediados de los años cuarenta y hasta 1975, los gastos de su ejecución fueron soportados íntegramente por el propio organismo triguero, con cargo a los denominados beneficios comerciales ${ }^{109}$. A su vez, la fuente fundamental, y casi única, de estos beneficios la constituyó el llamado canon comercial, que consistía en la diferencia entre los precios de venta y de compra de los productos que el Servicio manipulaba. Este canon comercial se fijaba anualmente por el Gobierno en el correspondiente decreto ordenador de la campaña.

En estas circunstancias, tanto el volumen de las construcciones como su ritmo venían limitados por los beneficios, fruto del volumen de productos comercializados y del canon legal. El canon estuvo congelado, por decisión política, en 0,24 ptas./kg desde la campaña 1959-1960, lo que limitó seriamente el crecimiento de los beneficios. No obstante, el aumento espectacular de la producción cerealista y el práctico monopolio que, en esta etapa, logró establecer el Servicio en la comercialización, permitió un incremento sostenido de los beneficios comerciales y financiar con ellos la gran expansión de la Red, que tuvo lugar en la segunda mitad de los años sesenta. Sin embargo, no es menos cierto que los planes del Servicio apostaban por un ritmo aún más rápido de construcción y, en este sentido, sí que es verdad que la congelación del canon comercial se convirtió en un elemento fuertemente restrictivo.

El canon comercial era pagado, inicialmente, por los fabricantes de harina al SNT al adquirir el grano. Evidentemente, los industriales harineros consideraron el canon como una parte de sus costes fijos, que hicieron recaer en el precio de la harina y, a su vez, las industrias panaderas lo trasladaron al precio del pan. El canon se trasladaba en cascada por toda la cadena productiva. En un mercado con un solo comprador-vendedor de trigo no existía ninguna posibilidad legal de evitar este pago y no podía, en consecuencia, establecerse ningún tipo de competencia vía precios entre los fabricantes de harina y pan en relación con el canon. Se trataba, en definitiva, de un coste fijo que todos tenían que asumir. En

109 SNT (1958: 148). La primera norma al respecto fue un Decreto de 5 de julio de 1944 que autorizaba al SNT a disponer de una parte de sus fondos propios para iniciar la construcción de los silos. 
conclusión, los que terminaron pagando el canon comercial y financiando la construcción de la Red fueron los consumidores de pan ${ }^{110}$.

Aclarada esta cuestión, intentaré, en las próximas páginas, evaluar el coste de la construcción de la Red Nacional de Silos. EI SENPA elaboró en 1975 y 1976 dos voluminosas memorias, que no se publicaron, en las que se ofrecía una abundante información histórica sobre las actividades desarrolladas por este organismo y, entre ellas, sobre la Red de Silos. Previamente, se había publicado una monografía en 1970, ya comentada, sobre la Red de Silos también con mucha información estadística. Sin embargo, sorprendentemente, en ninguna de estas tres publicaciones se ofrecían datos históricos sobre la vertiente económica de la construcción de la Red. Por su parte, los denominados «presupuestos» del organismo no son más explícitos. Es más, los presentados hasta 1964 no pueden considerarse realmente como tales, pues se limitan a ofrecer unas cifras totales de gastos e ingresos, sin desgloses y sin la más mínima explicación sobre su contenido.

A partir de dicha fecha, los presupuestos ofrecen una información algo más rica, aunque no con el desglose por partidas que sería deseable e, incluso, exigible en un organismo público. De hecho, en lo que a nuestro tema se refiere, tampoco se encuentran las cifras relativas a las inversiones en la Red.

En consecuencia, ha sido necesario recurrir a una serie más dispersa de fuentes, con las que he intentado reconstruir las cifras de las inversiones. Así, en la obra Veinte años de actuación, el Servicio afirmaba que en 1957 la capacidad de almacenamiento construida alcanzaba la cifra de 5691000 quintales y las construcciones en marcha ascendían a 1676500 con un presupuesto total de 247 millones de pesetas. Los planes del SNT, en dicha fecha, eran los de llegar a un total de capacidad de 20508000 quintales, lo que exigiría unas inversiones adicionales de más de 2000 millones de pesetas. En un trabajo posterior titulado Realizaciones del SNT en sus primeros veinticinco años, se señalaba que la capacidad construida alcanzaba ya la cifra de 10864500 quintales, que el número de unidades construidas o en construcción era de 571 y que las inversiones totales realizadas ascendían a 1393,3 millones de pesetas. Lamentablemente, no se

110 Conviene recordar que durante los años cincuenta y sesenta el consumo de pan en España se mantuvo en altos niveles absolutos y comparativos en relación con los países europeos más desarrollados. 
proporcionaba ningún desglose por años, ni tampoco se indicaba la forma en la que se había calculado esa cifra total, aunque todo hace pensar que se trata, sin más, de una suma de las cifras anuales en pesetas corrientes, lo que limita seriamente el valor de esta cifra. Se señalaba, igualmente, que se habían aprobado, como objetivos a medio plazo, construcciones adicionales por un volumen total de 7,5 millones de quintales, con una inversión de 1200 millones de pesetas. A largo plazo, se ampliaba el objetivo de capacidad futura de la red hasta situarla en los 24 millones, lo que exigiría una inversión adicional de otros 1000 millones más.

En conclusión, y sintetizando, en 1962 se fijaba como objetivo una red de 24 millones de quintales. El coste de la parte construida y en construcción ascendía a un total de 1393,3 millones de pesetas y se preveía una inversión adicional de 2200 millones para los 13,5 millones de quintales pendientes de construir.

A partir de 1963, y como se muestra en el cuadro 12 y gráfico 12, disponemos de cifras anuales relativas a las inversiones en la Red, y en el cuadro 13 y gráfico 13 aparecen los datos anuales en pesetas constantes. Para que el lector pueda hacerse una idea más precisa de lo que significaban estas cantidades, presento en el mismo cuadro 12 las cifras de inversión en la Red, junto con las de las inversiones totales del Ministerio de Agricultura. Como puede comprobarse, las inversiones en la Red llegaron a ser, en algunos años, casi el $10 \%$ de las inversiones totales destinadas al sector agrario. Dicho porcentaje era, sencillamente, espectacular si tenemos en cuenta la gran cantidad de líneas de inversión del Ministerio, las enormes necesidades del sector y, más aún, las apremiantes carencias de bienes públicos que tenía la España de aquellos años. En total, entre 1963 y 1984, en pesetas constantes de 1963, se invirtieron en la Red más de 5200 millones.

En 1975, año de la muerte del dictador, se produjo un giro en los planteamientos oficiales sobre la Red de Silos aunque, en mi opinión, no en la dirección adecuada. Según el SENPA, y los datos presentados así lo muestran, hasta 1975 se había concedido una atención prioritaria a la construcción de unidades locales de almacenamiento, las llamadas unidades de recepción. En consecuencia, la Red sufría un importante desequilibrio funcional, para cuya solución resultaba necesario emprender la construcción de unidades más grandes y muy equipadas técnicamente, que permitiesen constituir reservas reguladoras del mercado; en definitiva, grandes silos de tránsito, que recibieron el nombre de «macrosilos», y se insistía en el viejo proyecto de crear la red de silos portuarios. 
CUADRO 12. INVERSIÓN AGRARIA. (En millones de ptas.)

\begin{tabular}{|c|c|c|c|}
\hline AÑOS & $\begin{array}{l}\text { Inversión total } \\
\text { del Ministerio } \\
\text { de Agricultura }\end{array}$ & $\begin{array}{l}\text { Inversión } \\
\text { en la Red } \\
\text { de Silos }\end{array}$ & $\begin{array}{c}\% \\
\text { sobre } \\
\text { el total }\end{array}$ \\
\hline 1963 & 5572 & 142 & 2,55 \\
\hline 1964 & 6049 & 150 & 2,48 \\
\hline 1965 & 6239 & 264 & 4,23 \\
\hline 1966 & 6289 & 628 & 9,99 \\
\hline 1967 & 6337 & 526 & 8,30 \\
\hline 1968 & 6339 & 412 & 6,50 \\
\hline 1969 & 7706 & 414 & 5,37 \\
\hline 1970 & 8186 & 435 & 5,31 \\
\hline 1971 & 8842 & 412 & 4,66 \\
\hline 1972 & 11831 & 490 & 4,14 \\
\hline 1973 & 14757 & 429 & 2,91 \\
\hline 1974 & 17883 & 650 & 3,63 \\
\hline 1975 & 18934 & 645 & 3,41 \\
\hline 1976 & 19434 & 542 & 2,79 \\
\hline 1977 & 31881 & 1184 & 3,71 \\
\hline 1978 & 30579 & 433 & 1,42 \\
\hline 1979 & 43016 & 1142 & 2,65 \\
\hline 1980 & 47766 & 1588 & 3,32 \\
\hline 1981 & 49525 & 1475 & 2,98 \\
\hline 1982 & 84022 & 1478 & 1,76 \\
\hline 1983 & 82094 & 1879 & 2,29 \\
\hline 1984 & 76166 & 1770 & 2,32 \\
\hline
\end{tabular}

FUENTE: Anuarios del Ministerio de Agricultura, Archivo SENPA, Memorias SENPA y elaboración propia.

NOTAS: (1) A partir de 1981 los datos relativos al Ministerio corresponden a inversiones reales. En los años anteriores se incluían gastos de funcionamiento inherentes a la inversión pública.

(2) Hasta 1981 buena parte de las inversiones públicas en la agricultura se realizaban con cargo al presupuesto del Ministerio de Obras Públicas. A partir de dicha fecha el total de la inversión pública en la agricultura se gestiona por el Ministerio de Agricultura. 
CUADRO 13. INVERSIÓN EN LA RED DE SILOS.

(En millones de ptas. constantes de 1963)

\begin{tabular}{cc}
\hline AÑOS & Inversión \\
\hline 1963 & 142 \\
1964 & 140 \\
1965 & 218 \\
\hline 1966 & 488 \\
1967 & 384 \\
1968 & 287 \\
1969 & 282 \\
1970 & 280 \\
\hline 1971 & 245 \\
1972 & 269 \\
1973 & 212 \\
1974 & 277 \\
1975 & 235 \\
\hline 1976 & 168 \\
1977 & 295 \\
1978 & 90 \\
1979 & 205 \\
1980 & 247 \\
\hline 1981 & 200 \\
1982 & 175 \\
1983 & 199 \\
1984 & 168 \\
\hline
\end{tabular}

FUENTE: Anuarios del Ministerio de Agricultura, Archivo SENPA, Memorias SENPA y elaboración propia. 
GRÁFICO 12. INVERSIONES EN LA RED DE SILOS.

PORCENTAJE SOBRE EL TOTAL

DE LAS INVERSIONES

DEL MINISTERIO DE AGRICULTURA

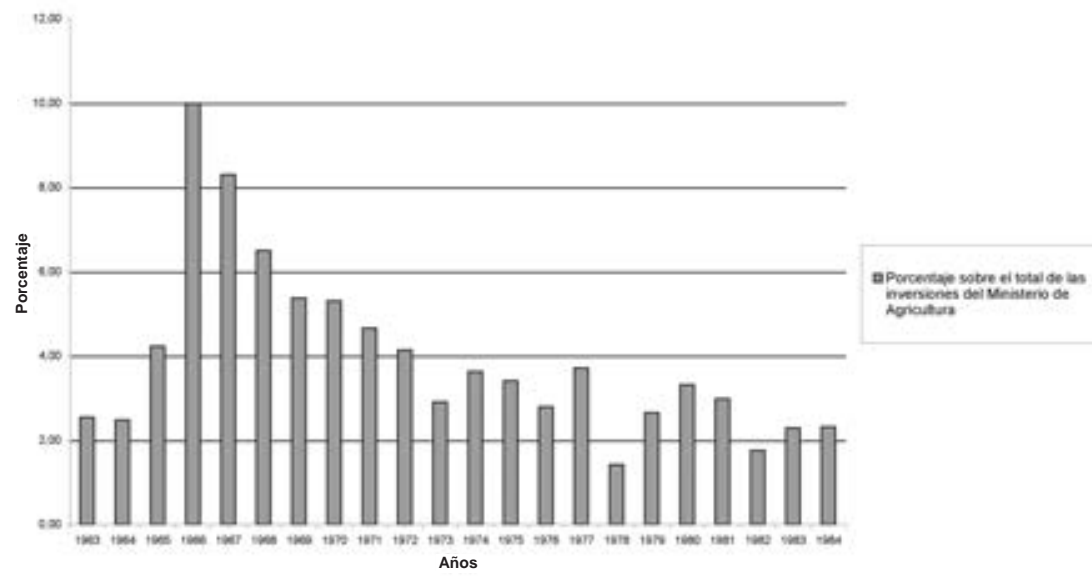

FUENTE: Cuadro 12.

GRÁFICO 13. INVERSIONES EN LA RED DE ALMACENAMIENTO. (En ptas. constantes de 1963)

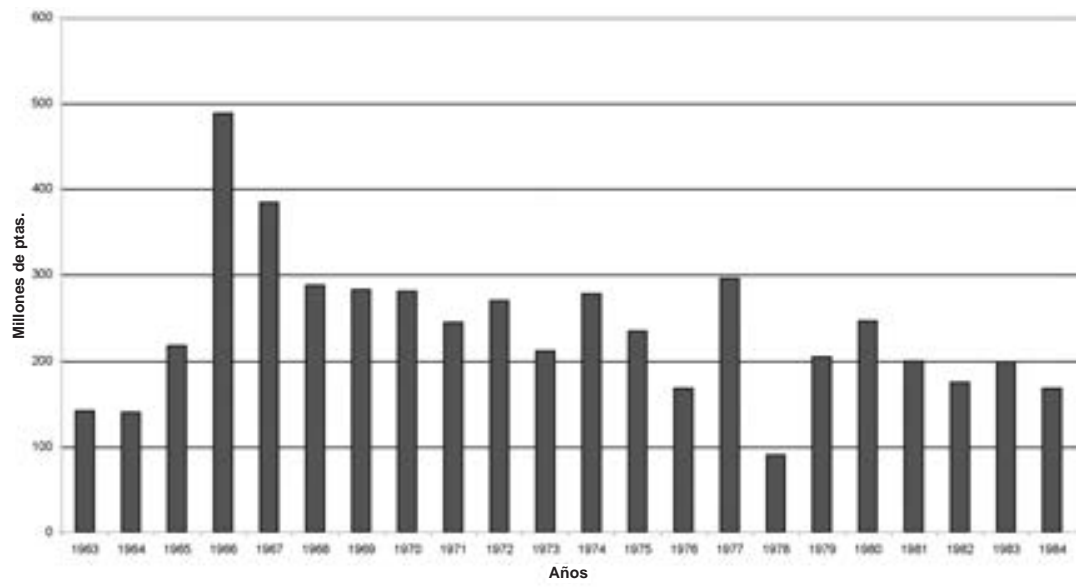

FUENTE: Cuadro 13. 
Los silos de esta nueva etapa habrían de emplazarse en lugares estratégicos, con buenas conexiones ferroviarias, lo más cerca posible de los centros consumidores y en el sentido de favorecer las corrientes comerciales naturales ${ }^{111}$. Además de los nuevos proyectos, se preveía la ampliación de algunos de los silos más modernos que, siendo susceptibles de reforma, encajasen con los nuevos criterios.

También se abordaba de manera general el problema de la conservación de la Red. Las primeras unidades construidas ya habían cumplido veinticinco años, y aunque se habían realizado obras de mantenimiento en casos aislados y urgentes, no se había planteado el problema general de diseñar una política planificada de conservación del sistema. El propio SENPA señalaba los principales problemas que estaban afectando a las instalaciones: filtraciones y goteras por el mal estado de las cubiertas y las terrazas, necesidad de impermeabilizar tolvas y fosos de elevadores para evitar la entrada de agua, arreglo de pavimentaciones, puertas y ventanas, y pintura de los silos y almacenes, entre otros. Por otra parte, se planteaba la necesidad de mejorar y modernizar las instalaciones. En esta línea, el catálogo de las actuaciones necesarias mostraba la precaria construcción de una buena parte de la Red, ya que se planteaba la necesidad de construir desde elementos básicos, como aseos para el personal, hasta todo tipo de instalaciones mecánicas y eléctricas, pasando por elementos esenciales como básculas-puente para camiones y vagones de ferrocarril. Según el propio SENPA la situación era «alarmante y nos obliga a ir considerando en el inmediato futuro la función de conservación en sus justos términos» ${ }^{112}$. En el cuadro 14 y gráfico 14, pueden verse desglosadas las inversiones en la red de almacenamiento distinguiendo entre las inversiones en nuevas unidades y las inversiones en conservación y mejora. Como puede comprobarse, los gastos de mantenimiento alcanzaron un peso muy notable, llegando a ser en 1977 el 78,9\% del total de las inversiones en la Red. Se confirmaban los temores del propio SENPA y se planteaba de manera amenazadora el problema financiero de mantener la red en un buen estado.

111 Se intentaba, de esta forma, equilibrar el exceso de silos construidos en zonas productoras, excedentarias y alejadas de los centros de consumo en las que tendían a «remansarse» los excedentes. Sobre este problema y la aplicación de «precios derivados» puede verse Barciela (1981a).

112 SENPA (1975: 108). 
CUADRO 14. INVERSIONES EN LA RED DE ALMACENAMIENTO. (En millones de ptas.)

\begin{tabular}{ccccc}
\hline Año & $\begin{array}{c}\text { Inversiones } \\
\text { en nuevas } \\
\text { unidades }\end{array}$ & $\begin{array}{c}\text { Inversiones } \\
\text { en conservación } \\
\text { y mejora }\end{array}$ & Total & $\begin{array}{c}\text { \% representado } \\
\text { por las inversiones } \\
\text { en conservación } \\
\text { y mejora }\end{array}$ \\
\hline 1972 & 155 & 335 & 490 & 68,4 \\
1973 & 229 & 200 & 429 & 46,6 \\
1974 & 496 & 154 & 650 & 23,7 \\
\hline 1975 & 559 & 87 & 646 & 13,5 \\
1976 & 243 & 300 & 543 & 55,2 \\
1977 & 250 & 934 & 1184 & 78,9 \\
\hline 1978 & 300 & 133 & 433 & 30,7 \\
1979 & 880 & 262 & 1142 & 22,9 \\
1980 & 1062 & 526 & 1588 & 33,1 \\
\hline 1981 & 1070 & 405 & 1475 & 27,5 \\
1982 & 477 & 1001 & 1478 & 67,7 \\
1983 & 1026 & 853 & 1879 & 45,4 \\
\hline 1984 & 849 & 921 & 1770 & 52,0 \\
\hline
\end{tabular}

FUENTE: Elaboración propia a partir de las Memorias del SENPA.

Finalmente, esta etapa presenta también una importante novedad desde el punto de vista del sistema de financiación. Hasta 1975, como ya hemos comentado, la red se había construido con cargo a los beneficios resultantes del llamado «Plan de operaciones comerciales», que se nutría casi exclusivamente con el canon comercial, congelado desde la campaña 1959-1960. Para afrontar los gastos de esta nueva fase de ampliación, conservación, modernización y mejora de la Red se aprobó un modelo de financiación, alimentado mediante fondos provenientes del «Presupuesto General Administrativo del SENPA» y, en última instancia, de los presupuestos generales del Estado, de los que dicho presupuesto se nutría.

El nuevo sistema desvinculaba la financiación de las obras de construcción de los silos del consumo de pan. Es evidente que una reforma de estas características resultaba ineludible, si el Gobierno persistía en sus 
GRÁFICO 14. INVERSIONES EN LA RED DE ALMACENAMIENTO. (En millones de ptas.)

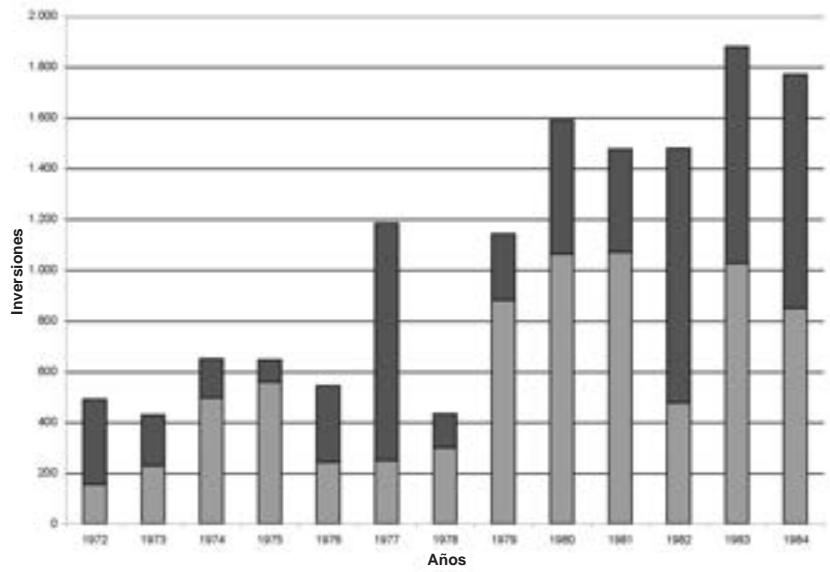

FUENTE: Cuadro 14.

planes de expansión de la Red, ante la marcada tendencia al descenso del consumo de pan que se estaba registrando en nuestro país. Por otra parte, al captar los recursos de los presupuestos generales del Estado se «democratizaban» los costes de la Red.

En 1978, el SENPA publicaba una monografía titulada Red de almacenamiento, en la que se exponía la filosofía que inspiraba la construcción de la Red y en la que la pervivencia de planteamientos cuasiautárquicos era muy patente, demostrando una vez más lo atinado de las reflexiones de J. A. Schumpeter, en el sentido de las grandes dificultades que se plantean para poder reformar, y no digamos suprimir, organismos en los que los viejos planteamientos que llevaron a su creación ya no tienen razón de ser, si alguna vez la tuvieron, pero que se hallan fuertemente enquistados en la trama institucional del Estado. A las puertas de una deseada y ya previsible entrada en la CEE, en el prólogo de esa obra se seguía justificando la necesidad de contar con una red suficiente y eficaz para proceder a la manipulación, conservación y comercialización de las cosechas nacionales de cereales y otros granos. Los responsables del SENPA, tras resaltar los «esfuerzos ininterrumpidos» realizados en la construcción de la 
Red, anunciaban que su objetivo era hacer posible «cada día más, como una de sus metas más deseadas, la normal recepción y conservación de las cosechas» ${ }^{113}$.

Este planteamiento contrario a las necesidades mayoritarias de la sociedad española, que se imponía oficialmente, solo puede ser entendido porque el SENPA, a pesar del tiempo transcurrido y de los cambios en su denominación, seguía llevando en su interior al viejo Servicio Nacional del Trigo. En definitiva, y conforme a estos planteamientos, entre 1975 y 1984, la Red Nacional continuó con su proceso de expansión y, como en anteriores etapas, los intereses de los cultivadores cerealistas se impusieron, por encima de toda lógica y racionalidad, a los intereses de los consumidores y a los de la mayor parte del país. El lobby triguero resistía en el mantenimiento de sus privilegios tras la muerte del dictador, como lo había hecho en 1951, en 1959 y durante los años de la industrialización.

En vísperas de que se promulgara la ley de 1984, que suprimía el monopolio triguero, la Red Nacional de Silos alcanzaba su mayor expansión y, también, su mayor nivel de ineficacia. El cuadro 15 proporciona un conjunto de información que permite analizar los diversos elementos que llevaron a esa crítica situación, que puede apreciarse perfectamente en el gráfico 15. Por una parte, la producción de trigo, dentro de las oscilaciones características de un aprovechamiento en el que las variaciones climatológicas seguían teniendo un gran impacto, se mantuvo siempre por encima de los 4 millones de toneladas anuales con picos que superaron los 5 millones y con una cosecha histórica de más de 6 millones en 1980. Este comportamiento tenía una explicación muy sencilla: la compra garantizada de toda la producción por parte del Servicio a unos precios muy atractivos.

Paralelamente al comportamiento expansivo de la producción, podemos comprobar cómo el consumo experimenta una lenta e inexorable caída. El descenso del consumo respondía a la actuación de la ley de Engel. El consumo per cápita de pan, un bien inferior, fue descendiendo, en este periodo, conforme aumentaba la renta y se tenía acceso a bienes superiores como carne, lácteos, huevos y productos frescos ${ }^{114}$. El consu-

113 SENPA (1978: 5).

114 En Barciela (1989), y Barciela, GEHR, Giráldez y López Ortiz (2005), pueden verse las series históricas sobre el consumo de los principales productos alimenticios. 
mo per cápita descendió de forma muy rápida, mientras que el consumo total lo hizo de manera más lenta como consecuencia del aumento de la población y del número de consumidores.

CUADRO 15. PRODUCCIÓN, CONSUMO Y STOCKS DE TRIGO. (En miles de $t$ )

\begin{tabular}{|c|c|c|c|c|}
\hline Año & Producción & $\begin{array}{c}\text { Consumo } \\
\text { (alimentación } \\
\text { humana) }\end{array}$ & $\begin{array}{c}\text { Stocks } \\
\text { (a fin de año) }\end{array}$ & $\begin{array}{l}\% \text { representado } \\
\text { por los stocks } \\
\text { frente al consumo }\end{array}$ \\
\hline 1960 & 3520 & 4104 & 445 & 10,8 \\
\hline 1961 & 3431 & 4009 & 180 & 4,5 \\
\hline 1962 & 4812 & 4244 & 1043 & 24,6 \\
\hline 1963 & 4860 & 3824 & 1657 & 43,3 \\
\hline 1964 & 3977 & 3622 & 1455 & 40,2 \\
\hline 1965 & 4715 & 3582 & 2038 & 56,9 \\
\hline 1966 & 4876 & 3960 & 2558 & 64,6 \\
\hline 1967 & 5650 & 3660 & 2958 & 80,8 \\
\hline 1968 & 5312 & 3400 & 3036 & 89,3 \\
\hline 1969 & 4624 & 3450 & 2409 & 69,8 \\
\hline 1970 & 4127 & 3380 & 1490 & 44,1 \\
\hline 1971 & 5449 & 3710 & 2423 & 65,3 \\
\hline 1972 & 4562 & 3225 & 2022 & 62,7 \\
\hline 1973 & 3966 & 3752 & 1412 & 37,6 \\
\hline 1974 & 4534 & 3598 & 1300 & 36,1 \\
\hline 1975 & 4302 & 3696 & 1691 & 45,8 \\
\hline 1976 & 4436 & 3563 & 2172 & 61,0 \\
\hline 1977 & 3963 & 3499 & 2293 & 65,5 \\
\hline 1978 & 4798 & 3461 & 3149 & 91,0 \\
\hline 1979 & 4101 & 3533 & 2919 & 82,6 \\
\hline 1980 & 6039 & 3689 & 4227 & 114,6 \\
\hline 1981 & 3408 & 3408 & 3656 & 107,3 \\
\hline 1982 & 4410 & 3489 & 3663 & 105,0 \\
\hline 1983 & 4330 & 3497 & 3233 & 92,5 \\
\hline
\end{tabular}

FUENTE: Elaboración propia a partir de las Memorias y del archivo del SENPA. 


\section{GRÁFICO 15. COMPARACIÓN ENTRE EL CONSUMO Y LOS STOCKS DE TRIGO DURANTE EL PERIODO 1960-1983}

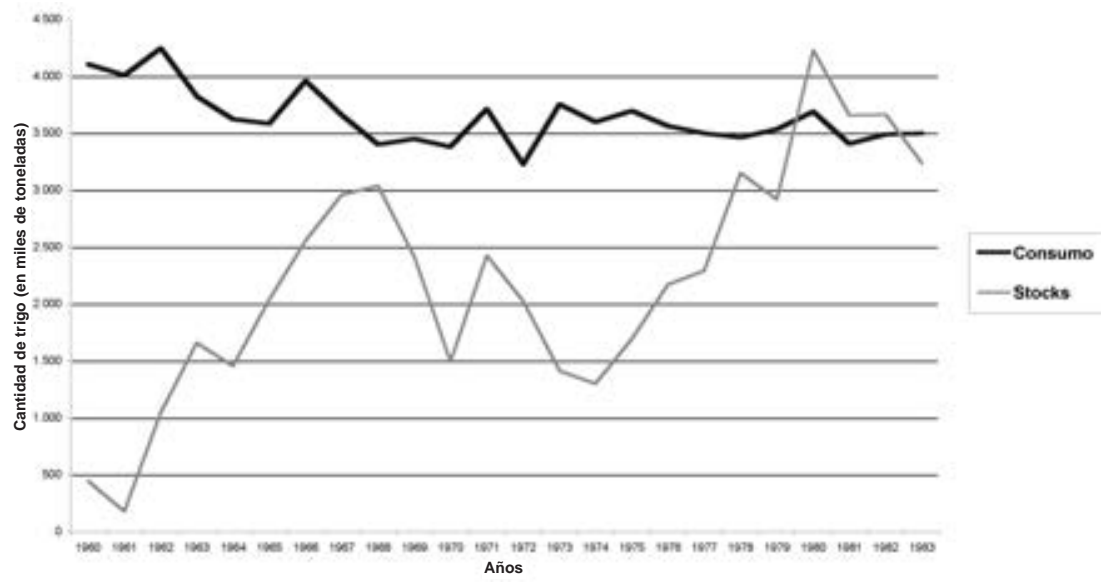

FUENTE: Cuadro 15.

El resultado de una producción elevada y sostenida y un consumo en claro declive, fue el aumento constante de los excedentes de trigo. Como puede verse en el cuadro y gráfico citados, los stocks, que eran de 445000 toneladas en 1960 y 180000 en 1961, crecieron después de forma exponencial. Entre 1962 y 1964 se situaron por encima del millón de toneladas, en 1965-1966 de los dos millones y en 1967-1968 superaron los tres. En 1968 se llega a una primera situación de colapso en la que los stocks de trigo alcanzaron un volumen equivalente al $90 \%$ del consumo, superando ampliamente la capacidad de almacenamiento de la Red Nacional. Se llegaba a una situación ciertamente absurda, incomprensible desde el punto de vista de los intereses de la mayor parte de los españoles. La política triguera estaba llenando los silos con un trigo invendible comercialmente.

Por otra parte, es preciso recordar que los efectos negativos de la acumulación de excedentes desbordaban, ampliamente, al sector agrario. La profunda implicación del Banco de España en la financiación del Servicio y en la movilización de las cosechas tuvo unas repercusiones negati- 
vas muy notables sobre la circulación monetaria. M. Friedman ya había advertido, en un artículo publicado en 1951, de que la existencia de grandes stocks de materias primas tenía claros efectos negativos sobre la circulación monetaria ${ }^{115}$.

La respuesta por parte de las autoridades, como sabemos, fue la de forzar la construcción de más silos y arrendar más unidades a particulares y, por otra parte, proceder a la eliminación periódica de excedentes con altos costes para las arcas públicas. En parte, estos excedentes se "exportaron» a precios del mercado internacional que eran, evidentemente, inferiores a los precios pagados por el SNT a los agricultores. Por otra, se vendieron, una vez desnaturalizados, como pienso para el ganado también con pérdidas. La desnaturalización de excedentes de trigo para su venta como pienso a precios más bajos de los de tasa dio lugar a uno de los característicos episodios fraudulentos típicos de nuestro país, con efectos negativos para la salud humana. Algunos industriales desaprensivos adquirieron este trigo barato desnaturalizado, destinado al ganado, y lo emplearon en la fabricación de harinas con un considerable rendimiento económico.

Además, con el fin de intentar agilizar las transacciones y aliviar la presión sobre la capacidad de almacenamiento oficial, el SENPA introdujo un nuevo sistema de compra-venta «simultánea» por el que el cultivador entregaba directamente el trigo al fabricante sin pasar por los almacenes del Servicio, aunque la operación financiera sí se realizaba a través del SENPA. Este sistema, que llegó a representar el $40 \%$ del total, era una invitación para que las transacciones se realizasen completamente al margen del organismo regulador. Una vez que la transacción física del producto se hacía de manera directa entre el agricultor y el industrial, ¿qué sentido tenía seguir utilizando la intermediación financiera, con sus correspondientes costes, del organismo triguero? El resultado fue el que cualquier economista hubiera pronosticado: aparecieron corrientes comerciales ilegales que se conocieron con el nombre de trigo de «bandeo» ${ }^{116}$, que según algunas estimaciones llegó a alcanzar el $20 \%$ del total del trigo comercializado.

115 M. Friedman (1951: 232). Los efectos de la acumulación de stocks trigueros y de la financiación de las cosechas sobre la circulación monetaria en España los he estudiado en Barciela (1981b).

116 Briz (1985: 93). 
Evidentemente, lo más sensato en esta situación hubiera sido una paulatina liberalización del mercado, una mayor flexibilidad en los precios de compra y el establecimiento de límites en la cantidad garantizada de las compras. Todo ello hubiera frenado el crecimiento de la producción y de los stocks y hubiera eliminado la presión a favor de la construcción de nuevos silos.

Esta situación de crisis se suavizó, como puede verse en el cuadro y gráfico citados, durante los años setenta, debido a la estabilización de la producción, a la entrada en funcionamiento de las nuevas unidades de almacenamiento y a la expansión de la red arrendada. Sin embargo, a partir de 1978 se entra en una etapa de colapso definitivo. En dicho año, los stocks superaban el $90 \%$ del consumo y rebasaban en casi un millón de toneladas la capacidad de la Red. Tras un respiro, por la relativamente mala cosecha de 1979, se llegó a una situación de máxima tensión en el periodo 1980-1982, fase en la que los stocks superaron ampliamente el consumo, alcanzando en 1980 el 114,6 \%. Se llegaba al apogeo del delirio de la política triguera.

\section{LA LIQUIDACIÓN Y EL DESMANTELAMIENTO DE LA RED}

El 29 de mayo de 1984 se publicaba una ley que terminaba con el régimen de monopolio estatal triguero, instaurando la libertad de comercio para productores e intermediarios. Esta norma derogaba, después de cuarenta y siete años, el Decreto-Ley de Ordenación Triguera de agosto de 1937, mediante el que se creó el SNT, y que se había convertido en la norma de intervención económica del franquismo de más larga vida. En su artículo único, se establecía que la producción y el comercio interior de trigo se regirían por los principios de libertad de producción, circulación y precios.

Resulta extraordinariamente llamativo, y muestra claramente la anomalía española en esta materia, el que se tuviera que promulgar en 1984 una ley que instaurase un marco de libertad en la economía triguera. Además, conviene insistir en que este nuevo marco legal venía forzado desde el exterior, ya que constituía un paso inexcusable para la integración de la agricultura española en la Política Agraria Común. Cabe, incluso, preguntarse cuánto tiempo más hubiese resistido el lobby triguero en su privilegiada posición en ausencia de las citadas exigencias legales derivadas del proceso de integración de España en las Comunidades Europeas. 
En lo que a nuestro trabajo se refiere, el casi medio siglo de monopolio estatal había condicionado de manera absoluta las características del sector: escaso desarrollo de las estructuras comerciales, tanto del subsector productor como del industrial y, lo que resultaba más problemático, la creación de una amplia red de almacenamiento estatal, concebida con planteamientos autárquicos y, en consecuencia, poco apta para un mercado relativamente liberalizado e integrado en el marco europeo ${ }^{117}$.

Con la supresión del monopolio, el SENPA pasaba a comprar en régimen de garantía, a un nivel mínimo de precios de sostenimiento, el trigo que los agricultores no pudiesen vender, a mejores precios, por los canales comerciales privados.

EI SENPA quedaba, además, encargado del mantenimiento de las reservas de seguridad que se fijasen anualmente por el Gobierno. En concreto, para la campaña 1984-1985 se fijaban en 400000 toneladas, cantidad que se consideraba suficiente para garantizar el normal abastecimiento nacional y para regular el mercado ${ }^{118}$.

La comercialización de la cosecha de dicho año se presentaba cargada de incógnitas. ¿Cómo funcionarían los canales privados de comercialización? ¿Cuál sería el papel del SENPA una vez perdido el monopolio? ¿Qué nivel de utilización tendría la Red Nacional de Silos? El desarrollo de la campaña 1984-1985, con una cosecha récord de 6 millones de toneladas de trigo, reveló pronto el difícil panorama que se abría para la Red Nacional. En efecto, la cosecha se comercializó sin problemas y en su mayor parte (un $90 \%$ ) por operadores privados, mientras que el SENPA canalizó el $10 \%$ restante ${ }^{119}$. Se mostraba, con claridad, que los

117 Como señalaba Briz (1985: 91), resulta «de todo punto necesario adecuar la infraestructura de almacenamiento tanto pública como privada, siendo este uno de los retos principales para el logro de una comercialización eficaz».

118 Real Decreto 1032 de 1984. El Real Decreto 1031, de 23 de mayo, contenía las directrices básicas reguladoras de las campañas denominadas de transición, las de 1984-1985 a 1986-1987. Igualmente, se derogó el Decreto 583/1970, de 26 de febrero, que regulaba la concesión de ayudas para la ampliación y mejora del almacenamiento privado, exceptuando, con condiciones, a las entidades asociativas del sector agrario.

119 Burgaz (1985: 47). Según este autor la experiencia de la campaña 1984-1985 mostraba que «la comercialización del trigo puede llevarse a efecto sin la intervención del SENPA, o en todo caso, habrá de quedar reducida a un pequeño 
operadores privados disponían de la suficiente capacidad de almacenamiento y de medios financieros para movilizar las cosechas, y que el SENPA quedaría reducido a una posición marginal.

En realidad, este era el resultado buscado y deseable, ya que se trataba, en definitiva, de acabar con el monopolio estatal ${ }^{120}$. El problema surgía con la Red Nacional de Silos, con los más de dos millones y medio de toneladas de capacidad de almacenamiento de propiedad pública, distribuidas en un millar de unidades por todo el territorio nacional, cuya funcionalidad y ubicación, concebidas con planteamientos autárquicos, no respondían ni a las nuevas circunstancias del mercado ni a los más que previsibles cambios regionales en el cultivo triguero, marcados por una tendencia regresiva en zonas tradicionalmente (y artificialmente) trigueras, como gran parte de las dos Castillas y Aragón, y el auge del cultivo en regiones, mejor dotadas, como Andalucía.

En ámbitos oficiales, en el Ministerio de Agricultura y, muy especialmente, en el SENPA, se generó una enorme inquietud por el futuro de los silos y por el de los miles de personas vinculadas a su actividad. El planteamiento inmediato de las autoridades fue, lógicamente, el de intentar mantener en valor las instalaciones. El propio SENPA todavía tenía que cumplir las tareas de regular el mercado y asegurar la compra a precios de garantía a los agricultores, así como conservar las reservas estratégicas, lo que exigía el mantenimiento de una parte de la Red, bajo su control o propiedad.

Precisamente, con esa finalidad, se desglosaron algunas unidades, las más importantes, que formaron lo que pasó a denominarse Red Básica, con una capacidad de almacenamiento de más de un millón de toneladas, que quedaron en manos del SENPA, bajo control de la Administración Central del Estado. Para el resto, el grueso de la antigua Red Nacional, compuesto por más de ochocientas unidades de diversos tamaños y funcionalidad, y repartidas por toda España, se buscaron diversas salidas. Por una parte, se intentó fomentar su uso mediante el sistema de

volumen de la cosecha [...] los resultados de esta campaña son un claro exponente de la suficiente capacidad (almacenamiento, financiación, etc.) de los diferentes operadores para comercializar la cosecha nacional de trigo».

120 Según Briz (1985: 96), el sistema directo de venta del agricultor en los almacenes del SENPA al precio de garantía: «debe ser una práctica residual, sólo de apoyo al mercado en una situación de crisis». 
"certificados de depósitos». Conforme a este sistema, los agricultores podían depositar sus cosechas en los silos y almacenes públicos, de forma provisional, hasta el momento en que decidieran venderlas a un operador privado o, de manera definitiva, al SENPA al precio de sostenimiento $^{121}$. Como se intuía que esto no sería suficiente para mantener la red en actividad, se pensó, también, en la posibilidad de vender o alquilar instalaciones a las organizaciones agrarias.

Lamentablemente para el SENPA ( $y$, sobre todo, para los contribuyentes), las peores expectativas se fueron haciendo realidad. La Red Nacional, como ya he comentado en varias ocasiones, era inadecuada para el nuevo marco de libertad comercial abierto con la ley de 1984. Pasadas las primeras campañas, denominadas de transición, la comercialización de la cosecha de 1988-1989 mostró con crudeza la situación. Con una cosecha de 12 millones de toneladas de cebada y 6 millones de trigo, los agricultores tan solo utilizaron instalaciones del SENPA hasta un volumen de 0,12 millones de t, un porcentaje insignificante. Este rechazo de los agricultores a utilizar la capacidad estatal se debió a la agilidad y a las fórmulas de pago practicadas por los operadores privados.

Así, en Andalucía, región que se convirtió en la principal productora de España, los grandes propietarios realizaron ventas masivas de cereales a grandes compañías multinacionales con cobro al contado y en metálico. Es de suponer que lo mismo pudo suceder en otras regiones productoras. Evidentemente esta forma de comercialización y de pago resultaba mucho más atractiva por su agilidad y, sobre todo, por su opacidad fiscal, que la comercialización oficial. Por su parte, los almacenistas e intermediarios tampoco tenían interés en arrendar los silos.

Además de los problemas de localización, de dispersión y de tamaño, las crisis petroleras de los años setenta habían repercutido muy negativamente en los costes de funcionamiento de las unidades de almacenamiento vertical, caracterizadas por un alto consumo energético. Se estaban imponiendo nuevos sistemas de almacenamiento horizontal, a nivel del suelo, con construcciones muy sencillas, en las que el grano podía mover-

121 Como señala Briz (1985: 97), con el sistema de certificados de depósito, «se pone a disposición de los agricultores la red de almacenamiento pública, evitando tener que duplicar las instalaciones y al mismo tiempo dando la posibilidad de dar una utilización a instalaciones y personas de la Administración que de otra manera podrían quedar ociosas o infrautilizadas». 
se con maquinaria móvil y con poco personal. Por último, las cooperativas y las organizaciones de productores se mostraban dispuestas a utilizar la Red, siempre que el precio del arrendamiento estuviese subvencionado. En definitiva, se hizo evidente lo que ya se intuía, que la mayor parte de las unidades que constituían la Red Nacional no resultaban adecuadas al nuevo marco comercial y que tendrían que ser abandonadas.

Las autoridades se encontraron, en consecuencia, con el dilema de hacer frente a los crecientes gastos de mantenimiento de la Red o a su definitivo abandono. Se pusieron en marcha varias líneas de actuación, en un intento de resolver la situación, mediante el desmembramiento patrimonial de la Red. Por una parte, se planteó la desafección del SENPA, en favor de la Dirección General del Patrimonio, de algunas instalaciones. En segundo lugar, se inició un proceso de reversión a los Ayuntamientos, de acuerdo con el Reglamento de Bienes de Entidades Locales, de las unidades construidas, en su día, en suelo cedido por los Entes Locales. Igualmente, se emprendió la reversión a particulares de las instalaciones construidas en terrenos expropiados, al haberse extinguido la razón de interés social que había justificado la expropiación. Finalmente, se planteó la cesión, a título gratuito, de otras instalaciones a los Ayuntamientos ${ }^{122}$.

En 1995 se abría, finalmente, otra línea de desmembración de la Red como consecuencia de las denominadas «encomiendas de gestión» a las Comunidades Autónomas. La estructura autonómica del Estado y las transferencias de competencias de la Administración Central a las autonomías en materia agraria, obligaba a los gobiernos autónomos a desarrollar actuaciones de intervención, de regulación de mercados y de compra, almacenamiento y venta de productos, particularmente de cereales ${ }^{123}$. En consecuencia, se empezaron a firmar los correspondientes convenios entre el Ministerio y las Comunidades Autónomas, mediante los que se cedían en uso los silos y almacenes de la Red Básica y se transferían en propiedad el resto de las instalaciones ${ }^{124}$. En 1996 se firmaban los conve-

122 Boletines Informativos del FEGA.

123 El Real-Decreto 2206/1995, de 28 de diciembre, establecía que el FEGA sería el organismo pagador, en el ámbito nacional, de las ayudas del Fondo Europeo de Garantía Agraria (FEOGA). A su vez, los departamentos de Agricultura de las Comunidades Autónomas asumieron estas funciones.

124 También en 1995, y mediante el Real Decreto 2205, de 28 de diciembre, se refundieron el FORPPA (Fondo para la Regulación de los Productos y Precios 
nios con Andalucía, Cataluña, Comunidad Valenciana, Galicia y el País Vasco; en 1997 con Aragón, Baleares, Navarra y Madrid; en 1998 con La Rioja y Murcia; en 1999 con Extremadura; en 2000 con Asturias y Castilla y León y en 2001 se preparaban los de Cantabria, Canarias y Castilla-La Mancha. Paralelamente, se fueron transfiriendo instalaciones a los Ayuntamientos, a la Dirección General del Patrimonio y a particulares conforme a las normas explicadas anteriormente.

Los resultados de todos estos procesos pueden verse con detalle en los cuadros $16,17,18,19$ y 20 . Así, en el cuadro 16 se refleja la trayectoria de la distribución de las unidades de almacenamiento del SENPAFEGA por Comunidades Autónomas entre 1989 y 1997 (últimos datos disponibles al finalizar este trabajo). En esos momentos el SENPA-FEGA había perdido ya 302 unidades y 642494 toneladas de capacidad y ya no disponía de ninguna unidad en Galicia, País Vasco y Comunidad Valenciana. La disminución del número de unidades fue mayor, un 33,2\%, que la de capacidad, un $24 \%$, lo que indica claramente que el SENPA-FEGA se estaba desprendiendo de las unidades más pequeñas que no se acomodaban a los criterios fijados para la Red Básica. Mantenía íntegra, prácticamente, la Red en Castilla y León, Castilla-La Mancha y Extremadura, en algunas Comunidades pequeñas como La Rioja y Murcia, así como el silo de puerto de Santa Cruz de Tenerife. En las demás regiones su presencia se había reducido en torno a un $50 \%$. En Andalucía, la red del FEGA había pasado de 151 unidades y 581248 toneladas de capacidad, a tan solo 16 grandes macrosilos con una capacidad de $248820 \mathrm{t}$.

En el cuadro 20 puede verse una información en cierto sentido complementaria de la anterior. Si en el cuadro 16 se veía cómo se iba reduciendo la Red del SENPA, en el cuadro 20 puede observarse cómo se estaban construyendo las redes autonómicas. Se puede comprobar el traspaso de unidades distinguiendo entre las que pasaban en propiedad definitivamente a las Comunidades Autónomas y aquellas en las que tan solo se producía una cesión de uso, ya que se trataba de unidades de la Red Básica que, como hemos visto, eran propiedad del FEGA y dependían de la Administración Central.

Agrarios) y el SENPA en un nuevo organismo autónomo de carácter comercial y financiero denominado FEGA (Fondo Español de Garantía Agraria). El FEGA asumió todas las competencias y funciones de los organismos que refundía, entre ellas la tarea de conservación de la Red de Silos. 


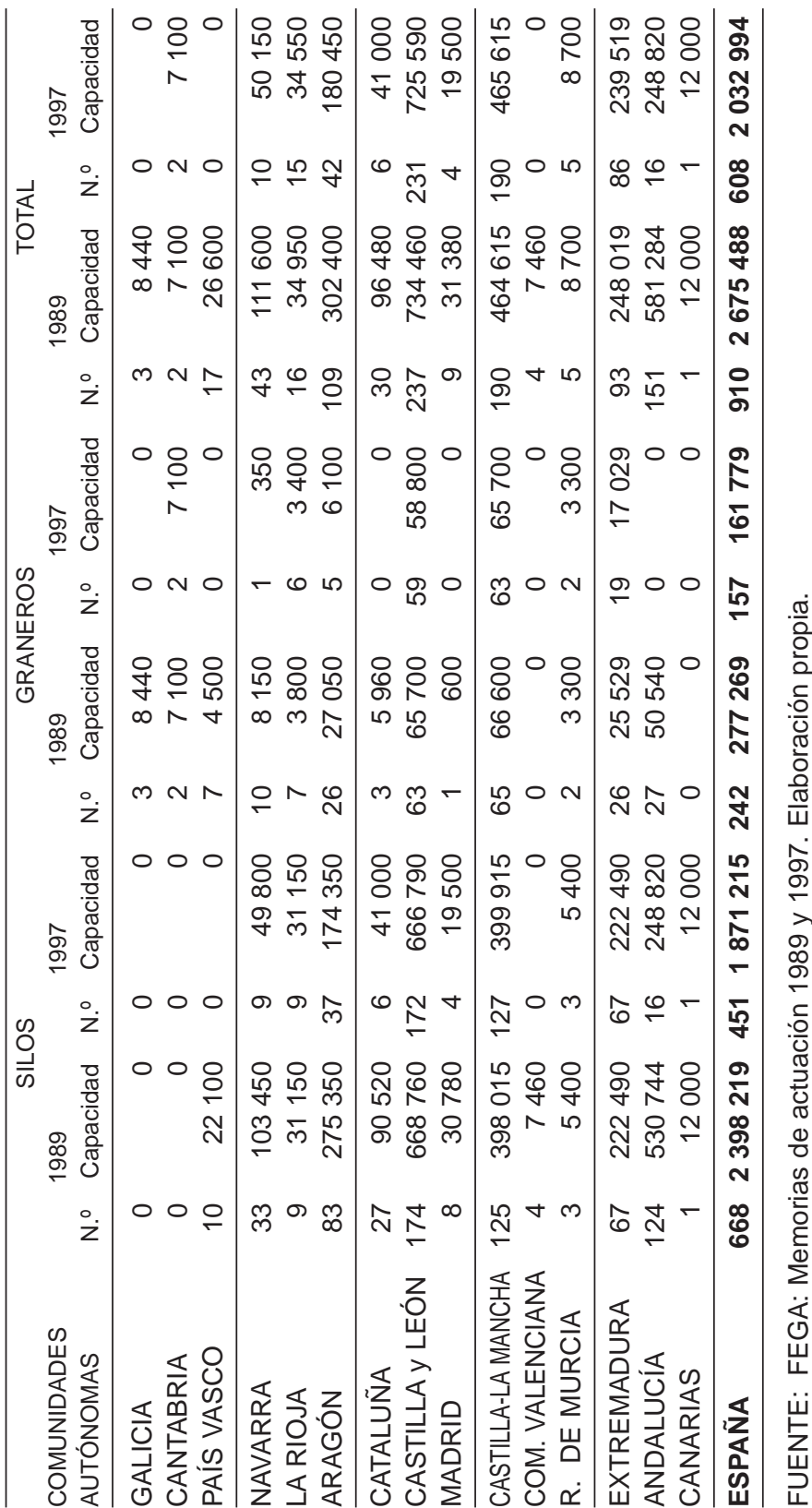


CUADRO 17. UNIDADES DE ALMACENAMIENTO DEL FEGA REVERTIDAS O DESAFECTADAS HASTA EL 31-12-2000

\begin{tabular}{|c|c|c|c|}
\hline Provincias/CC. AA. & N.. de unidades & Capacidad (t) & Destinatario \\
\hline $\begin{array}{l}\text { Cádiz } \\
\text { Córdoba } \\
\text { Huelva } \\
\text { Jaén } \\
\text { Málaga } \\
\text { ANDALUCíA }\end{array}$ & $\begin{array}{l}4 \\
1 \\
1 \\
1 \\
1 \\
8\end{array}$ & $\begin{array}{r}3500 \\
2400 \\
600 \\
800 \\
1500 \\
8800 \\
\end{array}$ & $\begin{array}{l}\text { Ayuntamiento } \\
\text { Ayuntamiento } \\
\text { D. G. Patrimonio } \\
\text { D. G. Patrimonio } \\
\text { Ayuntamiento }\end{array}$ \\
\hline $\begin{array}{l}\text { Huesca } \\
\text { Zaragoza } \\
\text { ARAGóN }\end{array}$ & $\begin{array}{l}4 \\
2\end{array}$ & $\begin{array}{l}4350 \\
2.000 \\
6350\end{array}$ & $\begin{array}{l}\text { D. G. Patrimonio } \\
1 \text { Ayuntamiento } \\
1 \text { D. G. Patrimonio }\end{array}$ \\
\hline $\begin{array}{l}\text { Ciudad Real } \\
\text { Cuenca } \\
\text { Toledo } \\
\text { CASTILLA-LA MANCHA }\end{array}$ & $\begin{array}{r}8 \\
1 \\
2 \\
11\end{array}$ & $\begin{array}{l}5500 \\
1400 \\
1600 \\
8500\end{array}$ & $\begin{array}{l}\text { Ayuntamiento } \\
\text { Ayuntamiento } \\
\text { Ayuntamiento }\end{array}$ \\
\hline $\begin{array}{l}\text { Ávila } \\
\text { Salamanca } \\
\text { Segovia } \\
\text { Soria } \\
\text { Valladolid } \\
\text { Zamora }\end{array}$ & $\begin{array}{l}6 \\
4 \\
2 \\
1 \\
1 \\
2\end{array}$ & $\begin{array}{r}3400 \\
3600 \\
1800 \\
600 \\
1200 \\
2970\end{array}$ & $\begin{array}{l}\text { Ayuntamiento } \\
\text { Ayuntamiento } \\
\text { Ayuntamiento } \\
\text { Ayuntamiento } \\
\text { D. G. Patrimonio } \\
1 \text { D. G. Patrimonio } \\
1 \text { Ayuntamiento }\end{array}$ \\
\hline CASTILLA y LEÓN & 16 & 13570 & \\
\hline $\begin{array}{l}\text { Barcelona } \\
\text { Gerona } \\
\text { Lérida } \\
\text { CATALUÑA }\end{array}$ & $\begin{array}{l}1 \\
1 \\
1 \\
3\end{array}$ & $\begin{array}{r}1000 \\
2500 \\
7500 \\
11000 \\
\end{array}$ & $\begin{array}{l}\text { D. G. Patrimonio } \\
\text { D. G. Patrimonio } \\
\text { D. G. Patrimonio }\end{array}$ \\
\hline $\begin{array}{l}\text { Castellón } \\
\text { COM. VALENCIANA }\end{array}$ & $\begin{array}{l}1 \\
1\end{array}$ & $\begin{array}{l}1170 \\
1170\end{array}$ & D. G. Patrimonio \\
\hline $\begin{array}{l}\text { Badajoz } \\
\text { Cáceres } \\
\text { EXTREMADURA }\end{array}$ & $\begin{array}{l}5 \\
4 \\
9\end{array}$ & $\begin{array}{l}4500 \\
2800 \\
7300 \\
\end{array}$ & $\begin{array}{l}\text { Ayuntamiento } \\
\text { Ayuntamiento }\end{array}$ \\
\hline $\begin{array}{l}\text { Orense } \\
\text { La Coruña } \\
\text { GALICIA }\end{array}$ & $\begin{array}{l}1 \\
1 \\
2\end{array}$ & $\begin{array}{r}720 \\
720 \\
1440 \\
\end{array}$ & $\begin{array}{l}\text { Particulares } \\
\text { Particulares }\end{array}$ \\
\hline MADRID & 1 & 600 & Particulares \\
\hline NAVARRA & 4 & 3800 & $\begin{array}{l}1 \text { Ayuntamiento } \\
3 \text { D. G. Patrimonio }\end{array}$ \\
\hline $\begin{array}{l}\text { Álava } \\
\text { PAÍS VASCo }\end{array}$ & 2 & $\begin{array}{l}1000 \\
1000\end{array}$ & Ayuntamiento \\
\hline LA RIOJA & 3 & 3800 & $\begin{array}{l}2 \text { Ayuntamiento } \\
1 \text { D. G. Patrimonio }\end{array}$ \\
\hline ESPAÑA & 66 & 67330 & \\
\hline
\end{tabular}

FUENTE: Fondo Español de Garantía Agraria. Informes de Actividad 1997 y 2000. 
CUADRO 18. UNIDADES DE ALMACENAMIENTO DEL SENPA CEDIDAS GRATUITAMENTE EN USO A AYUNTAMIENTOS

\begin{tabular}{lccrr}
\hline & \multicolumn{2}{c}{ Número de unidades } & \multicolumn{2}{c}{ Capacidad $(\mathrm{t})$} \\
Comunidades Autónomas & a $31-12-95$ & a $31-12-97$ & a $31-12-95$ & a 31-12-97 \\
\hline ANDALUCíA & 28 & 0 & 61824 & \\
ARAGÓN & 23 & 25 & 30100 & 35250 \\
CASTILLA-LA MANCHA & 58 & 92 & 70370 & 131070 \\
CASTILLA y LEÓN & 34 & 47 & 34500 & 56460 \\
CATALUÑA & 2 & 0 & 2850 & \\
COM. VALENCIANA & 1 & 0 & 3000 & \\
EXTREMADURA & 34 & 49 & 49039 & 97788 \\
MADRID & 1 & 1 & 600 & 600 \\
NAVARRA & 8 & 10 & 15500 & 20750 \\
PAÍS VASCO & 10 & 0 & 12500 & \\
LA RIOJA & 3 & 3 & 4400 & 4400 \\
\hline ESPAÑA & $\mathbf{2 0 2}$ & $\mathbf{2 2 7}$ & $\mathbf{2 8 4} 683$ & $\mathbf{3 4 6 3 1 8}$ \\
\hline
\end{tabular}

FUENTE: Fondo Español de Garantía Agraria. Informes de Actividad (1995 y 1997).

CUADRO 19. UNIDADES DE ALMACENAMIENTO DEL SENPA-FEGA CEDIDAS GRATUITAMENTE EN USO A AYUNTAMIENTOS. (Situación a 31 de diciembre de cada año)

\begin{tabular}{cccc}
\hline Año & N.o de unidades & Capacidad $(\mathrm{t})$ & Tamaño medio $(\mathrm{t})$ \\
\hline 1991 & 109 & 135639 & 1244 \\
1992 & 143 & 175799 & 1229 \\
1993 & 189 & 247109 & 1307 \\
1994 & 192 & 250759 & 1306 \\
1995 & 202 & 284683 & 1409 \\
1996 & 178 & 240589 & 1352 \\
1997 & 227 & 346318 & 1526 \\
1998 & 249 & 385968 & 1550 \\
1999 & 159 & 225030 & 1415 \\
2000 & 117 & 178595 & 1526 \\
\hline
\end{tabular}

FUENTE: Elaboración propia y FEGA. Informe de Actividad (años 1991 a 2000). 
CUADRO 20. TRASPASO A LAS COMUNIDADES AUTÓNOMAS Y CESIONES DE USO (RED BÁSICA) DURANTE 1996 Y 1997. (Derivado de la encomienda de gestión)

\begin{tabular}{lrrrrrr}
\hline & \multicolumn{3}{c}{ Traspasos } & \multicolumn{2}{c}{ Cesiones de uso (red básica) } \\
Comunidades Autónomas & Número & Capacidad (t) & Número & Capacidad (t) & Número & Capacidad (t) \\
\hline ANDALUCíA & 106 & 275984 & 26 & 48140 & 16 & 248820 \\
ARAGÓN & 45 & 96400 & 20 & 19950 & 37 & 174350 \\
CATALUÑA & 19 & 46020 & 3 & 5960 & 6 & 41000 \\
COM. VALENCIANA & 4 & 7460 & & & & \\
GALICIA & 4 & 11200 & 1 & 600 & 4 & 19500 \\
MADRID & 24 & 53650 & 8 & 6800 & 9 & 49800 \\
NAVARRA & 10 & 22100 & 5 & 3500 & & \\
PAÍS VASCO & $\mathbf{2 1 2}$ & $\mathbf{5 1 2} \mathbf{8 1 4}$ & $\mathbf{6 5}$ & $\mathbf{9 2 6 7 0}$ & $\mathbf{7 2}$ & $\mathbf{5 3 3 4 7 0}$ \\
\hline ESPAÑA & & & & & & \\
\hline
\end{tabular}

FUENTE: Fondo Español de Garantía Agraria. Informes de Actividad (1995 y 1997).

El cuadro 17 refleja el proceso de desafección y reversión de unidades hasta el 31 de diciembre de 2000. Como puede comprobarse, este proceso afectó a 66 unidades con una capacidad total de 67330 t, es decir, unidades muy pequeñas, fundamentalmente graneros, con una capacidad media un poco mayor de mil toneladas. De estas 66 unidades, 14 pasaron a la Dirección General del Patrimonio, por ser almacenes o graneros construidos en edificios históricos rehabilitados ${ }^{125}$. La mayor parte de las reversiones tuvo por destinatarios a los Ayuntamientos. Finalmente, en los cuadros 18 y 19 he recogido la información relativa a las unidades de almacenamiento cedidas gratuitamente a los Ayuntamientos. En el cuadro 19 puede verse el número de unidades cedidas, su capacidad total y su capacidad media entre 1991 y 2000, y en el cuadro 18 su distribución por Comunidades Autónomas. También en este caso se trataba de unidades que tenían un interés nulo para el SENPA, ya que por su pequeño tamaño y mala situación no eran adecuadas para formar parte de la Red Básica. En 1997 la mayor parte de ellas estaban situadas en Castilla-

125 Además de castillos, a los que ya hemos hecho referencia, el SNT adquirió, rehabilitó y transformó en granero el palacio de Carlos III en La Carolina y una casa señorial en Rueda. SNT (1958). 
La Mancha, Extremadura, Castilla y León y Aragón. Conviene advertir que con el cambio de la titularidad de las instalaciones de la Administración Central a las Comunidades Autónomas, a los Ayuntamientos o a la Dirección General del Patrimonio, el problema de la Red de Silos no se resolvía. Tan solo se trasladaba a otras administraciones públicas. Los nuevos titulares se encontraban con el mismo dilema: abandonar las instalaciones y dejar que se arruinasen o hacer frente, indefinidamente, a los costes de mantenimiento, sin ninguna perspectiva de futuro ${ }^{126}$.

El propio FEGA, a pesar de haberse desprendido de la mayor parte de la Red, tuvo que hacer frente a importantes gastos de mantenimiento, como puede verse en el cuadro 21. Entre 1989 y 2001, y en pesetas constantes de 1992, el SENPA-FEGA realizó unas inversiones totales de 9178 millones para mantener la Red. En el cuadro se observa que los gastos anuales de mantenimiento fueron descendiendo. En realidad, no sabemos con exactitud lo que sucedía porque la información refleja solo los gastos en la Red propiedad del SENPA e ignoramos los costes de mantenimiento de las unidades transferidas a las Comunidades Autónomas y a los Ayuntamientos. Por su parte, la política de arrendamiento de servicios de almacenamiento tuvo unos resultados casi despreciables. Como puede verse en el cuadro 22, las unidades arrendadas oscilaron entre un máximo de 121 en la campaña 1989-1990 y un mínimo de 17 en la de 19921993. Estos arrendamientos proporcionaron al SENPA unos ingresos de entre 69 y 7 millones de pesetas, cantidades insignificantes en relación con el valor teórico de las instalaciones y a los costes efectivos de mantenimiento. Estas modestas cifras confirman lo ya comentado sobre el escasísimo interés que mostraron las asociaciones agrarias y los operadores comerciales privados en arrendar los silos y graneros del SENPA, a causa, como ya he repetido, de su inadecuación al nuevo marco establecido por la ley de 1984.

126 Lamentablemente, el FEGA no facilita información sobre lo que está pasando con los silos. Cualquier viajero un poco observador puede comprobar el actual estado de abandono de muchas instalaciones. El emblemático silo de Alcalá de Henares, con el que comenzó la Red, está actualmente abandonado, aunque las últimas noticias apuntaban a la posible instalación de un museo. En algunos casos los silos se están, sencillamente, derribando. Así, La Glorieta, el periódico informativo del Ayuntamiento de Calahorra, en el número de junio de 2001, daba la noticia de que la Comisión de Gobierno había adjudicado las obras para el derribo del silo. 


\section{CUADRO 21. INVERSIONES EN LA RED DE ALMACENAMIENTO} DEL SENPA-FEGA. (En millones de ptas.)

\begin{tabular}{|c|c|c|c|c|c|c|c|c|}
\hline Año & $\begin{array}{c}\text { Mejora } \\
\text { Moder- } \\
\text { nización }\end{array}$ & $\begin{array}{l}\text { Obra civil } \\
\text { Conser- } \\
\text { vación } \\
\text { Reparación }\end{array}$ & Total & $\begin{array}{c}\text { Instalacio } \\
\text { Mejora } \\
\text { Moder- } \\
\text { nización }\end{array}$ & $\begin{array}{l}\text { Conser- } \\
\text { vación } \\
\text { Reparación }\end{array}$ & léctricas & $\begin{array}{c}\text { Total } \\
\text { General }\end{array}$ & $\begin{array}{c}\text { Total } \\
\text { ptas. } 1992\end{array}$ \\
\hline 1989 & 180 & 649 & 829 & 62 & 83 & 145 & 974 & 1142 \\
\hline 1990 & 270 & 574 & 844 & 33 & 172 & 205 & 1049 & 1167 \\
\hline 1991 & 74 & 510 & 584 & 68 & 46 & 114 & 698 & 735 \\
\hline 1992 & 81 & 539 & 620 & 50 & 153 & 203 & 823 & 823 \\
\hline 1993 & 193 & 668 & 861 & 34 & 13 & 47 & 908 & 880 \\
\hline 1994 & 74 & 367 & 441 & 21 & 208 & 229 & 670 & 619 \\
\hline 1995 & 147 & 490 & 637 & 39 & 116 & 155 & 792 & 700 \\
\hline 1996 & 223 & 82 & 305 & 3 & 87 & 90 & 395 & 336 \\
\hline 1997 & 220 & 264 & 484 & 24 & 22 & 46 & 530 & 439 \\
\hline 1998 & 498 & 216 & 714 & 0 & 35 & 35 & 749 & 608 \\
\hline 1999 & 215 & 241 & 456 & 309 & 31 & 340 & 796 & 636 \\
\hline 2000 & 402 & 150 & 552 & 167 & 0 & 167 & 719 & 559 \\
\hline 2001 & 353 & 55 & 408 & 240 & 65 & 305 & 713 & 534 \\
\hline
\end{tabular}

FUENTE: Elaboración propia a partir de FEGA. Informe de Actividad (años 1989-2001).

A la altura del año 2000, la Red Nacional de Silos, uno de los proyectos más emblemáticos del franquismo, en el que se habían invertido cuantiosos recursos públicos, se desmoronaba de forma irremediable. En el cuadro 23 puede observarse el rápido declive de la red que pasó de tener 910 unidades y una capacidad de 2,67 millones de toneladas en 1989 a 410 unidades y 1,69 millones de toneladas en 2001. En doce años la Red había perdido el $55 \%$ de sus unidades y el $37 \%$ de su capacidad de almacenamiento. El descenso más acentuado del número de unidades significa, evidentemente, que el Servicio se fue desprendiendo de las unidades pequeñas y antiguas y se fue reservando las más grandes y modernas, las más adecuadas, en definitiva, para constituir la Red Básica. Uno más de los elevados costes que la mayoría de los españoles tuvo que pagar por la desmedida y desacertada política agraria del franquismo. 


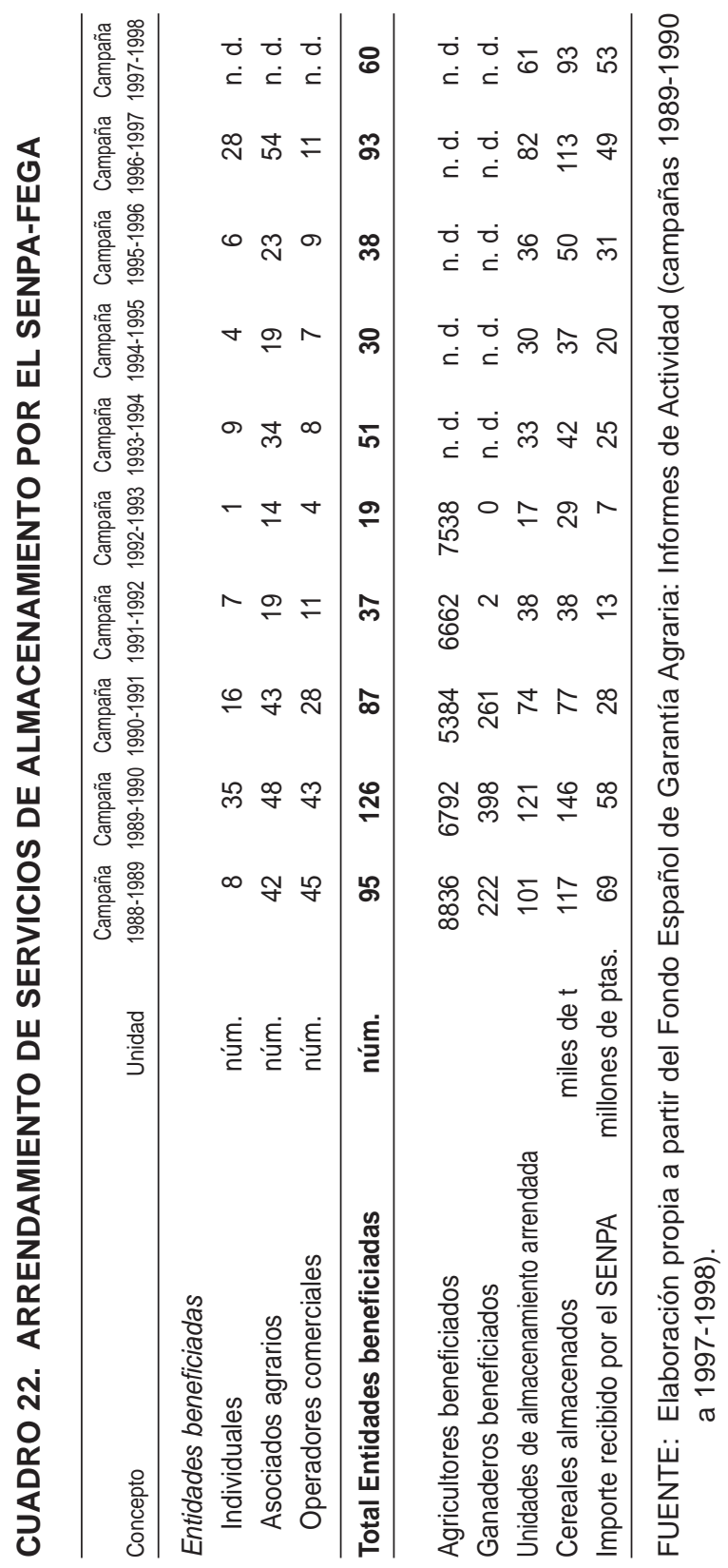




\section{CUADRO 23. EVOLUCIÓN DE LA RED NACIONAL DE ALMACENAMIENTO}

\begin{tabular}{rrrrr}
\hline & \multicolumn{2}{c}{ Datos anuales } & \multicolumn{2}{c}{ Datos acumulados } \\
Número & $\begin{array}{c}\text { Capacidad } \\
(\mathrm{t})\end{array}$ & Número & $\begin{array}{c}\text { Capacidad } \\
(\mathrm{t})\end{array}$ \\
\hline 1989 & 1 & 20000 & 910 & 2675488 \\
1990 & -7 & -7300 & 903 & 2668188 \\
1991 & -5 & -5500 & 898 & 2662688 \\
1992 & -4 & -4100 & 894 & 2658588 \\
1993 & -5 & -14940 & 889 & 2643648 \\
1994 & -3 & -4370 & 886 & 2639278 \\
1995 & -1 & -720 & 885 & 2638558 \\
1996 & -175 & -416884 & 710 & 2221674 \\
1997 & -102 & -188680 & 608 & 2032994 \\
1998 & 0 & 0 & 608 & 2032994 \\
1999 & -84 & -161699 & 524 & 1871295 \\
2000 & -114 & -183140 & 410 & 1688155 \\
2001 & 0 & 0 & 410 & 1688155 \\
\hline
\end{tabular}

FUENTE: Elaboración propia a partir de los Informes de Actividad del SENPAFEGA (años 1989 a 2001). 



\section{Algunas reflexiones finales}

Para finalizar este trabajo, expondré algunas reflexiones y conclusiones. En principio, parece indiscutible la necesidad de que un país disponga de una red de almacenamiento para cereales capaz de regular la oferta, estabilizar los precios y asegurar el normal abastecimiento de la población. Incluso con una política agraria relativamente liberal, y en la que se hubiera optado por abastecer una parte esencial del consumo con importaciones, la construcción de silos modernos de puerto y de tránsito hubiera sido necesaria. Sin embargo, esta necesidad se podía satisfacer de diversas maneras, tanto en lo relativo a si la red tenía que ser estatal o privada, como en lo concerniente a su dimensión y, por supuesto, en el caso de una red estatal respecto a su forma de financiación.

En mi opinión, en los años treinta, y dadas las circunstancias socioeconómicas del país, resultaba necesaria la construcción de una red de almacenamiento, pues uno de los determinantes fundamentales del problema triguero era el brusco descenso de los precios en las épocas de recolección por la imperiosa necesidad que tenían los pequeños propietarios de vender su cosecha de forma inmediata. Para cientos de miles de agricultores trigueros la posibilidad de almacenar sus cosechas en unas condiciones razonables era su tabla de salvación, ya que carecían de recursos económicos para construir almacenes y de recursos financieros para esperar el momento más idóneo de vender sus cosechas. La opción de haber procedido a desmantelar de forma brusca la protección de la que gozaba el sector triguero no era factible porque hubiera tenido unos costes sociales y políticos insoportables para la República. El planteamiento de una red estatal era, como hemos visto, ampliamente compartida. Estaba en la línea ideológica dominante en esos tiempos y presentaba incuestionables ventajas para los cultivadores. 
Sin embargo, no existían razones técnicas o económicas que justificaran el rechazo de la alternativa de una red privada. Los temores a que los almacenes y silos estuvieran en manos privadas y que, por lo tanto, la gestión se hiciese con planteamientos de búsqueda del beneficio particular y en perjuicio de los agricultores eran infundados. Sin embargo, se aceptaba, casi sin discusión, la idea de que una red estatal funcionaría mejor. Nada de esto se demuestra, como hemos visto en este trabajo, con la experiencia española ${ }^{127}$.

Una vez que el Gobierno optó por la creación de una red estatal se tendría que haber planteado la cuestión de su financiación. En la práctica, como hemos visto, la Red fue financiada por los consumidores de pan. Sin embargo, los principales beneficiarios de la Red fueron los grandes cultivadores trigueros. En mi opinión, hubiera sido mucho más justo y eficiente que la construcción se hubiera financiado con cargo a los productores $y$, sobre todo, con cargo a los beneficios extraordinarios de los mayores productores. EI SNT podría haber descontado de los pagos que realizaba a los agricultores un porcentaje progresivo, en función del volumen de ventas. Esta solución hubiera corregido el resultado injusto de la política de precio único del SNT que, como sabemos, implicaba beneficios extraordinarios para las grandes explotaciones, que producían con menores costes que las pequeñas. Además de corregir ese elemento de injusticia, si la Red se hubiera financiado de esta forma, se habría construido también de manera más eficiente. Si la financiación de las construcciones hubiera recaído sobre los productores, la presión para construir más y más unidades no se hubiera producido. Tal y como se financió, los productores trigueros no tenían, todo lo contrario, razón alguna para dejar de solicitar al SNT nuevas construcciones, que garantizasen la recogida lo más cómodamente posible de sus cosechas. Está bien establecido en la ciencia económica que la demanda de bienes gratuitos tiende a ser ilimitada. En el peor de los casos, la Red se podría haber financiado con cargo a los presupuestos generales del Estado, de forma que, a pesar del carácter regresivo del sistema fiscal, su coste se hubiese repartido más equitativamente y no hubiese recaído en exclusiva en los consumidores de pan.

127 En realidad, como sucede en cualquier otro sector de la economía, los potenciales problemas de prácticas abusivas por un sistema de almacenamiento, radicaban no en su carácter privado, sino en el grado de control sobre el mercado. 
Además del beneficio extraordinario que implicaba la política de precio único, la propia forma en la que se construyó la Red benefició particularmente a los grandes propietarios. Como creo haber demostrado en otros trabajos, durante los años cuarenta se produjo un espectacular desarrollo del mercado negro nutrido fundamentalmente por los excedentes de los grandes propietarios que acumularon grandes fortunas, con graves consecuencias para los consumidores que vieron cómo el precio subía hasta niveles abusivos, a la vez que descendía la calidad del llamado pan negro.

En los años cincuenta comenzó la construcción de la Red, ahora necesaria porque, tras las sucesivas elevaciones del precio oficial del trigo, la producción así como la parte de esta que los agricultores vendían al Servicio aumentaron de forma continuada. En esos momentos la Red empezó a jugar un papel estabilizador impidiendo que los precios bajasen conforme iba aumentando la oferta. Es indudable que la estabilización de los precios es un objetivo deseable. Sin embargo, hay que destacar la asimetría: a partir de los años sesenta los precios se sostienen y se impide su baja, mientras que no se consiguió frenar sus alzas durante los años cuarenta ni tampoco la proliferación del mercado negro. Finalmente, a partir de los años sesenta, con el comienzo de la producción de excedentes, la existencia de la Red benefició hasta límites difícilmente justificables a los productores trigueros, perjudicando a los consumidores que hubieran podido beneficiarse de un pan más barato si el mercado hubiese sido más libre. Por supuesto, los perjuicios para la economía fueron más generales, ya que la excesiva protección al trigo impidió una adecuada y «natural» reordenación de los cultivos. En definitiva, los mismos que en los años cuarenta comercializaron su trigo en el mercado negro con altísimos beneficios son los que llenaron los silos de excedentes, a partir de los años sesenta, socializando los costes de su liquidación.

Tiene también interés relacionar la construcción de la Red con la evolución del mercado exterior. No deja de ser sorprendente que el comienzo de la construcción de la Red coincida con el inicio de la década de los cincuenta, años en los que ya estaba claro el final de la etapa aislacionista y en los que Europa vivía una fase de prosperidad y de cooperación económica. Más concretamente en esos años se habían despejado, también, las dudas respecto a las garantías futuras de un abastecimiento exterior de trigo tras la adhesión de España al Convenio Internacional del Trigo, primero, y la firma de los Acuerdos con los 
EE. UU., después. Si el comienzo de la construcción plantea serias dudas sobre su oportunidad, sucede lo mismo con otros momentos significativos de su expansión. Así, el gran «boom» de la construcción de los años 19661970 coincide plenamente con la fase del comienzo de la producción masiva de excedentes, imposibles de vender en el mercado internacional sino a costa de graves pérdidas. Esta situación, imposible de justificar, de producción de excedentes invendibles y de paralela expansión de la Red, se mantuvo, como hemos visto, hasta el final de la vida del organismo triguero en 1984. Tampoco se comprende bien por qué el Servicio desarrolló la Red paralela de almacenamiento arrendada, por qué se pagaban alquileres de almacenes a propietarios y harineros que eran, en definitiva, los que se beneficiaban de la Red Nacional de Silos. 


\section{Apéndice}

En el siguiente apéndice presento una relación de todas las unidades de almacenamiento que formaron la denominada Red Nacional, así como su distribución por provincias. Además de distinguir entre silos y graneros, se incluye información sobre las instalaciones que tuvieron su origen en castillos restaurados, los centros de secado de grano y los de selección de semillas. Se proporcionan, igualmente, diferentes datos de interés como su fecha de inauguración, su capacidad y, siempre que ha sido posible, la casa montadora de la maquinaria.

Para una mayor facilidad en el estudio de esta densa información presento, además, un conjunto de cuatro mapas. En el mapa número 1 aparece la distribución provincial de los silos y los graneros. Algunas de las conclusiones que pueden extraerse de este son las siguientes:

- Hay un grupo importante, formado por 20 provincias, en las que el número de silos es inferior a 6 . Son todas, excepto Orense, provincias costeras mediterráneas y atlánticas que podríamos calificar como de escasa vocación triguera: Gerona, Barcelona, Tarragona, Castellón, Valencia, Alicante, Murcia, Almería, Huelva, Orense, Pontevedra, La Coruña, Lugo, Oviedo, Santander, Vizcaya, Guipúzcoa, Baleares, Tenerife y Las Palmas.

-Un segundo conjunto intermedio integrado por 18 provincias que tienen entre 7 y 32 unidades (que en el mapa aparecen subdivididas en dos grupos de 7 a 21 y de 22 a 32): Huesca, Lérida, Teruel, Albacete, Jaén, Granada, Málaga, Cádiz, Álava, Logroño, Soria, Guadalajara, Madrid, Segovia, Ávila, Palencia, León y Zamora.

-Finalmente, hay un tercer grupo (también subdividido en dos, en el mapa) con 12 provincias, las mejor dotadas en términos absolutos, que 
tienen entre 33 y 59 unidades, formado por Navarra, Zaragoza, Cuenca, Toledo, Ciudad Real, Córdoba, Sevilla, Badajoz, Cáceres, Salamanca, Valladolid y Burgos.

Evidentemente, los silos y los graneros son muy distintos en lo que concierne, entre otras cosas, a su capacidad. En general, las unidades más pequeñas son las más antiguas y las menos funcionales, por lo que no siempre un mayor número de instalaciones significa una mejor dotación. Para intentar corregir este efecto, se presenta el mapa 2 en el que aparece la distribución, no del número de silos, sino de su capacidad de almacenamiento por provincias. Los resultados, en este caso, refuerzan y matizan los que aparecen en el mapa 1 en los siguientes sentidos:

- Se confirma la escasa relevancia de las 20 provincias del primer grupo, las costeras y de escasa vocación triguera.

-La posición relativa de 16 provincias no cambia: Cádiz, Málaga, Granada, Jaén, Albacete, Cuenca, Ávila, Madrid, Guadalajara, Teruel, Navarra, Valladolid, Palencia, León, Logroño y Ávila. En este caso podemos sostener que existe una relación proporcional entre el número de silos y su capacidad media.

-Un tercer grupo de 7 provincias asciende en el ranking: Burgos, Córdoba, Sevilla, Salamanca, Soria, Lérida y Huesca. Son las provincias cuya dotación es mejor en función de la capacidad que en términos de unidades 0 , lo que es lo mismo, que disponían de silos relativamente más grandes y, en principio, mejor equipados.

-Contrariamente a lo que sucede con las provincias del grupo anterior, se presenta el caso de 4 provincias: Ciudad Real, Cáceres, Salamanca y Segovia, que pierden posiciones en el ranking de capacidad en relación con el del número de silos. Eso significa que en estas provincias existían unidades de almacenamiento de capacidad media más reducida.

-Finalmente, dos provincias, Badajoz y Zaragoza, ocupan posiciones de cabeza, tanto en lo que concierne al número de silos como a su capacidad.

-En conjunto, se observa una amplia región en el suroeste de la península (exceptuando la poco triguera Huelva) con provincias dotadas de abundantes silos y de una gran capacidad, con un núcleo formado por Sevilla, Córdoba y Badajoz, rodeado por Cádiz, Ciudad Real, Toledo y Cáceres. 
Esta distribución de la capacidad de almacenamiento, tan concentrada en esta zona del suroeste, zona muy excedentaria en cuanto a la producción y consumo, produjo importantes problemas en la normal circulación de los trigos que tendían a "embalsarse» en los silos de esta región. El Servicio pagó durante muchos años, como es sabido, el mismo precio de garantía para el trigo en todas las regiones de España y lo vendía, a su vez, a un precio único. Mientras la situación de los mercados de consumo fue deficitaria o equilibrada no se planteó problema alguno, pues los industriales harineros se veían obligados a retirar el grano en los silos en los que hubiese existencias y a cargar con los costes de transporte. Sin embargo, cuando a partir de los años sesenta la situación del mercado se tornó excedentaria, empezó a plantearse un grave problema. Los industriales se abastecían de los granos más cercanos y los sobrantes empezaron a concentrarse en las regiones del suroeste con un balance de consumo más excedentario y más alejadas de los grandes núcleos consumidores, formados por la España atlántica y cantábrica y las provincias del centro y norte del Mediterráneo. Evidentemente, la solución económicamente racional a este problema hubiera sido la de aplicar a los productores precios más bajos en estas zonas excedentarias o bien la de imponer cuotas en las cantidades a adquirir con precio garantizado. Como sabemos, el Servicio fue muy reacio a la adopción de medidas de este tipo que perjudicaban a los grandes productores latifundistas de provincias como Sevilla, Córdoba, Cádiz y Badajoz, y que constituían el núcleo duro de los propietarios trigueros.

En estos dos primeros mapas hemos representado las dotaciones por provincias del número de silos y la capacidad de almacenamiento en valores absolutos. Sin embargo, podemos hacer más aproximaciones que nos permitan contemplar desde otras facetas la distribución de la Red Nacional. En esta línea, se presenta el mapa 3 en el que se relaciona, no la superficie total provincial, sino la superficie provincial dedicada al cultivo triguero con la capacidad de almacenamiento. Esta relación tiene la ventaja de que se establece entre magnitudes que hacen referencia exclusivamente al trigo. Tiene el inconveniente de que las superficies trigueras no están distribuidas homogéneamente en el espacio provincial y es diferente, también, dentro de cada una de las provincias. En este mapa se han suprimido las 20 provincias del primer grupo que hemos caracterizado como de escasa vocación triguera, para una mayor claridad. Los resultados son de gran interés y se matizan, de forma sustancial, las conclusiones extraídas de los mapas 1 y 2 . En efecto, de la simple impresión visual 
se observa una mayor homogeneidad del colorido del mapa. Han desaparecido los dos tonos más oscuros, los que señalaban a provincias mejor dotadas en valores absolutos, tanto en términos de unidades como en términos de capacidad de almacenamiento. Al relacionar la capacidad exclusivamente con la superficie triguera se comprueba que la distribución es mucho más homogénea. No obstante, a pesar de esa mayor regularidad, sigue destacando un grupo de provincias con una clara mejor dotación: Cáceres, Badajoz, Toledo, Valladolid, Navarra, Zaragoza, Huesca, Albacete y Granada.

Finalmente, en el mapa 4 se representa la relación entre la producción de trigo y la capacidad de almacenamiento. Se observa también una distribución más homogénea que en los mapas 1 y 2 , pero menos que en el mapa 3. La causa estriba en las diferencias en los rendimientos medios trigueros provinciales, y por eso precisamente vuelven a aparecer tonos oscuros, en Cádiz y Sevilla, provincias de alta productividad. Aparece una ancha franja horizontal de provincias bien dotadas relativamente en capacidad de almacenamiento respecto a la producción formada por Cáceres, Badajoz, Toledo, Ciudad Real y Albacete.

Es evidente que este tipo de análisis y comparaciones podría ampliarse y seguiríamos matizando los resultados. Por ejemplo, sería muy interesante relacionar las dotaciones de silos y de capacidad con las superficies de las comarcas trigueras y sus rendimientos medios. Igualmente, se podría analizar la regularidad en la distribución espacial de los silos; diferenciar entre las dotaciones relativas de silos y graneros, o sus características técnicas. Sin embargo, entiendo que estas aproximaciones encajarían mejor en estudios de carácter comarcal y provincial que en un trabajo como este de carácter nacional. 


\section{LA RED NACIONAL DE SILOS Y GRANEROS}

\begin{tabular}{|c|c|c|c|c|}
\hline Localidad & Tipo & $\begin{array}{l}\text { Capa- } \\
\text { cidad } \\
\text { (t) }\end{array}$ & $\begin{array}{c}\text { Puesta } \\
\text { en } \\
\text { servicio }\end{array}$ & $\begin{array}{c}\text { Casa } \\
\text { montadora } \\
\text { maquinaria }\end{array}$ \\
\hline \multicolumn{5}{|l|}{ ÁLAVA (provincia) } \\
\hline Alegría & $S$ & 1000 & 1963 & Autocampo \\
\hline Bermejo & $\mathrm{G}$ & 400 & 1956 & - \\
\hline Elciego & $\mathrm{G}$ & 600 & 1957 & - \\
\hline Espejo & $\mathrm{S}$ & 1500 & 1971 & Prados Hermanos \\
\hline Laguardia & $G$ & 600 & 1954 & - \\
\hline Oyón & $S$ & 2800 & 1964 & Imad \\
\hline Peñacerrada & $\mathrm{G}$ & 400 & 1956 & - \\
\hline Pobes & $S$ & 1400 & 1965 & Imad \\
\hline Pobes & $G$ & 1000 & 1967 & - \\
\hline Rillabellosa & $S$ & 2300 & 1967 & Imad \\
\hline Salvatierra & $S$ & 2800 & 1968 & Jubus \\
\hline Salvatierra & S & 950 & 1951 & Miguelnos \\
\hline Santa Cruz de Campezo & $G$ & 800 & 1956 & - \\
\hline Vitoria & $S$ & 5000 & 1966 & Prados Hermanos \\
\hline Vitoria & $S$ & 1950 & 1952 & Imad \\
\hline Zambrana & $\mathrm{G}$ & 700 & 1959 & - \\
\hline Zambrana & $S$ & 2400 & 1970 & Imad \\
\hline \multicolumn{5}{|l|}{ ALBACETE (provincia) } \\
\hline Albacete & $S$ & 300 & 1967 & Jubus \\
\hline Albacete & $S$ & 7500 & 1965 & Imad \\
\hline Alcaraz & $\mathrm{G}$ & 800 & 1953 & - \\
\hline Almansa & $S$ & 1400 & 1965 & Jubus \\
\hline Balazote & $G$ & 1000 & 1953 & - \\
\hline Ballesteros, El & G & 1000 & 1960 & - \\
\hline Barrax & $G$ & 1500 & 1954 & - \\
\hline Bonete & $G$ & 1000 & 1953 & - \\
\hline Bonillo, El & $G$ & 1000 & 1950 & - \\
\hline Casas de Juan Núñez & $G$ & 800 & 1955 & - \\
\hline Casas Ibáñez & $\mathrm{G}$ & 1000 & 1953 & - \\
\hline Chinchilla & $S$ & 2800 & 1966 & Jubus \\
\hline Chinchilla & $S$ & 950 & 1954 & Morros \\
\hline Gineta, La & $G$ & 600 & 1956 & - \\
\hline Hellín & $\mathrm{G}$ & 1000 & 1953 & - \\
\hline Hellín & $S$ & 3350 & 1971 & Jubus \\
\hline Lazuza & $\mathrm{G}$ & 1000 & 1961 & - \\
\hline
\end{tabular}




\section{LA RED NACIONAL DE SILOS Y GRANEROS (continuación)}

\begin{tabular}{|c|c|c|c|c|}
\hline Localidad & Tipo & $\begin{array}{c}\text { Capa- } \\
\text { cidad } \\
\text { (t) }\end{array}$ & $\begin{array}{c}\text { Puesta } \\
\text { en } \\
\text { servicio }\end{array}$ & $\begin{array}{c}\text { Casa } \\
\text { montadora } \\
\text { maquinaria }\end{array}$ \\
\hline Madrigueras & $S$ & 1400 & 1957 & Visimar \\
\hline Mahora & $S$ & 1500 & 1970 & Moreo \\
\hline Minaya & $\mathrm{G}$ & 1000 & 1961 & - \\
\hline Minaya & $S$ & 25000 & 1975 & Imad \\
\hline Munera & $\mathrm{G}$ & 1000 & 1961 & - \\
\hline Pozo Cañada & S & 2300 & 1962 & Jubus \\
\hline Pozohondo & $\mathrm{G}$ & 1000 & 1960 & - \\
\hline Roda, La & $S$ & 2100 & 1950 & Jubus \\
\hline Roda, La & $S$ & 1800 & 1955 & - \\
\hline Tarazona de la Mancha & S & 1400 & 1969 & Moreo \\
\hline Villar de Chinchilla & SS & 6500 & 1972 & Imad \\
\hline Villarrobledo & $S$ & 4700 & 1967 & Jubus \\
\hline Viveros & $\mathrm{G}$ & 1000 & 1961 & - \\
\hline \multicolumn{5}{|l|}{ ALICANTE (provincia) } \\
\hline Alicante & S & 3000 & 1966 & Visimar \\
\hline \multicolumn{5}{|l|}{ ALMERÍA (provincia) } \\
\hline Vélez Rubio & S & 1500 & 1970 & Jubus \\
\hline \multicolumn{5}{|l|}{ ÁVILA (provincia) } \\
\hline Arenas de San Pedro & $\mathrm{G}$ & 400 & 1958 & - \\
\hline Arévalo & S & 6500 & 1958 & Visimar \\
\hline Arévalo & Z & 1080 & 1955 & - \\
\hline Ávila & $S$ & 3950 & 1951 & Imad \\
\hline Crespos & S & 3700 & 1961 & Daverio \\
\hline Fontiveros & $S$ & 1400 & 1955 & Imad \\
\hline Fontiveros (ampliación) & S & 2300 & 1970 & Imad \\
\hline Gallegos de Sobrinos & $\mathrm{G}$ & 400 & 1958 & - \\
\hline Hernansandro & $\mathrm{S}$ & 1000 & 1966 & Jubus \\
\hline Madrigal de las Altas Torres & S & 2800 & 1967 & Jubus \\
\hline Madrigal de las Altas Torres & $S$ & 1950 & 1952 & Daverio \\
\hline Muñana & $\mathrm{G}$ & 400 & 1957 & - \\
\hline Muñico & $S$ & 1500 & 1971 & Moreo \\
\hline Narros del Castillo & $S$ & 2500 & 1967 & - \\
\hline Narros del Castillo & $\mathrm{G}$ & 600 & 1955 & - \\
\hline Pedro Rodríguez & G & 600 & 1956 & - \\
\hline
\end{tabular}




\section{LA RED NACIONAL DE SILOS Y GRANEROS (continuación)}

\begin{tabular}{|c|c|c|c|c|}
\hline Localidad & Tipo & $\begin{array}{l}\text { Capa- } \\
\text { cidad } \\
(\mathrm{t})\end{array}$ & $\begin{array}{c}\text { Puesta } \\
\text { en } \\
\text { servicio }\end{array}$ & $\begin{array}{c}\text { Casa } \\
\text { montadora } \\
\text { maquinaria }\end{array}$ \\
\hline Piedrahíta & G & 800 & 1957 & - \\
\hline San Miguel de Serrezuela & $\mathrm{G}$ & 800 & 1957 & - \\
\hline San Pedro del Arroyo & S & 1400 & 1955 & Imad \\
\hline San Pedro del Arroyo (ampliación) & $\mathrm{S}$ & 1900 & 1971 & - \\
\hline Sanchidrián & S & 1900 & 1957 & Visimar \\
\hline Velayos & G & 600 & 1956 & - \\
\hline \multicolumn{5}{|l|}{ BADAJOZ (provincia) } \\
\hline Albuera, La & S & 2400 & 1969 & Imad \\
\hline Alburquerque & $\mathrm{S}$ & 2820 & 1969 & Moreo \\
\hline Alconchel & S & 2400 & 1968 & Miguelnos \\
\hline Alconchel & $\mathrm{G}$ & 1000 & 1957 & - \\
\hline Almendral & $\mathrm{G}$ & 800 & 1956 & - \\
\hline Almendralejo & $S$ & 3200 & 1955 & Visimar \\
\hline Arroyo de San Serván & $S$ & 1700 & 1951 & Daverio \\
\hline Azuaga & $S$ & 4100 & 1956 & Buhler \\
\hline Azuaga & $\mathrm{S}$ & 1400 & 1966 & Imad \\
\hline Badajoz & $S$ & 7500 & 1965 & Imad \\
\hline Badajoz & SS & 3000 & 1971 & Imad \\
\hline Barcarrota & $\mathrm{G}$ & 800 & 1956 & - \\
\hline Berlanga & $S$ & 3250 & 1964 & Imad \\
\hline Bienvenida & $\mathrm{S}$ & 2400 & 1967 & Imad \\
\hline Cabeza de Buey & $G$ & 800 & 1957 & - \\
\hline Cabeza de Buey & $S$ & 3360 & 1969 & Moreo \\
\hline Campanario & $S$ & 1400 & 1966 & Imad \\
\hline Campillo de Llerena & $\mathrm{G}$ & 1600 & 1958 & - \\
\hline Castuera & $\mathrm{S}$ & 3250 & 1967 & Jubus \\
\hline Don Benito & $S$ & 4000 & 1958 & Buhler \\
\hline Don Benito & S & 600 & 1966 & Jubus \\
\hline Don Benito & $\mathrm{S}$ & 8000 & 1982 & - \\
\hline Frenegal de la Sierra & S & 2300 & 1961 & Imad \\
\hline Fuente de Cantos & $\mathrm{S}$ & 2750 & 1965 & Imad \\
\hline Granja de Torrehermosa, La & $\mathrm{S}$ & 4850 & 1966 & Visimar \\
\hline Guareña & S & 4050 & 1961 & Imad \\
\hline Herrera del Duque & $\mathrm{G}$ & 1500 & 1957 & - \\
\hline Hornachos & $S$ & 1800 & 1960 & Imad \\
\hline Jerez de los Caballeros & $\mathrm{S}$ & 3250 & 1961 & Imad \\
\hline
\end{tabular}




\section{LA RED NACIONAL DE SILOS Y GRANEROS (continuación)}

\begin{tabular}{|c|c|c|c|c|}
\hline Localidad & Tipo & $\begin{array}{l}\text { Capa- } \\
\text { cidad } \\
\text { (t) }\end{array}$ & $\begin{array}{c}\text { Puesta } \\
\text { en } \\
\text { servicio }\end{array}$ & $\begin{array}{c}\text { Casa } \\
\text { montadora } \\
\text { maquinaria }\end{array}$ \\
\hline La Roca de la Sierra & $S$ & 3850 & 1982 & - \\
\hline Llerena & $S$ & 4920 & 1963 & Imad \\
\hline Mérida & S & 10500 & 1950 & Imad \\
\hline Monesterio & $S$ & 1000 & 1965 & Autocampo \\
\hline Monterrubio de la Serena & $G$ & 1000 & 1956 & - \\
\hline Montijo & $S$ & 2300 & 1957 & Moreo \\
\hline Montijo & $\mathrm{G}$ & 350 & 1966 & - \\
\hline Montijo & $S$ & 20000 & 1985 & - \\
\hline Navalvillar de Pela & $\mathrm{G}$ & 1800 & 1958 & - \\
\hline Oliva de la Frontera & $\mathrm{G}$ & 800 & 1963 & - \\
\hline Olivenza & $S$ & 4740 & 1957 & Jubus \\
\hline Orellana la Vieja & $S$ & 1410 & 1967 & Jubus \\
\hline Peñalsordo & $G$ & 600 & 1957 & - \\
\hline Puebla de Alcorcer & $G$ & 1400 & 1958 & - \\
\hline Puebla de Alcorcer & $S$ & 2400 & 1969 & Imad \\
\hline Quintana de la Serena & $S$ & 1360 & 1957 & Jubus \\
\hline Santa Amalia & $S$ & 1500 & 1970 & Jubus \\
\hline Santa Marta & $S$ & 2300 & 1963 & Imad \\
\hline Siruela & G & 400 & 1958 & - \\
\hline Talavera la Real & $S$ & 1600 & 1967 & Jubus \\
\hline Valencia de las Torres & $S$ & 2400 & 1969 & Imad \\
\hline Valencia del Ventoso & $S$ & 1400 & 1964 & Imad \\
\hline Villafranca de los Barros & S & 6200 & 1956 & Buhler \\
\hline Villanueva de la Serena & S & 3250 & 1961 & Imad \\
\hline Villanueva del Fresno & $\mathrm{G}$ & 800 & 1957 & - \\
\hline Villanueva del Fresno & $S$ & 2000 & 1969 & Moreo \\
\hline Zafra & $S$ & 5030 & 1966 & Visimar \\
\hline Zalamea de la Serena & S & 1360 & 1957 & Visimar \\
\hline \multicolumn{5}{|l|}{ BARCELONA (provincia) } \\
\hline Igualada & $S$ & 2500 & 1968 & Jubus \\
\hline Manresa & $S$ & 1000 & 1964 & Imad \\
\hline Vic & $S$ & 3000 & 1969 & Jubus \\
\hline Villafranca del Panadés & S & 3420 & 1968 & - \\
\hline \multicolumn{5}{|l|}{ BURGOS (provincia) } \\
\hline Aranda de Duero & $S$ & 5000 & 1967 & - \\
\hline Bahabón de Esgueva & $\mathrm{G}$ & 1200 & 1953 & - \\
\hline
\end{tabular}




\section{LA RED NACIONAL DE SILOS Y GRANEROS (continuación)}

\begin{tabular}{|c|c|c|c|c|}
\hline Localidad & Tipo & $\begin{array}{l}\text { Capa- } \\
\text { cidad } \\
(\mathrm{t})\end{array}$ & $\begin{array}{c}\text { Puesta } \\
\text { en } \\
\text { servicio }\end{array}$ & $\begin{array}{c}\text { Casa } \\
\text { montadora } \\
\text { maquinaria }\end{array}$ \\
\hline Belorado & $S$ & 1900 & 1958 & Visimar \\
\hline Belorado & $\mathrm{G}$ & 1000 & 1958 & - \\
\hline Briviesca & $S$ & 2200 & 1955 & Morros \\
\hline Briviesca & SS & 2300 & 1960 & Morros \\
\hline Burgos & $S$ & 22000 & 1961 & Henry Simon \\
\hline Calzada de Bureva & $S$ & 4700 & 1967 & Jubus \\
\hline Castrojeriz & $S$ & 3250 & 1959 & Visimar \\
\hline Cojóbar & $\mathrm{G}$ & 800 & 1953 & - \\
\hline Estepar & $G$ & 1000 & 1952 & - \\
\hline Lerma & $S$ & 3250 & 1957 & Visimar \\
\hline Lerma & SS & 5850 & 1971 & Jubus \\
\hline Medina de Pomar & SS & 1960 & 1967 & - \\
\hline Medina de Pomar & $S$ & 1900 & 1961 & Imad \\
\hline Melgar de Fernamental & $S$ & 3000 & 1956 & Moreo \\
\hline Miranda de Ebro & $S$ & 7500 & 1967 & Moreo \\
\hline Poza de la Sal & $\mathrm{G}$ & 1000 & 1961 & - \\
\hline Puebla de Argazón, La & $S$ & 1400 & 1964 & Imad \\
\hline Quincoces de Yuso & $G$ & 1000 & 1960 & - \\
\hline Quintana Martín Galíndez & $G$ & 1000 & 1961 & - \\
\hline Roa de Duero & $S$ & 4700 & 1969 & Visimar \\
\hline Roa de Duero & $S$ & 1900 & 1955 & Visimar \\
\hline San Martín de Rubiales & $S$ & 4700 & 1972 & Visimar \\
\hline Santibáñez & $G$ & 600 & 1953 & - \\
\hline Santa María del Campo & S & 3250 & 1966 & Jubus \\
\hline Sasamón & $\mathrm{G}$ & 1000 & 1956 & - \\
\hline Sotopalacios & $\mathrm{G}$ & 2300 & 1952 & - \\
\hline Sotresgudo & S & 2000 & 1968 & Imad \\
\hline Sotresgudo & $G$ & 800 & 1952 & - \\
\hline Torresandino & $\mathrm{G}$ & 1000 & 1952 & - \\
\hline Torresandino & S & 3350 & 1970 & Visimar \\
\hline Trespaderne & $\mathrm{G}$ & 1000 & 1961 & - \\
\hline Trespaderne & $\mathrm{S}$ & 4700 & 1971 & Jubus \\
\hline Treviño & $S$ & 1400 & 1964 & Imad \\
\hline Treviño & $\mathrm{G}$ & 800 & & - \\
\hline Villadiego & $S$ & 2370 & 1954 & Buhler \\
\hline Villaquirán & S & 2200 & 1954 & Imad \\
\hline Villaquirán (ampliación) & $S$ & 1800 & 1970 & - \\
\hline
\end{tabular}




\section{LA RED NACIONAL DE SILOS Y GRANEROS (continuación)}

\begin{tabular}{|c|c|c|c|c|}
\hline Localidad & Tipo & $\begin{array}{l}\text { Capa- } \\
\text { cidad } \\
(\mathrm{t})\end{array}$ & $\begin{array}{c}\text { Puesta } \\
\text { en } \\
\text { servicio }\end{array}$ & $\begin{array}{c}\text { Casa } \\
\text { montadora } \\
\text { maquinaria }\end{array}$ \\
\hline Villarcayo & S & 1400 & 1964 & Imad \\
\hline Pancorbo & S & 30000 & 1977 & Buhler \\
\hline \multicolumn{5}{|l|}{ CÁCERES (provincia) } \\
\hline Albala & $G$ & 400 & 1956 & - \\
\hline Alcuéscar & $\mathrm{G}$ & 400 & 1956 & - \\
\hline Aldea del Cano & $G$ & 800 & 1956 & - \\
\hline Aldeacentenera & $S$ & 1000 & 1968 & Miguelnos \\
\hline Alia & $S$ & 1740 & 1958 & Visimar \\
\hline Arroyo de la Luz & $S$ & 2500 & 1956 & Buhler \\
\hline Brozas & $S$ & 1800 & 1961 & Imad \\
\hline Brozas & $G$ & 1029 & 1963 & - \\
\hline Cáceres & $S$ & 7500 & 1967 & Imad \\
\hline Cáceres & $\mathrm{G}$ & 600 & 1963 & - \\
\hline Cáceres & G & 3500 & 1963 & - \\
\hline Coria & S & 1600 & 1961 & Imad \\
\hline Coria & $G$ & 350 & 1965 & - \\
\hline Cruce de Campolugar & $S$ & 5000 & 1982 & - \\
\hline Garrovillas & $\mathrm{G}$ & 1000 & 1960 & - \\
\hline Ibahernando & $S$ & 2850 & 1969 & Jubus \\
\hline Logrosán & S & 1400 & 1964 & Imad \\
\hline Logrosán & $G$ & 600 & 1963 & - \\
\hline Madrigalejo & $S$ & 1900 & 1961 & Imad \\
\hline Madroñera & $S$ & 2000 & 1969 & Moreo \\
\hline Membrio & G & 1000 & 1959 & - \\
\hline Miajadas & $S$ & 2800 & 1966 & Jubus \\
\hline Miajadas & $\mathrm{S}$ & 750 & 1952 & Mafasa \\
\hline Mirabel & $S$ & 3850 & 1982 & - \\
\hline Monroy & S & 1500 & 1970 & Jubus \\
\hline Moraleja & G & 1000 & 1959 & - \\
\hline Navalmoral de la Mata & S & 2050 & 1963 & Imad \\
\hline Plasencia & $\mathrm{S}$ & 2750 & 1961 & Imad \\
\hline Torrecilla de la Tiesa & $S$ & 1250 & 1967 & Miguelnos \\
\hline Torrejón el Rubio & S & 1000 & 1968 & Moreo \\
\hline Torremocha & $S$ & 1400 & 1958 & Visimar \\
\hline Trujillo & $S$ & 4150 & 1951 & Buhler \\
\hline Valencia de Alcántara & $S$ & 1900 & 1957 & Visimar \\
\hline
\end{tabular}




\section{LA RED NACIONAL DE SILOS Y GRANEROS (continuación)}

\begin{tabular}{|c|c|c|c|c|}
\hline Localidad & Tipo & $\begin{array}{l}\text { Capa- } \\
\text { cidad } \\
(\mathrm{t})\end{array}$ & $\begin{array}{c}\text { Puesta } \\
\text { en } \\
\text { servicio }\end{array}$ & $\begin{array}{c}\text { Casa } \\
\text { montadora } \\
\text { maquinaria }\end{array}$ \\
\hline Villanueva de la Sierra & $G$ & 1000 & 1960 & - \\
\hline Villar del Pedroso & $\mathrm{G}$ & 400 & 1957 & - \\
\hline Zorita & $S$ & 1500 & 1968 & Moreo \\
\hline Zorita & $G$ & 1000 & 1951 & - \\
\hline Trujillo & $S$ & 15000 & 1976 & Prados Hermanos \\
\hline \multicolumn{5}{|l|}{ CÁDIZ (provincia) } \\
\hline Arcos de la Frontera & $S$ & 3250 & 1957 & Visimar \\
\hline Barca de la Florida, La & S & 3250 & 1967 & Jubus \\
\hline Bornos & $S$ & 2750 & 1955 & Visimar \\
\hline Estación el Cuervo & $\mathrm{S}$ & 3250 & 1968 & Jubus \\
\hline Estación el Cuervo & $S$ & 20000 & 1976 & Imad \\
\hline Espera & S & 2300 & 1965 & Jubus \\
\hline Facinas & $G$ & 800 & 1962 & - \\
\hline Jédula (Arcos de la Frontera) & S & 3000 & 1969 & Miguelnos \\
\hline Jerez de la Frontera & $S$ & 6500 & 1955 & Imad \\
\hline Jimena de la Frontera & $S$ & 2000 & 1970 & Jubus \\
\hline Jimena de la Frontera & S & 600 & 1960 & Jubus \\
\hline Medina Sidonia & $S$ & 3300 & 1958 & Visimar \\
\hline Olvera & $\mathrm{G}$ & 1000 & 1960 & - \\
\hline Olvera & $S$ & 1500 & 1970 & Moreo \\
\hline Puerto de Santa María, El & $S$ & 3350 & 1968 & Visimar \\
\hline Rota & S & 2000 & 1971 & Jubus \\
\hline San Roque & G & 1000 & 1962 & - \\
\hline Sanlúcar de Barrameda & $\mathrm{G}$ & 2000 & 1965 & - \\
\hline Setenil & S & 2150 & 1970 & Miguelnos \\
\hline Trebujena & $\mathrm{G}$ & 700 & 1962 & - \\
\hline Vejer de la Frontera & $\mathrm{G}$ & 2000 & 1965 & - \\
\hline Villamartín & $S$ & 1400 & 1960 & Visimar \\
\hline Villamartín & S & 2400 & 1969 & Imad \\
\hline \multicolumn{5}{|l|}{ CASTELLÓN (provincia) } \\
\hline Morella & S & 1560 & 1968 & Jubus \\
\hline San Mateo & S & 1500 & 1971 & Moreo \\
\hline \multicolumn{5}{|l|}{ CIUDAD REAL (provincia) } \\
\hline Abenojar & S & 2400 & 1968 & Imad \\
\hline Agudo & $G$ & 600 & 1957 & - \\
\hline
\end{tabular}




\section{LA RED NACIONAL DE SILOS Y GRANEROS (continuación)}

\begin{tabular}{|c|c|c|c|c|}
\hline Localidad & Tipo & $\begin{array}{l}\text { Capa- } \\
\text { cidad } \\
(\mathrm{t})\end{array}$ & $\begin{array}{c}\text { Puesta } \\
\text { en } \\
\text { servicio }\end{array}$ & $\begin{array}{c}\text { Casa } \\
\text { montadora } \\
\text { maquinaria }\end{array}$ \\
\hline Alcázar de San Juan & S & 1900 & 1963 & Imad \\
\hline Alcoba & $G$ & 600 & 1957 & - \\
\hline Almadén & $S$ & 2850 & 1968 & Moreo \\
\hline Almagro & $S$ & 5000 & 1983 & - \\
\hline Almodóvar del Campo & $S$ & 2150 & 1956 & Moreo \\
\hline Almuradiel & $S$ & 2650 & 1954 & Moreo \\
\hline Arroba & $\mathrm{G}$ & 400 & 1957 & - \\
\hline Brazatortas & $\mathrm{G}$ & 1500 & 1959 & - \\
\hline Calzada de Calatrava & $S$ & 5000 & 1983 & - \\
\hline Campo de Criptana & $S$ & 2175 & 1966 & Imad \\
\hline Cinco Casas & $S$ & 20000 & 1985 & - \\
\hline Ciudad Real & $S$ & 2800 & 1966 & Jubus \\
\hline Ciudad Real & $S$ & 1680 & 1954 & Imad \\
\hline Ciudad Real & SS & 3000 & 1972 & Seeger \\
\hline Corral de Calatrava & $S$ & 5000 & 1983 & - \\
\hline Daimiel & $S$ & 1900 & 1964 & Imad \\
\hline Fontanarejo & $\mathrm{G}$ & 400 & 1957 & - \\
\hline Herencia & $S$ & 1400 & 1967 & Moreo \\
\hline Horcajo de los Montes & $\mathrm{G}$ & 600 & 1957 & - \\
\hline Infantes, Villanueva de los & $S$ & 2800 & 1967 & Jubus \\
\hline Infantes, Villanueva de los & $S$ & 1650 & 1954 & - \\
\hline Malagón & $S$ & 1900 & 1955 & Visimar \\
\hline Manzanares & S & 2150 & 1955 & Imad \\
\hline Manzanares & $S$ & 1400 & 1964 & Moreo \\
\hline Manzanares (ampliación) & $S$ & 1900 & 1970 & Moreo \\
\hline Montiel & $S$ & 2000 & 1971 & Imad \\
\hline Navalpino & $G$ & 400 & 1957 & - \\
\hline Navas de Estepa & G & 400 & 1960 & - \\
\hline Piedrabuena & $S$ & 7500 & 1984 & - \\
\hline Porzuna & $S$ & 4700 & 1970 & Jubus \\
\hline Puebla de Don Rodrigo & $\mathrm{G}$ & 400 & 1958 & - \\
\hline Restuerta del Bullaque & $\mathrm{G}$ & 1500 & 1957 & - \\
\hline Saceruela & $\mathrm{G}$ & 600 & 1958 & - \\
\hline Santa Cruz de Mudela & $S$ & 3250 & 1965 & Imad \\
\hline Solana, La & $S$ & 2630 & 1968 & Mafasa \\
\hline Valdepeñas & $S$ & 1840 & 1964 & Imad \\
\hline Valdepeñas & $S$ & 1370 & 1954 & Visimar \\
\hline Villahermosa & $\mathrm{G}$ & 2000 & 1958 & - \\
\hline
\end{tabular}




\section{LA RED NACIONAL DE SILOS Y GRANEROS (continuación)}

\begin{tabular}{|c|c|c|c|c|}
\hline Localidad & Tipo & $\begin{array}{l}\text { Capa- } \\
\text { cidad } \\
\text { (t) }\end{array}$ & $\begin{array}{c}\text { Puesta } \\
\text { en } \\
\text { servicio }\end{array}$ & $\begin{array}{c}\text { Casa } \\
\text { montadora } \\
\text { maquinaria }\end{array}$ \\
\hline \multicolumn{5}{|l|}{ CÓRDOBA (provincia) } \\
\hline Alcaracejos & S & 4000 & 1970 & Imad \\
\hline Baena & S & 5000 & 1967 & Visimar \\
\hline Bujalance & $S$ & 2310 & 1965 & Autocampo \\
\hline Bujalance & S & 680 & 1966 & Jubus \\
\hline Cansinos, Los & S & 5400 & 1968 & - \\
\hline Cañete de las Torres & $\mathrm{S}$ & 4600 & 1957 & Imad \\
\hline Carlota, La & $\mathrm{G}$ & 3750 & 1957 & - \\
\hline Carpio, El & $S$ & 2494 & 1950 & Moreo \\
\hline Carpio, El & $S$ & 20000 & 1976 & Imad \\
\hline Castro del Río & $S$ & 3400 & 1968 & Imad \\
\hline Castro del Río & $\mathrm{G}$ & 2400 & 1956 & - \\
\hline Córdoba & $S$ & 19200 & 1950 & Buhler \\
\hline Espejo & $\mathrm{G}$ & 2400 & 1957 & - \\
\hline Espejo & $S$ & 2850 & 1983 & - \\
\hline Fernán Núñez & $S$ & 5000 & 1968 & - \\
\hline Fernán Núñez & $\mathrm{G}$ & 2400 & 1957 & - \\
\hline Fuenteovejuna & $S$ & 1900 & 1957 & Visimar \\
\hline Guadalcázar & $S$ & 1900 & 1963 & Imad \\
\hline Hinojosa del Duque & $S$ & 1900 & 1956 & Moreo \\
\hline Hinojosa del Duque & $S$ & 1800 & 1966 & Jubus \\
\hline Montilla & $\mathrm{G}$ & 2400 & 1961 & - \\
\hline Montilla & $S$ & 1400 & 1961 & Imad \\
\hline Montoro & $\mathrm{G}$ & 800 & 1957 & - \\
\hline Montoro & $S$ & 2000 & 1970 & Moreo \\
\hline Palma del Río & $S$ & 2260 & 1956 & Autocampo \\
\hline Palma del Río & $S$ & 4800 & 1968 & Miguelnos \\
\hline Peñarroya & $S$ & 3800 & 1957 & Buhler \\
\hline Posadas & $\mathrm{G}$ & 600 & 1957 & - \\
\hline Posadas & $S$ & 4520 & 1958 & Jubus \\
\hline Pozoblanco & $S$ & 1900 & 1956 & Visimar \\
\hline Puente Genil & $S$ & 2300 & 1966 & Imad \\
\hline Rambla, La & $S$ & 3120 & 1964 & Imad \\
\hline Santaella & $S$ & 3300 & 1956 & Moreo \\
\hline Santa Cruz & $S$ & 7000 & 1983 & - \\
\hline Valchillón & $S$ & 20000 & 1989 & \\
\hline Valenzuela & $\mathrm{G}$ & 1500 & 1957 & - \\
\hline Villanueva de Córdoba & S & 1440 & 1968 & Imad \\
\hline
\end{tabular}


LA RED NACIONAL DE SILOS Y GRANEROS (continuación)

\begin{tabular}{|c|c|c|c|c|}
\hline Localidad & Tipo & $\begin{array}{l}\text { Capa- } \\
\text { cidad } \\
\text { (t) }\end{array}$ & $\begin{array}{c}\text { Puesta } \\
\text { en } \\
\text { servicio }\end{array}$ & $\begin{array}{c}\text { Casa } \\
\text { montadora } \\
\text { maquinaria }\end{array}$ \\
\hline \multicolumn{5}{|l|}{ LA CORUÑA (provincia) } \\
\hline Betanzos & $\mathrm{G}$ & 720 & 1964 & - \\
\hline \multicolumn{5}{|l|}{ CUENCA (provincia) } \\
\hline Almarcha, La & $\mathrm{S}$ & 4700 & 1969 & Visimar \\
\hline Barajas de Melo & $G$ & 1000 & 1956 & - \\
\hline Belmonte & $S$ & 1400 & 1955 & Visimar \\
\hline Cañaveras & $S$ & 2400 & 1969 & Miguel Mateu \\
\hline Carrascosa del Campo & $S$ & 2300 & 1957 & Moreo \\
\hline Chilarón de Cuenca & $\mathrm{S}$ & 4700 & 1973 & Moreo \\
\hline Cuenca & $S$ & 3250 & 1961 & Imad \\
\hline Honrubia & $G$ & 2000 & 1956 & - \\
\hline Horcajo de Santiago & G & 1600 & 1956 & - \\
\hline Huelves & $\mathrm{G}$ & 600 & 1960 & - \\
\hline Huete & S & 1100 & 1950 & Daverio \\
\hline Huete & $\mathrm{S}$ & 6000 & 1981 & - \\
\hline Iniesta & S & 1000 & 1967 & Moreo \\
\hline Ledaña & $\mathrm{G}$ & 800 & 1957 & - \\
\hline Ledaña & $S$ & 1500 & 1969 & Jubus \\
\hline Mota del Cuervo & $\mathrm{S}$ & 2850 & 1967 & Imad \\
\hline Motilla del Palancar & S & 1400 & 1961 & Imad \\
\hline Osa de la Vega & $G$ & 1000 & 1955 & - \\
\hline Pedroñeras, Las & $S$ & 2000 & 1971 & Imad \\
\hline Peraleja, La & $S$ & 1400 & 1969 & Miguelnos \\
\hline Priego & $G$ & 800 & 1960 & - \\
\hline Provencio, El & $G$ & 800 & 1956 & - \\
\hline Quintana del Rey & $G$ & 1500 & 1957 & - \\
\hline Saelices & S & 1650 & 1955 & Imad \\
\hline Saelices & $S$ & 4700 & 1970 & Jubus \\
\hline San Clemente & $S$ & 1400 & 1956 & Visimar \\
\hline San Lorenzo de la Parrilla & $\mathrm{S}$ & 2500 & 1968 & Imad \\
\hline Santa María del Campo Rus & S & 2500 & 1968 & - \\
\hline Sisante & $S$ & 2500 & 1968 & Miguelnos \\
\hline Tarancón & $S$ & 2750 & 1955 & Visimar \\
\hline Tarancón & $G$ & 800 & 1962 & - \\
\hline Tarancón & SS & 1650 & 1972 & Jubus \\
\hline Torrejoncillo del Rey & S & 1900 & 1957 & Visimar \\
\hline
\end{tabular}




\section{LA RED NACIONAL DE SILOS Y GRANEROS (continuación)}

\begin{tabular}{|c|c|c|c|c|}
\hline Localidad & Tipo & $\begin{array}{l}\text { Capa- } \\
\text { cidad } \\
(\mathrm{t})\end{array}$ & $\begin{array}{c}\text { Puesta } \\
\text { en } \\
\text { servicio }\end{array}$ & $\begin{array}{c}\text { Casa } \\
\text { montadora } \\
\text { maquinaria }\end{array}$ \\
\hline Valverde de Júcar & $S$ & 1900 & 1957 & Visimar \\
\hline Ventosa, La & $\mathrm{G}$ & 1000 & 1966 & - \\
\hline Villalba del Rey & S & 3000 & 1970 & Miguel Mateu \\
\hline Villamayor de Santiago & $G$ & 1400 & 1956 & - \\
\hline Villamayor de Santiago & $S$ & 3850 & 1971 & Moreo \\
\hline Villanueva de la Jara & $\mathrm{G}$ & 1500 & 1960 & - \\
\hline Villar de Domingo García & $\mathrm{G}$ & 800 & 1956 & - \\
\hline Villarejo de Fuentes & $\mathrm{G}$ & 1000 & 1960 & - \\
\hline Villares del Saz & $S$ & 1650 & 1956 & Imad \\
\hline Villarrubio & $S$ & 2500 & 1967 & Imad \\
\hline Tarancón & $S$ & 21000 & 1976 & Imad \\
\hline \multicolumn{5}{|l|}{ GERONA (provincia) } \\
\hline Bisbal, La & S & 1350 & 1958 & Visimar \\
\hline Figueras & $S$ & 1350 & 1959 & Visimar \\
\hline Fornells de la Selva & $S$ & 3000 & 1968 & Jubus \\
\hline Olot & S & 2500 & 1968 & Jubus \\
\hline \multicolumn{5}{|l|}{ GRANADA (provincia) } \\
\hline Alhama de Granada & $S$ & 1900 & 1959 & Imad \\
\hline Benalúa de Guadix & $S$ & 2400 & 1969 & Imad \\
\hline Calahorra, La & $S$ & 2000 & 1971 & Imad \\
\hline Cúllar-Baza & $S$ & 3000 & 1983 & - \\
\hline Granada & $S$ & 5000 & 1968 & Imad \\
\hline Guadahortuna & $S$ & 4700 & 1968 & Imad \\
\hline Guadix & $S$ & 2300 & 1954 & Jubus \\
\hline Huéscar & $S$ & 1400 & 1955 & Visimar \\
\hline Huetor-Tajar & $\mathrm{G}$ & 2000 & 1960 & - \\
\hline Iznalloz & $S$ & 2300 & 1961 & Imad \\
\hline Loja & $S$ & 1400 & 1956 & Jubus \\
\hline Loja & $S$ & 3850 & 1971 & Moreo \\
\hline Montefrío & $S$ & 2750 & 1967 & Imad \\
\hline Moreda & $S$ & 2300 & 1961 & Imad \\
\hline Padul & $S$ & 2300 & 1966 & Imad \\
\hline Pedro Martínez & $S$ & 1900 & 1956 & Visimar \\
\hline Pinos Puente & $S$ & 4500 & 1955 & Imad \\
\hline Pinos Puente & $\mathrm{G}$ & 7000 & 1956 & - \\
\hline
\end{tabular}




\section{LA RED NACIONAL DE SILOS Y GRANEROS (continuación)}

\begin{tabular}{|c|c|c|c|c|}
\hline Localidad & Tipo & $\begin{array}{l}\text { Capa- } \\
\text { cidad } \\
(\mathrm{t})\end{array}$ & $\begin{array}{c}\text { Puesta } \\
\text { en } \\
\text { servicio }\end{array}$ & $\begin{array}{c}\text { Casa } \\
\text { montadora } \\
\text { maquinaria }\end{array}$ \\
\hline Pinos Puente & $S G$ & 350 & 1966 & - \\
\hline Santa Fe & S & 4700 & 1968 & Imad \\
\hline Tocón & S & 1400 & 1956 & Daverio \\
\hline Venta de Andar & $S$ & 2400 & 1972 & Prados Hermanos \\
\hline Ventas de Huelma & $G$ & 2000 & 1961 & - \\
\hline
\end{tabular}

GUADALAJARA (provincia)

\begin{tabular}{|c|c|c|c|c|}
\hline Albares & $S$ & 2500 & 1969 & Imad \\
\hline Alcocer & $\mathrm{G}$ & 800 & 1957 & - \\
\hline Alcolea del Pinar & $S$ & 1500 & 1969 & Jubus \\
\hline Atienza & $\mathrm{G}$ & 800 & 1957 & - \\
\hline Brihuega & $S$ & 1000 & 1966 & Moreo \\
\hline Casar de Talamanca, El & $S$ & 1400 & 1966 & Imad \\
\hline Cifuentes & $\mathrm{G}$ & 800 & 1957 & - \\
\hline Cifuentes & $S$ & 2000 & 1969 & Visimar \\
\hline Cogolludo & $\mathrm{G}$ & 800 & 1957 & - \\
\hline Galápagos & $\mathrm{G}$ & 600 & 1956 & - \\
\hline Guadalajara & $S$ & 5000 & 1967 & Visimar \\
\hline Guadalajara & $S$ & 20000 & 1975 & Buhler \\
\hline Horche & $\mathrm{G}$ & 800 & 1957 & - \\
\hline Humanes & $S$ & 1400 & 1958 & Visimar \\
\hline Jadraque & $S$ & 2200 & 1955 & Moreo \\
\hline Milmarcos & $\mathrm{G}$ & 1000 & 1957 & - \\
\hline Molina de Aragón & $\mathrm{G}$ & 2000 & 1956 & - \\
\hline Molina de Aragón & $\mathrm{S}$ & 2000 & 1970 & Imad \\
\hline Mondéjar & $\mathrm{G}$ & 1000 & 1957 & - \\
\hline Paredes & $\mathrm{G}$ & 600 & 1957 & - \\
\hline Pastrana & S & 2750 & 1966 & Imad \\
\hline Sacedón & $\mathrm{G}$ & 600 & 1957 & - \\
\hline Sigüenza & S & 1900 & 1958 & Visimar \\
\hline Tomelloso de Tajuña & $\mathrm{G}$ & 800 & 1957 & - \\
\hline Torija & $S$ & 1400 & 1962 & - \\
\hline Torremocha del Campo & G & 800 & 1956 & - \\
\hline Viñuelas & G & 1000 & 1957 & - \\
\hline Yunquera de Henares & $\mathrm{S}$ & 1000 & 1966 & Jubus \\
\hline
\end{tabular}


LA RED NACIONAL DE SILOS Y GRANEROS (continuación)

\begin{tabular}{ccccc}
\hline & & Capa- & Puesta & Casa \\
Lidad & en & montadora \\
Localidad & Tipo & $(\mathrm{t})$ & servicio & maquinaria \\
\hline
\end{tabular}

\section{HUELVA (provincia)}

Almonte

Escacena-Paterma

Escacena-Paterma

Escacena-Paterma (ampliación)

Huelva

Palma del Condado, La

San Juan del Puerto

Trigueros

$\begin{array}{lrrl}\text { G } & 600 & 1958 & - \\ \text { S } & 2300 & 1961 & \text { Autocampo } \\ \text { S } & 3000 & 1967 & - \\ \text { S } & 1350 & 1984 & - \\ \text { S } & 1400 & 1967 & \text { Jubus } \\ \text { S } & 2200 & 1953 & \text { Imad } \\ \text { G } & 600 & 1956 & - \\ \text { S } & 1500 & 1971 & \text { Moreo }\end{array}$

\section{HUESCA (provincia)}

\begin{tabular}{|c|c|c|c|c|}
\hline Albalate de Cinca & S & 2400 & 1970 & Miguel Mateu \\
\hline Alcubierre & S & 1900 & 1962 & Autocampo \\
\hline Almudévar & S & 5000 & 1968 & Jubus \\
\hline Angüés & S & 2400 & 1967 & - \\
\hline Ayerbe & G & 2000 & 1954 & - \\
\hline Barbastro & S & 3250 & 1958 & Visimar \\
\hline Barbastro & S & 3000 & 1972 & Seeger \\
\hline Berbegal & S & 1800 & 1955 & Visimar \\
\hline Berbegal & S & 150 & 1955 & - \\
\hline Berdún & S & 1000 & 1966 & Jubus \\
\hline Binéfar & S & 4700 & 1963 & Imad \\
\hline Candasnos & $\mathrm{S}$ & 1400 & 1958 & Visimar \\
\hline Castejón de Monegros & S & 2300 & 1966 & Moreo \\
\hline Fraga & S & 1900 & 1963 & Imad \\
\hline Grañén & S & 4700 & 1962 & Moreo \\
\hline Huesca & S & 7500 & 1957 & - \\
\hline Jaca & $\mathrm{S}$ & 2300 & 1967 & Imad \\
\hline Lanaja & S & 2300 & 1958 & Moreo \\
\hline Monzón & S & 7500 & 1967 & Imad \\
\hline Monzón & G & 1500 & 1955 & - \\
\hline Peñalba & G & 600 & 1962 & - \\
\hline Plasencia del Monte & $\mathrm{S}$ & 7150 & 1983 & - \\
\hline Sabiñánigo & S & 1000 & 1966 & Moreo \\
\hline Sariñena & S & 2500 & 1956 & Buhler \\
\hline Sariñena & S & 2400 & 1971 & Prados Hermanos \\
\hline Selgua & S & 6400 & 1957 & Jubus \\
\hline
\end{tabular}




\section{LA RED NACIONAL DE SILOS Y GRANEROS (continuación)}

\begin{tabular}{|c|c|c|c|c|}
\hline Localidad & Tipo & $\begin{array}{l}\text { Capa- } \\
\text { cidad } \\
(\mathrm{t})\end{array}$ & $\begin{array}{c}\text { Puesta } \\
\text { en } \\
\text { servicio }\end{array}$ & $\begin{array}{c}\text { Casa } \\
\text { montadora } \\
\text { maquinaria }\end{array}$ \\
\hline Sena & $S$ & 1900 & 1962 & Autocampo \\
\hline Siétamo & $\mathrm{G}$ & 400 & 1959 & - \\
\hline Tamarite-Altorricón & $S$ & 4700 & 1968 & Moreo \\
\hline Tamarite de Litera & $S$ & 1800 & 1955 & Visimar \\
\hline Tardienta & $S$ & 4700 & 1968 & Moreo \\
\hline Valfarta & $S$ & 1000 & 1966 & Jubus \\
\hline \multicolumn{5}{|l|}{ JAÉN (provincia) } \\
\hline Alcalá la Real & $S$ & 3250 & 1960 & Imad \\
\hline Andújar & $S$ & 2100 & 1950 & Visimar \\
\hline Andújar & $S$ & 2800 & 1965 & Jubus \\
\hline Andújar & $G$ & 350 & 1964 & - \\
\hline Arjona & $S$ & 3800 & 1964 & Imad \\
\hline Carolina, La & $\mathrm{G}$ & 800 & 1958 & - \\
\hline Fuerte del Rey & $S$ & 1500 & 1968 & Moreo \\
\hline Higuera de Arjona & $S$ & 1000 & 1964 & Autocampo \\
\hline Jaén & $S$ & 2750 & 1956 & Autocampo \\
\hline Jodar & $S$ & 2750 & 1961 & Imad \\
\hline Linares & $S$ & 2750 & 1955 & Visimar \\
\hline Mancha Real & $G$ & 800 & 1956 & - \\
\hline Mengíbar & $S$ & 3000 & 1968 & - \\
\hline Peal de Becerro & $S$ & 2000 & 1970 & Imad \\
\hline Porcuna & $S$ & 1900 & 1955 & Visimar \\
\hline Porcuna & $S$ & 1900 & 1965 & Visimar \\
\hline Torreperogil & $\mathrm{G}$ & 1000 & 1957 & - \\
\hline Úbeda & $S$ & 1100 & 1959 & Imad \\
\hline Úbeda & $S$ & 2800 & 1969 & Imad \\
\hline Villacarrillo & $\mathrm{G}$ & 1000 & 1956 & - \\
\hline Villanueva de la Reina & $\mathrm{S}$ & 2400 & 1968 & Moreo \\
\hline \multicolumn{5}{|l|}{ LEÓN (provincia) } \\
\hline Alvires & $G$ & 1000 & 1963 & - \\
\hline Astorga & $\mathrm{S}$ & 2850 & 1970 & Visimar \\
\hline Bañeza, La & $S$ & 4700 & 1968 & Imad \\
\hline Burgo Ranero, El & $S$ & 1400 & 1964 & Imad \\
\hline Cea & $S$ & 1900 & 1959 & Visimar \\
\hline Palanquinos & $S$ & 2400 & 1973 & Miguel Mateu \\
\hline
\end{tabular}




\section{LA RED NACIONAL DE SILOS Y GRANEROS (continuación)}

\begin{tabular}{|c|c|c|c|c|}
\hline Localidad & Tipo & $\begin{array}{c}\text { Capa- } \\
\text { cidad } \\
\text { (t) }\end{array}$ & $\begin{array}{c}\text { Puesta } \\
\text { en } \\
\text { servicio }\end{array}$ & $\begin{array}{c}\text { Casa } \\
\text { montadora } \\
\text { maquinaria }\end{array}$ \\
\hline Puente Villarente & $G$ & 1500 & 1961 & - \\
\hline Sahagún & $S$ & 4700 & 1962 & Visimar \\
\hline Santa María del Páramo & S & 2300 & 1966 & Imad \\
\hline Santas Martas & $S$ & 4700 & 1962 & Visimar \\
\hline Valderas & $S$ & 2550 & 1954 & Moreo \\
\hline Valencia de Don Juan & $S$ & 4700 & 1962 & Imad \\
\hline Villaquejida & $S$ & 1500 & 1971 & Prados Hermanos \\
\hline \multicolumn{5}{|l|}{ LÉRIDA (provincia) } \\
\hline Agramunt & $S$ & 7500 & 1967 & Jubus \\
\hline Alcarraz & $S$ & 3850 & 1969 & Moreo \\
\hline Almacellas & $S$ & 2850 & 1967 & Imad \\
\hline Artesa de Segre & $S$ & 1900 & 1965 & Imad \\
\hline Artesa de Segre & $S$ & 600 & 1966 & Jubus \\
\hline Balaguer & $\mathrm{S}$ & 5000 & 1968 & Jubus \\
\hline Balaguer & $S$ & 1900 & 1955 & Visimar \\
\hline Bell-Lloch & $S$ & 7500 & 1968 & Imad \\
\hline Bellpuig & $S$ & 12000 & 1968 & Miguelnos \\
\hline Borjas Blancas & $S$ & 1900 & 1963 & Moreo \\
\hline Cervera de Segarra & $S$ & 5000 & 1968 & Imad \\
\hline Guissona & $S$ & 2300 & 1967 & Imad \\
\hline Lérida & $S$ & 7500 & 1968 & Imad \\
\hline Lérida & $S$ & 4000 & 1960 & Mafasa \\
\hline Lérida & SS & 3000 & 1965 & Moreo \\
\hline Mollerusa & $S$ & 2300 & 1962 & Imad \\
\hline Solsona & $S$ & 5000 & 1969 & Jubus \\
\hline Tárrega & $S$ & 2300 & 1954 & Moreo \\
\hline Tárrega & $\mathrm{G}$ & 1000 & 1960 & - \\
\hline \multicolumn{5}{|l|}{ LOGROÑO (provincia) } \\
\hline Alfaro & $S$ & 3000 & 1957 & Autocampo \\
\hline Arnedo & $\mathrm{G}$ & 400 & 1953 & - \\
\hline Badarán & $\mathrm{S}$ & 2500 & 1968 & Prados Hermanos \\
\hline Badarán & $\mathrm{G}$ & 400 & 1954 & - \\
\hline Calahorra & S & 1800 & 1967 & Moreo \\
\hline Calahorra & $\mathrm{G}$ & 600 & 1952 & - \\
\hline Cervera del Río Alhama & $\mathrm{G}$ & 1000 & 1958 & - \\
\hline
\end{tabular}


LA RED NACIONAL DE SILOS Y GRANEROS (continuación)

\begin{tabular}{|c|c|c|c|c|}
\hline Localidad & Tipo & $\begin{array}{c}\text { Capa- } \\
\text { cidad } \\
\text { (t) }\end{array}$ & $\begin{array}{c}\text { Puesta } \\
\text { en } \\
\text { servicio }\end{array}$ & $\begin{array}{c}\text { Casa } \\
\text { montadora } \\
\text { maquinaria }\end{array}$ \\
\hline Corera & $\mathrm{G}$ & 600 & 1953 & - \\
\hline Fuenmayor & S & 3850 & 1970 & Visimar \\
\hline Haro & $S$ & 4500 & 1961 & Visimar \\
\hline Leiva & $S$ & 3000 & 1968 & Miguelnos \\
\hline Leiva & $\mathrm{G}$ & 800 & 1954 & - \\
\hline Logroño & S & 3500 & 1961 & Mafasa \\
\hline Logroño & $\mathrm{G}$ & 600 & 1961 & - \\
\hline Nájera & $S$ & 4300 & 1962 & Imad \\
\hline San Millán de la Cogolla & $\mathrm{G}$ & 400 & 1954 & - \\
\hline Santo Domingo de la Calzada & S & 4700 & 1962 & Imad \\
\hline \multicolumn{5}{|l|}{ LUGO (provincia) } \\
\hline Guitiniz & G & 7000 & 1980 & - \\
\hline \multicolumn{5}{|l|}{ MADRID (provincia) } \\
\hline Aljalvir & $S$ & 3000 & 1968 & Imad \\
\hline Alcalá de Henares & S & 2300 & 1949 & Buhler \\
\hline Alcalá de Henares & $S$ & 4450 & 1969 & Moreo \\
\hline Arganda & $S$ & 1400 & 1962 & Imad \\
\hline Fuenlabrada & $\mathrm{G}$ & 600 & 1958 & - \\
\hline Griñón & $\mathrm{G}$ & 600 & 1958 & - \\
\hline Navalcarnero & $S$ & 1880 & 1958 & Visimar \\
\hline Navalcarnero & $S$ & 10000 & 1981 & - \\
\hline Valdemoro & $S$ & 5000 & 1968 & - \\
\hline Villarejo de Salvanés & S & 2750 & 1969 & Moreo \\
\hline \multicolumn{5}{|l|}{ MÁLAGA (provincia) } \\
\hline Almargen & $S$ & 2900 & 1970 & Jubus \\
\hline Antequera & $S$ & 2370 & 1953 & Buhler \\
\hline Archidona & $S$ & 2000 & 1968 & Moreo \\
\hline Bobadilla & $S$ & 5000 & 1970 & - \\
\hline Campillos & $\mathrm{S}$ & 1400 & 1964 & Imad \\
\hline Campillos & $\mathrm{G}$ & 1000 & 1953 & - \\
\hline Colmenar & $S$ & 1500 & 1968 & Moreo \\
\hline Fuente de Piedra & $S$ & 3350 & 1970 & Moreo \\
\hline Málaga & $S$ & 14000 & 1952 & Henry Simon \\
\hline Ronda & $\mathrm{G}$ & 800 & 1953 & - \\
\hline
\end{tabular}


LA RED NACIONAL DE SILOS Y GRANEROS (continuación)

\begin{tabular}{|c|c|c|c|c|}
\hline Localidad & Tipo & $\begin{array}{l}\text { Capa- } \\
\text { cidad } \\
\text { (t) }\end{array}$ & $\begin{array}{c}\text { Puesta } \\
\text { en } \\
\text { servicio }\end{array}$ & $\begin{array}{c}\text { Casa } \\
\text { montadora } \\
\text { maquinaria }\end{array}$ \\
\hline \multicolumn{5}{|l|}{ MURCIA (provincia) } \\
\hline Caravaca & $G$ & 1000 & 1963 & - \\
\hline Jumilla & $S$ & 1500 & 1970 & Jubus \\
\hline Lorca & $\mathrm{G}$ & 2300 & 1963 & - \\
\hline Lorca & $\mathrm{S}$ & 2400 & 1971 & Visimar \\
\hline Mula & $S$ & 1500 & 1967 & Moreo \\
\hline \multicolumn{5}{|l|}{ NAVARRA (provincia) } \\
\hline Acedo & $G$ & 1000 & 1956 & - \\
\hline Aguilar de Codes & $\mathrm{G}$ & 1000 & 1954 & - \\
\hline Aibar & $\mathrm{S}$ & 3350 & 1967 & Jubus \\
\hline Aibar & $\mathrm{G}$ & 400 & 1954 & - \\
\hline Allo & $S$ & 2300 & 1966 & Imad \\
\hline Ancín & $\mathrm{G}$ & 1000 & 1956 & - \\
\hline Andosilla & S & 1000 & 1966 & - \\
\hline Arcos, Los & $S$ & 2500 & 1967 & Miguelnos \\
\hline Arguedas & $S$ & 1400 & 1967 & Visimar \\
\hline Arizala & $S$ & 2400 & 1969 & Imad \\
\hline Artajona & $S$ & 1900 & 1963 & Imad \\
\hline Barasoaín & $S$ & 3350 & 1970 & Visimar \\
\hline Buñuel & $S$ & 2750 & 1963 & Autocampo \\
\hline Caparroso & $S$ & 3800 & 1955 & Imad \\
\hline Carcastillo & $S$ & 2300 & 1966 & Imad \\
\hline Carcastillo & $\mathrm{G}$ & 1000 & 1955 & - \\
\hline Cascante & $\mathrm{G}$ & 800 & 1955 & - \\
\hline Cintruénigo & $S$ & 1400 & 1965 & Jubus \\
\hline Corella & $S$ & 1900 & 1966 & Imad \\
\hline Corella & $G$ & 600 & 1954 & - \\
\hline Estella & $S$ & 4700 & 1968 & Moreo \\
\hline Falces & $S$ & 3250 & 1966 & Jubus \\
\hline Fustiñana & $S$ & 3000 & 1968 & Miguelnos \\
\hline Irurzun & $G$ & 1000 & 1955 & - \\
\hline Larraga & $S$ & 1900 & 1962 & Imad \\
\hline Lerín & $S$ & 1400 & 1966 & Jubus \\
\hline Lerín (ampliación) & S & 3400 & 1972 & - \\
\hline Lumbier & $S$ & 2400 & 1967 & Imad \\
\hline Mendavia & S & 2000 & 1967 & Jubus \\
\hline
\end{tabular}




\section{LA RED NACIONAL DE SILOS Y GRANEROS (continuación)}

\begin{tabular}{|c|c|c|c|c|}
\hline Localidad & Tipo & $\begin{array}{c}\text { Capa- } \\
\text { cidad } \\
\text { (t) }\end{array}$ & $\begin{array}{c}\text { Puesta } \\
\text { en } \\
\text { servicio }\end{array}$ & $\begin{array}{c}\text { Casa } \\
\text { montadora } \\
\text { maquinaria }\end{array}$ \\
\hline Monreal & $G$ & 1000 & 1956 & - \\
\hline Noaín & $\mathrm{G}$ & 1000 & 1954 & - \\
\hline Olite & $G$ & 800 & 1956 & - \\
\hline Olite & $S$ & 3350 & 1970 & Visimar \\
\hline Pamplona & $S$ & 7500 & 1964 & Autocampo \\
\hline Peralta & $S$ & 2500 & 1967 & Miguelnos \\
\hline Peralta & $\mathrm{G}$ & 1000 & 1953 & - \\
\hline Puente la Reina & $S$ & 3700 & 1956 & Moreo \\
\hline Sangüesa & $S$ & 2000 & 1967 & Jubus \\
\hline Sesma & $S$ & 2400 & 1967 & Imad \\
\hline Tafalla & $\mathrm{G}$ & 2000 & 1943 & - \\
\hline Tafalla & $S$ & 15000 & 1982 & - \\
\hline Torres del Río & $S$ & 1400 & 1963 & Imad \\
\hline Tudela & $S$ & 3250 & 1956 & Jubus \\
\hline Tudela (ampliación) & $S$ & 1400 & 1967 & - \\
\hline Tudela & $\mathrm{G}$ & 350 & 1967 & - \\
\hline Urroz & $S$ & 2300 & 1956 & Imad \\
\hline Urroz & S & 600 & 1966 & Imad \\
\hline Viana & $S$ & 2400 & 1967 & Imad \\
\hline Villafranca & S & 3250 & 1963 & Visimar \\
\hline \multicolumn{5}{|l|}{ ORENSE (provincia) } \\
\hline Celanova & $\mathrm{G}$ & 720 & 1965 & - \\
\hline \multicolumn{5}{|l|}{ PALENCIA (provincia) } \\
\hline Alar del Rey & $G$ & 1000 & 1961 & - \\
\hline Ampudia & $\mathrm{S}$ & 3000 & 1967 & Prados Hermanos \\
\hline Amusco & $S$ & 2000 & 1968 & Imad \\
\hline Astudillo & $S$ & 2000 & 1970 & Imad \\
\hline Baltanas & $S$ & 2700 & 1958 & Imad \\
\hline Carrión de los Condes & $S$ & 2800 & 1965 & Jubus \\
\hline Carrión de los Condes & $S$ & 1030 & 1951 & Buhler \\
\hline Castromocho & $\mathrm{S}$ & 2400 & 1954 & Buhler \\
\hline Cévico de la Torre & $S$ & 1900 & 1964 & Imad \\
\hline Cisneros & $S$ & 1400 & 1966 & Imad \\
\hline Cisneros & $\mathrm{G}$ & 1000 & 1956 & - \\
\hline Frechilla & $S$ & 1330 & 1957 & Visimar \\
\hline
\end{tabular}




\section{LA RED NACIONAL DE SILOS Y GRANEROS (continuación)}

\begin{tabular}{|c|c|c|c|c|}
\hline Localidad & Tipo & $\begin{array}{l}\text { Capa- } \\
\text { cidad } \\
\text { (t) }\end{array}$ & $\begin{array}{c}\text { Puesta } \\
\text { en } \\
\text { servicio }\end{array}$ & $\begin{array}{c}\text { Casa } \\
\text { montadora } \\
\text { maquinaria }\end{array}$ \\
\hline Frómista & $S$ & 1650 & 1954 & Imad \\
\hline Frómista & $S$ & 2850 & 1969 & Moreo \\
\hline Herrera de Pisuerga & $S$ & 2300 & 1959 & Imad \\
\hline Osorno & $S$ & 2200 & 1955 & Moreo \\
\hline Osorno & S & 3350 & 1971 & Jubus \\
\hline Palencia & $S$ & 21000 & 1964 & Henry Simon \\
\hline Paredes de Nava & $S$ & 1650 & 1954 & Imad \\
\hline Paredes de Nava & $S$ & 10000 & 1984 & - \\
\hline Quintana del Puente & $S$ & 2630 & 1970 & Miguel Mateu \\
\hline Saldaña & $S$ & 3000 & 1961 & Imad \\
\hline Torquemada & $\mathrm{G}$ & 600 & 1955 & - \\
\hline Torquemada & $\mathrm{S}$ & 2000 & 1969 & Moreo \\
\hline Venta de Baños & $S$ & 2600 & 1961 & Imad \\
\hline Villada & $S$ & 2800 & 1966 & Jubus \\
\hline Villada & S & 750 & 1949 & Daverio \\
\hline Villoldo & $\mathrm{G}$ & 1500 & 1961 & - \\
\hline \multicolumn{5}{|l|}{ PONTEVEDRA (provincia) } \\
\hline Portas & $\mathrm{G}$ & 720 & 1965 & - \\
\hline \multicolumn{5}{|l|}{ SALAMANCA (provincia) } \\
\hline Alba de Tormes & $S$ & 2750 & 1955 & Autocampo \\
\hline Alba de Tormes & $S$ & 2750 & 1957 & Imad \\
\hline Aldehuela de la Bóveda & S & 2300 & 1966 & Imad \\
\hline Armenteros & $\mathrm{G}$ & 400 & 1956 & - \\
\hline Babilafuente & $\mathrm{S}$ & 2750 & 1962 & Imad \\
\hline Barbadillo & $\mathrm{S}$ & 1000 & 1957 & Daverio \\
\hline Barbadillo & $\mathrm{G}$ & 1000 & 1954 & - \\
\hline Cantalapiedra & $S$ & 3250 & 1957 & Visimar \\
\hline Cantalapiedra & S & 1650 & 1954 & Imad \\
\hline Ciudad Rodrigo & $\mathrm{S}$ & 2300 & 1956 & Moreo \\
\hline Ciudad Rodrigo & S & 2300 & 1968 & - \\
\hline Fuente de San Esteban, La & $\mathrm{S}$ & 3300 & 1956 & Visimar \\
\hline Fuente de San Esteban, La & $\mathrm{G}$ & 600 & 1956 & - \\
\hline Galinduste & $\mathrm{G}$ & 1000 & 1956 & - \\
\hline Gallegos de Argañán & $\mathrm{G}$ & 800 & 1955 & - \\
\hline Gomecello & $\mathrm{S}$ & 1900 & 1957 & Visimar \\
\hline
\end{tabular}




\section{LA RED NACIONAL DE SILOS Y GRANEROS (continuación)}

\begin{tabular}{|c|c|c|c|c|}
\hline Localidad & Tipo & $\begin{array}{c}\text { Capa- } \\
\text { cidad } \\
\text { (t) }\end{array}$ & $\begin{array}{c}\text { Puesta } \\
\text { en } \\
\text { servicio }\end{array}$ & $\begin{array}{c}\text { Casa } \\
\text { montadora } \\
\text { maquinaria }\end{array}$ \\
\hline Gomecello & $\mathrm{S}$ & 3000 & 1954 & Moreo \\
\hline Guijuelo & $S$ & 1900 & 1963 & Imad \\
\hline Huelmos & S & 2850 & 1970 & Visimar \\
\hline Ledesma & $S$ & 2750 & 1961 & Imad \\
\hline Macotera & $S$ & 3250 & 1962 & Moreo \\
\hline Maya, La & $G$ & 1000 & 1959 & - \\
\hline Pedroso de la Armuña & $S$ & 2500 & 1967 & - \\
\hline Peñaranda de Bracamonte & $S$ & 2500 & 1956 & Moreo \\
\hline Peñaranda de Bracamonte & $G$ & 1000 & 1960 & - \\
\hline Peñaranda de Bracamonte & $S$ & 15000 & 1976 & Buhler \\
\hline Robliza de Cojos & $S$ & 2300 & 1967 & Imad \\
\hline Salamanca-Tejares & $S$ & 4000 & 1960 & Imad \\
\hline Salamanca-Tejares & $G$ & 1000 & 1960 & - \\
\hline Sancti-Spiritus & $G$ & 1000 & 1955 & - \\
\hline Tamames & $\mathrm{G}$ & 1000 & 1954 & - \\
\hline Tarazona de Guareña & $\mathrm{G}$ & 400 & 1957 & - \\
\hline Vecinos & $\mathrm{G}$ & 800 & 1956 & - \\
\hline Villar de Gallinazo & $\mathrm{G}$ & 1000 & 1962 & - \\
\hline Villar de Peralonso & $G$ & 600 & 1963 & - \\
\hline Villares de la Reina & $S$ & 3350 & 1968 & Jubus \\
\hline Vitigudino & S & 1400 & 1964 & Jubus \\
\hline \multicolumn{5}{|c|}{ SANTA CRUZ DE TENERIFE (provincia) } \\
\hline Santa Cruz de Tenerife & $S$ & 12000 & 1965 & Hartman \\
\hline \multicolumn{5}{|l|}{ SANTANDER (provincia) } \\
\hline Torrelavega & $\mathrm{G}$ & 350 & 1966 & - \\
\hline Torrelavega & $\mathrm{G}$ & 6750 & 1979 & - \\
\hline \multicolumn{5}{|l|}{ SEGOVIA (provincia) } \\
\hline Ayllón & $S$ & 2400 & 1971 & Imad \\
\hline Boceguillas & $S$ & 1400 & 1964 & Imad \\
\hline Boceguillas & $\mathrm{G}$ & 800 & 1955 & - \\
\hline Campo de San Pedro & $S$ & 1900 & 1957 & Visimar \\
\hline Campo de San Pedro & $S$ & 1900 & 1965 & Imad \\
\hline Cantalejo & $S$ & 1900 & 1957 & Visimar \\
\hline Carbonero el Mayor & $S$ & 2300 & 1967 & Autocampo \\
\hline
\end{tabular}




\section{LA RED NACIONAL DE SILOS Y GRANEROS (continuación)}

\begin{tabular}{|c|c|c|c|c|}
\hline Localidad & Tipo & $\begin{array}{c}\text { Capa- } \\
\text { cidad } \\
\text { (t) }\end{array}$ & $\begin{array}{c}\text { Puesta } \\
\text { en } \\
\text { servicio }\end{array}$ & $\begin{array}{c}\text { Casa } \\
\text { montadora } \\
\text { maquinaria }\end{array}$ \\
\hline Coca & $G$ & 600 & 1955 & - \\
\hline Cuéllar & S & 2850 & 1969 & Moreo \\
\hline Cuéllar & $\mathrm{G}$ & 800 & 1957 & - \\
\hline Fuente de Santa Cruz & $\mathrm{G}$ & 800 & 1956 & - \\
\hline Fuentepelayo & $\mathrm{G}$ & 1000 & 1955 & - \\
\hline Hontalbilla & $G$ & 1000 & 1956 & - \\
\hline Martín Muñoz de las Posadas & $\mathrm{G}$ & 1000 & 1957 & - \\
\hline Naca de la Asunción & $\mathrm{G}$ & 1000 & 1957 & - \\
\hline Olombrada & $\mathrm{G}$ & 800 & 1955 & - \\
\hline Ortigosa de Pestaño & $S$ & 1900 & 1956 & Visimar \\
\hline Sacramenia & $\mathrm{G}$ & 800 & 1955 & - \\
\hline San Cristóbal de la Vega & $\mathrm{G}$ & 800 & 1954 & - \\
\hline San Cristóbal de la Vega & $S$ & 4000 & 1982 & - \\
\hline Sangarcía & $S$ & 1400 & 1956 & Visimar \\
\hline Segovia & $S$ & 2500 & 1956 & Imad \\
\hline Sepúlveda & $S$ & 900 & 1957 & Imad \\
\hline Sepúlveda (ampliación) & $S$ & 3750 & 1971 & Imad \\
\hline Tejares & $S$ & 2500 & 1967 & - \\
\hline Turégano & $S$ & 1400 & 1956 & Visimar \\
\hline Villacastín & $\mathrm{G}$ & 800 & 1956 & - \\
\hline Zarzuela del Monte & G & 1000 & 1963 & - \\
\hline \multicolumn{5}{|l|}{ SEVILLA (provincia) } \\
\hline Alcalá de Guadaira & $S$ & 5000 & 1967 & - \\
\hline Alcalá del Río & $G$ & 2700 & 1962 & Autocampo \\
\hline Arahal, El & $S$ & 1400 & 1960 & Imad \\
\hline Cabezas de San Juan, Las & $G$ & 4000 & 1962 & - \\
\hline Cabezas de San Juan, Las & $S$ & 30000 & 1982 & - \\
\hline Carmona & $S$ & 3800 & 1950 & Imad \\
\hline Coria del Río & $S$ & 3000 & 1967 & Miguelnos \\
\hline Coronil, El & $S$ & 3250 & 1962 & Imad \\
\hline Écija & $S$ & 4000 & 1959 & Buhler \\
\hline Écija & $\mathrm{G}$ & 2000 & 1959 & - \\
\hline Écija & SS & 2000 & 1971 & Imad \\
\hline Écija & $\mathrm{G}$ & 2000 & 1964 & - \\
\hline Estepa & $S$ & 1900 & 1965 & Imad \\
\hline Fuentes de Andalucía & $S$ & 2300 & 1971 & Imad \\
\hline
\end{tabular}




\section{LA RED NACIONAL DE SILOS Y GRANEROS (continuación)}

\begin{tabular}{|c|c|c|c|c|}
\hline Localidad & Tipo & $\begin{array}{l}\text { Capa- } \\
\text { cidad } \\
\text { (t) }\end{array}$ & $\begin{array}{c}\text { Puesta } \\
\text { en } \\
\text { servicio }\end{array}$ & $\begin{array}{c}\text { Casa } \\
\text { montadora } \\
\text { maquinaria }\end{array}$ \\
\hline Gerena & $S$ & 1000 & 1962 & Autocampo \\
\hline Herrera & $S$ & 2850 & 1969 & Moreo \\
\hline Lebrija & $S$ & 3250 & 1965 & Imad \\
\hline Lora del Río & $S$ & 4700 & 1968 & Moreo \\
\hline Marchena & $S$ & 4450 & 1952 & Imad \\
\hline Marchena & $S$ & 20000 & 1985 & - \\
\hline Montellano & $S$ & 2850 & 1970 & Jubus \\
\hline Morón de la Frontera & $S$ & 3250 & 1962 & Imad \\
\hline Osuna & $S$ & 2800 & 1965 & Jubus \\
\hline Osuna & $S$ & 2500 & 1955 & Buhler \\
\hline Paradas & $\mathrm{G}$ & 1000 & 1961 & - \\
\hline Paradas & $S$ & 4700 & 1971 & Visimar \\
\hline Pruna & $S$ & 1500 & 1968 & Jubus \\
\hline Roda de Andalucía, La & $S$ & 1400 & 1962 & Imad \\
\hline Sanlúcar la Mayor & $S$ & 2300 & 1962 & Autocampo \\
\hline Saucejo, El & $S$ & 3350 & 1968 & Jubus \\
\hline Sevilla & $S$ & 10000 & 1967 & Imad \\
\hline Sevilla & SS & 6500 & 1971 & Imad \\
\hline Utrera & $S$ & 2750 & 1955 & Visimar \\
\hline Utrera & $S$ & 2750 & 1965 & Visimar \\
\hline Utrera & S & 15000 & 1976 & Imad \\
\hline \multicolumn{5}{|l|}{ SORIA (provincia) } \\
\hline Ágreda & $S$ & 1900 & 1958 & Jubus \\
\hline Ágreda (ampliación) & $S$ & 2300 & 1969 & Jubus \\
\hline Aliud & $S$ & 15000 & 1985 & - \\
\hline Almazán & $\mathrm{S}$ & 2370 & 1953 & Moreo \\
\hline Almazán & $\mathrm{S}$ & 7500 & 1971 & Imad \\
\hline Almenar & $\mathrm{G}$ & 2000 & 1960 & - \\
\hline Arcos de Jalón & $S$ & 1900 & 1966 & - \\
\hline Berlanga de Duero & S & 2400 & 1967 & Imad \\
\hline Burgo de Osma & $\mathrm{S}$ & 2000 & 1967 & Jubus \\
\hline Cihuela & $\mathrm{G}$ & 800 & 1961 & - \\
\hline Coscurita & S & 15000 & 1982 & - \\
\hline Gomera & S & 5150 & 1956 & Jubus \\
\hline Langa de Duero & S & 1400 & 1967 & Moreo \\
\hline Monteagudo de las Vicarías & $S$ & 2750 & 1968 & Moreo \\
\hline
\end{tabular}




\section{LA RED NACIONAL DE SILOS Y GRANEROS (continuación)}

\begin{tabular}{|c|c|c|c|c|}
\hline Localidad & Tipo & $\begin{array}{l}\text { Capa- } \\
\text { cidad } \\
(\mathrm{t})\end{array}$ & $\begin{array}{c}\text { Puesta } \\
\text { en } \\
\text { servicio }\end{array}$ & $\begin{array}{c}\text { Casa } \\
\text { montadora } \\
\text { maquinaria }\end{array}$ \\
\hline Morón de Almazán & $G$ & 2000 & 1961 & - \\
\hline Olvega & $\mathrm{G}$ & 600 & 1963 & - \\
\hline Osma La Rasa & S & 20000 & 1984 & - \\
\hline Salinas de Medinaceli & $S$ & 1500 & 1969 & Jubus \\
\hline San Esteban de Gormaz & $S$ & 3300 & 1955 & Visimar \\
\hline Santa María de Huerta & $S$ & 1500 & 1967 & Moreo \\
\hline Soria & $S$ & 3350 & 1967 & Imad \\
\hline \multicolumn{5}{|l|}{ TARRAGONA (provincia) } \\
\hline Aldea-Tortosa & SG & 1960 & 1967 & - \\
\hline Montblanch & $S$ & 1500 & 1970 & Jubus \\
\hline Santa Coloma de Queralt & $S$ & 2000 & 1970 & Moreo \\
\hline Tarragona & G & 3000 & 1957 & - \\
\hline \multicolumn{5}{|l|}{ TERUEL (provincia) } \\
\hline Alcañiz & $\mathrm{S}$ & 2750 & 1966 & Moreo \\
\hline Alcañiz & $\mathrm{G}$ & 1000 & 1956 & - \\
\hline Alcorisa & $S$ & 2000 & 1969 & Moreo \\
\hline Alfambra & $S$ & 1500 & 1968 & Moreo \\
\hline Aliaga & $\mathrm{G}$ & 600 & 1960 & - \\
\hline Allepuz & $G$ & 400 & 1954 & - \\
\hline Bañón & $S$ & 2850 & 1972 & Prados Hermanos \\
\hline Barrachina & $\mathrm{G}$ & 800 & 1956 & - \\
\hline Bello & $S$ & 1400 & 1961 & Visimar \\
\hline Calamocha & $S$ & 1900 & 1955 & Visimar \\
\hline Calamocha & $S$ & 1900 & 1967 & Moreo \\
\hline Calanda & $S$ & 2850 & 1973 & Jubus \\
\hline Cantavieja & $S$ & 1100 & 1968 & Miguelnos \\
\hline Cella & $S$ & 3250 & 1982 & - \\
\hline Ferreruela de Huerva & $\mathrm{G}$ & 1000 & 1961 & - \\
\hline Ferreruela de Huerva & $S$ & 3350 & 1972 & Seeger \\
\hline Híjar & $S$ & 2300 & 1964 & Imad \\
\hline Monreal del Campo & $S$ & 1400 & 1956 & Imad \\
\hline Monreal del Campo (ampliación) & $S$ & 3250 & 1970 & Jubus \\
\hline Muniesa & S & 2500 & 1968 & Imad \\
\hline Perales de Alfambra & $\mathrm{G}$ & 800 & 1957 & - \\
\hline Perales de Alfambra & $S$ & 2000 & 1970 & Imad \\
\hline
\end{tabular}




\section{LA RED NACIONAL DE SILOS Y GRANEROS (continuación)}

\begin{tabular}{|c|c|c|c|c|}
\hline Localidad & Tipo & $\begin{array}{l}\text { Capa- } \\
\text { cidad } \\
(\mathrm{t})\end{array}$ & $\begin{array}{c}\text { Puesta } \\
\text { en } \\
\text { servicio }\end{array}$ & $\begin{array}{c}\text { Casa } \\
\text { montadora } \\
\text { maquinaria }\end{array}$ \\
\hline Puebla de Híjar, La & S & 1400 & 1965 & Jubus \\
\hline Puebla de Híjar, La (ampliación) & S & 5000 & 1974 & Mafasa \\
\hline Santa Eulalia & $\mathrm{G}$ & 1000 & 1956 & - \\
\hline Santa Eulalia del Campo & $S$ & 6500 & 1982 & - \\
\hline Teruel & $\mathrm{G}$ & 1000 & 1953 & - \\
\hline Teruel & $S$ & 3750 & 1972 & Moreo \\
\hline Torres de Albarracín & $S$ & 2000 & 1970 & Imad \\
\hline Vivel del Río & G & 1000 & 1955 & - \\
\hline \multicolumn{5}{|l|}{ TOLEDO (provincia) } \\
\hline Alcaudete de la Jara & $S$ & 1500 & 1967 & Moreo \\
\hline Anchuras de los Montes & $G$ & 800 & 1957 & - \\
\hline Belvis de Jara & $\mathrm{S}$ & 1400 & 1965 & Jubus \\
\hline Cabañas de la Sagra & S & 3250 & 1966 & Imad \\
\hline Cabañas de la Sagra (ampliación) & $S$ & 3750 & 1971 & Jubus \\
\hline Cabañas de la Sagra & $\mathrm{G}$ & 800 & 1966 & - \\
\hline Calera y Chozas & S & 2500 & 1968 & Mafasa \\
\hline Calera y Chozas & G & 1000 & 1955 & - \\
\hline Camarena & S & 1400 & 1966 & Jubus \\
\hline Consuegra & G & 1500 & 1956 & - \\
\hline Consuegra & S & 2400 & 1969 & Imad \\
\hline Corral de Almaguer & S & 1650 & 1954 & Imad \\
\hline Corral de Almaguer & $S$ & 3000 & 1967 & Imad \\
\hline Dosbarrios & $\mathrm{G}$ & 800 & 1957 & - \\
\hline Erustes & $S$ & 3100 & 1961 & Imad \\
\hline Escalona & $\mathrm{G}$ & 600 & 1957 & - \\
\hline Esquivias & $S$ & 2400 & 1969 & Imad \\
\hline Gálvez & $S$ & 1500 & 1970 & Jubus \\
\hline Guardia, La & $S$ & 3420 & 1968 & - \\
\hline Illescas & $S$ & 2850 & 1969 & Visimar \\
\hline Lillo & $S$ & 2400 & 1970 & Imad \\
\hline Madridejos & $S$ & 2400 & 1967 & Imad \\
\hline Mora de Toledo & $S$ & 1650 & 1956 & Imad \\
\hline Navahermosa & $\mathrm{G}$ & 1000 & 1957 & - \\
\hline Navalmorales, Los & $S$ & 2300 & 1957 & Moreo \\
\hline Noez & $S$ & 1100 & 1968 & Miguelnos \\
\hline Ocaña & $S$ & 3300 & 1958 & Jubus \\
\hline
\end{tabular}




\section{LA RED NACIONAL DE SILOS Y GRANEROS (continuación)}

\begin{tabular}{|c|c|c|c|c|}
\hline Localidad & Tipo & $\begin{array}{l}\text { Capa- } \\
\text { cidad } \\
(\mathrm{t})\end{array}$ & $\begin{array}{c}\text { Puesta } \\
\text { en } \\
\text { servicio }\end{array}$ & $\begin{array}{c}\text { Casa } \\
\text { montadora } \\
\text { maquinaria }\end{array}$ \\
\hline Orgaz & S & 1500 & 1969 & Jubus \\
\hline Oropesa & $\mathrm{G}$ & 1000 & 1957 & - \\
\hline Pantoja-Alameda & S & 800 & 1957 & Visimar \\
\hline Pantoja-Alameda & $\mathrm{G}$ & 600 & 1975 & - \\
\hline Polan & S & 1400 & 1965 & Jubus \\
\hline Puebla de Montalbán, La & $G$ & 1500 & 1957 & - \\
\hline Puente del Arzobispo & $S$ & 1500 & 1967 & Moreo \\
\hline Quintanar de la Orden & S & 1400 & 1957 & Visimar \\
\hline San Bartolomé de la Abierta & $\mathrm{G}$ & 1500 & 1960 & - \\
\hline San Pablo de los Montes & $\mathrm{G}$ & 600 & 1957 & - \\
\hline Santa Cruz de la Zarza & $S$ & 2500 & 1968 & - \\
\hline Santa Cruz de la Zarza & $\mathrm{G}$ & 1000 & 1956 & - \\
\hline Santa Cruz de Retamar & $S$ & 1400 & 1965 & Jubus \\
\hline Santa Olalla & $S$ & 1400 & 1957 & Mafasa \\
\hline Seseña & $S$ & 5000 & 1969 & Imad \\
\hline Talavera de la Reina & $S$ & 7500 & 1967 & Mafasa \\
\hline Talavera de la Reina & SS & 3000 & 1972 & Moreo \\
\hline Tembleque & $G$ & 4000 & 1961 & - \\
\hline Tembleque & $S$ & 600 & 1966 & Imad \\
\hline Torrijos & $S$ & 4700 & 1960 & Imad \\
\hline Torrijos (ampliación) & $S$ & 3300 & 1970 & Imad \\
\hline Toledo & $S$ & 3350 & 1968 & Jubus \\
\hline Toledo C. S. & $G$ & 1200 & 1973 & Mafasa \\
\hline Turleque & $S$ & 3350 & 1982 & - \\
\hline Urda & $S$ & 1400 & 1957 & Visimar \\
\hline Urda & $\mathrm{G}$ & 1000 & 1957 & - \\
\hline Urda & $S$ & 2400 & 1970 & Imad \\
\hline Ventas con Peña Aguilera & G & 1000 & 1957 & - \\
\hline Villacañas & S & 1650 & 1954 & Imad \\
\hline Villanueva de Alcardete & $S$ & 1500 & 1969 & Moreo \\
\hline Villatobas & S & 2300 & 1964 & Imad \\
\hline Yébenes, Los & $\mathrm{G}$ & 2000 & 1958 & - \\
\hline Yepes & S & 2400 & 1968 & Moreo \\
\hline Yuncos & S & 1400 & 1957 & Moreo \\
\hline \multicolumn{5}{|l|}{ VALENCIA (provincia) } \\
\hline Requena & $S$ & 1400 & 1957 & Visimar \\
\hline
\end{tabular}




\section{LA RED NACIONAL DE SILOS Y GRANEROS (continuación)}

\begin{tabular}{ccccc}
\hline & & Capa- & Puesta & Casa \\
cidad & en & montadora \\
Localidad & Tipo & $(\mathrm{t})$ & servicio & maquinaria \\
\hline
\end{tabular}

VALLADOLID (provincia)

\begin{tabular}{|c|c|c|c|c|}
\hline Alaejos & S & 1400 & 1956 & Visimar \\
\hline Arrabal del Portillo & $S$ & 2400 & 1969 & Imad \\
\hline Ataquines & $S$ & 3250 & 1957 & Autocampo \\
\hline Becilla de Valderaduey & $S$ & 3350 & 1967 & Jubus \\
\hline Becilla de Valderaduey & $\mathrm{G}$ & 1000 & 1955 & - \\
\hline Castromonte & $G$ & 1700 & 1956 & - \\
\hline Corcos & $S$ & 3350 & 1968 & Jubus \\
\hline Encinas de Esgueva & Z & 1200 & 1945 & - \\
\hline Esguevillas & $S$ & 1400 & 1956 & Visimar \\
\hline Fresno el Viejo & $\mathrm{G}$ & 1600 & 1956 & - \\
\hline Matapozuelo & $S$ & 1900 & 1963 & Imad \\
\hline Mayorga & $S$ & 3150 & 1953 & Moreo \\
\hline Medina de Rioseco & $S$ & 12000 & 1956 & Henry Simon \\
\hline Medina del Campo & $S$ & 3700 & 1953 & Moreo \\
\hline Medina del Campo & SS & 3000 & 1972 & - \\
\hline Medina del Campo & S & 20000 & 1975 & Imad \\
\hline Montealegre & Z & 1200 & 1956 & - \\
\hline Mota del Marqués & $S$ & 3300 & 1983 & - \\
\hline Nava del Rey & $S$ & 3350 & 1969 & Moreo \\
\hline Olmedo & $S$ & 2300 & 1965 & Imad \\
\hline Peñafiel & $S$ & 2300 & 1953 & Moreo \\
\hline Peñafiel & $S$ & 2800 & 1967 & Mafasa \\
\hline Pozaldez & $S$ & 900 & 1956 & Imad \\
\hline Quintina de Onésimo & $G$ & 1000 & 1955 & - \\
\hline Rueda & $\mathrm{G}$ & 1000 & 1961 & - \\
\hline Santervas de Campos & $\mathrm{G}$ & 1000 & 1957 & - \\
\hline Simancas & $S$ & 3250 & 1966 & Moreo \\
\hline Simancas & $\mathrm{G}$ & 350 & 1966 & - \\
\hline Tordehumos & S & 3250 & 1953 & Jubus \\
\hline Tordesillas & $S$ & 1650 & 1952 & Imad \\
\hline Torre de Esgueva & $G$ & 1000 & 1940 & - \\
\hline Torrecilla de la Orden & $\mathrm{S}$ & 2500 & 1966 & - \\
\hline Torrelobatón & Z & 1700 & 1956 & - \\
\hline Tudela de Duero & $S$ & 3250 & 1958 & Visimar \\
\hline Valladolid & $S$ & 2950 & 1949 & Mafasa \\
\hline Villalón & $S$ & 2500 & 1955 & Visimar \\
\hline
\end{tabular}




\section{LA RED NACIONAL DE SILOS Y GRANEROS (continuación)}

\begin{tabular}{|c|c|c|c|c|}
\hline Localidad & Tipo & $\begin{array}{c}\text { Capa- } \\
\text { cidad } \\
\text { (t) }\end{array}$ & $\begin{array}{c}\text { Puesta } \\
\text { en } \\
\text { servicio }\end{array}$ & $\begin{array}{c}\text { Casa } \\
\text { montadora } \\
\text { maquinaria }\end{array}$ \\
\hline Villalón (ampliación) & $S$ & 2400 & 1968 & Visimar \\
\hline Villardefrades & $S$ & 1900 & 1955 & Visimar \\
\hline Villavicencio & G & 1000 & 1954 & - \\
\hline \multicolumn{5}{|l|}{ ZAMORA (provincia) } \\
\hline Alcañices & $\mathrm{S}$ & 2000 & 1983 & - \\
\hline Argujillo & $\mathrm{G}$ & 800 & 1956 & - \\
\hline Aspariegos & $S$ & 2750 & 1961 & Imad \\
\hline Barate & $G$ & 800 & 1957 & - \\
\hline Barcial del Barco & $S$ & 15000 & 1981 & - \\
\hline Benavente & $S$ & 2370 & 1955 & Moreo \\
\hline Benavente & $S$ & 4700 & 1971 & Imad \\
\hline Castroverde de Campos & $S$ & 1400 & 1963 & Imad \\
\hline Cerecinos de Campos & $S$ & 3350 & 1969 & Jubus \\
\hline Corrales del Vino & $S$ & 5000 & 1981 & - \\
\hline Fuentelapeña & $S$ & 1410 & 1957 & Imad \\
\hline Fuentelapeña (ampliación) & $S$ & 2300 & 1970 & Imad \\
\hline Fuentesaúco & $S$ & 2800 & 1955 & Visimar \\
\hline Manganeses de la Lampreana & $S$ & 3350 & 1968 & Jubus \\
\hline Moraleja del Vino & $\mathrm{G}$ & 600 & 1956 & - \\
\hline Piedrahíta de Castro & S & 2500 & 1967 & - \\
\hline Piedrahíta de Castro & $S$ & 1400 & 1955 & Visimar \\
\hline Pozoantiguo & $S$ & 1400 & 1964 & Imad \\
\hline San Esteban del Molar & $S$ & 1400 & 1967 & Imad \\
\hline Santibáñez de Vidriales & $\mathrm{G}$ & 400 & 1957 & - \\
\hline Tabara & S & 2800 & 1954 & Visimar \\
\hline Tabla, La & $S$ & 2800 & 1954 & Visimar \\
\hline Toro & $S$ & 2450 & 1955 & Moreo \\
\hline Toro & $S$ & 19000 & 1973 & Buhler \\
\hline Verdemarbán & G & 1000 & 1954 & - \\
\hline Villalpando & $S$ & 2500 & 1955 & Mafasa \\
\hline Villalpando & $S$ & 2800 & 1968 & Mafasa \\
\hline Villanueva del Campo & $S$ & 1400 & 1956 & Visimar \\
\hline Zamora & $S$ & 4000 & 1964 & Mafasa \\
\hline \multicolumn{5}{|l|}{ ZARAGOZA (provincia) } \\
\hline Alagón & S & 3250 & 1958 & Visimar \\
\hline Almolda, La & S & 2850 & 1969 & Imad \\
\hline
\end{tabular}


LA RED NACIONAL DE SILOS Y GRANEROS (continuación)

\begin{tabular}{|c|c|c|c|c|}
\hline Localidad & Tipo & $\begin{array}{l}\text { Capa- } \\
\text { cidad } \\
(\mathrm{t})\end{array}$ & $\begin{array}{c}\text { Puesta } \\
\text { en } \\
\text { servicio }\end{array}$ & $\begin{array}{c}\text { Casa } \\
\text { montadora } \\
\text { maquinaria }\end{array}$ \\
\hline Almudia de Doña Godina, La & $\mathrm{S}$ & 1400 & 1961 & Imad \\
\hline Almudia de Doña Godina, La & $\mathrm{G}$ & 600 & 1954 & - \\
\hline Ariza & S & 1400 & 1957 & Visimar \\
\hline Ariza & G & 800 & 1957 & - \\
\hline Belchite & S & 3850 & 1968 & Jubus \\
\hline Biota & $\mathrm{S}$ & 3300 & 1957 & Visimar \\
\hline Borja & S & 2300 & 1958 & Imad \\
\hline Bujaraloz & S & 1900 & 1969 & Imad \\
\hline Calatayud & S & 2750 & 1957 & Visimar \\
\hline Cariñena & S & 1500 & 1968 & Moreo \\
\hline Casetas & $S$ & 3500 & 1965 & Mafasa \\
\hline Casetas & $\mathrm{G}$ & 1800 & 1952 & - \\
\hline Caspe & $S$ & 2850 & 1968 & Imad \\
\hline Castejón de Valdejasa & $S$ & 1500 & 1971 & Moreo \\
\hline Castiliscar & $\mathrm{G}$ & 1000 & 1955 & - \\
\hline Cetina & $\mathrm{G}$ & 1500 & 1960 & - \\
\hline Daroca & S & 3700 & 1956 & Imad \\
\hline Ejea de los Caballeros & $\mathrm{S}$ & 4700 & 1965 & Jubus \\
\hline Ejea de los Caballeros & $S$ & 2800 & 1950 & Morros \\
\hline Ejea de los Caballeros & $\mathrm{G}$ & 1000 & 1953 & - \\
\hline Épila & $S$ & 2750 & 1957 & Visimar \\
\hline Erla & $\mathrm{G}$ & 2250 & 1946 & - \\
\hline Farlete & $\mathrm{S}$ & 2400 & 1970 & Miguel Mateu \\
\hline Fuentes de Ebro & S & 1400 & 1966 & Imad \\
\hline Gallur (con secadero incorporado) & S & 3250 & 1962 & Jubus \\
\hline Luna & $\mathrm{S}$ & 4700 & 1968 & Moreo \\
\hline Malón & $\mathrm{G}$ & 1000 & 1960 & - \\
\hline Mallén & $\mathrm{S}$ & 2600 & 1963 & Imad \\
\hline Mallén & $\mathrm{G}$ & 1500 & 1964 & - \\
\hline Muel & S & 3850 & 1967 & Imad \\
\hline Nuévalos & S & 1000 & 1964 & Jubus \\
\hline Pedrosas, Las & S & 1900 & 1957 & Visimar \\
\hline Piedratajada & $\mathrm{S}$ & 2300 & 1957 & Moreo \\
\hline Pina de Ebro & $\mathrm{G}$ & 1000 & 1960 & - \\
\hline Quinto de Ebro & S & 2400 & 1967 & Imad \\
\hline Sádaba & $S$ & 2950 & 1950 & Morros \\
\hline Sos del Rey Católico & $\mathrm{G}$ & 600 & 1952 & - \\
\hline
\end{tabular}




\section{LA RED NACIONAL DE SILOS Y GRANEROS (continuación)}

\begin{tabular}{lcccl}
\hline & & $\begin{array}{c}\text { Capa- } \\
\text { cidad } \\
\text { Localidad }\end{array}$ & $\begin{array}{c}\text { Puesta } \\
\text { en } \\
\text { servicio }\end{array}$ & $\begin{array}{c}\text { Casa } \\
\text { montadora } \\
\text { maquinaria }\end{array}$ \\
\hline Tarazona & S & 1900 & 1961 & Imad \\
Tauste & S & 5000 & 1968 & Miguelnos \\
Tauste & S & 2950 & 1955 & Morros \\
Uncastillo & G & 1000 & 1955 & - \\
Used & S & 3850 & 1969 & Moreo \\
Villanueva de Gállego & G & 500 & 1957 & - \\
Zaragoza-Barcelona & S & 2300 & 1957 & Moreo \\
Zaragoza-Barcelona & G & 1000 & 1957 & - \\
Zaragoza-Castellón & S & 2200 & 1963 & Visimar \\
Zaragoza-Castellón & G & 1000 & 1963 & - \\
Zuera & S & 3250 & 1957 & Morros \\
Zuera & S & 20000 & 1982 & - \\
Cariñena & S & 15000 & 1976 & Buhler \\
\hline
\end{tabular}

FUENTE: Elaboración propia. Hasta 1978: SENPA (1978). De 1978 en adelante SENPA y FEGA: Memorias de actividades (anuales). S: Silos; G: Graneros; Z: Castillos restaurados; SG: Centros de secado de granos; SS: Centros de selección de semillas. 
MAPA 1. RED NACIONAL DE SILOS Y GRANEROS. DISTRIBUCIÓN PROVINCIAL POR NÚMERO DE UNIDADES

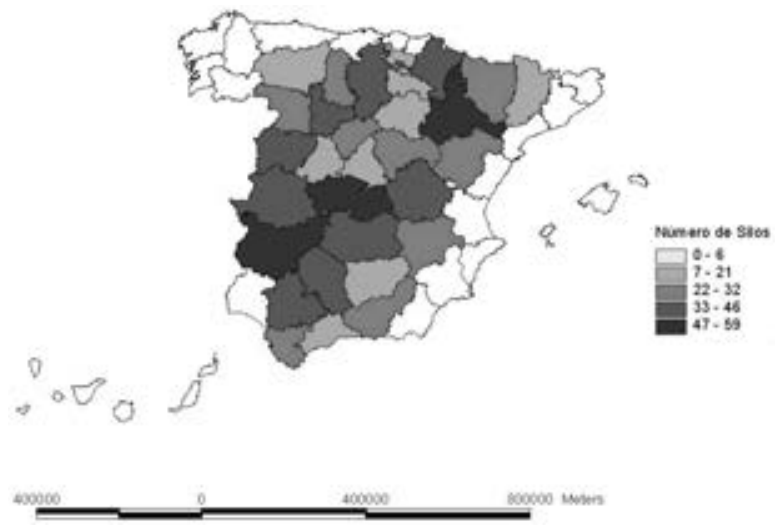

MAPA 2. RED NACIONAL DE SILOS Y GRANEROS. DISTRIBUCIÓN PROVINCIAL DE LA CAPACIDAD DE ALMACENAMIENTO

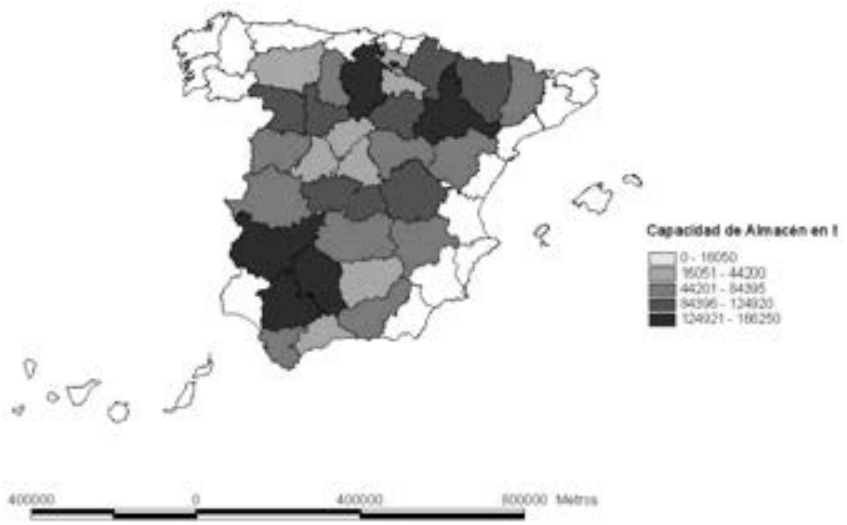


MAPA 3. RED NACIONAL DE SILOS Y GRANEROS.

RELACIÓN ENTRE LA SUPERFICIE CULTIVADA DE TRIGO

Y LA CAPACIDAD DE ALMACENAMIENTO POR PROVINCIAS

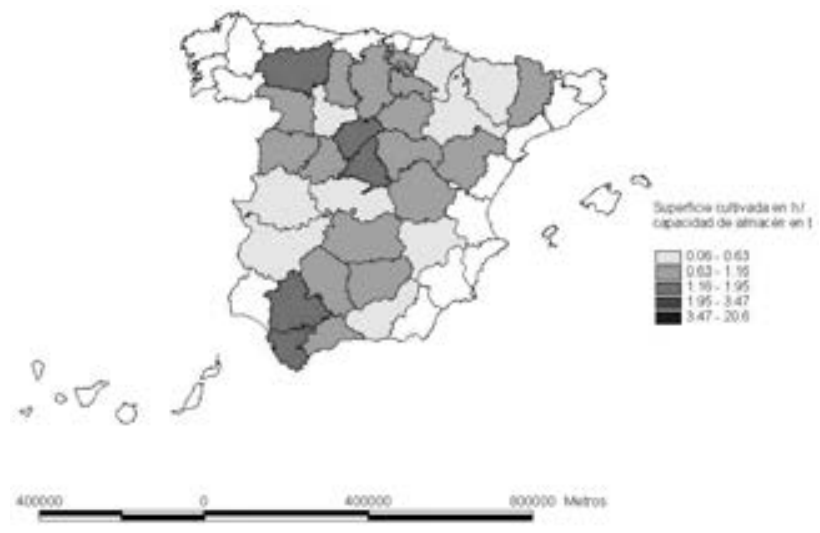

MAPA 4. RED NACIONAL DE SILOS Y GRANEROS.

RELACIÓN ENTRE LA PRODUCCIÓN TRIGUERA

Y LA CAPACIDAD DE ALMACENAMIENTO POR PROVINCIAS
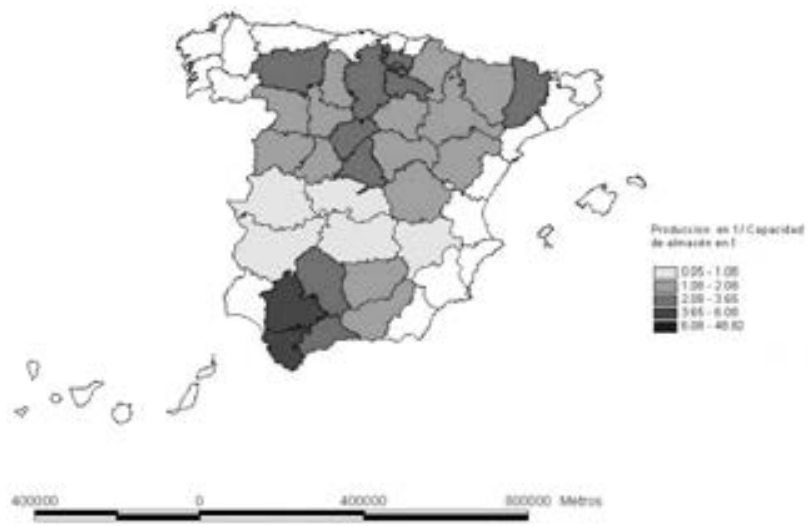



\section{Bibliografía}

AlmiRAL, A. (1963): «Los problemas y soluciones del ciclo trigo-harina-pan», CERES, núm. 320.

ANES, G. (1968): «Los Pósitos en la España del siglo XVIII», Moneda y Crédito, núm. 105.

ArÉvalo, J., y J. J. Burgaz (1984): «Una Ley para el futuro» (Preámbulo a la Ley 16/1984, de 29 de mayo, por la que se regula la producción y el comercio del trigo y sus derivados), Publicaciones del Ministerio de Agricultura, Pesca y Alimentación (Reproducido en la Revista de Estudios Agro-Sociales, n.ำ 130, 1985.

Asociación Nacional de Ingenieros Agrónomos (1967): Agricultura y desarrollo, Madrid, Gráficas Uguina.

BANCO INTERNACIONAL DE RECONSTRUCCIÓN Y FOMENTO (1962): El desarrollo económico en España, OCYPE, Documentación Económica, n.ํ35, Madrid, Imprenta del Boletín Oficial del Estado.

- y FAO (1966): Informe del Banco de Reconstrucción y Fomento y de la FAO sobre el desarrollo de la agricultura en España, Madrid, Ministerio de Hacienda.

BAndinI, M. (1959): Economia agraria, vol. VI del Trattato Italiano di Economia, dirigido por G. del Vecchio y C. Arena, Turín, UTET.

- (1959): Politica agraria, Bolonia, Edizioni Agrícola (1.a edición, 1943).

BARCIELA, C. (1981a): La agricultura cerealista en la España contemporánea. El mercado triguero y el Servicio Nacional del Trigo (1937-1971), Madrid, Editorial de la Universidad Complutense.

- (1981b): La financiación del Servicio Nacional del Trigo, 1937-1971, Estudios de Historia Económica, n.ำ5, Madrid, Banco de España.

- (1981c): «El estraperlo de trigo en la posguerra», Moneda y Crédito, núm. 151.

- (1985a): «Intervencionismo y crecimiento agrario en España 1936-1971», en P. Martín Aceña y L. Prados de la Escosura (eds.), La nueva historia económica en España, Madrid, Tecnos.

- $\quad$ (1985b): «Las investigaciones sobre el mercado negro de productos agrarios en la posguerra: situación actual y perspectivas», Revista de Historia Económica, $\mathrm{n} . \stackrel{\circ}{ } 3$. 
BARCiela, C. (1986): «Introducción», en R. Garrabou, C. Barciela y J. I. Jiménez Blanco (eds.), Historia agraria de la España contemporánea. 3. El fin de la agricultura tradicional (1900-1960), Barcelona, Crítica.

- (1989): "Sector agrario (desde 1936)», en A. Carreras (coord.), Estadísticas históricas de España. Siglos XIX-XX, Madrid, Fundación Banco Exterior.

- (1997): «La modernización de la agricultura y la política agraria», Papeles de Economía Española, n. 73.

- (1999): "La política de precios agrarios y sus efectos sobre la calidad de la producción, 1937-1971", en A. Carreras, P. Pascual, D. Reher y C. Sudrià (eds.), La industrialización y el desarrollo económico de España, Barcelona, Universidad de Barcelona.

BARCiela, C.; J. GiRÁlDEZ, y M. a I. LóPEZ ORTIZ (2005): «Sector agrario y pesca», en A. Carreras y X. Tafunell (coords.), Estadísticas históricas de España. Siglos $x I x y X X$, Bilbao, Fundación BBVA.

BecattinI, G., y N. Bellanca (1986): «Economia di guerra e mercato nero. Note e riflessione sulla Toscana», Italia contemporanea, n.. 165.

Bornás, G. et alii (1941): El hombre. La explotación. El mercado. Organización de la economía agrícola dirigida en Alemania, prólogo de R. Fernández Cuesta, Madrid, Gráficas Afrodisio Aguado.

Briz EscribANO, J. (1985): «Anotaciones al funcionamiento del mercado español del trigo", Revista de Estudios Agro-Sociales, n. -130.

- (1985): «El mercado internacional triguero; análisis funcional», Revista de Estudios Agro-Sociales, n.. 130 .

BurGaz, J. J. (1985): «Un marco jurídico para el futuro: la ley por la que se regula la producción y el comercio del trigo y sus derivados», Revista de Estudios Agro-Sociales, n.․ 130.

Calatrava, A. (1987): «El sector de cereales en España y su adecuación a la situación comunitaria», Información Comercial Española, n.ำ 652.

Caño García, R. del (1933): Producción y mercado del trigo, Madrid, IMP-ROT.

CAstañón, G., y D. Martín SAnz (1935): «Proyecto de silo para $60 \mathrm{~m}^{3}$ », Agricultura, núm. 63.

Cavestany y de Anduaga, R. (1958): Una política agraria (discursos), Dirección General de Coordinación, Crédito y Capacitación del Ministerio de Agricultura, Madrid, Ministerio de Agricultura.

CentenARIO DE LA CREACIÓN DE LAS CARRERAS DE INGENIEROS AGRÓNOMOS Y PERITOS AGRíCOLAS Y DE LA FUNDACIÓN DE LA Escuela CeNTRAL de AgRICULtURA (1955): Un siglo de progreso agrícola 1855-1955, Libro de Honor, Madrid.

Comité NACIONAL EsPañol para LA FAO (1955): Informe a la VIII Sesión de la Conferencia de la Organización de las Naciones Unidas para la Agricultura y la Alimentación 1953-1954, Madrid, Sucesores de Rivadeneyra.

Congreso Agrario Regional del Duero (1945): Ediciones de la Delegación Provincial de la Vicesecretaría de Educación Popular, Valladolid, Afrodisio Aguado. 
Consejo EConómico Nacional Sindical (1957): Actas y conclusiones de la Comisión II "Agricultura» del IX Pleno del Consejo Económico Sindical Nacional, Madrid, ciclostilado.

Comisaría del Plan de Desarrollo Económico y Social (1964,1968 y 1972): I, II y III Plan de Desarrollo Económico y Social, Madrid, Presidencia del Gobierno. CoRNI, G. (1989): La politica agraria del nazionalsocialismo, Milán, Franco Angeli.

D'ATtORRE, P. P. (1982): «Non di solo pane. Gli agrari bolognesi e la battaglia del grano", en M. Legnani, D. Preti y G. Rochat (a cura di), Le campagne Emiliane in periodo fascista. Materiali e Ricerche sulla Battaglia del Grano, Istituto Regionale per la Storia della Resistenza e della Guerra de Liberacione in Emilia Romagna, Annale 1981-1982, n.ำ 2, Bolonia, Editrice CLUEB.

DondLinger, P. T. (1908): The Book of Wheat. An Economic History and Practical Manual of the Wheat Industry, Nueva York, Orange Judd Company y Londres, Kegan Paul, Trench, Trübner \& Co., Limited.

- «El problema de los almacenamientos cerealistas», editorial del número 385, de julio de 1968, de la revista CERES.

ESPINAR, V. (1985): «Estadísticas básicas del sector triguero», Revista de Estudios Agro-Sociales, n.․ 130.

FANO, E. (1975): «Problemi e vicende dell'agricoltura italiana tra le due guerre», Quaderni Storici, n. $29-30$.

FAO (1952): Segunda encuesta mundial alimentaria, Roma, FAO.

- (1959): Proyecto de desarrollo de la región mediterránea. El desarrollo combinado de la agricultura y los montes en conexión con el desarrollo económico. Un estudio sobre propuestas de acción, Roma, FAO.

Fondo Español de Garantía AgraRia (FEGA) (1995-2002): Informe de Actividad, Madrid, Ministerio de Agricultura.

Friedman, M. (1951): «Conmodity Reserve Currency», Journal of Political Economy, vol. LIX, junio.

García de OteYzA, J. (1985): «El sector del trigo en la CEE», Revista de Estudios Agro-Sociales, n. -130 .

GarcíA FeRnÁndeZ, J. (1945): Grandes almacenes para trigo, Madrid, Ministerio de Agricultura.

García González, A., y B. Sánchez-Altomuro (1962): Compendio de disposiciones fundamentales relativas al Servicio Nacional del Trigo, Madrid, Gráficas F. Martínez.

HathaWAY, D. (1963): Government and Agriculture, Londres, Macmillan.

InStiTUtO DE Estudios AgRo-sociales (1959): Proyecto de desarrollo de la región mediterránea. España, Madrid, Ministerio de Agricultura (no publicado).

JoHnson, D. G. (1976): Problemas y perspectivas de la alimentación mundial, México, DIMELISA. (Traducción del estudio n. -20 de Foreign Affaire.)

Junta Nacional de Hermandades Sindicales de Labradores y Ganaderos (1950): Hacia la libertad del Pan, Madrid, Junta Nacional de Hermandades en colaboración con el Servicio Nacional del Trigo.

- (1953): El campo español en 1953. Estudios, conclusiones y trabajos de la $V$ Asamblea Nacional, Madrid, Delegación Nacional de Sindicatos. 
LAMO DE ESPINOSA, J. (1971): «Reflexiones sobre la política de precios y su armonización con la política general agraria», Revista de Estudios Agro-Sociales, ก. -75 .

LARRAZ, J. (1935): El ordenamiento del mercado triguero en España, Madrid, CEU. Ley $16 / 84$, de 29 de mayo, por la que se regula la producción y el comercio del trigo y sus derivados. BOE, n. 0 129, de 30 de mayo de 1984 .

LóPEZ DE SEBAStIÁN, J. (1985): «Antecedentes de la nueva ley del trigo», Revista de Estudios Agro-Sociales, ‥ 130.

MARESCALCHI, A. (1938): L'agricoltura italiana e l'autarchia, Turín, Einaudi.

MARTín SANZ, D. (1936): «Bases para el emplazamiento de una red nacional de silos para trigo", Economía y Técnica Agrícola, núm. 51.

- (1937): El problema triguero y el nacional-sindicalismo, Valladolid, Talleres tipográficos de A. Aguado.

- (1946): Técnica y política agraria, Madrid, Gráficas Uguina.

MARTín VARGAS, V. (1985): «Almacenamiento, conservación y transporte de trigo», Revista de Estudios Agro-Sociales, n. 0130.

MARTínez Soto, Á. P. (inédito): «Los pósitos en los inicios del siglo xx: ¿el declive de una red pública de crédito agrícola?».

METCALF, D. (1974): La economía de la agricultura, Madrid, Alianza.

MONTOJO SUREDA, J. (1945): La política española sobre trigos y harinas (años 19001945), Madrid, Afrodisio Aguado.

NúÑEz-MAYO, O. (1957): Red Nacional de Silos, Temas españoles, núm. 292, Madrid, Publicaciones Españolas.

OEEC (mayo 1956): Agricultural Policies in Europe and North America. First Report of the Ministerial Committee for Agriculture and Food, París, OEEC.

PRETI, D. (1973): «La politica agraria del fascismo: note introduttive», Studi Storici, núm. 4.

- (1982): «Per una storia agraria e del malessere agrario nell'Italia fascista: la battaglia del grano", en M. Legnani, D. Preti y G. Rochat (a cura di), Le Campagne Emiliane in periodo fascista. Materiali e Ricerche sulla Battaglia del Grano, Istituto Regionale per la Storia della Resistenza e della Guerra de Liberazione in Emilia Romagna, Annale 1981-1982, n.․ 2, Bolonia, Editrice CLUEB.

I Congreso Nacional de Ingeniería Agronómica (1950): Madrid, Talleres Gráficos Altamira, IX vols.

Profumieri, P. L. (1971): «La "Battaglia del grano": costi e ricavi», Rivista di Storia dell'Agricoltura, n. 02 .

Rodríguez Pérez, A. (1935): «El problema del trigo», conferencia pronunciada el día 16 de marzo de 1935 en el curso organizado por la Agrupación de Madrid del Partido Nacional Republicano.

Ruiz DE ALDA, J. (1936): «Discurso en el Teatro Calderón de Madrid el día 12 de enero de 1936», ARRIBA, 13 de enero de 1936.

Sala Ríos, M. (1991): La evolución del sector triguero en España en el período 1967-1984. Análisis de la intervención administrativa llevada a cabo y de sus repercusiones sobre el sector, tesis doctoral, Facultad de Ciencias Económicas, Universidad de Barcelona. 
Sala Ríos, M. (1992): «Análisis de los resultados de la política de precios iniciada a finales de la década de 1960, sobre la superficie y producción del sector triguero", Revista de Estudios Agro-Sociales, n. .162.

Schultz, T. W. (1956): La organización económica de la agricultura, Madrid, Alianza.

SEgRE, L. (1988): La «battaglia del grano». Depressione economica e politica cerealicola fascista, Bolonia, CLESAV.

II CONSEJo Sindical (1941): Política agraria. La Falange y su contribución al problema del campo, Madrid, Gráficas Reunidas.

Serpieri, A. (1946): Istituzioni di Economia Agraria, Bolonia, Edizione Agricole.

STADERINI, A. (1978): «La politica cerealicola del regime: l'impostazione della batta-

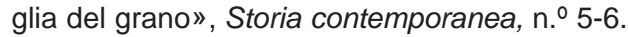

Servicio Nacional de Productos Agrarios (1975-1994): Memoria de actividades, Madrid, Ministerio de Agricultura, (no publicadas).

- (1978): Red de almacenamiento, Madrid, Ministerio de Agricultura.

- (varios años): Boletín informativo, Gabinete Técnico, Sección de Estudios (documentos internos).

Servicio Nacional del Trigo (1958): Veinte años de actuación, Madrid, Ministerio de Agricultura.

- (1959): Ponencia sobre la Red Nacional de Silos en España. Los diversos tipos de silos y su construcción, Publicaciones Específicas, n.ำ 4, Madrid, Ministerio de Agricultura.

- (1962): Realizaciones del Servicio Nacional del Trigo en sus primeros veinticinco años, Madrid, Ministerio de Agricultura.

SNC (1970): Red Nacional de Almacenamiento del SNC, Madrid, Ministerio de Agricultura.

Velarde Fuertes, J., y R. Campos Nordmann (1968): Lecciones de Estructura e Instituciones Económicas de España, Madrid, SMAR, S. L., Artes Gráficas, 2 vols.

TATTARA, G. (1973): "Cerealicoltura e politica agraria durante il fascismo», en G. Toniolo (a cura di): Lo sviluppo economico italiano 1861-1940, Bari, Laterza.

TONIOLO, G. (1980): L'economia dell'Italia fascista, Bari, Laterza.

TORRES, M. de (1944): El problema triguero y otras cuestiones fundamentales de la agricultura española, Madrid, CSIC.

www.falange.info/onesimoredondo/vida.htm. 



\section{Ilustraciones}





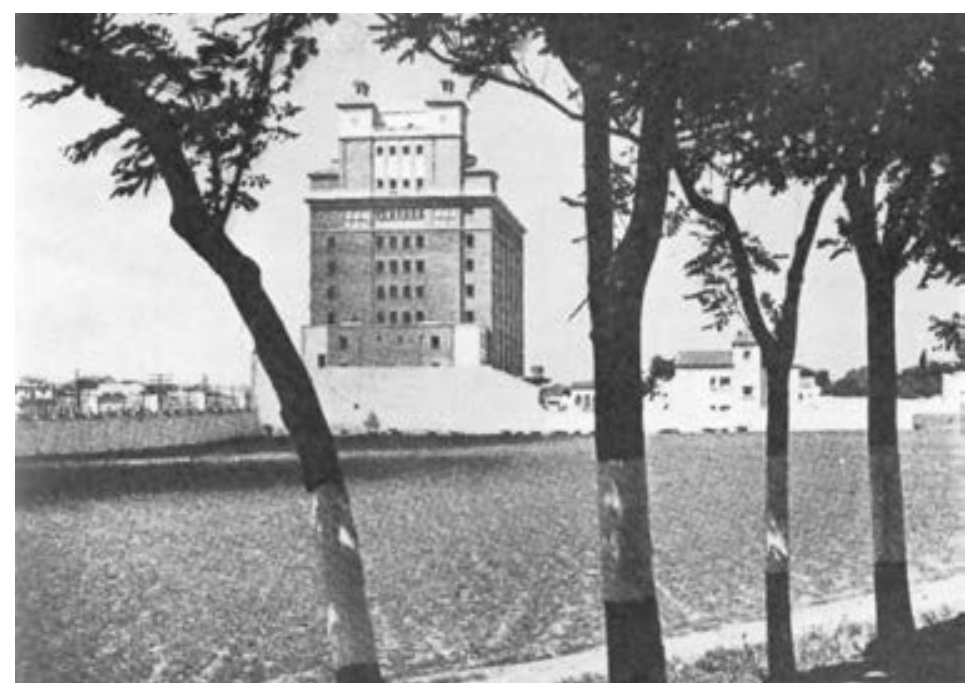

Vista general del silo de Córdoba.

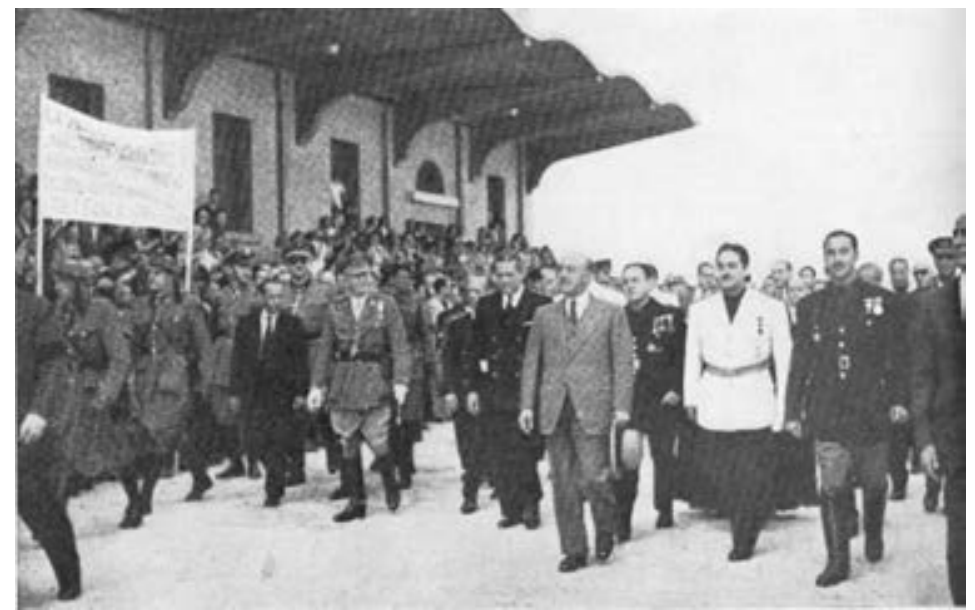

El jefe del Estado llega al silo de Córdoba. 


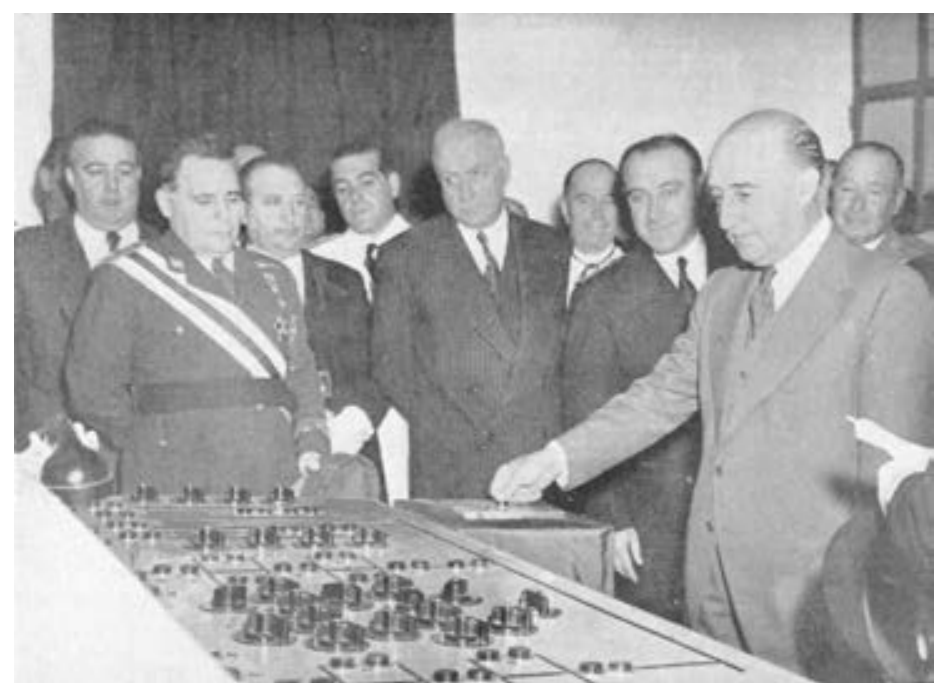

Puesta en marcha del silo por S. E. el Generalísimo Franco.

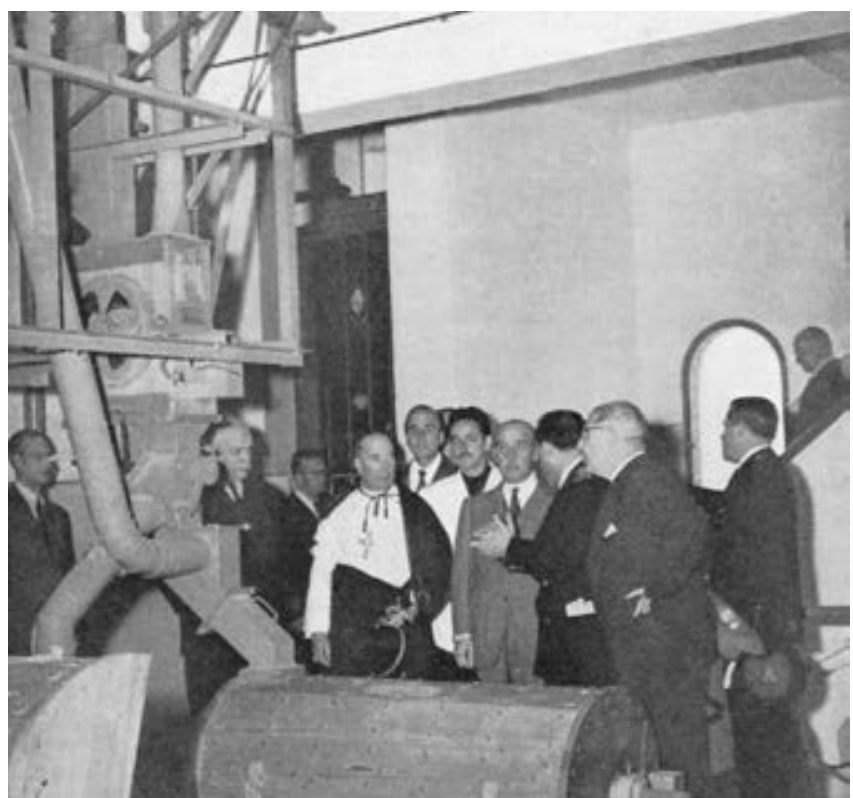

El Caudillo y su séquito examinan el funcionamiento de las instalaciones. 


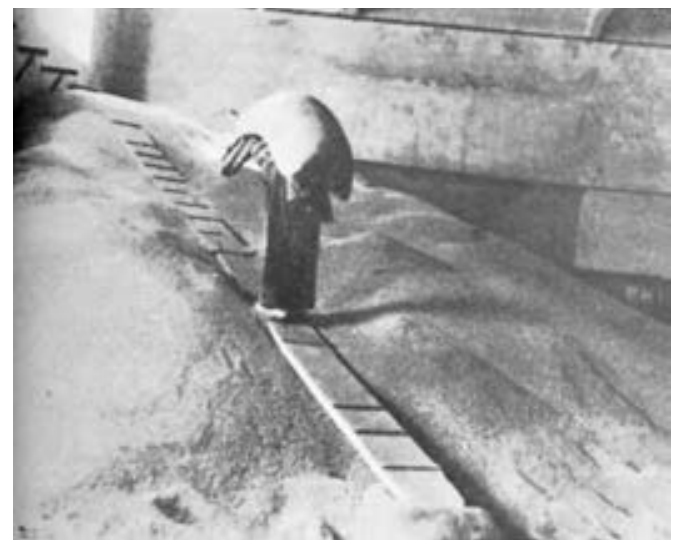

Rudo trabajo de un obrero subiendo el trigo al montón.

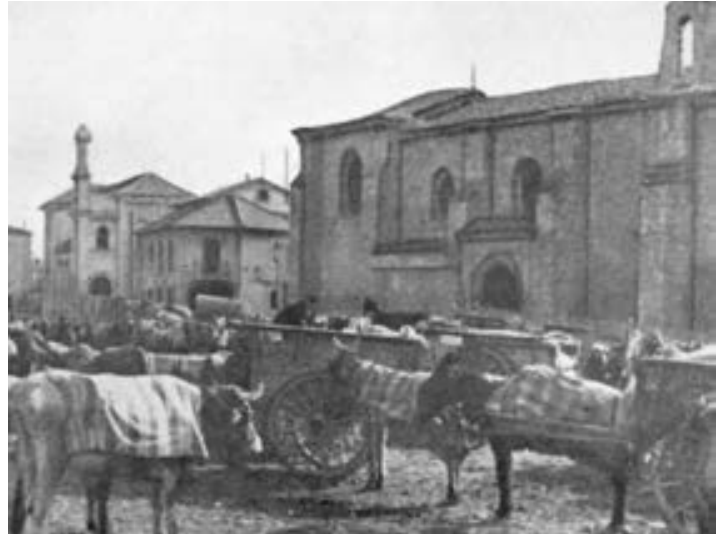

Los labradores hacen largas esperas con sus carros para que les recojan el trigo. 


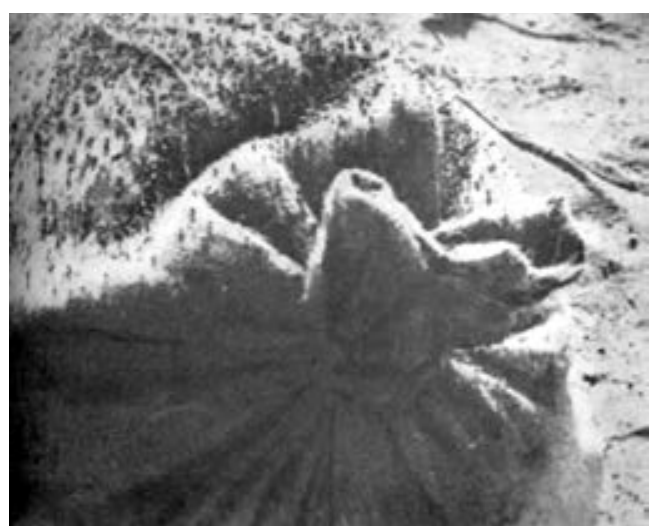

Los gorgojos se apoderan del cereal.

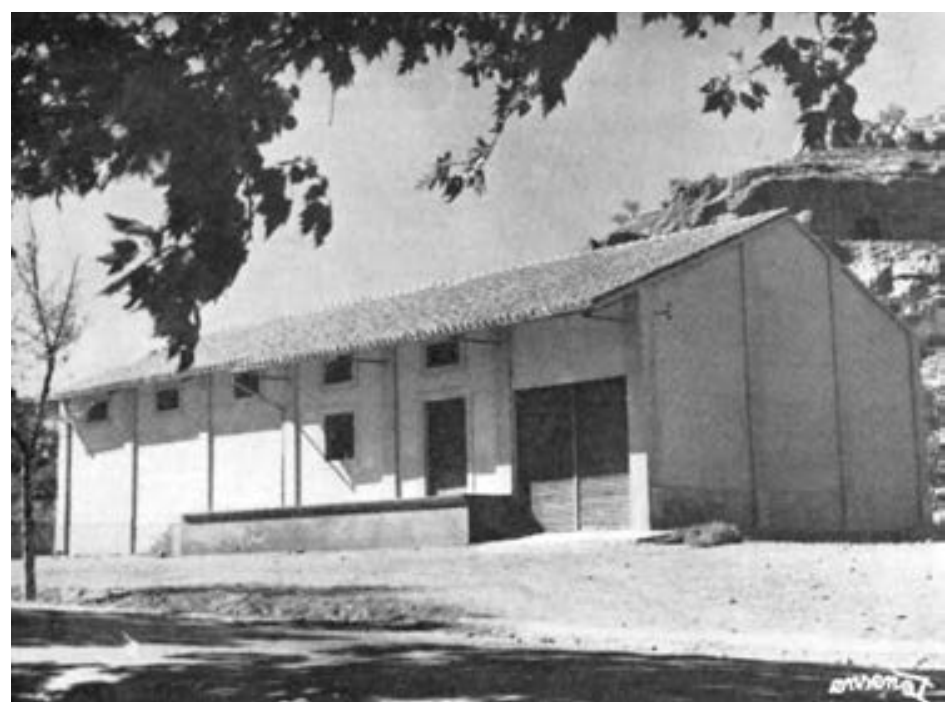

Exterior del almacén de Arnedo. 


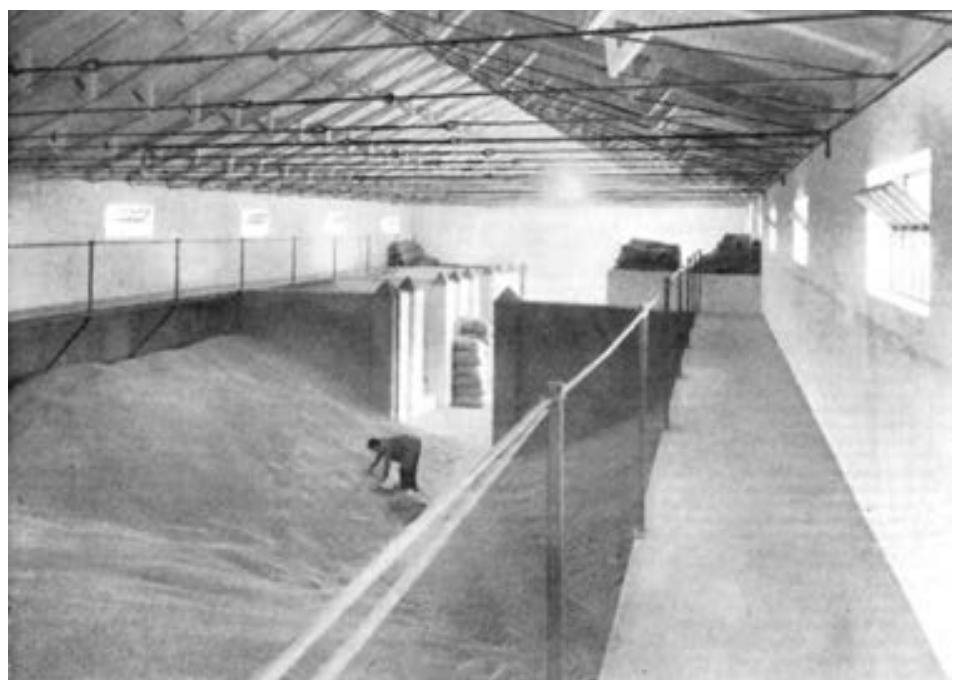

Interior del almacén de Arnedo.

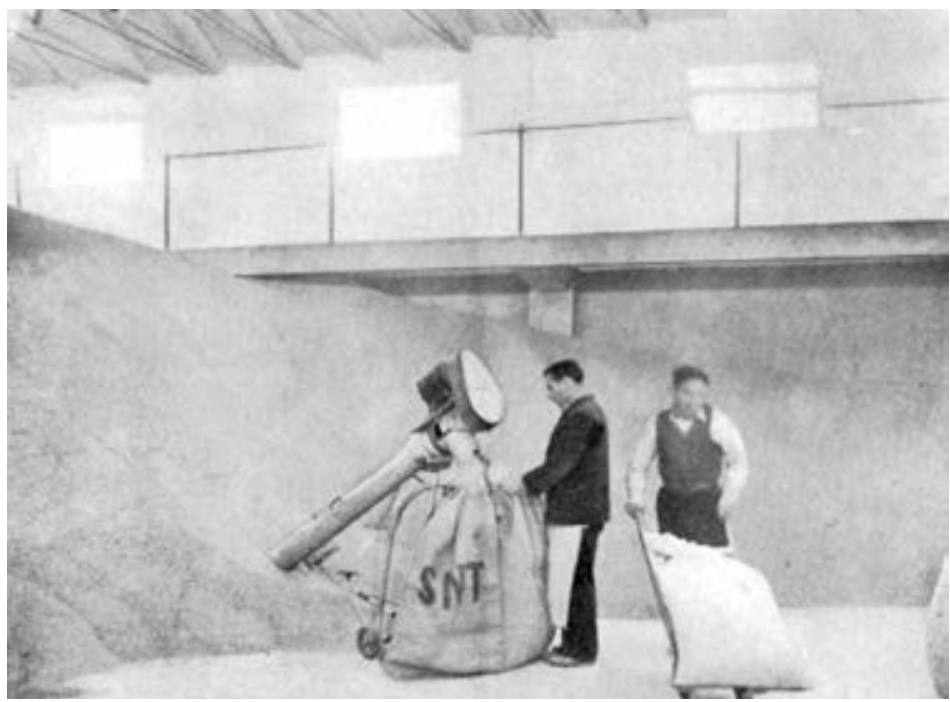

Almacén de Boceguillas. Ensacado mecánico del grano. 


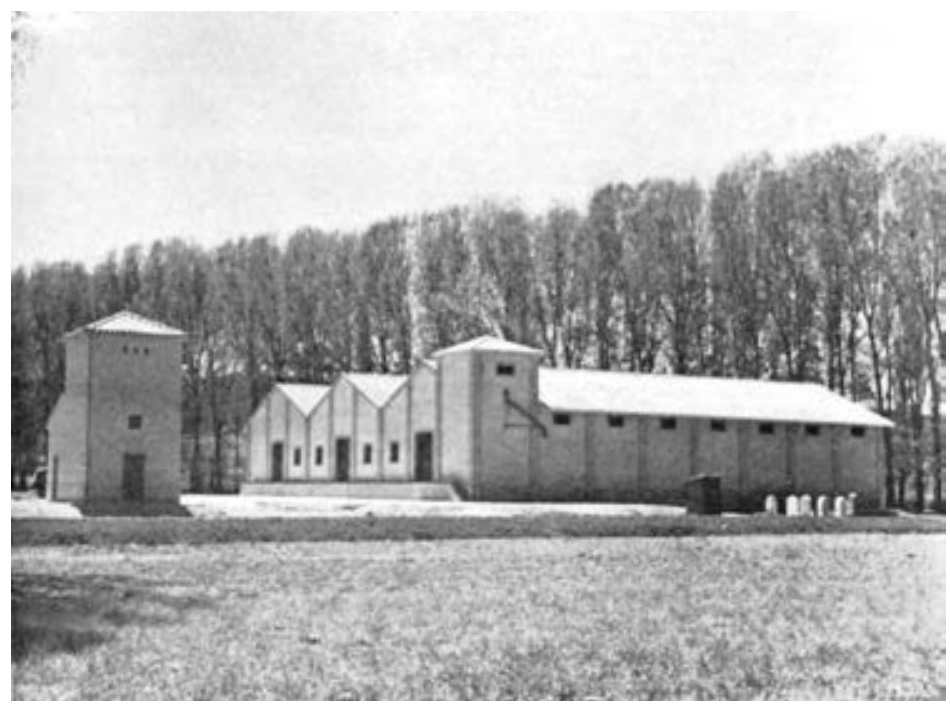

Exterior del almacén de Molina de Aragón.

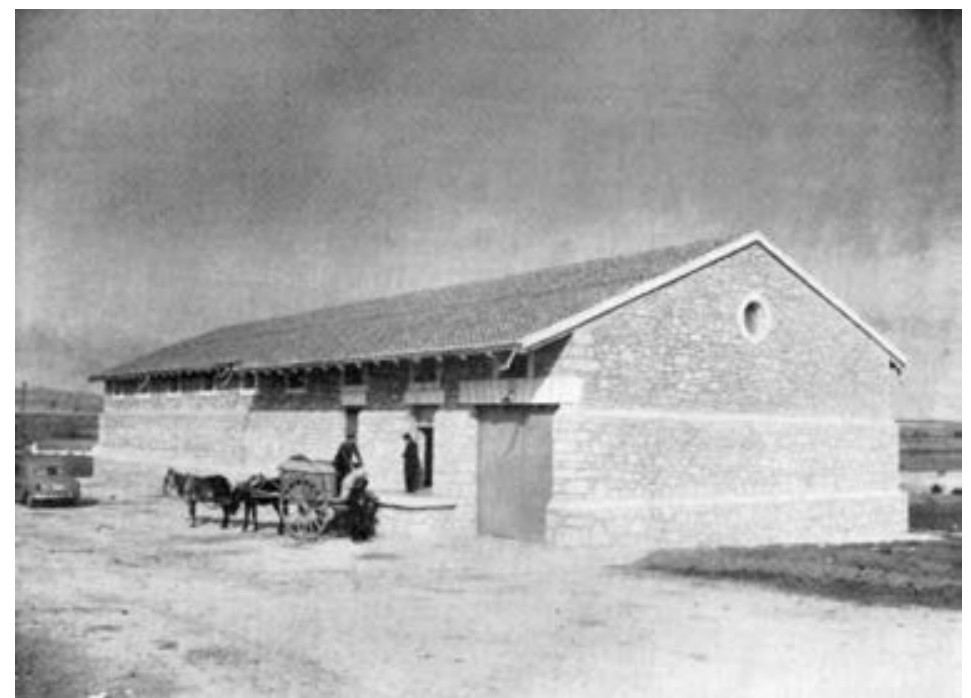

Exterior del almacén de Boceguillas. 


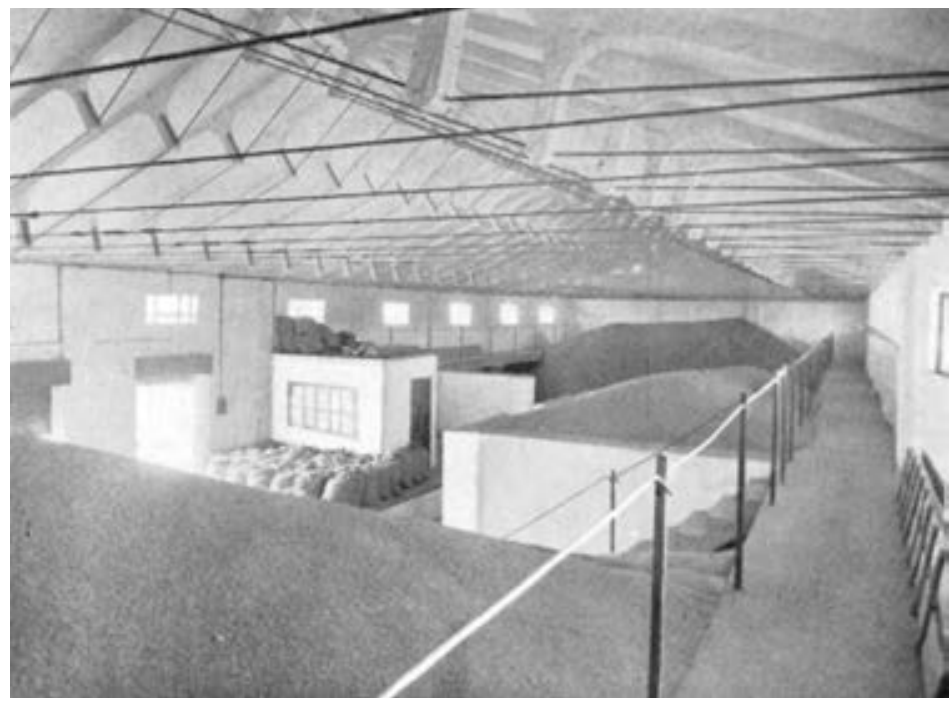

Interior del almacén de Boceguillas.

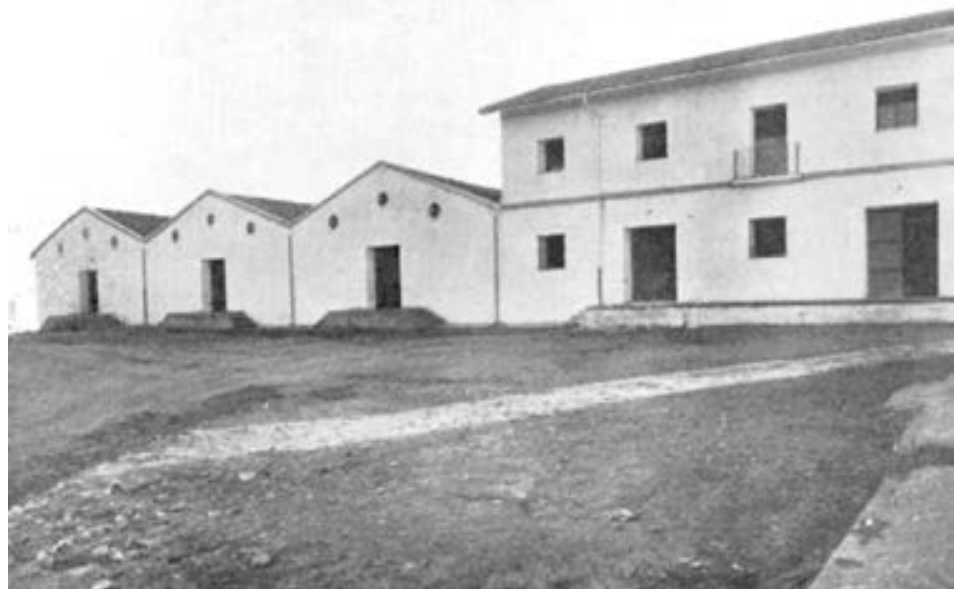

Exterior del almacén de Cáceres. 


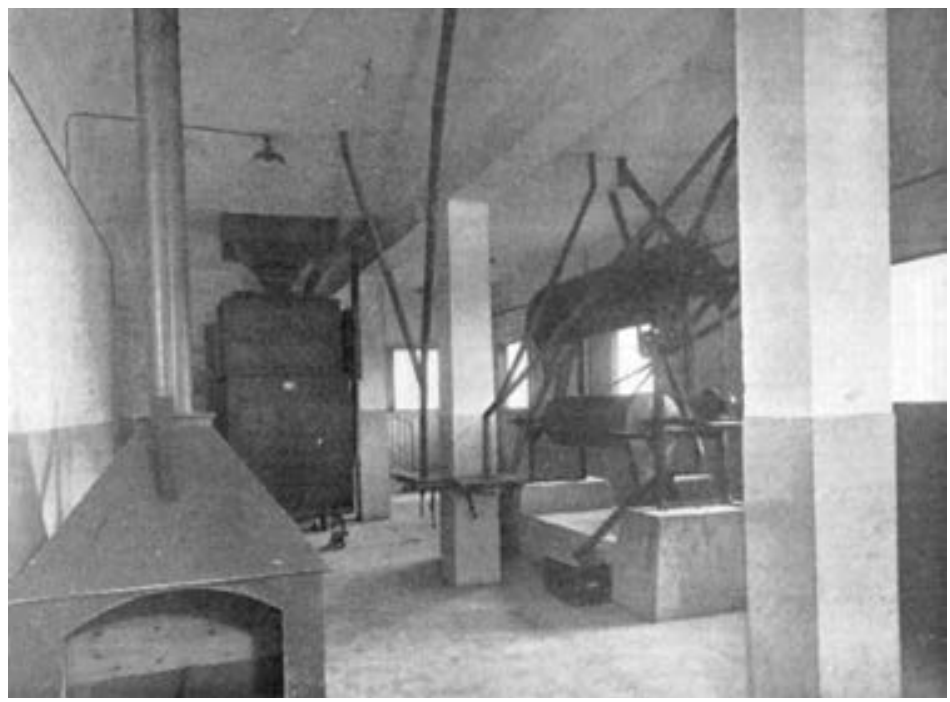

Almacén de Cáceres. Instalación de selección de semillas.

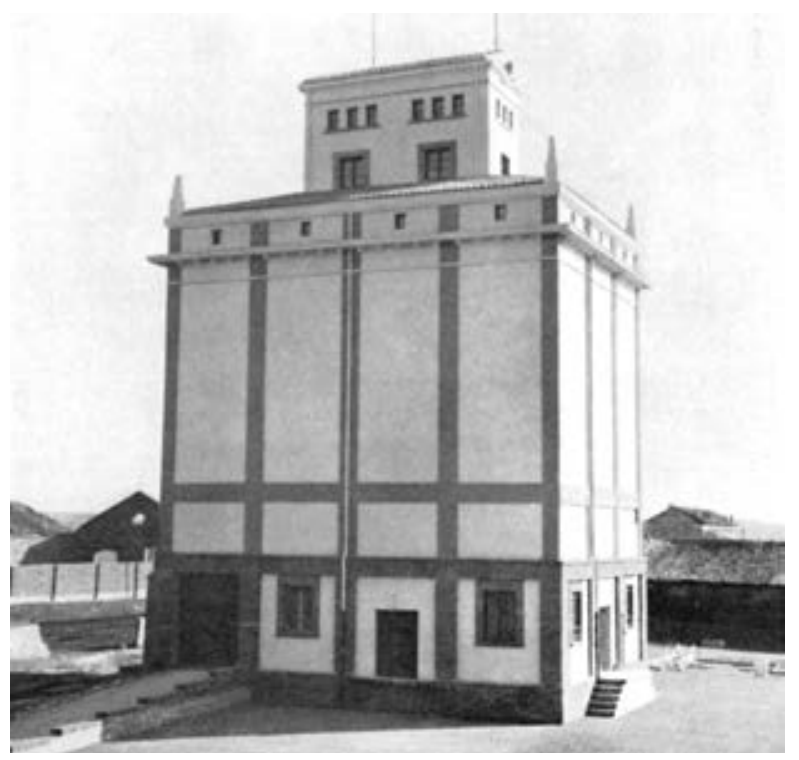

Silo de Villada (Palencia). 


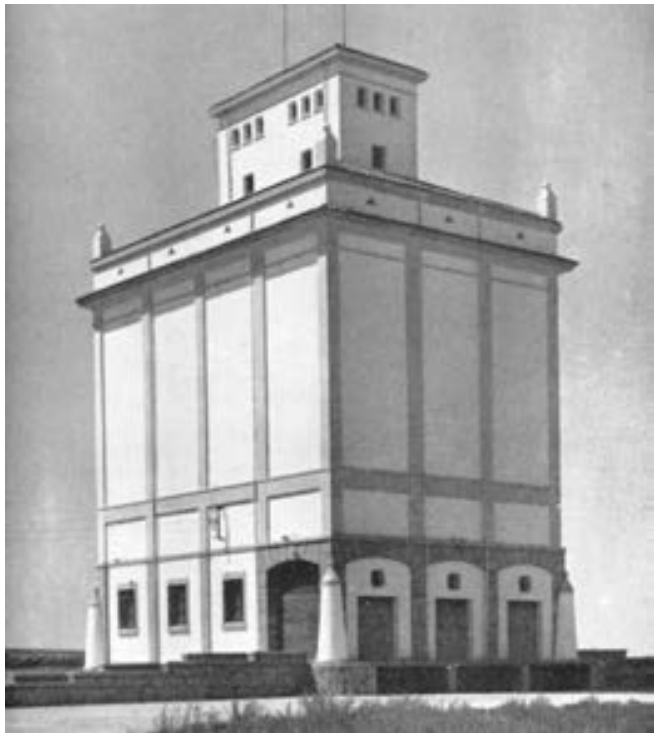

Silo de Miajadas (Cáceres).

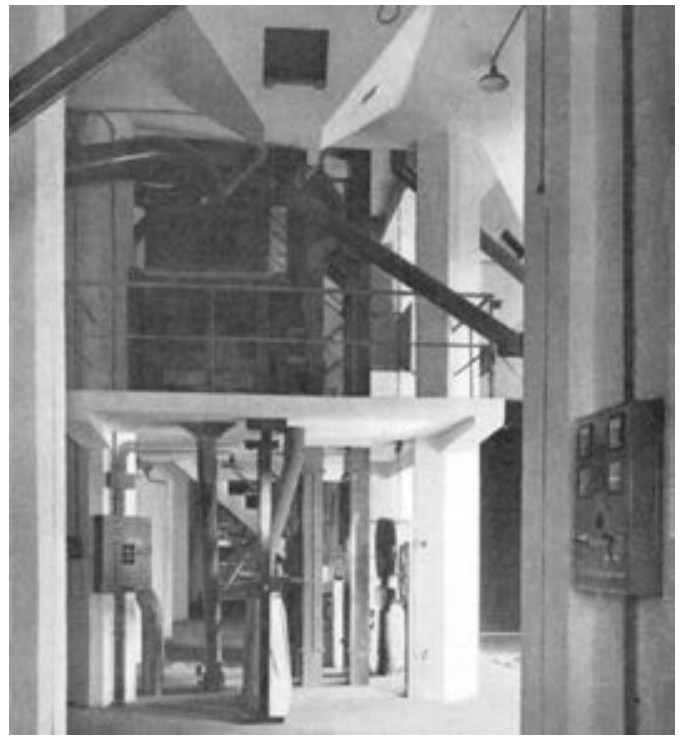

Silo tipo A. Separador de antelimpia. 


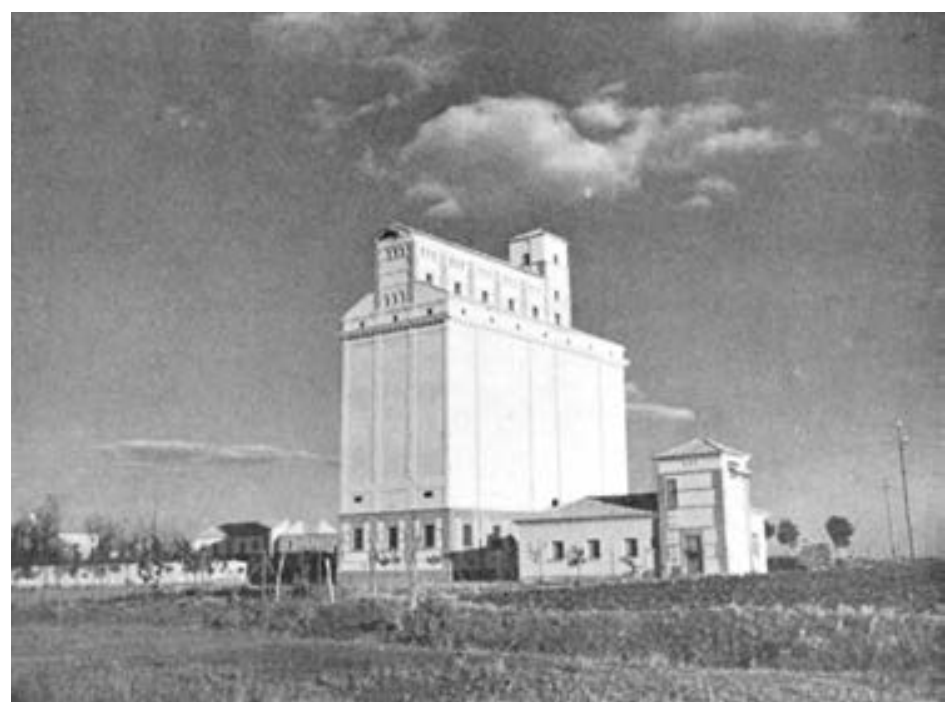

Silo del Madrigal de las Altas Torres (Ávila).

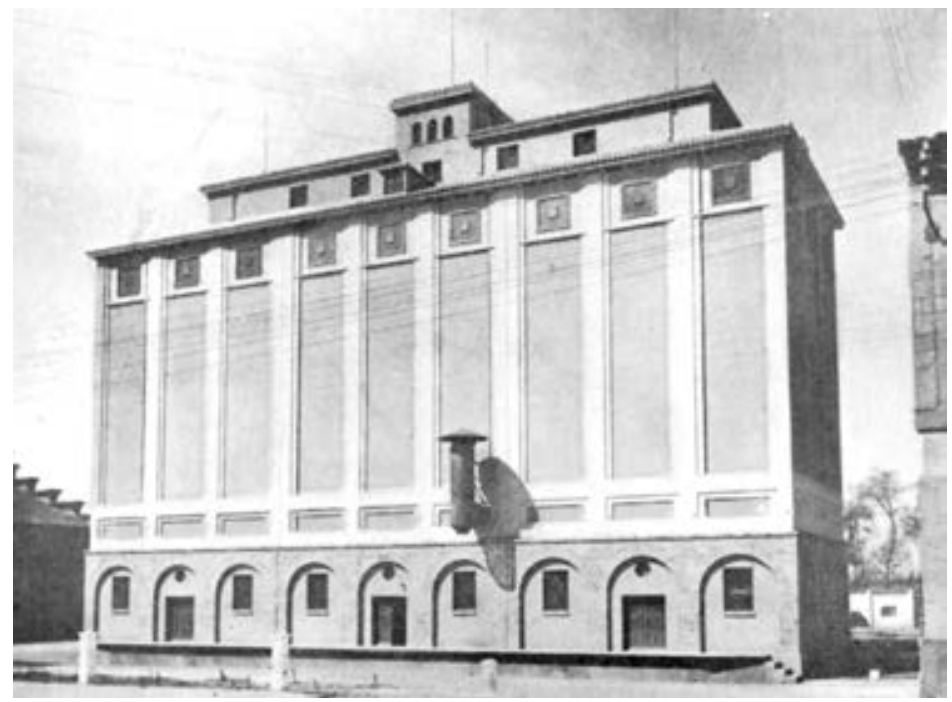

Silo de Ejea de los Caballeros (Zaragoza). 


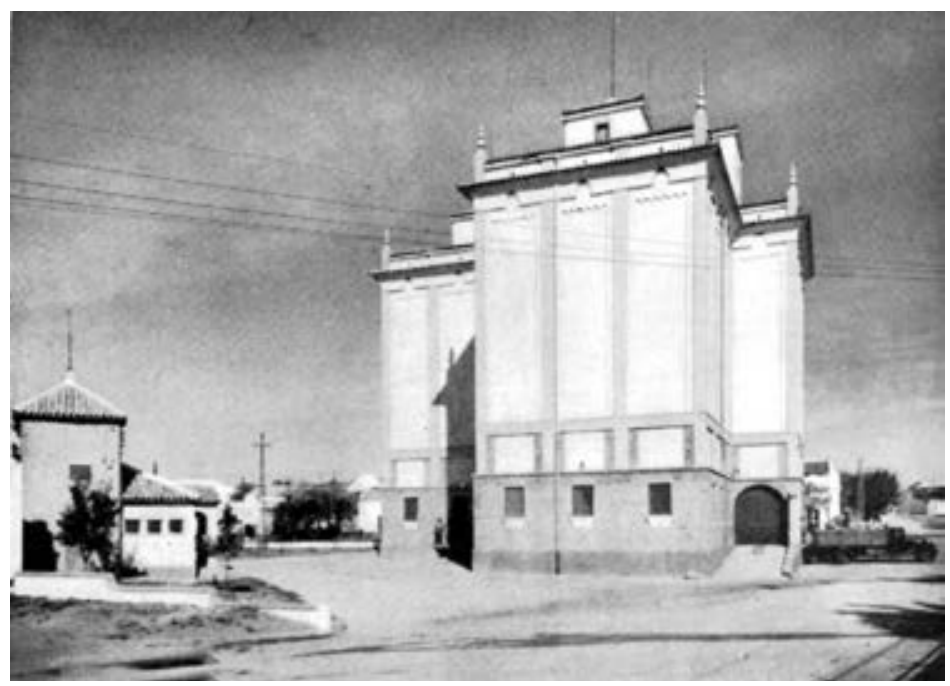

Silo de Carmona (Sevilla).

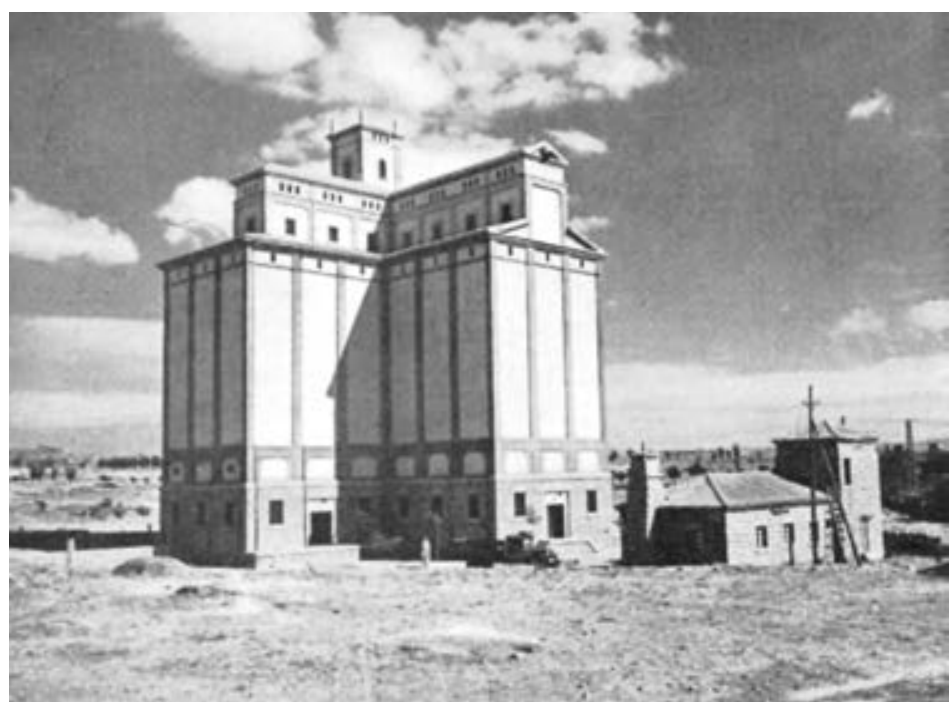

Silo de Ávila. 


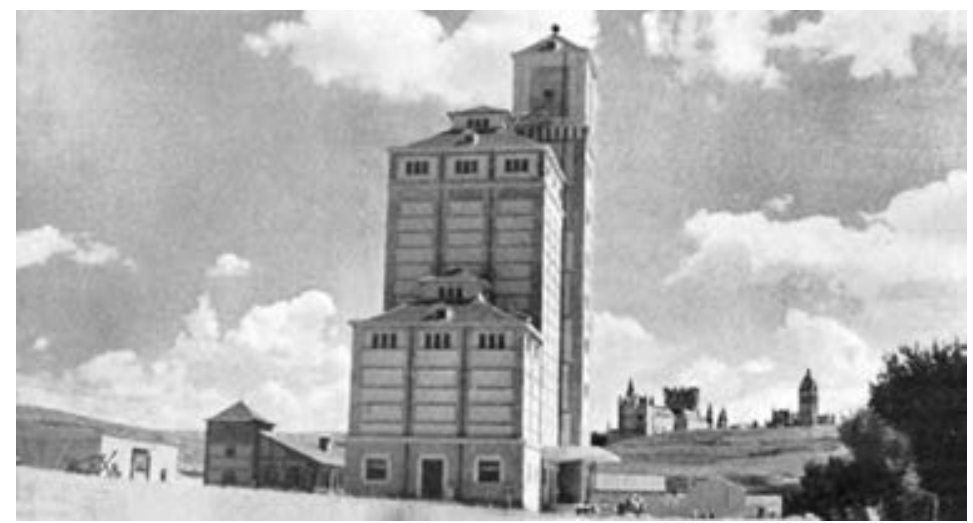

Silo de Segovia.

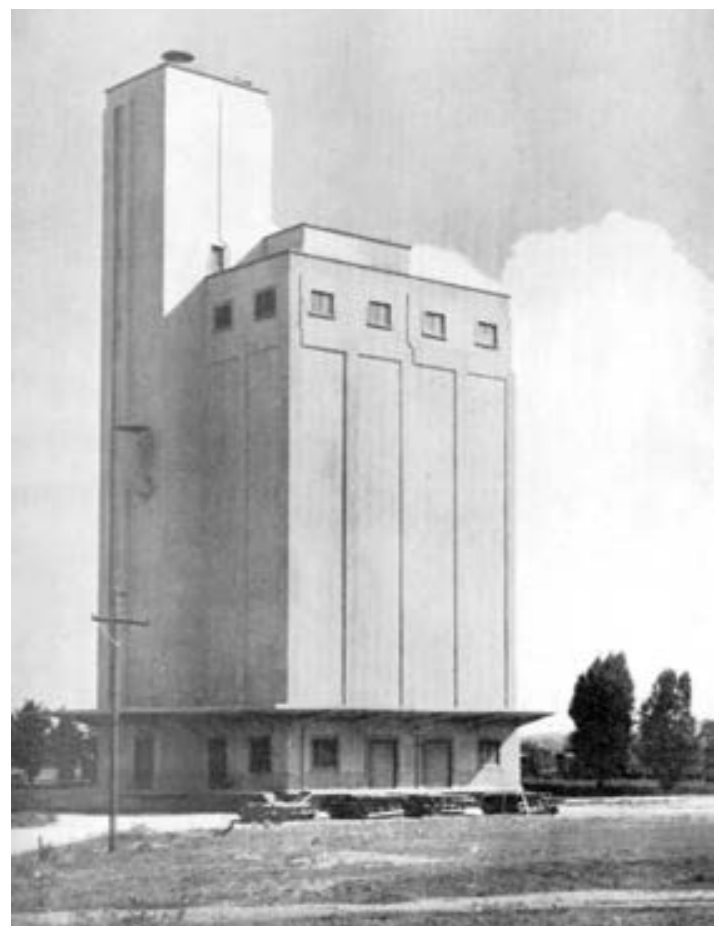

Silo de Villaquirán de los Infantes (Burgos). 


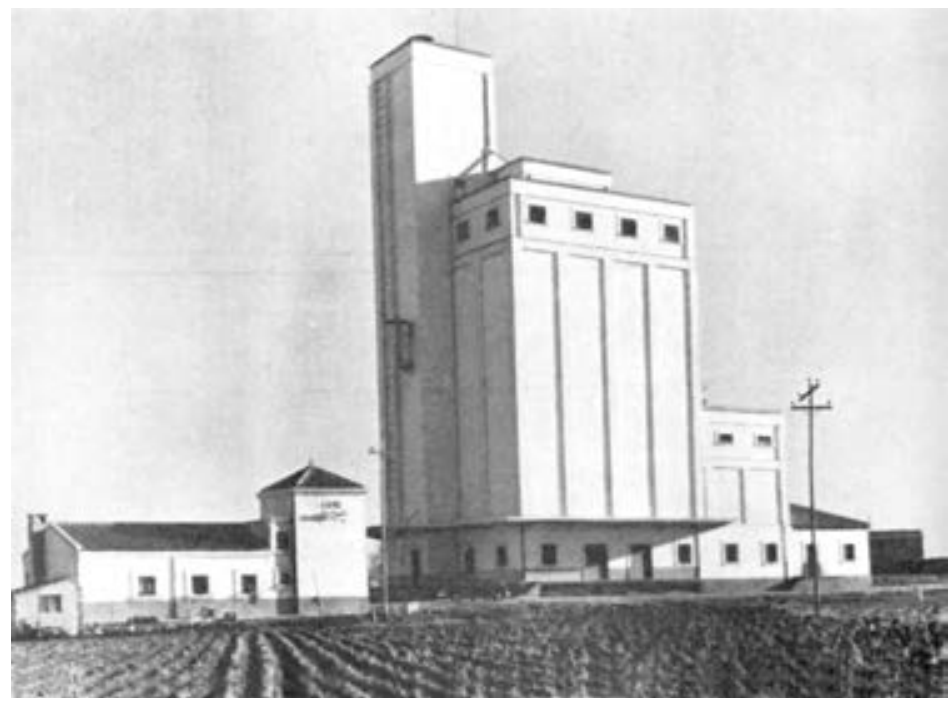

Silo de Peñaranda de Bracamonte (Salamanca), con anejo de selección de semillas a él adosado.

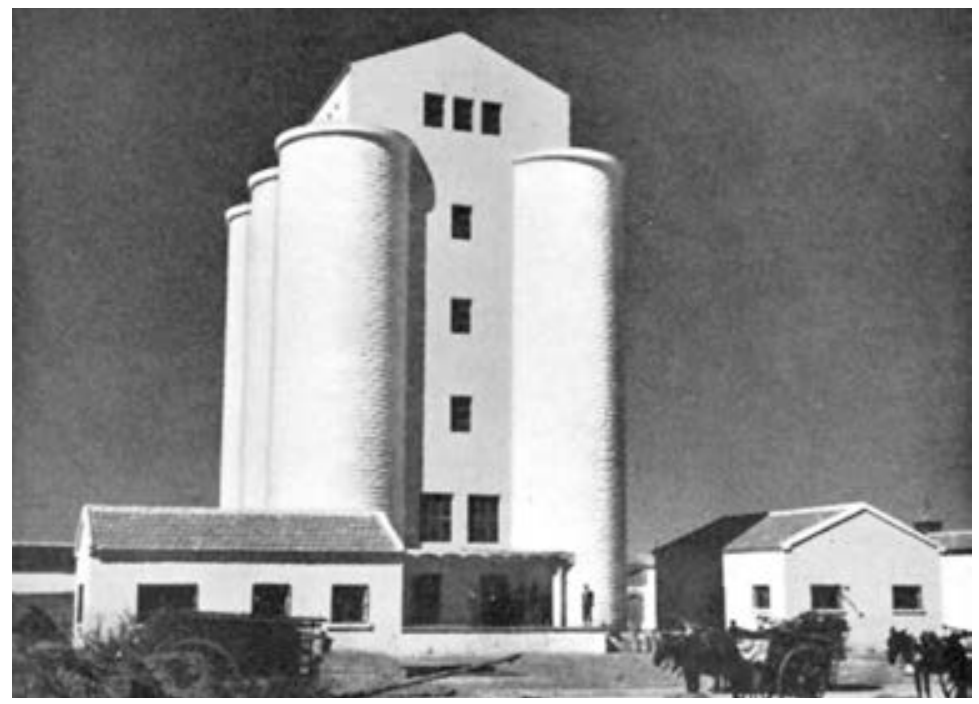

Silo de Infantes (Ciudad Real). 


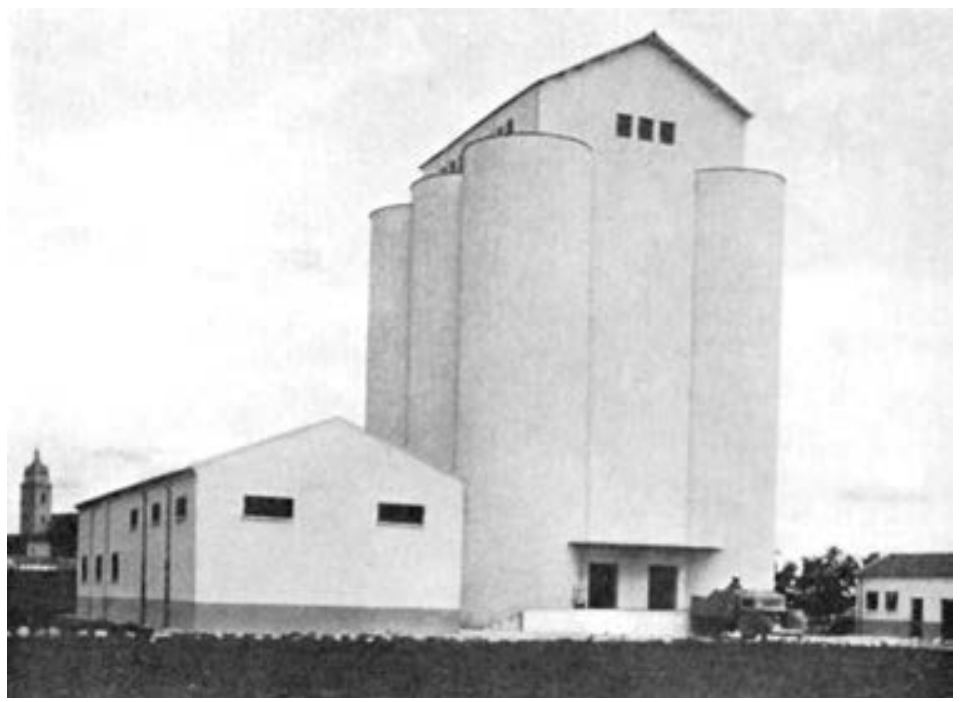

Silo de Tordesillas (Valladolid).

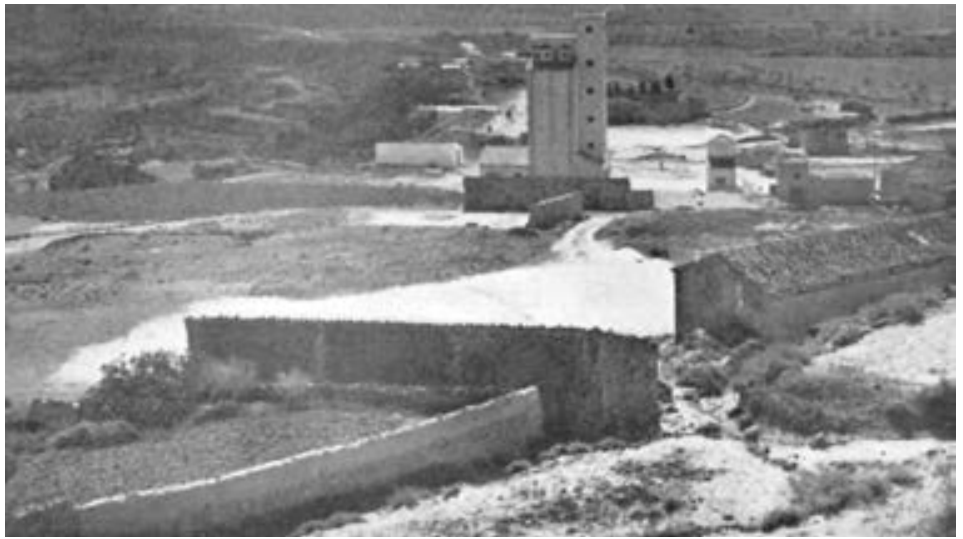

Silo de Berbegal (Huesca). 


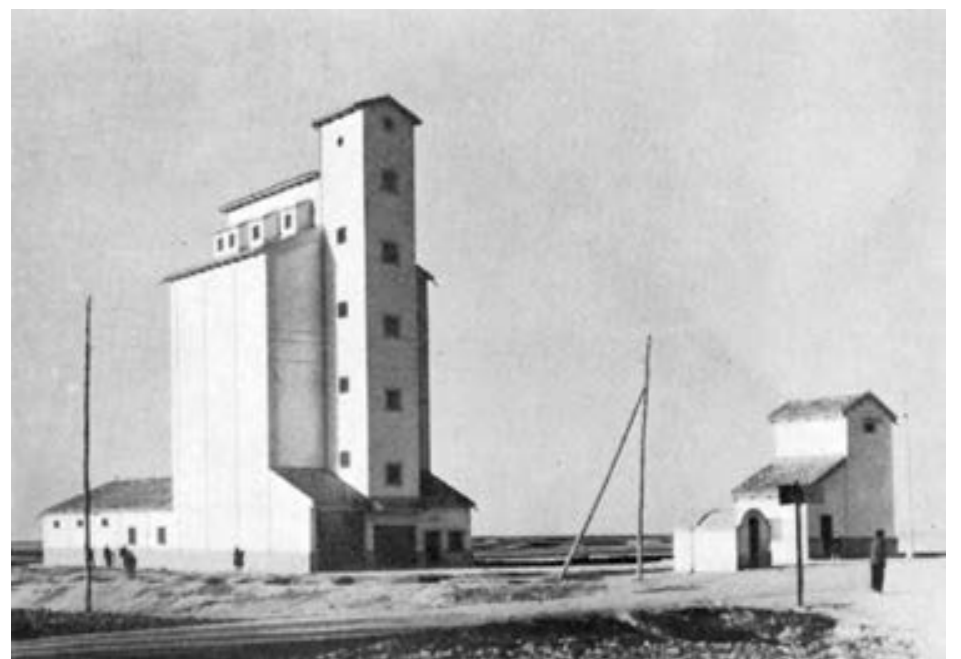

Silo de Fontiveros (Ávila).

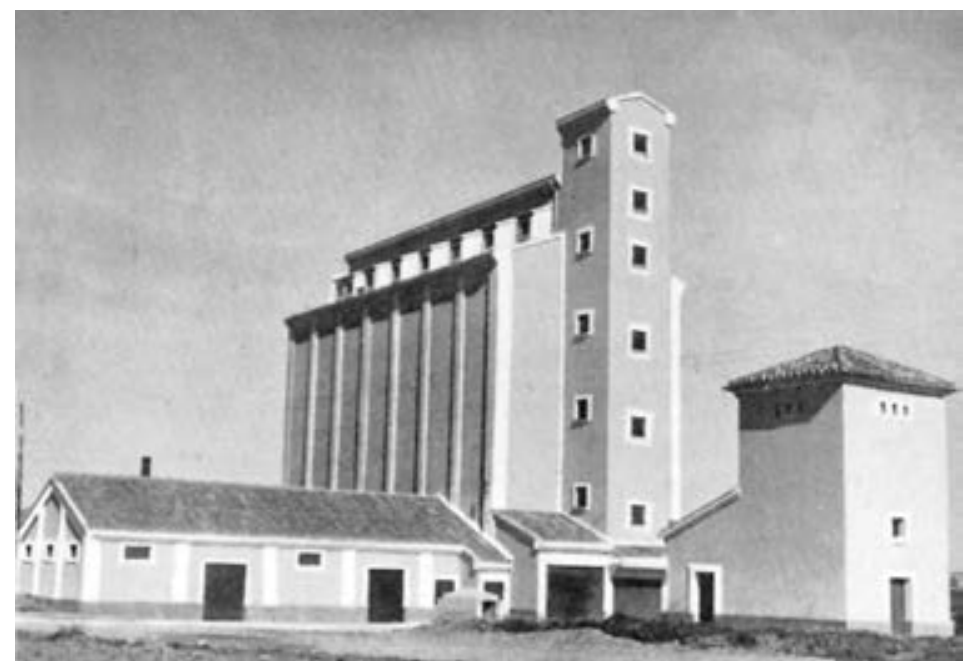

Silo de Tudela (Navarra). 


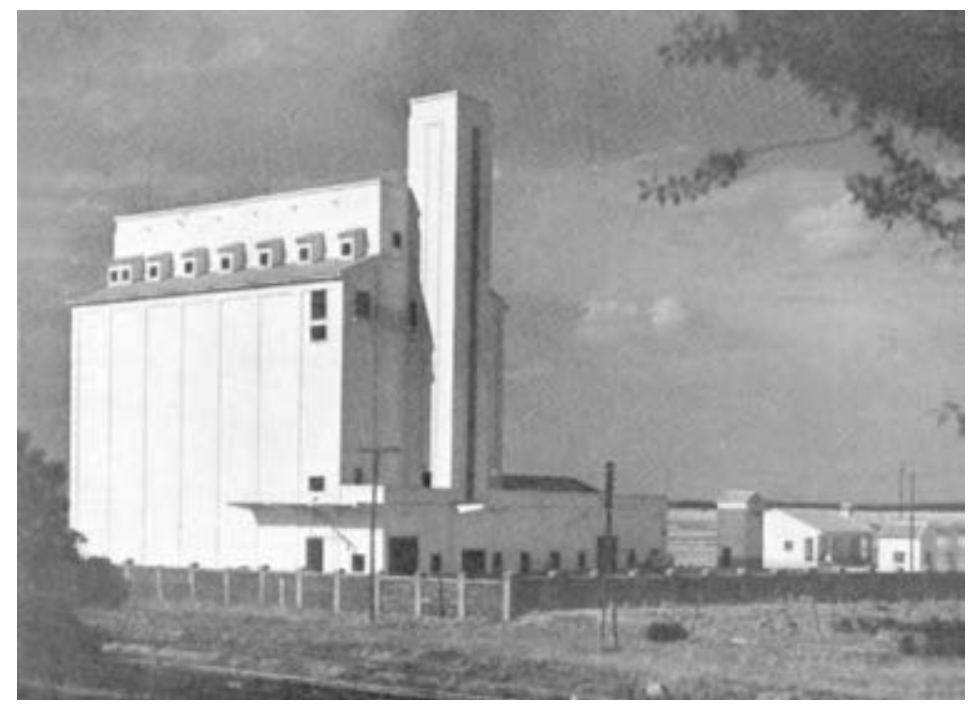

Silo de Arévalo (Ávila).

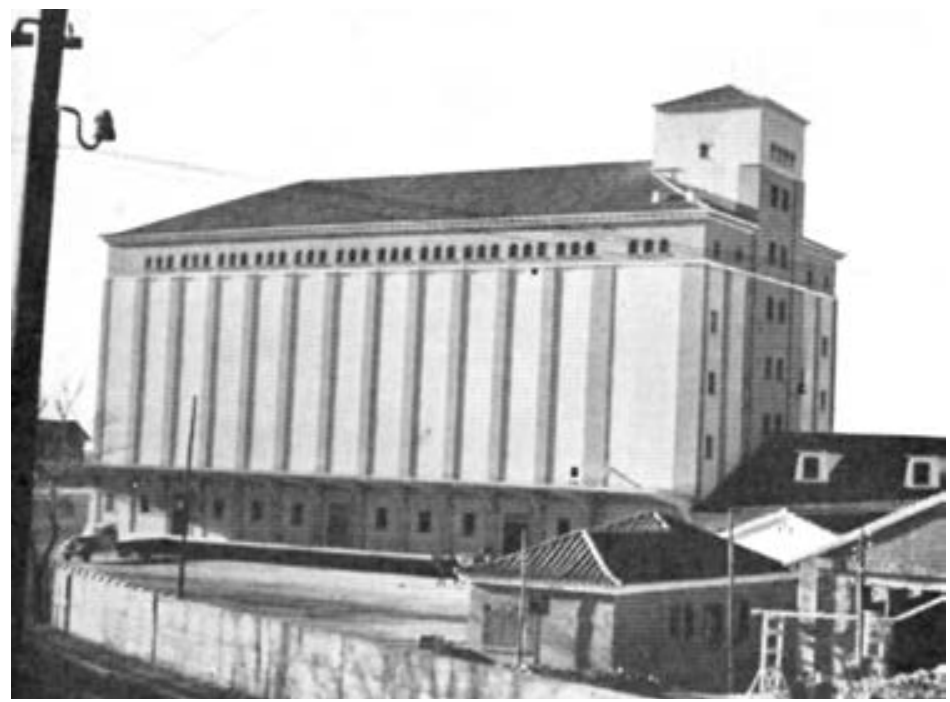

Silo de Huesca. 


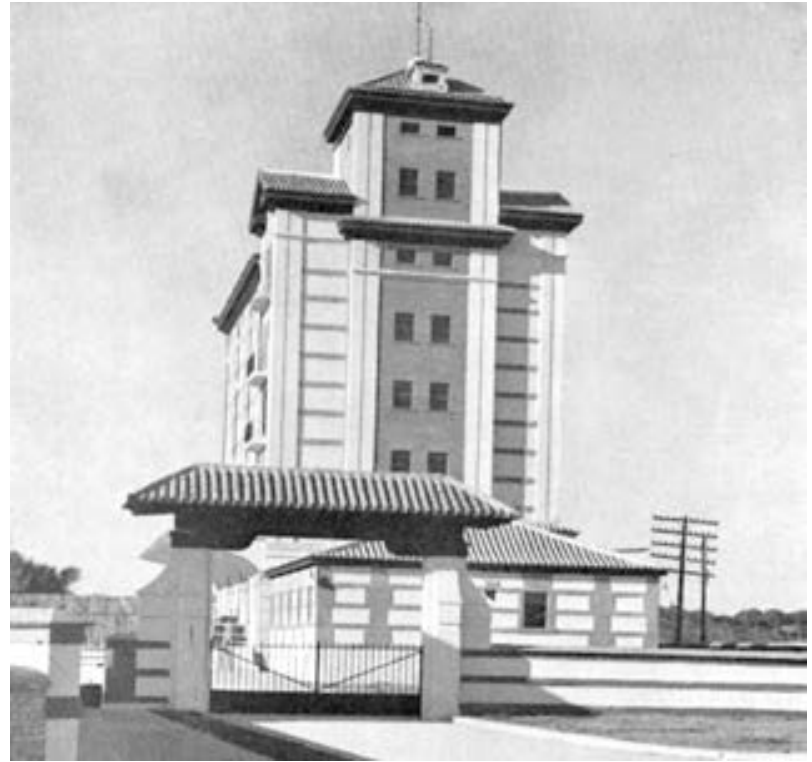

Silo de Alcalá de Henares (Madrid).

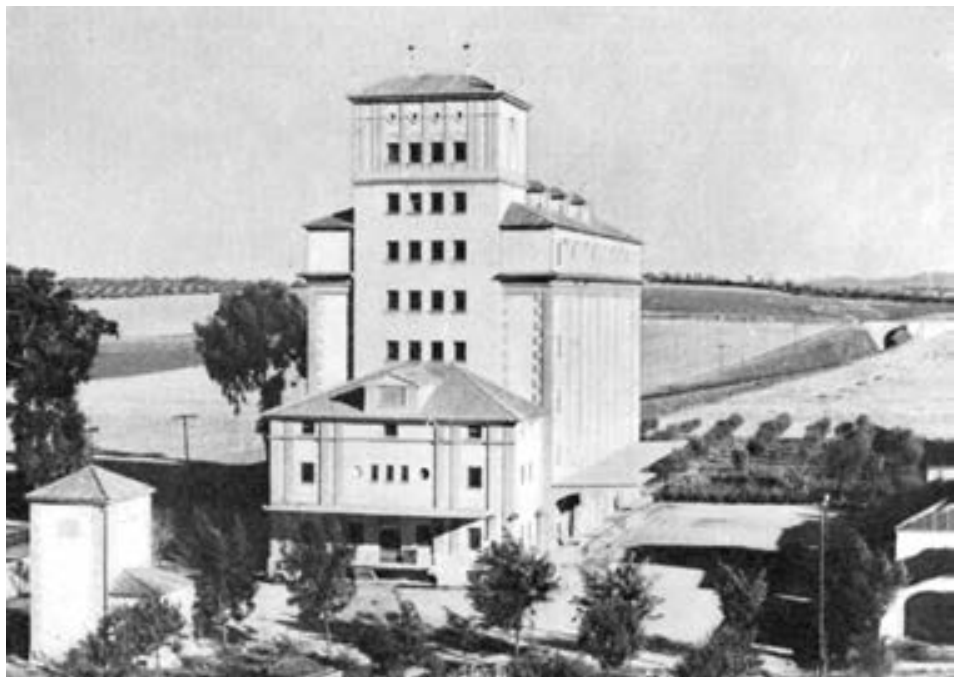

Silo de Mérida (Badajoz). 


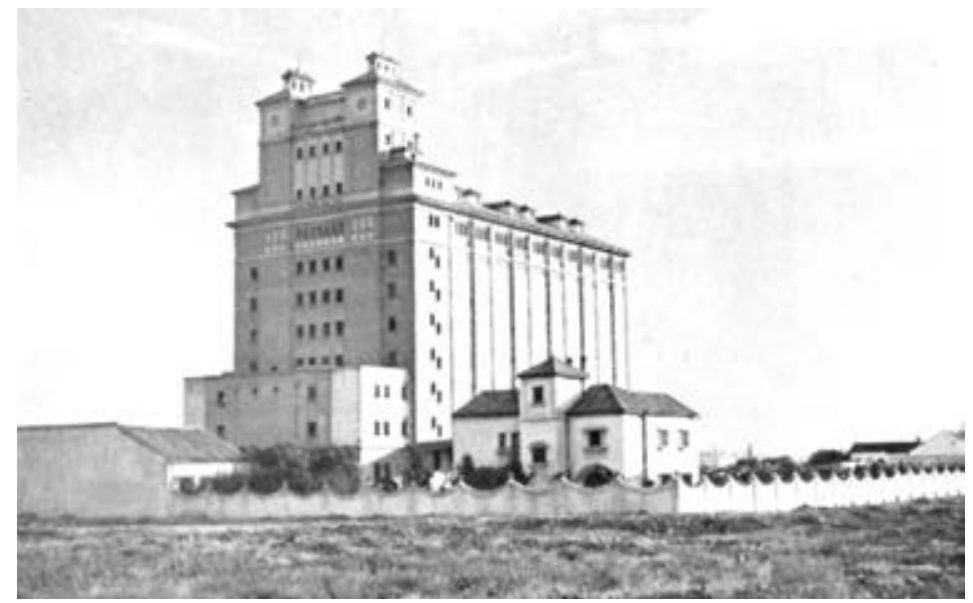

Silo de Córdoba.

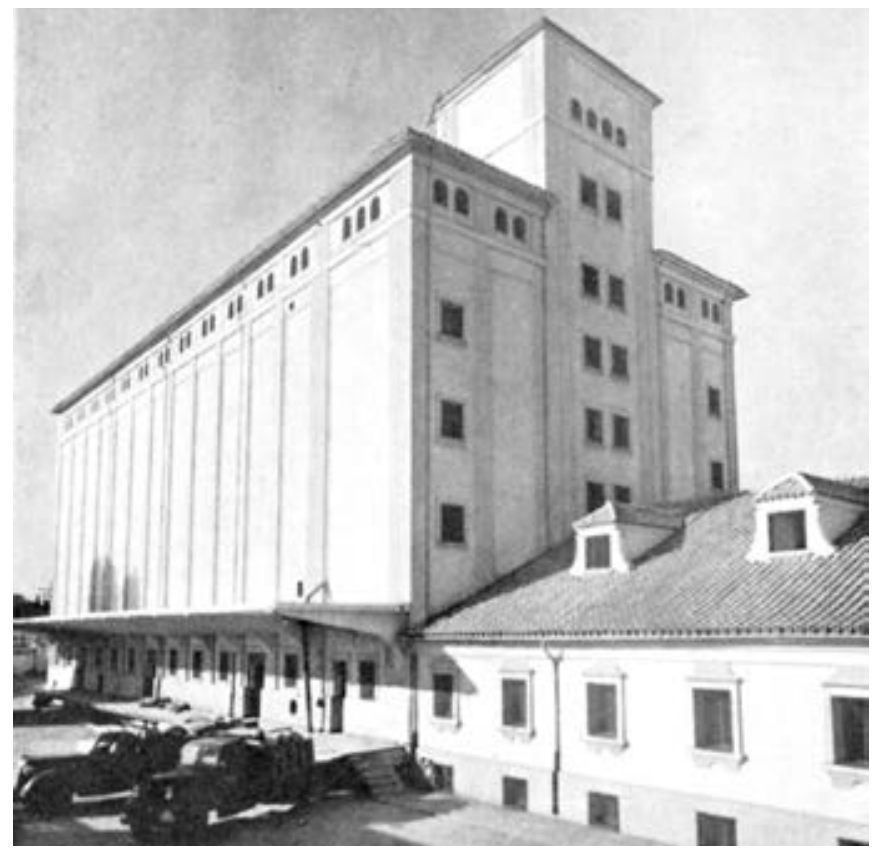

Silo de Jerez de la Frontera (Cádiz). 


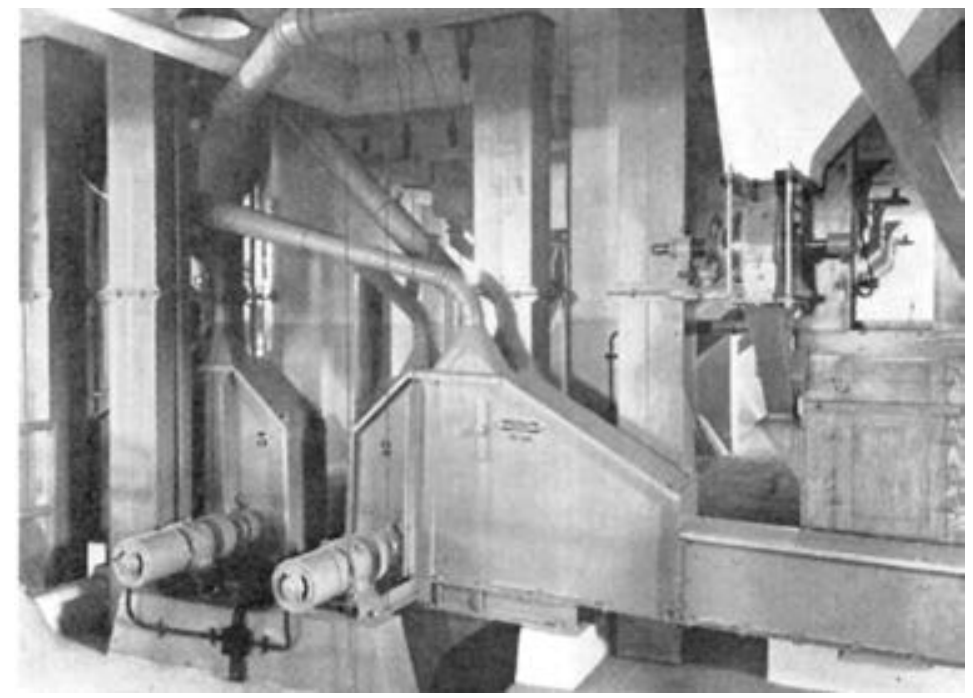

Silos de tránsito. Transportadores transversales de recepción.

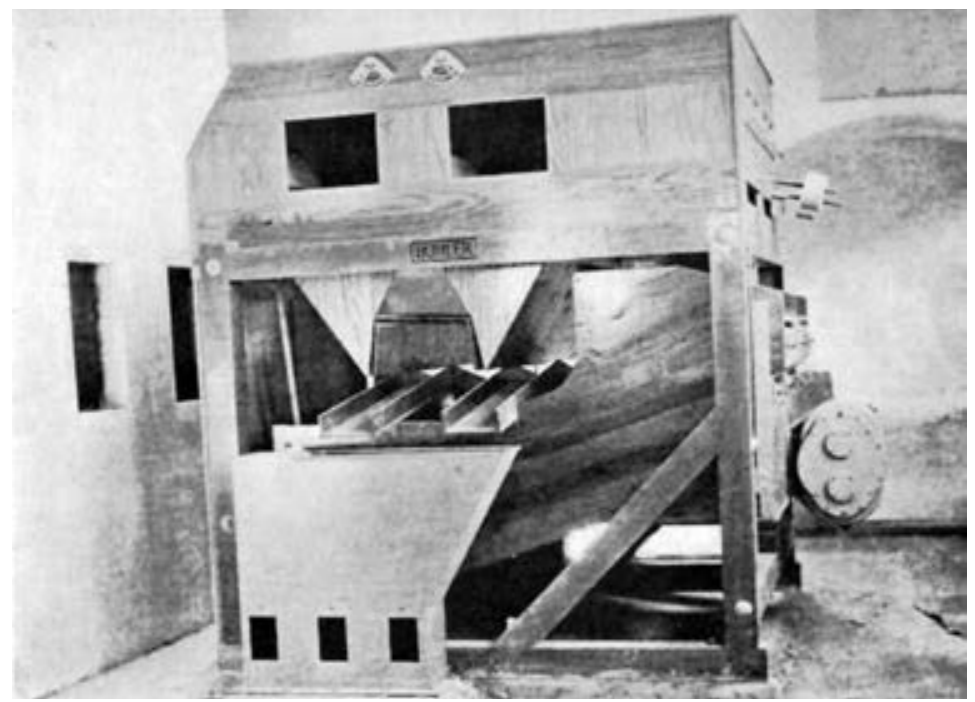

Silos de tránsito. Separador de antelimpia. 


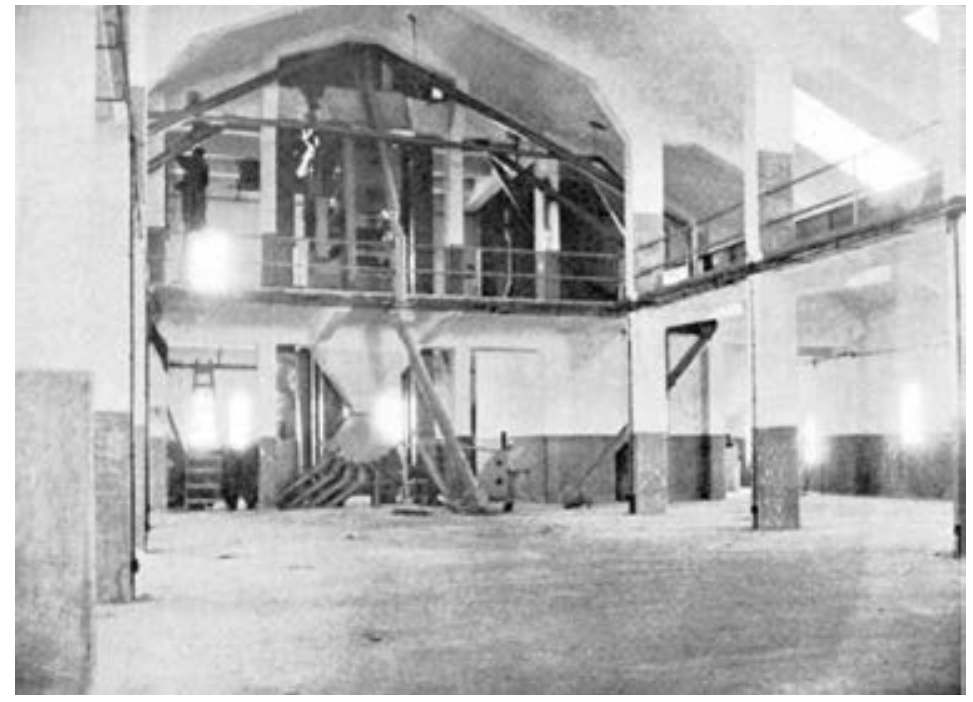

Silos de tránsito. Válvula distribuidora.

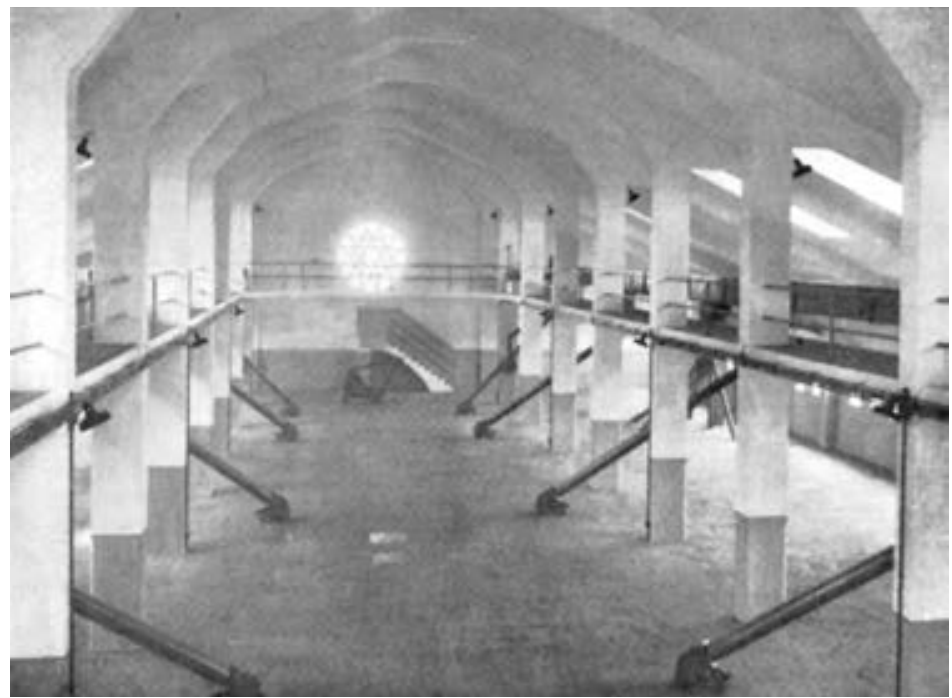

Silos de tránsito. Transportadores distribuidores. 


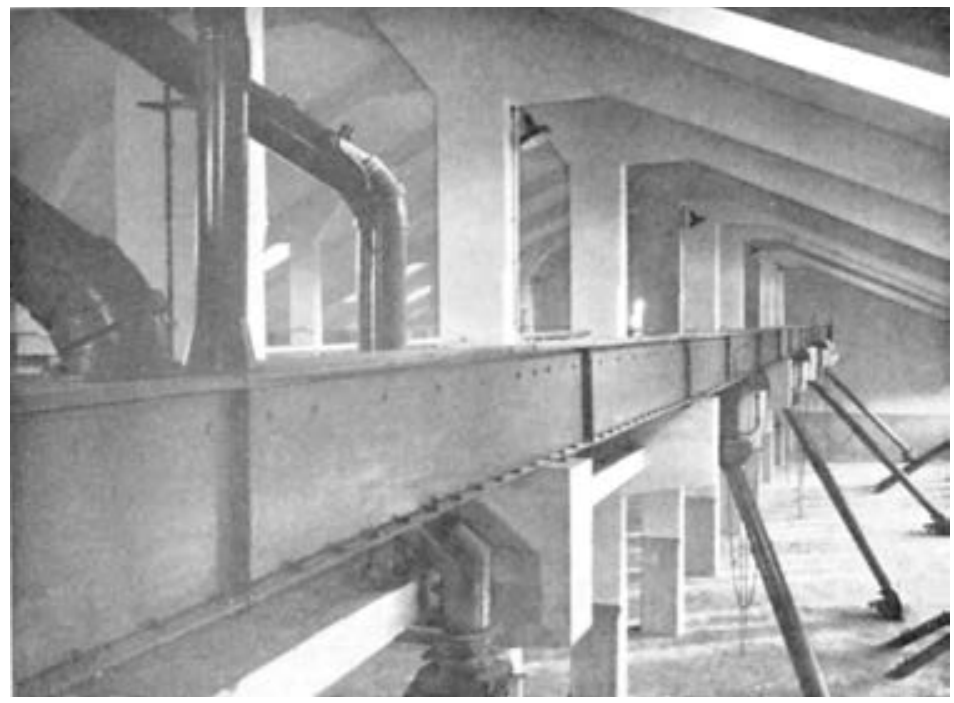

Silos de tránsito. Transportadores distribuidores.

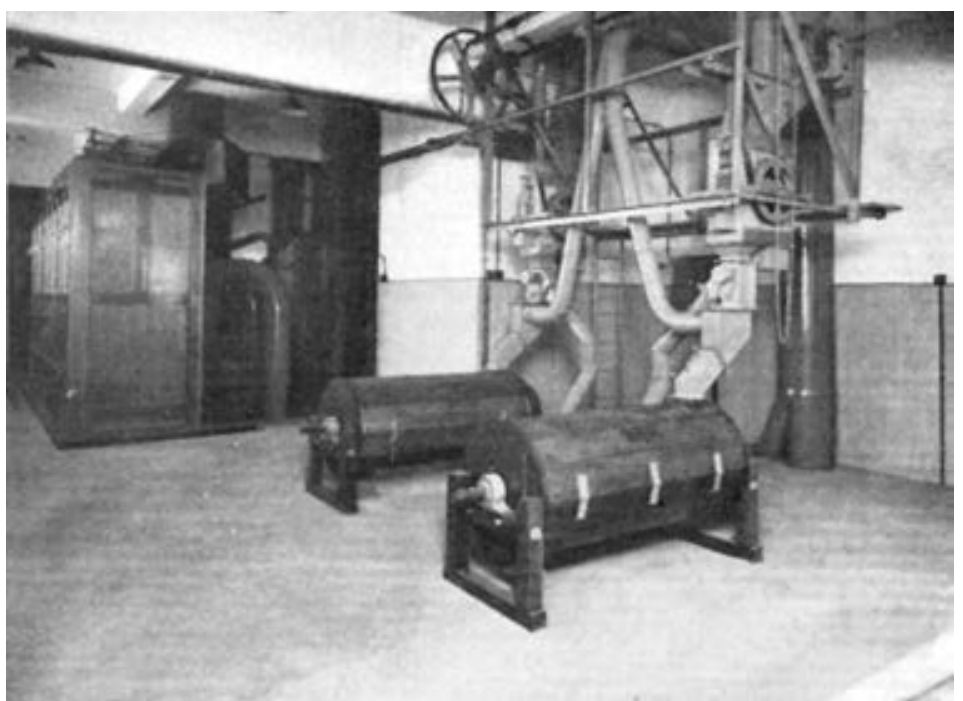

Silos de tránsito. Selección de semillas. Desbarbadores de cebada. 


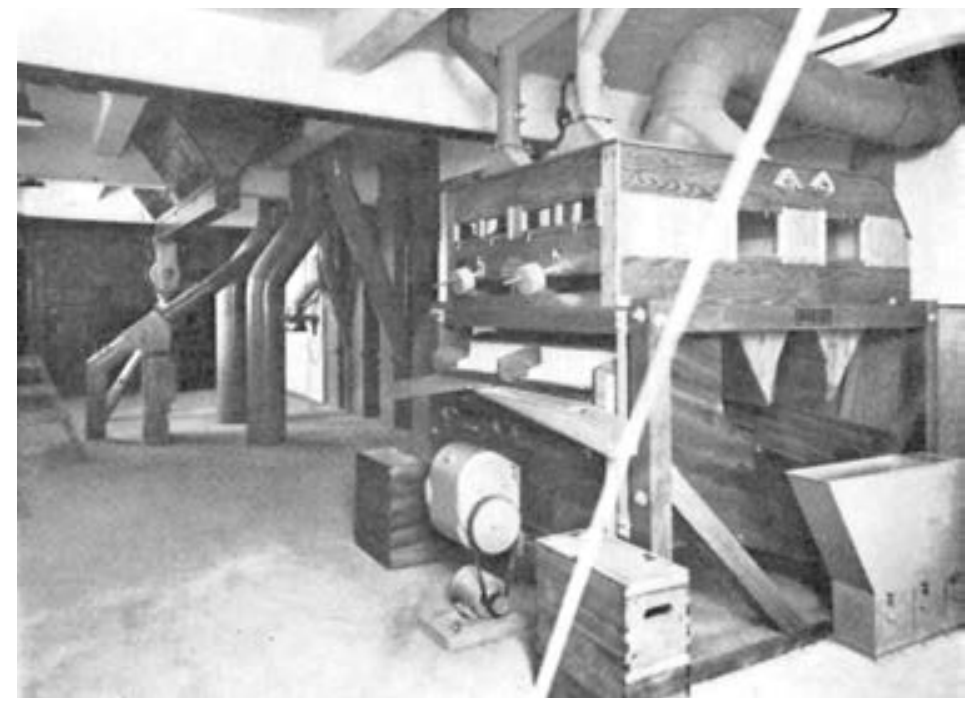

Silos de tránsito. Selección de semillas.

Separador de impurezas de gran tamaño y poco peso.

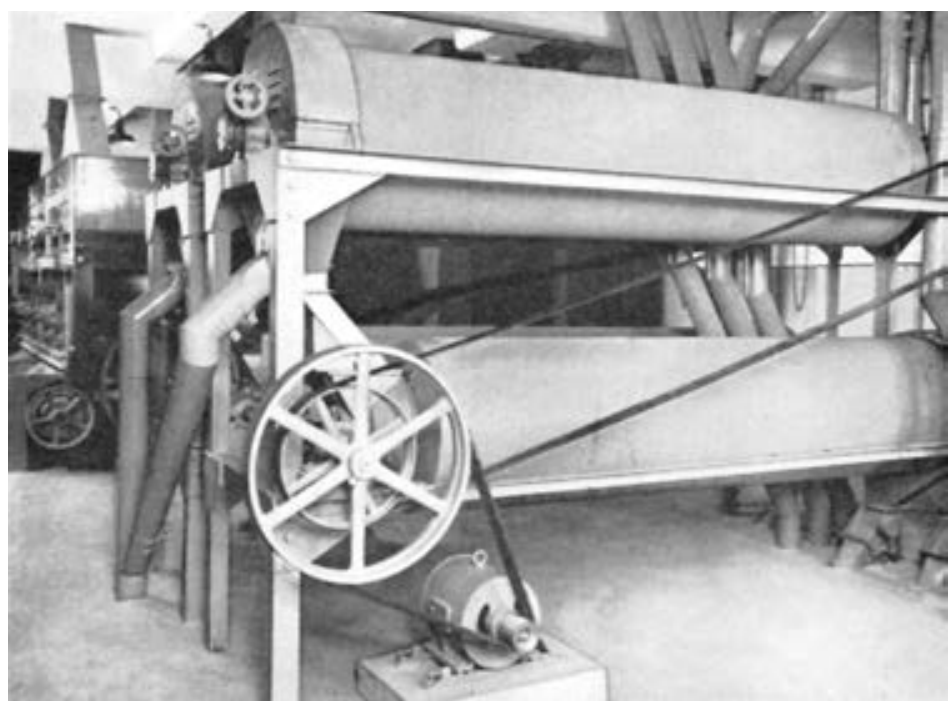

Silos de tránsito. Selección de semillas. Equipo de triarvejones. 


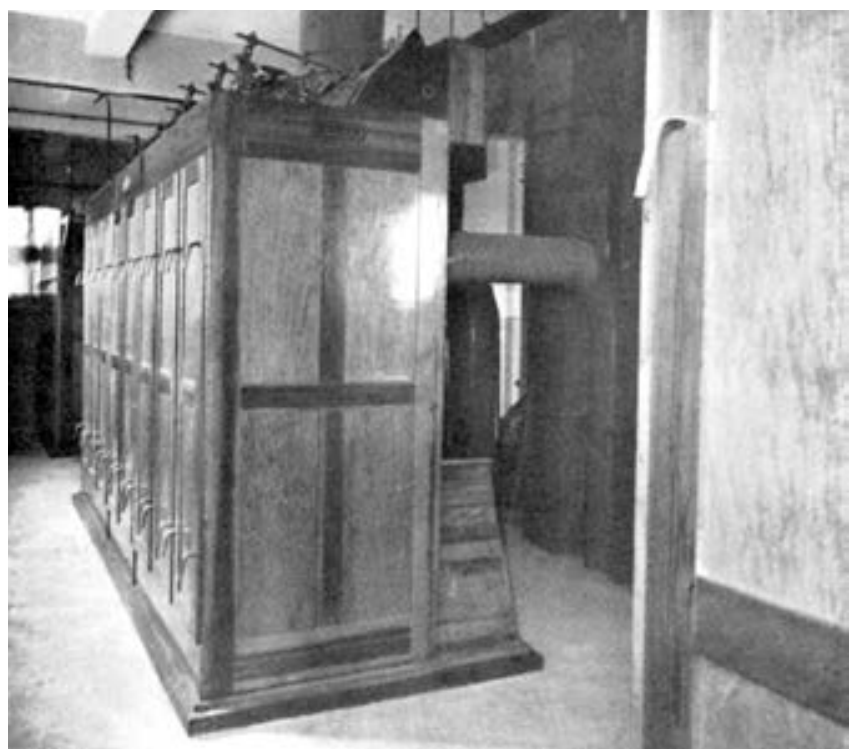

Silos de tránsito. Aspiradores de polvo.

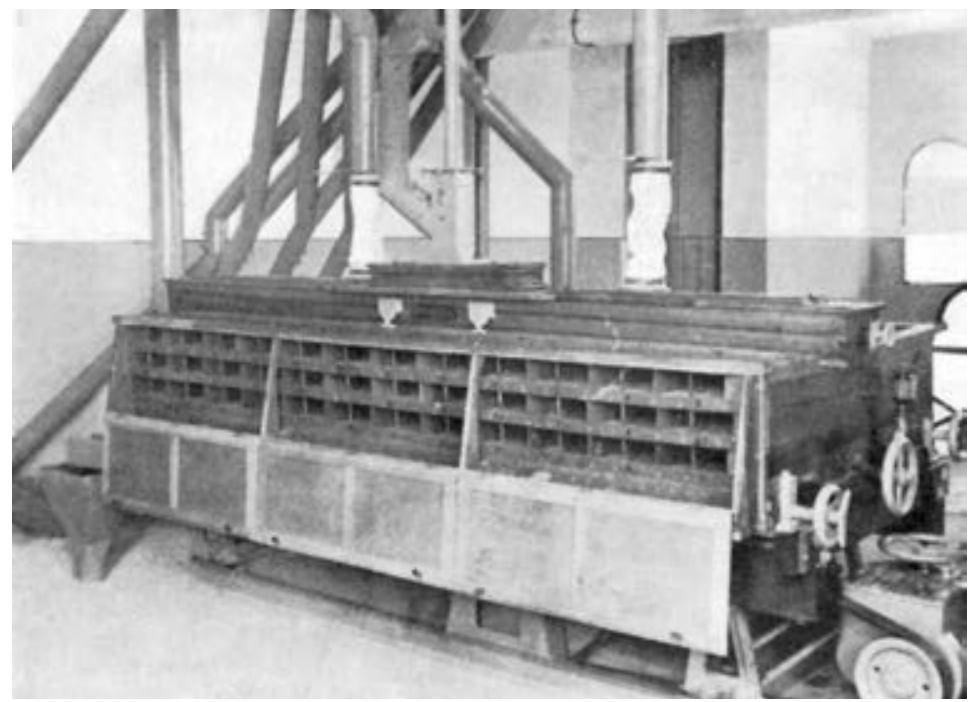

Silos de tránsito. Selección de semillas. Mesa densimétrica. 


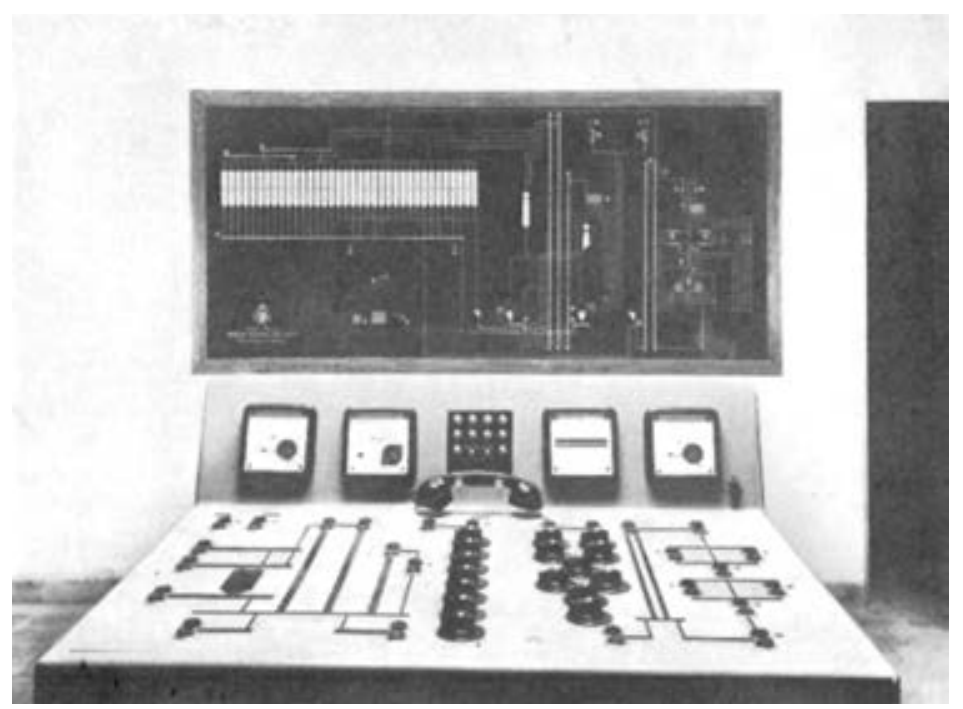

Silos de tránsito. Mesa de mandos y esquema luminoso.

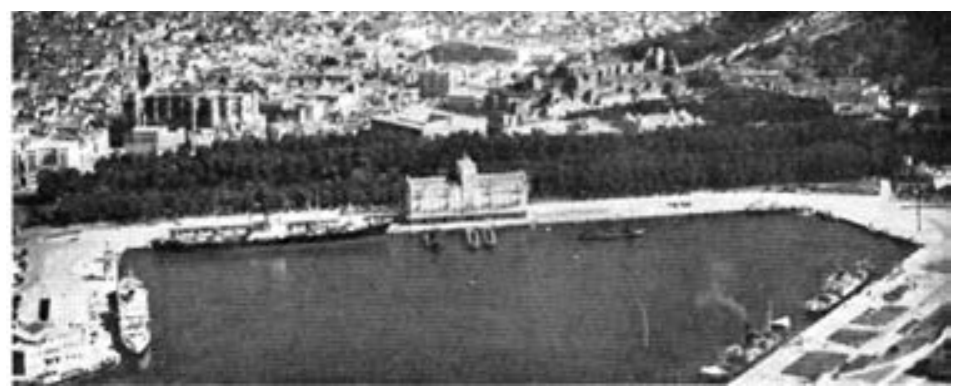

Silo de Málaga. Emplazamiento. 


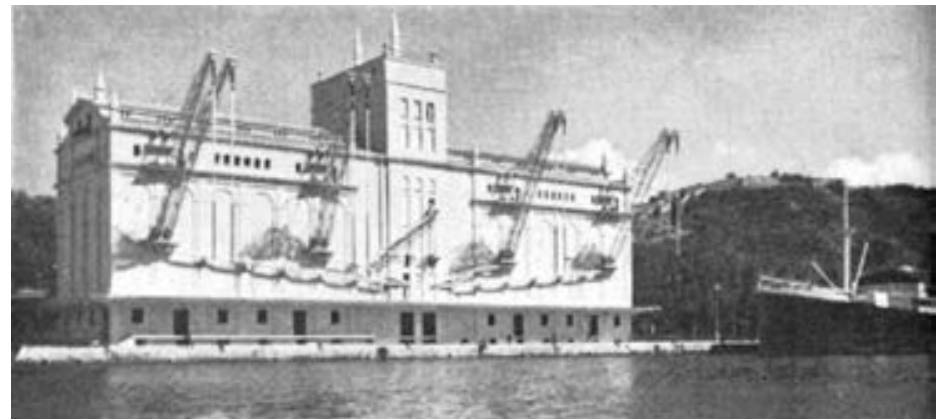

Silo de Málaga. Vista general.

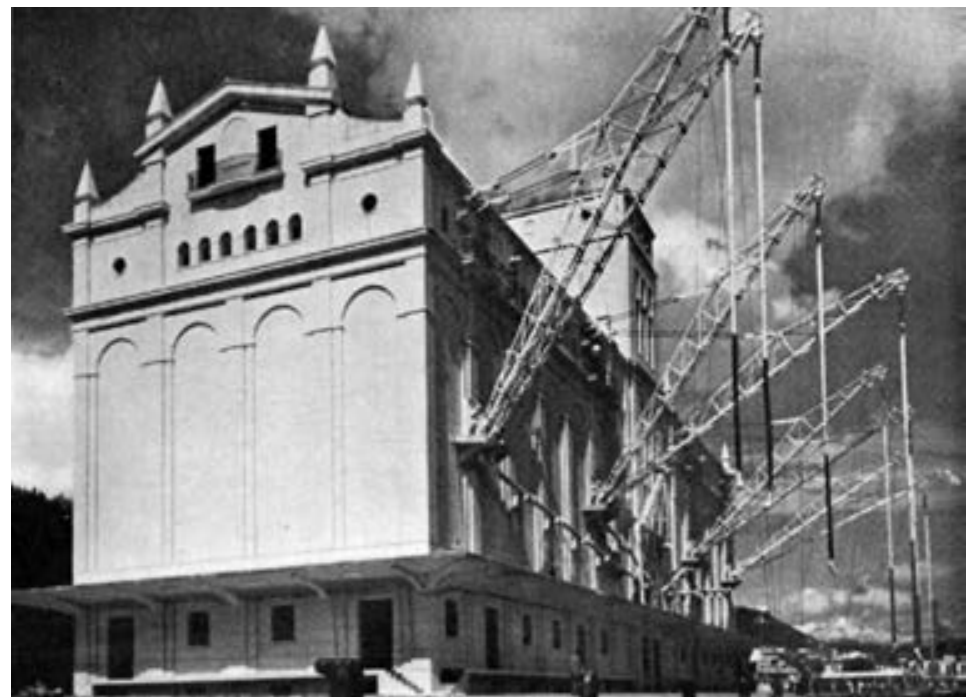

Silo de Málaga. Detalle de la instalación neumática de carga y descarga de buques. 


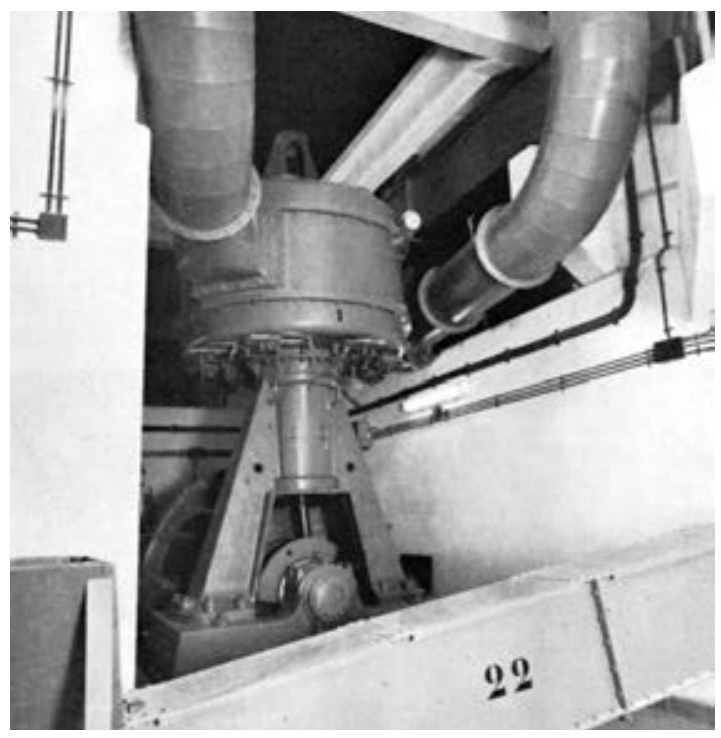

Silo de Málaga. Recepción procedente de buque. Bombas aspiradoras de grano.

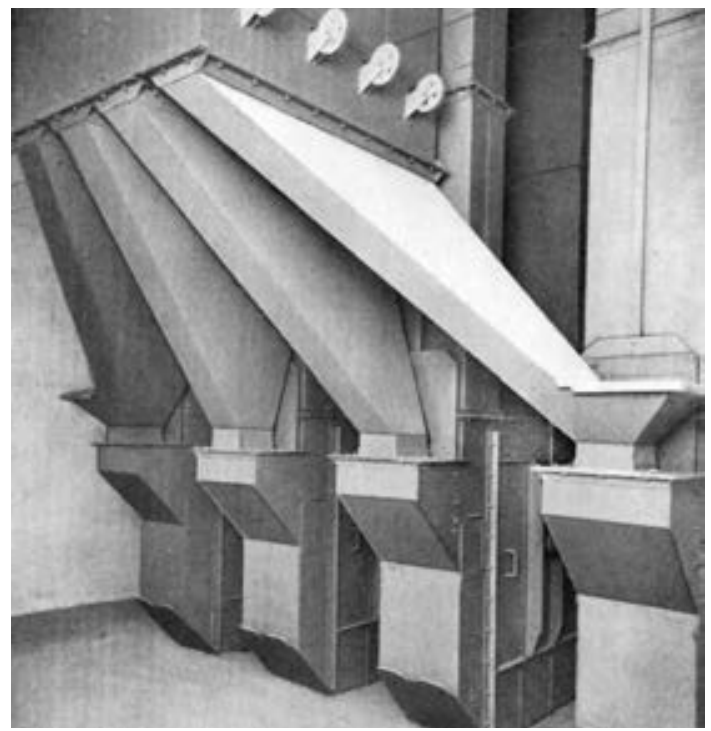

Silo de Málaga. Recepción procedente de buque. Elevadores secundarios. 


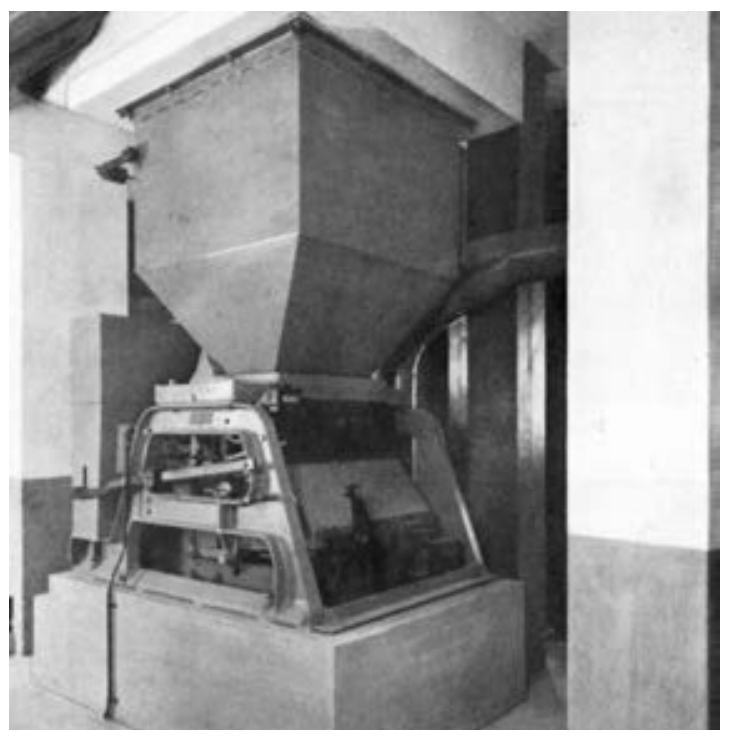

Silo de Málaga. Báscula automática.

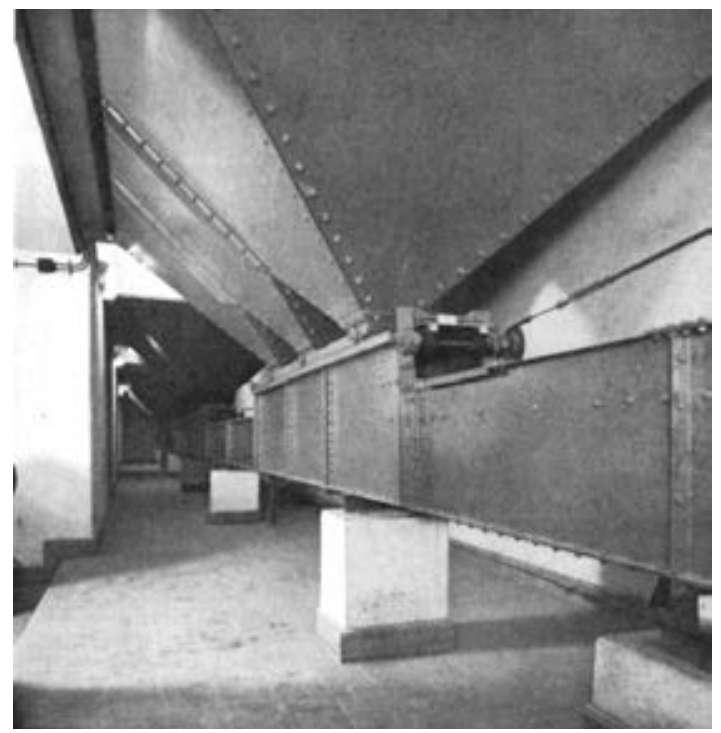

Silo de Málaga. Transportadores colectores inferiores. 


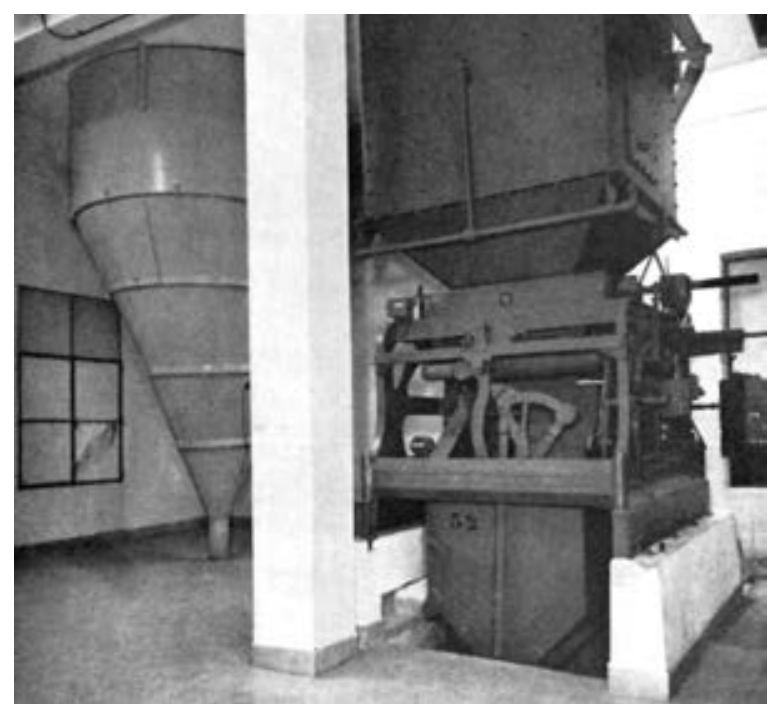

Silo de Málaga. Aspiración de polvo.

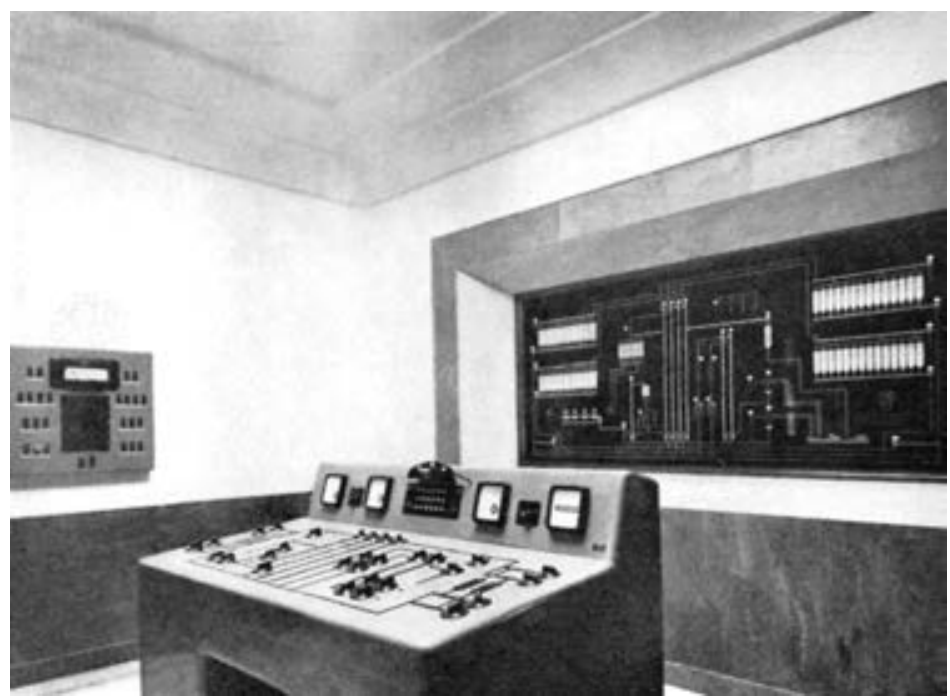

Silo de Málaga. Sala de mandos. 


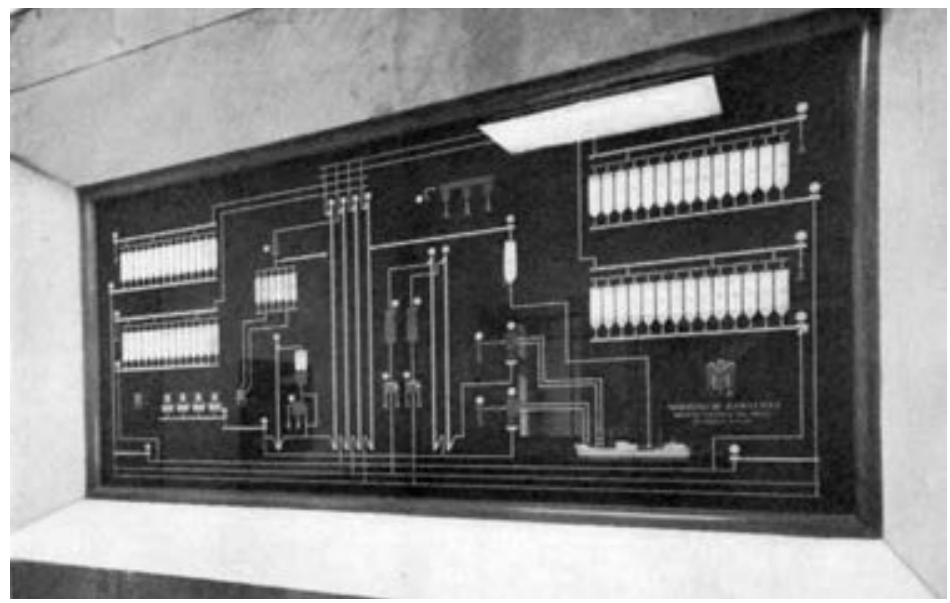

Silo de Málaga. Esquema luminoso de funcionamiento.

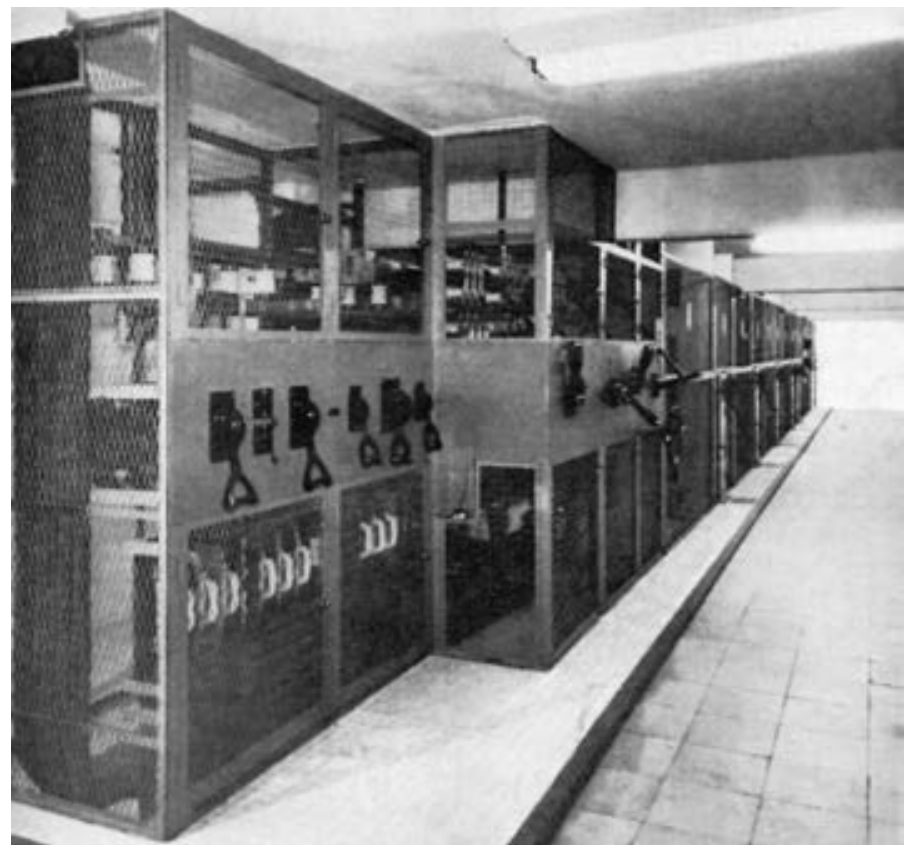

Silo de Málaga. Instalación de transformación de corriente eléctrica. 


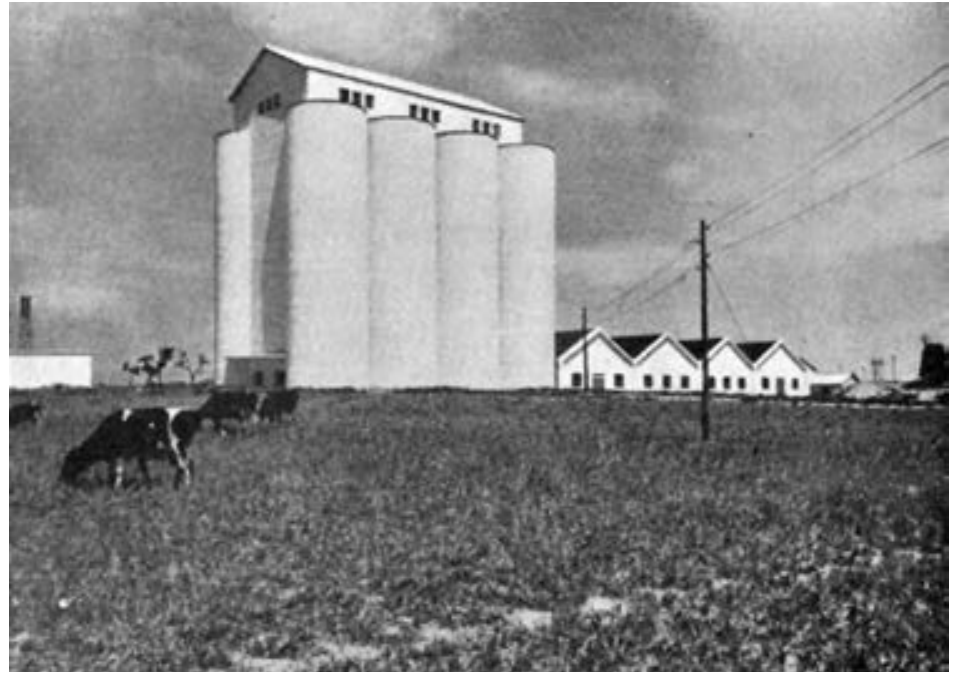

Silo de Medina del Campo (Valladolid).

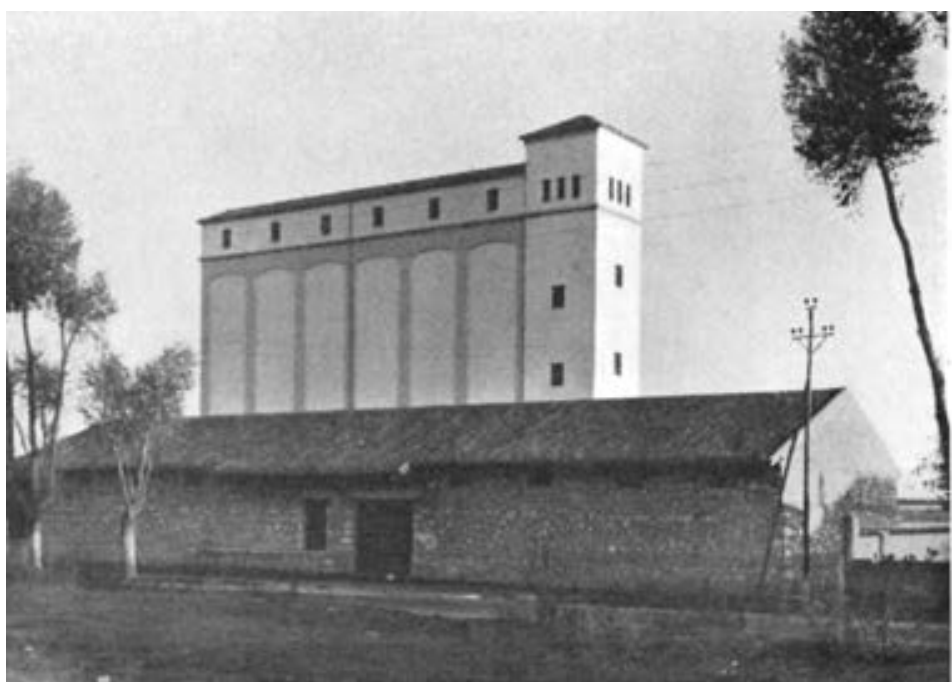

Silo de Barbadillo (Salamanca). 


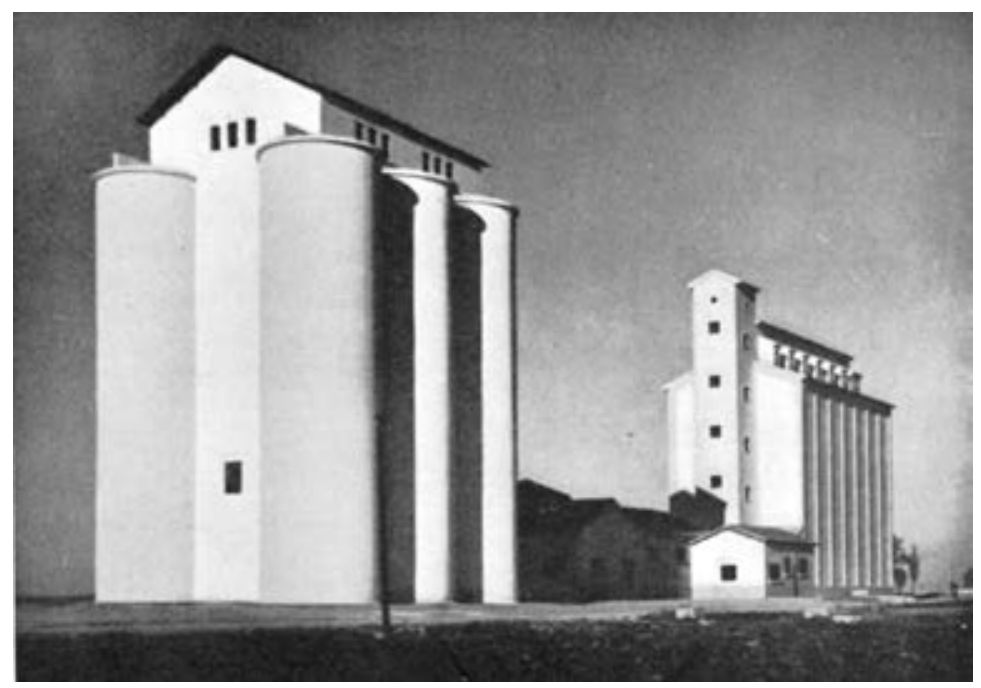

Silo de Cantalapiedra (Salamanca).

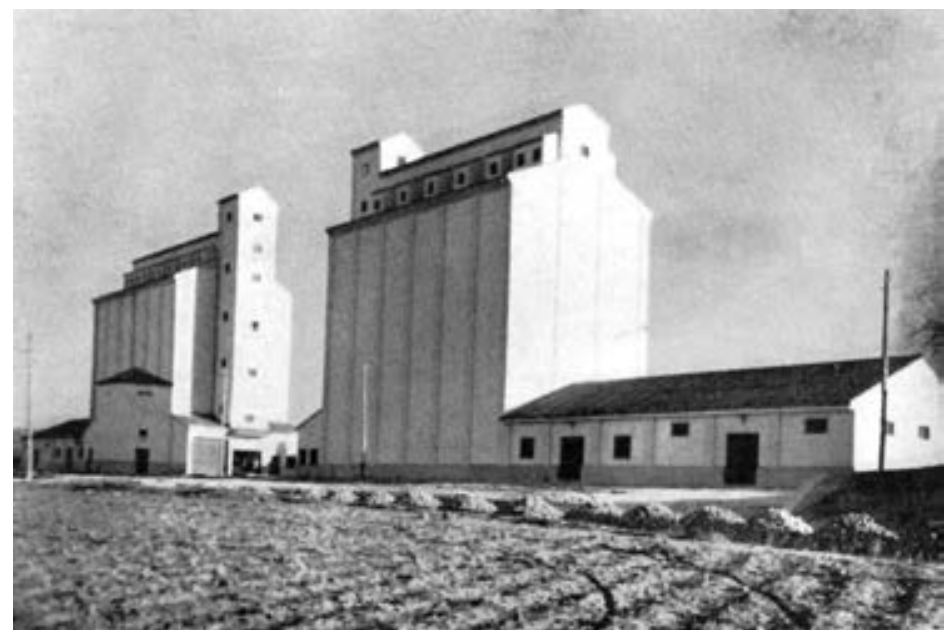

Silos de Alba de Tormes (Salamanca). 


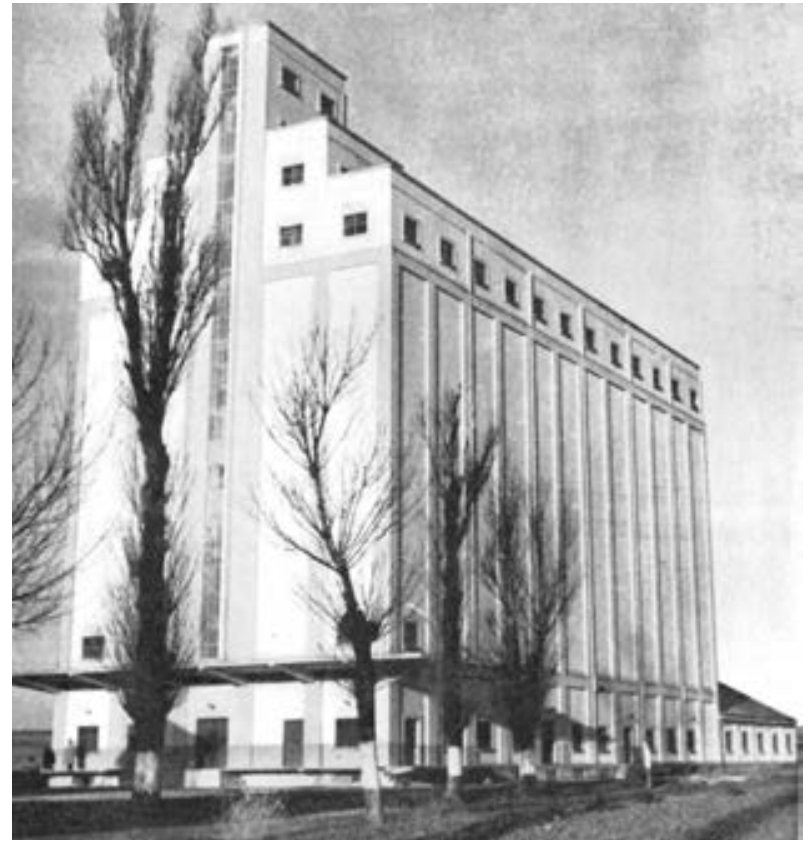

Silo de Medina de Rioseco (Valladolid).

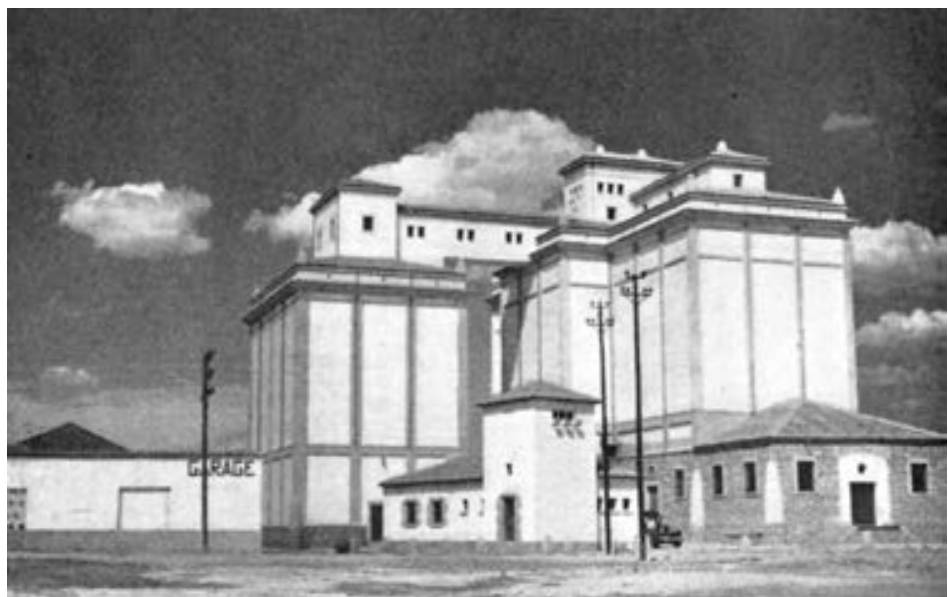

Silo de Trujillo (Cáceres). 


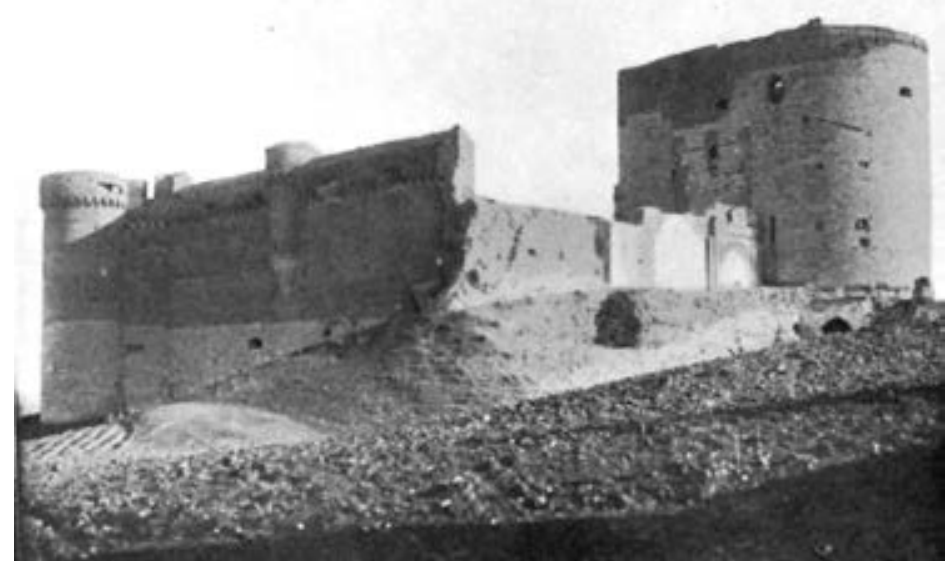

El castillo de Arévalo (Ávila) al iniciarse los trabajos.

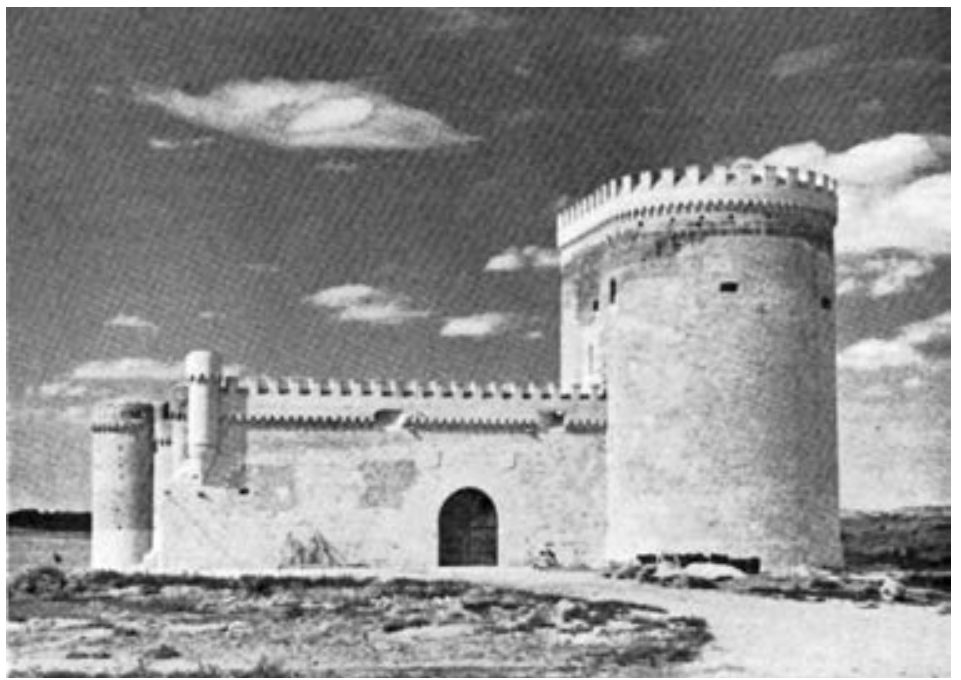

Castillo de Arévalo. Restauración exterior. 


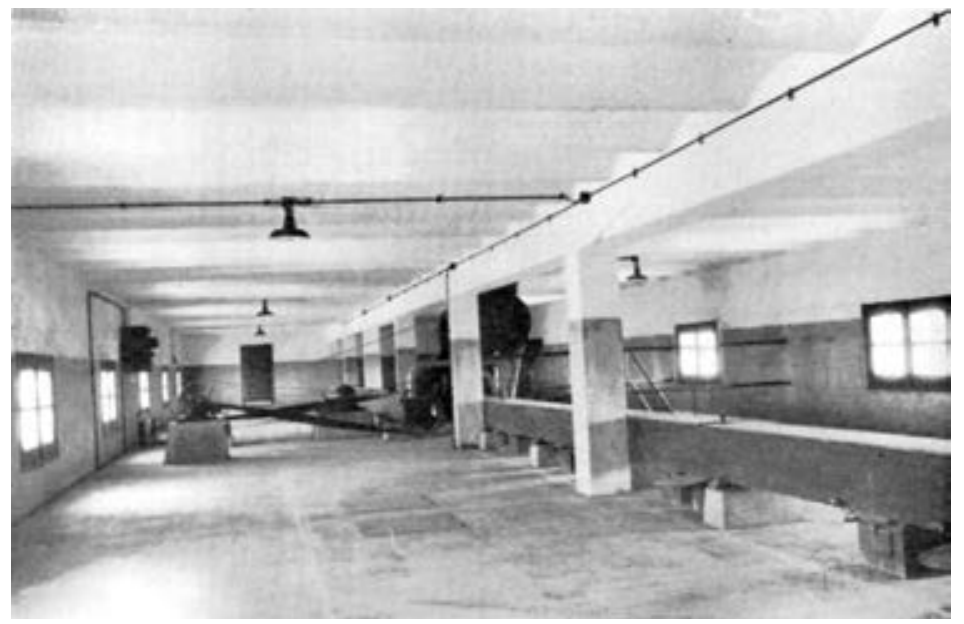

Castillo de Arévalo. Celdas para almacenamiento de grano.

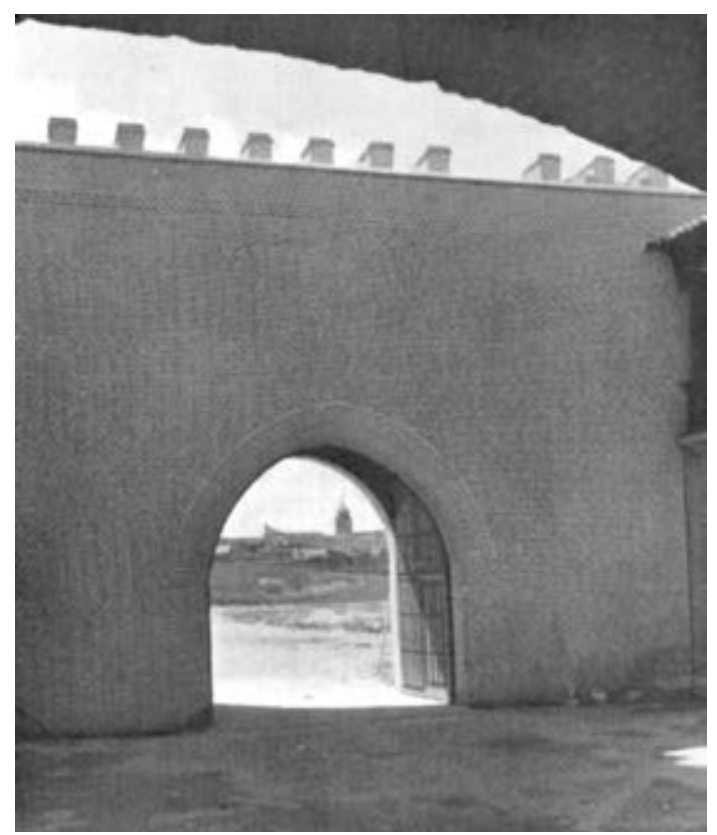

Castillo de Arévalo. Detalle de la parte restaurada. 


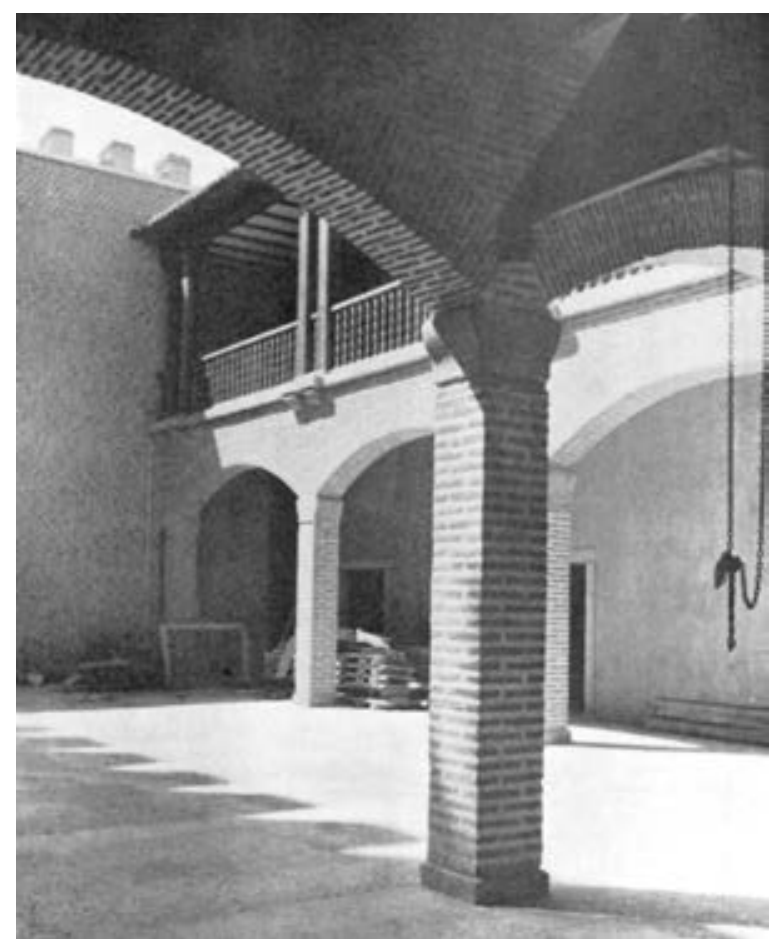

Castillo de Arévalo. Detalle de la parte restaurada.

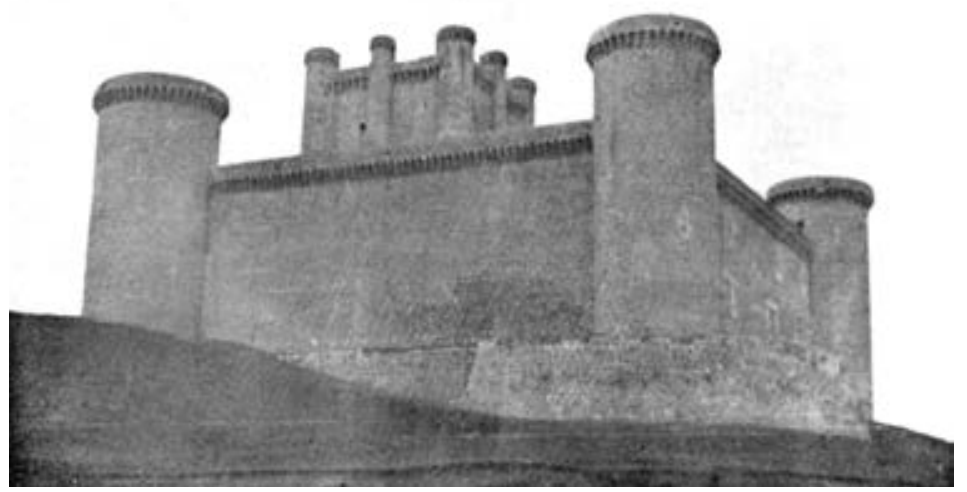

Castillo de Torrelobatón (Valladolid). 


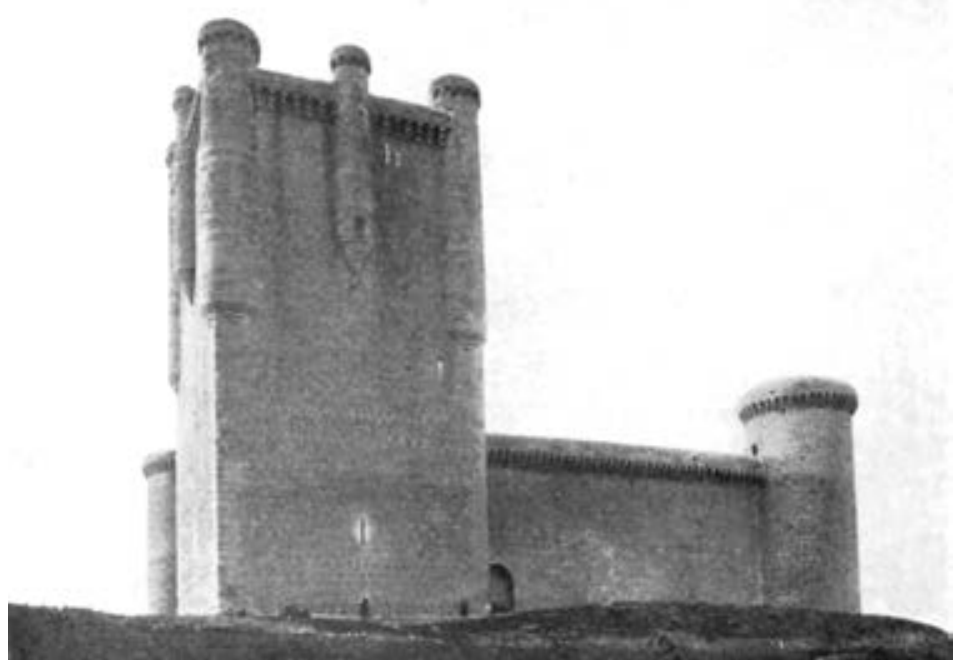

Castillo de Torrelobatón.

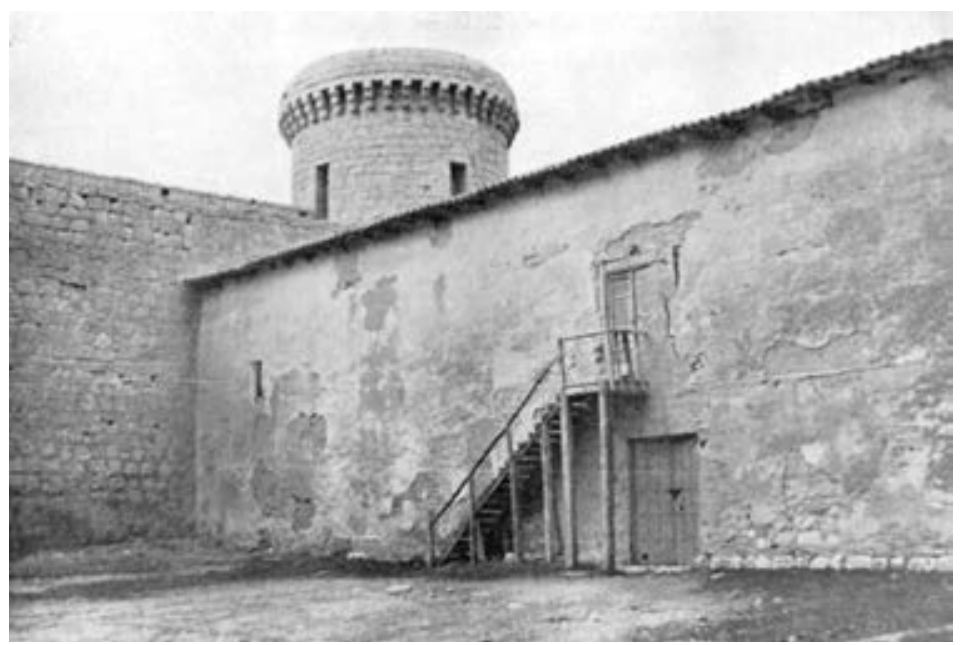

Castillo de Torrelobatón. Patio interior antes de ser restaurado. 


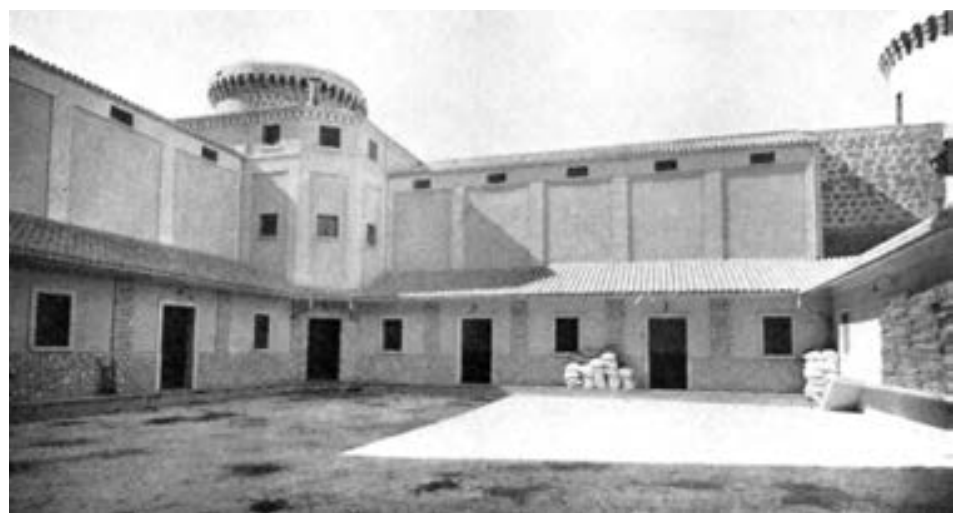

Castillo de Torrelobatón. Un aspecto de la parte restaurada.

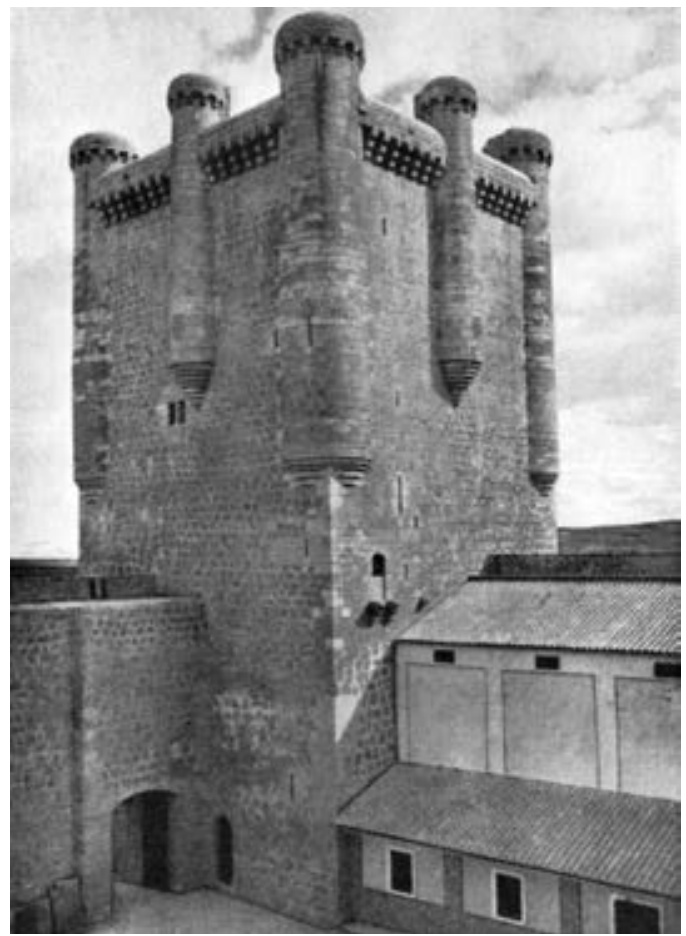

Castillo de Torrelobatón. Aspecto de la parte restaurada. 


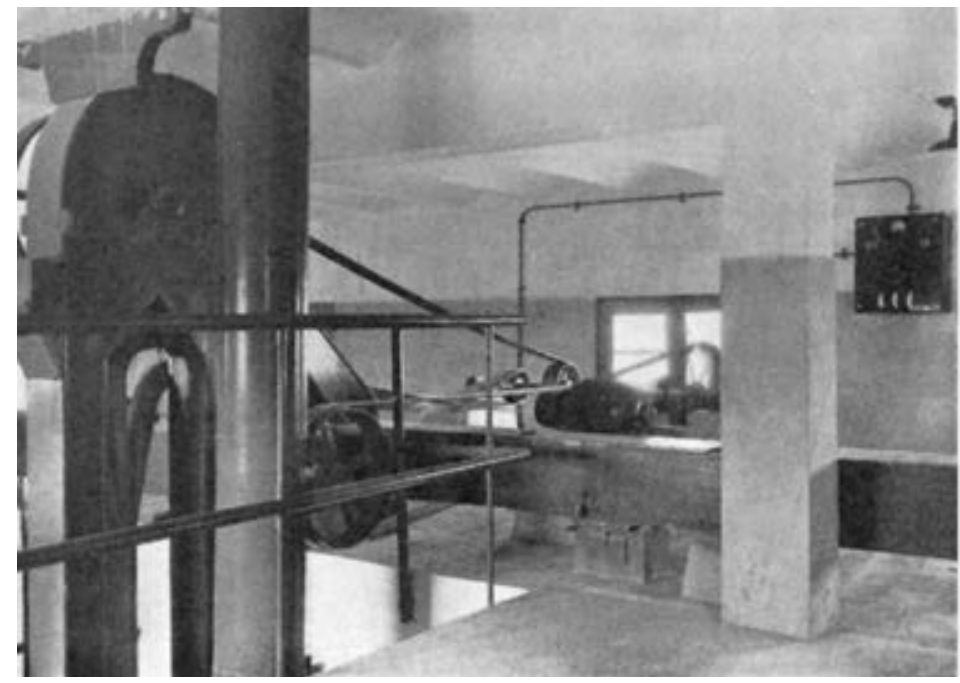

Castillo de Torrelobatón. Instalación mecánica para el movimiento de trigo.

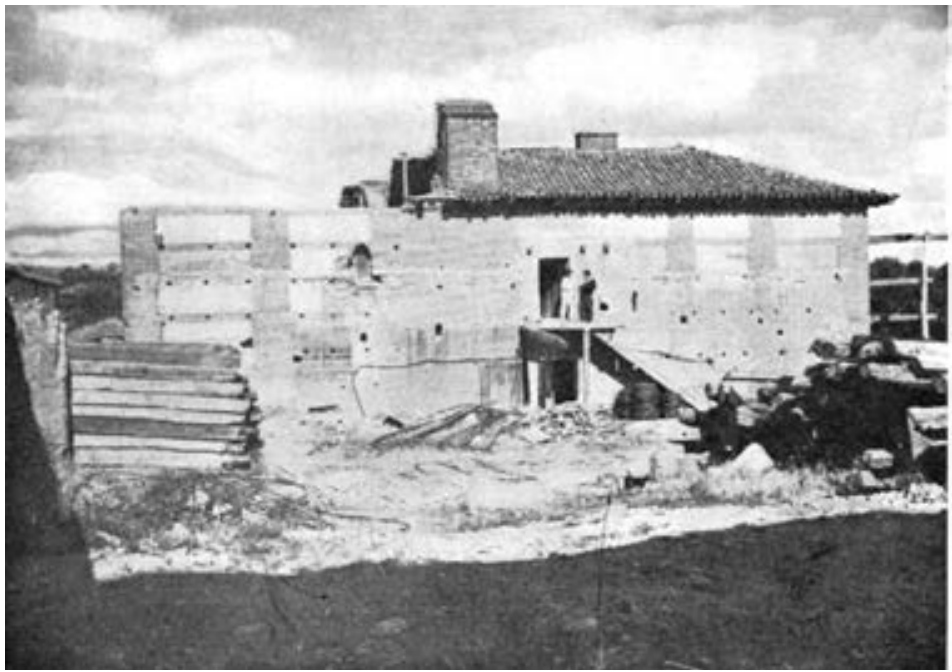

Casa señorial de Rueda (Valladolid). Aspecto ruinoso al adquirirla. 


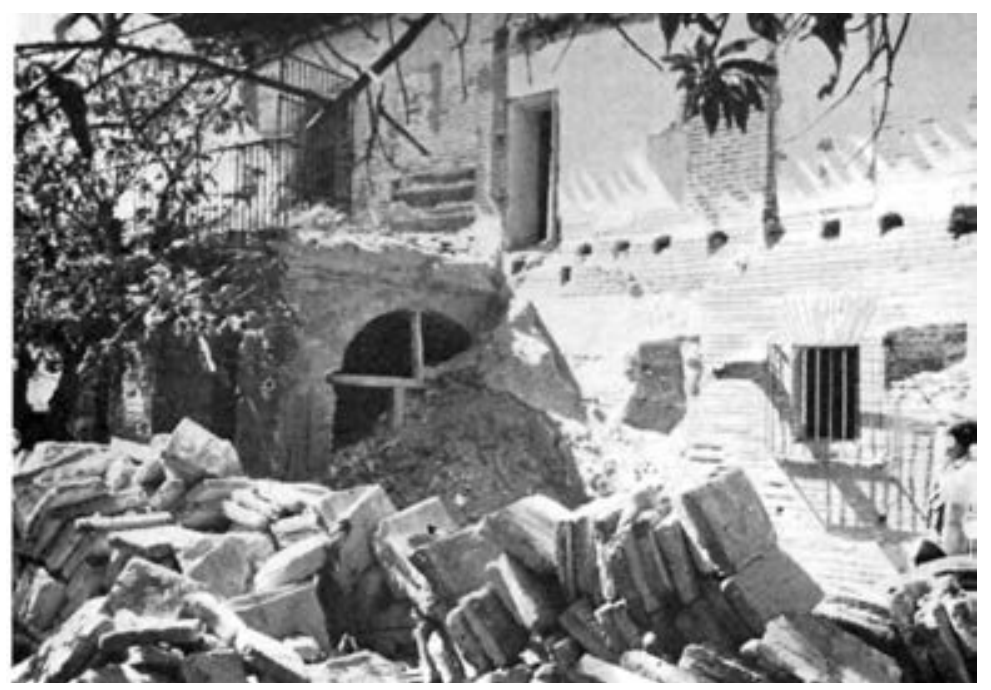

Casa señorial de Rueda (Valladolid). Aspecto ruinoso al adquirirla.

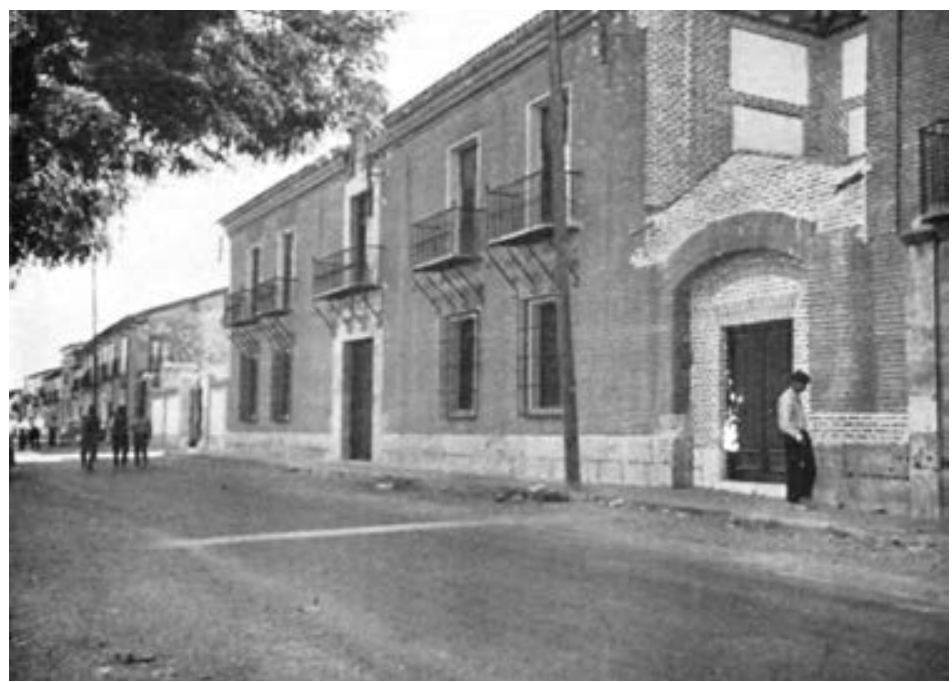

Casa señorial de Rueda (Valladolid). La fachada principal restaurada. 


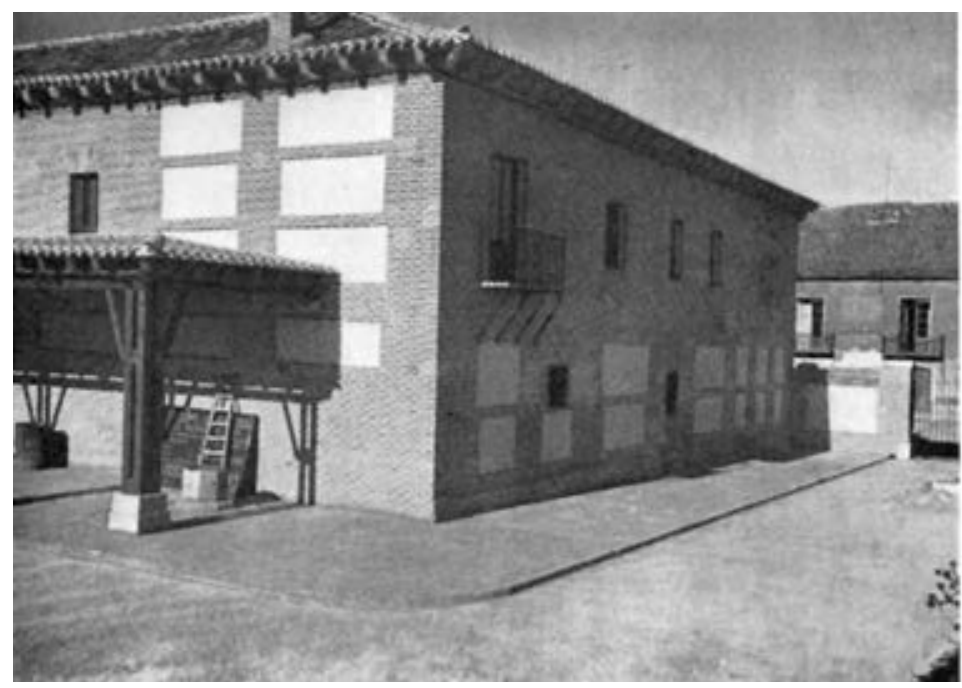

Casa señorial de Rueda (Valladolid). Aspecto parcial de la restauración.

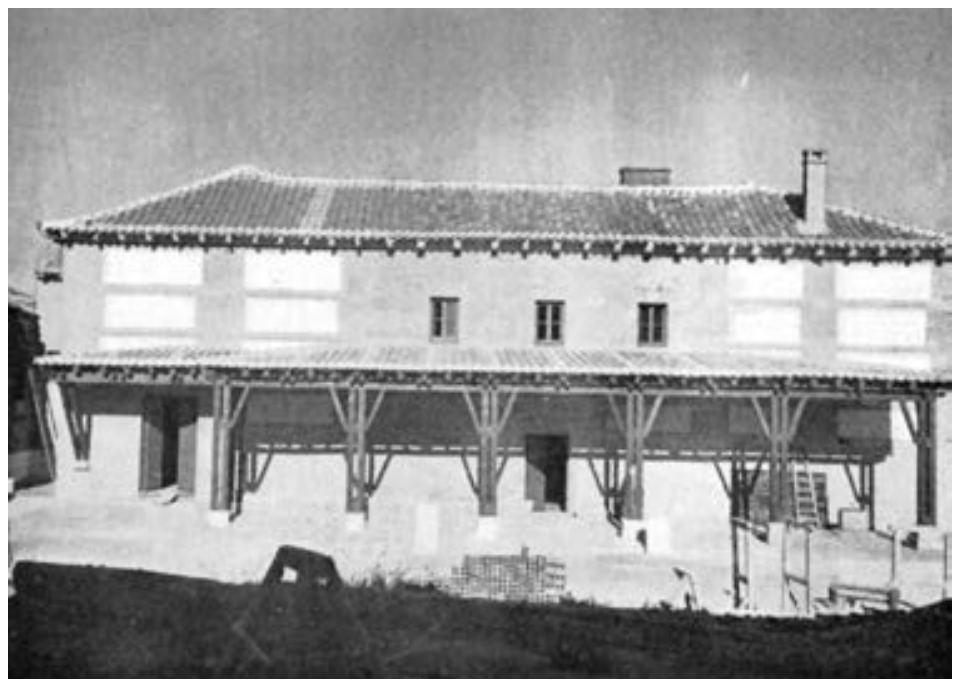

Casa señorial de Rueda (Valladolid). Aspecto parcial de la restauración. 


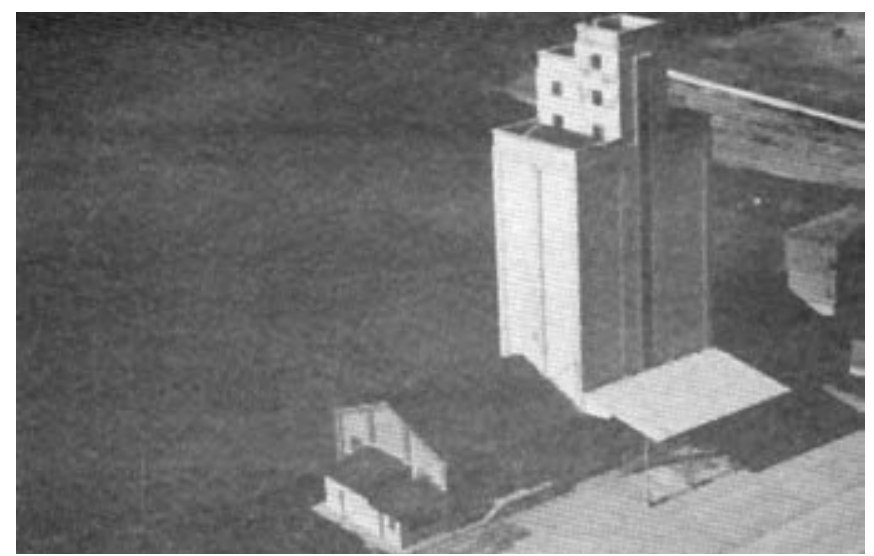

Alegría (Álava) (Tipo GV).

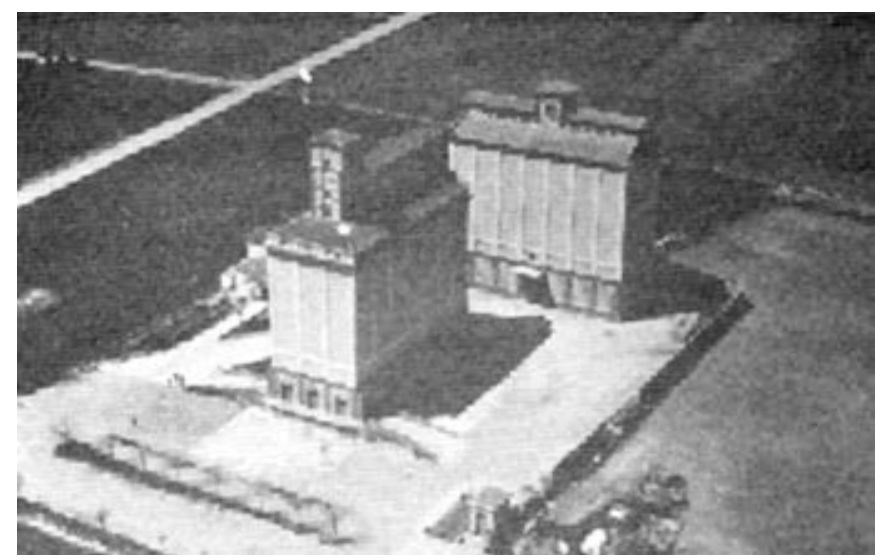

Madrigal de las Altas Torres (Ávila) (Tipos A y H). 


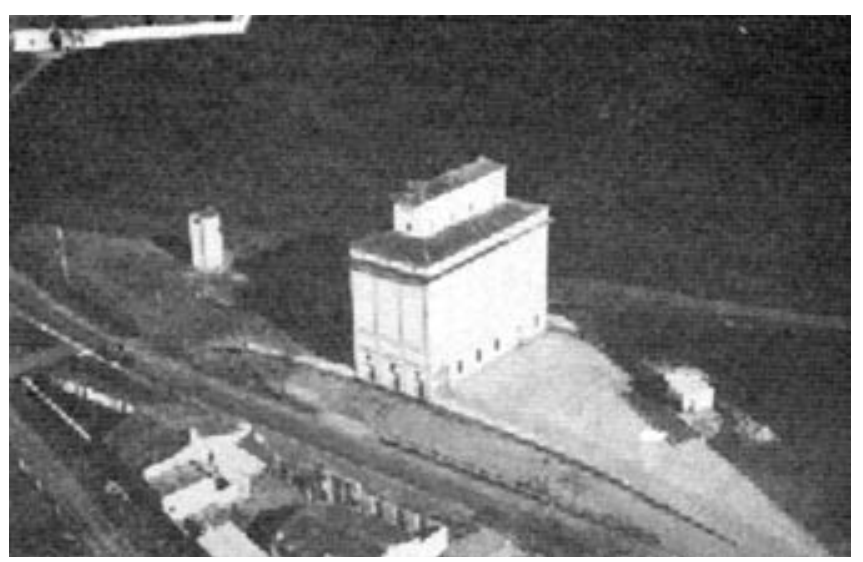

Arroyo de San Serván (Badajoz) (Tipo A).

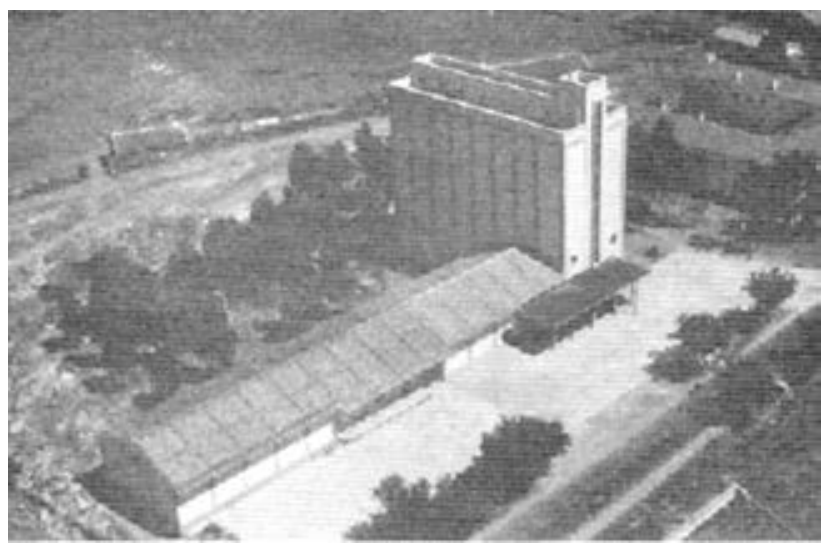

Cabeza de Buey (Badajoz) (Tipo D y Granero G). 


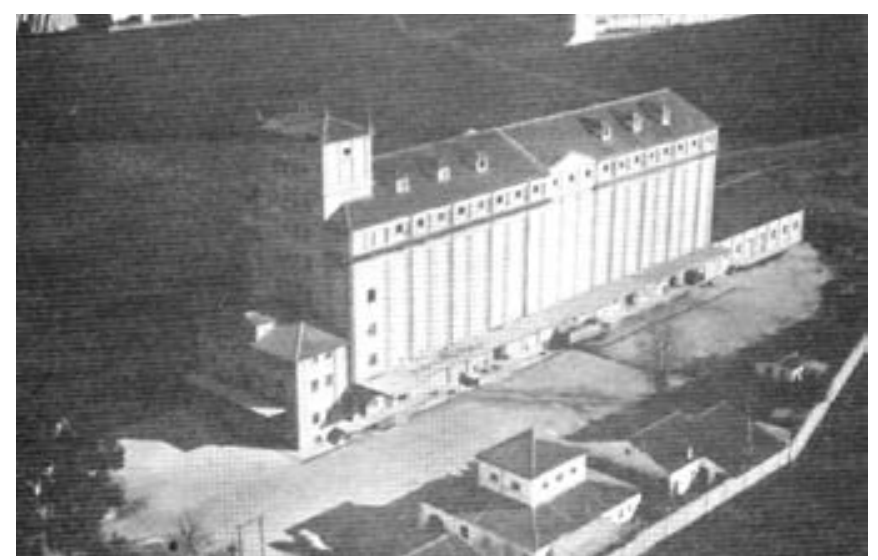

Mérida (Badajoz) (Tipo T).

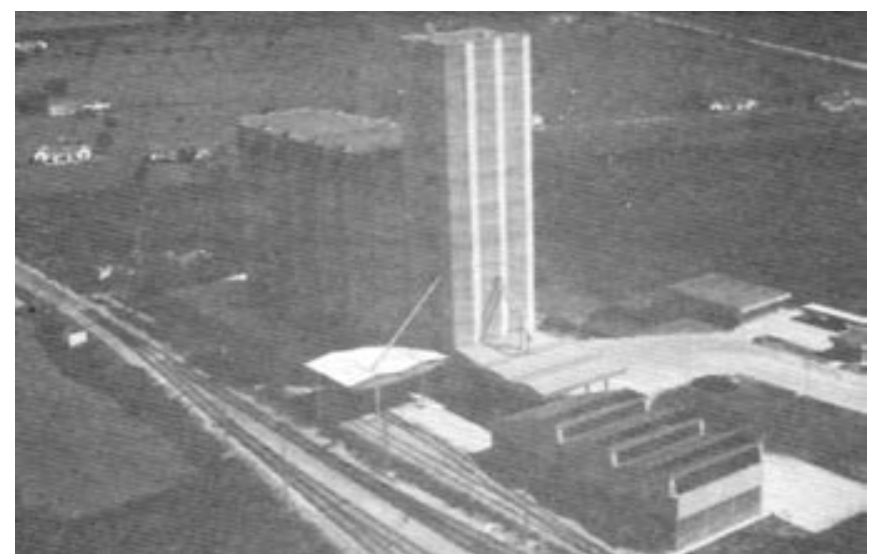

El Carpio (Córdoba) (Tipo T). 


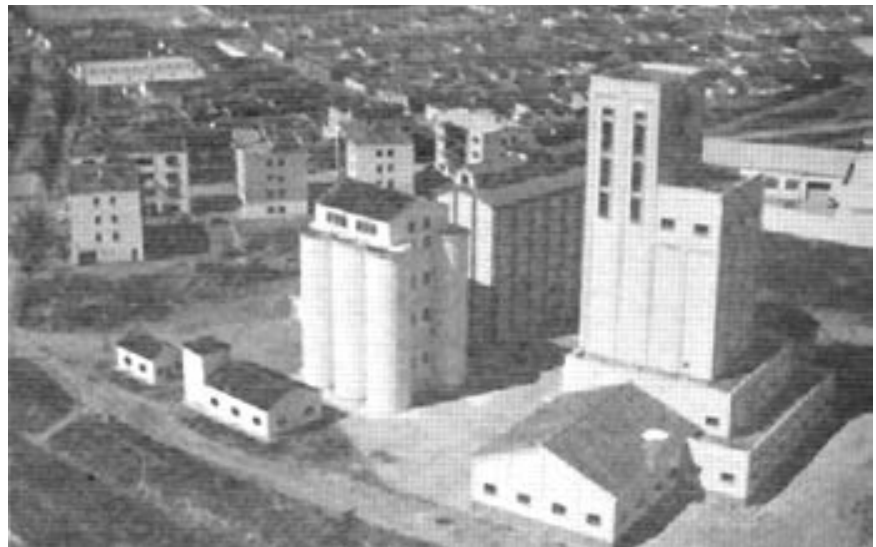

Ciudad Real (Tipos C, H y SV).

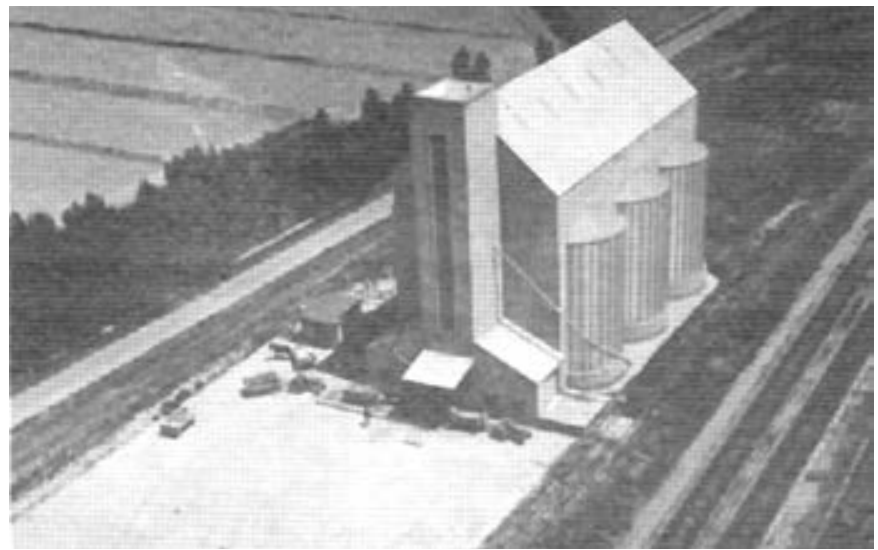

Almudévar (Huesca) (Tipo MC). 


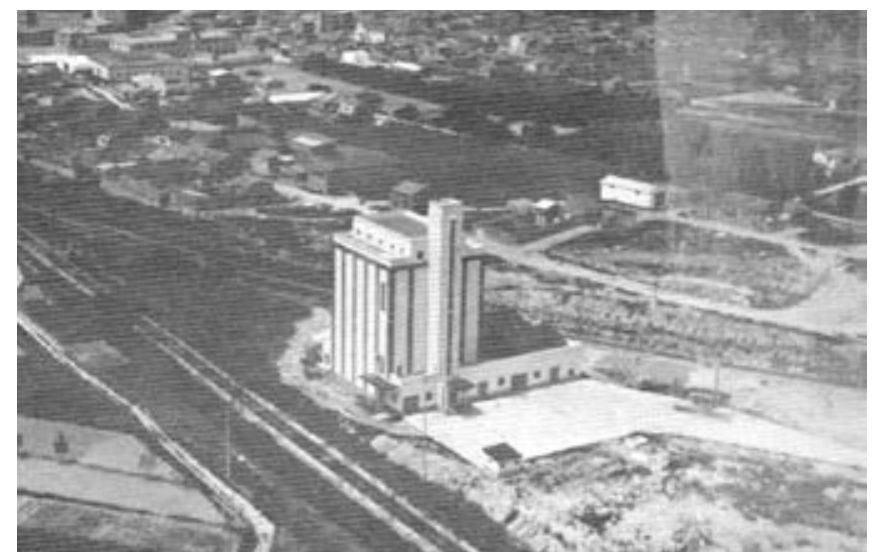

Tardienta (Huesca) (Tipo E).

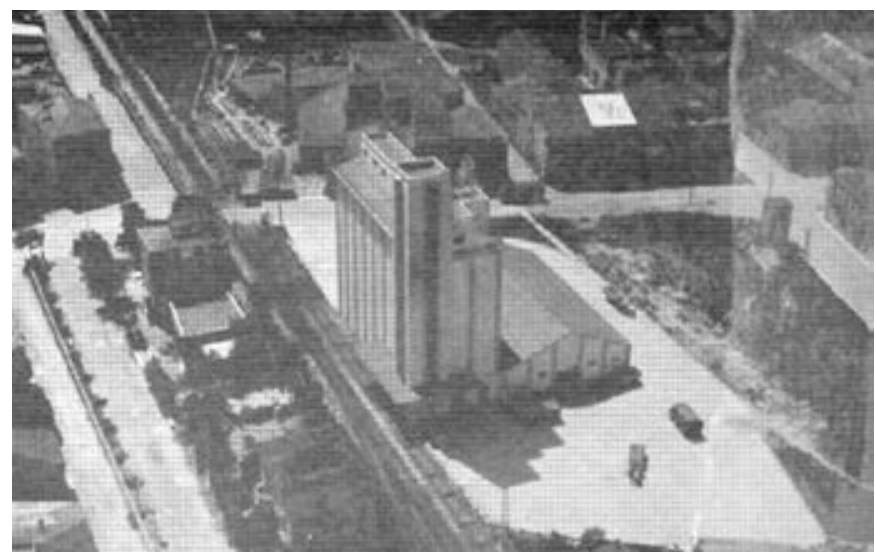

Cervera de Segarra (Lérida) (Tipo B). 


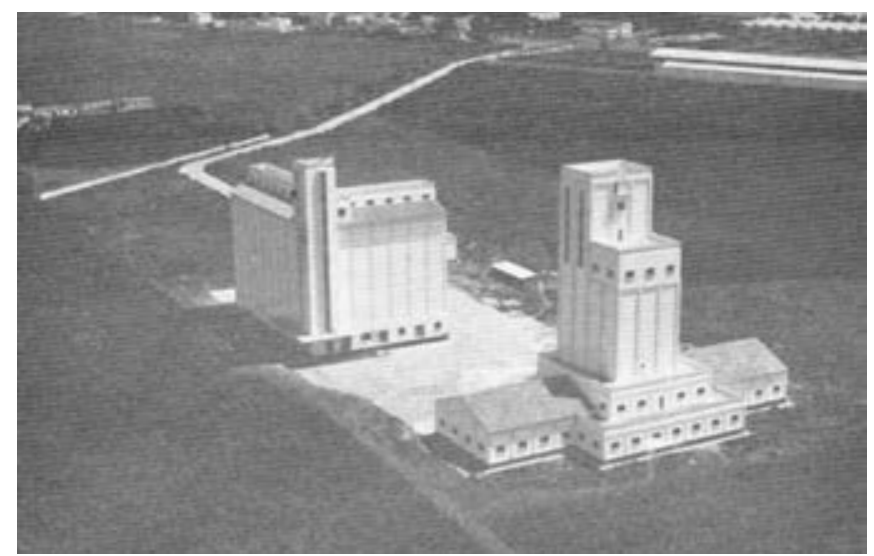

Sevilla (Tipo B y SV).

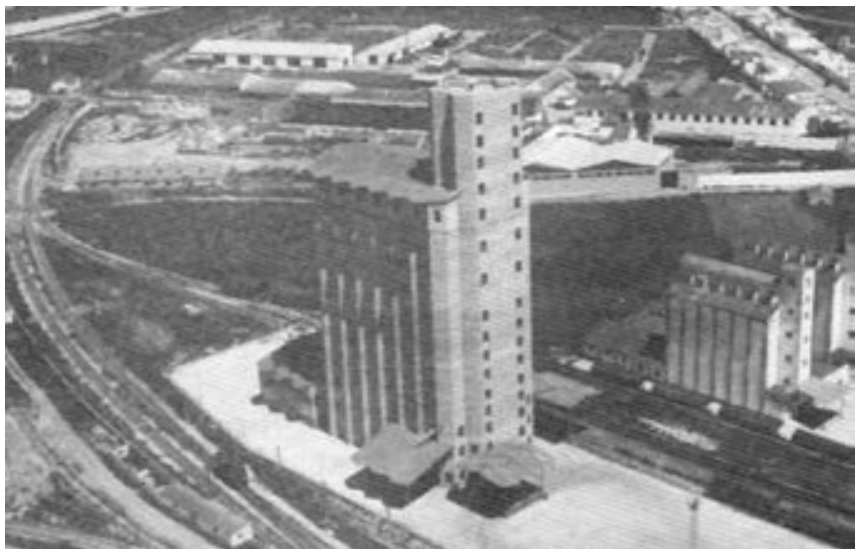

Utrera (Sevilla) (Tipo T). 


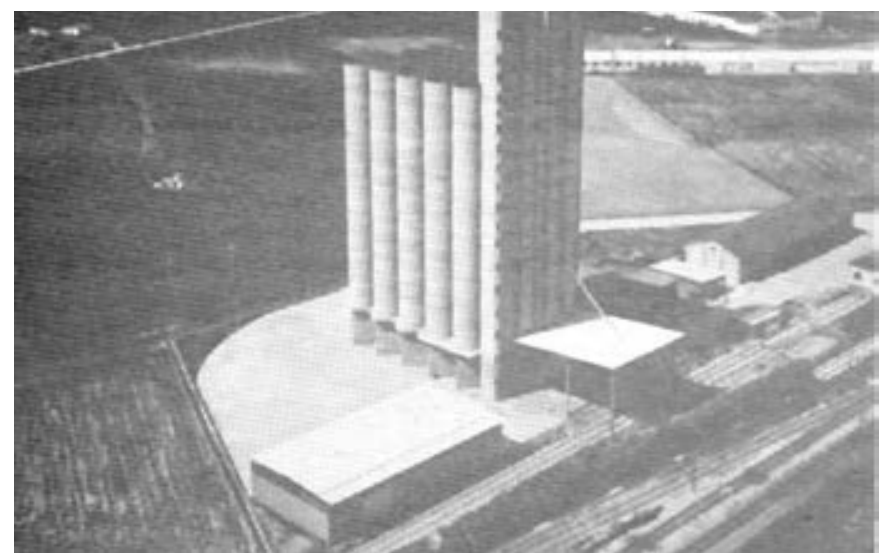

Peñaranda de Bracamonte (Salamanca) (Tipo T).

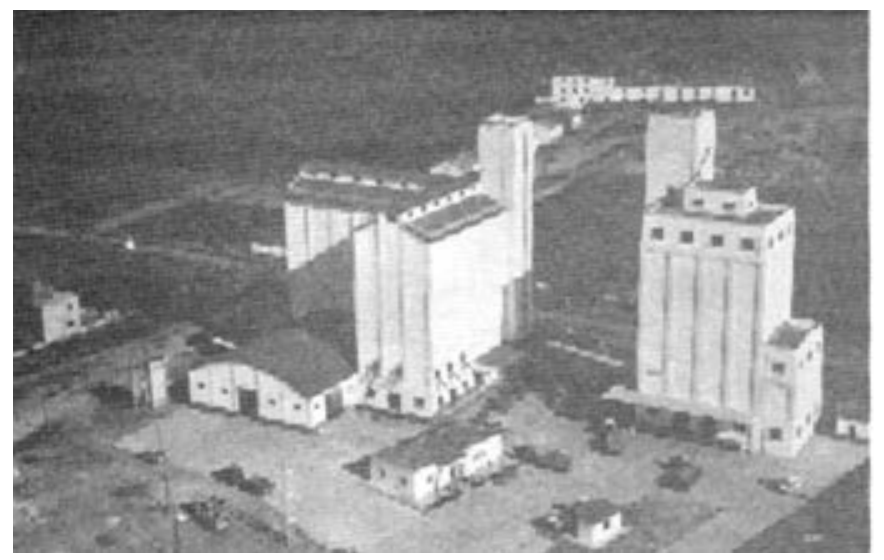

Almazán (Soria) (Tipos B y B 7.500). 

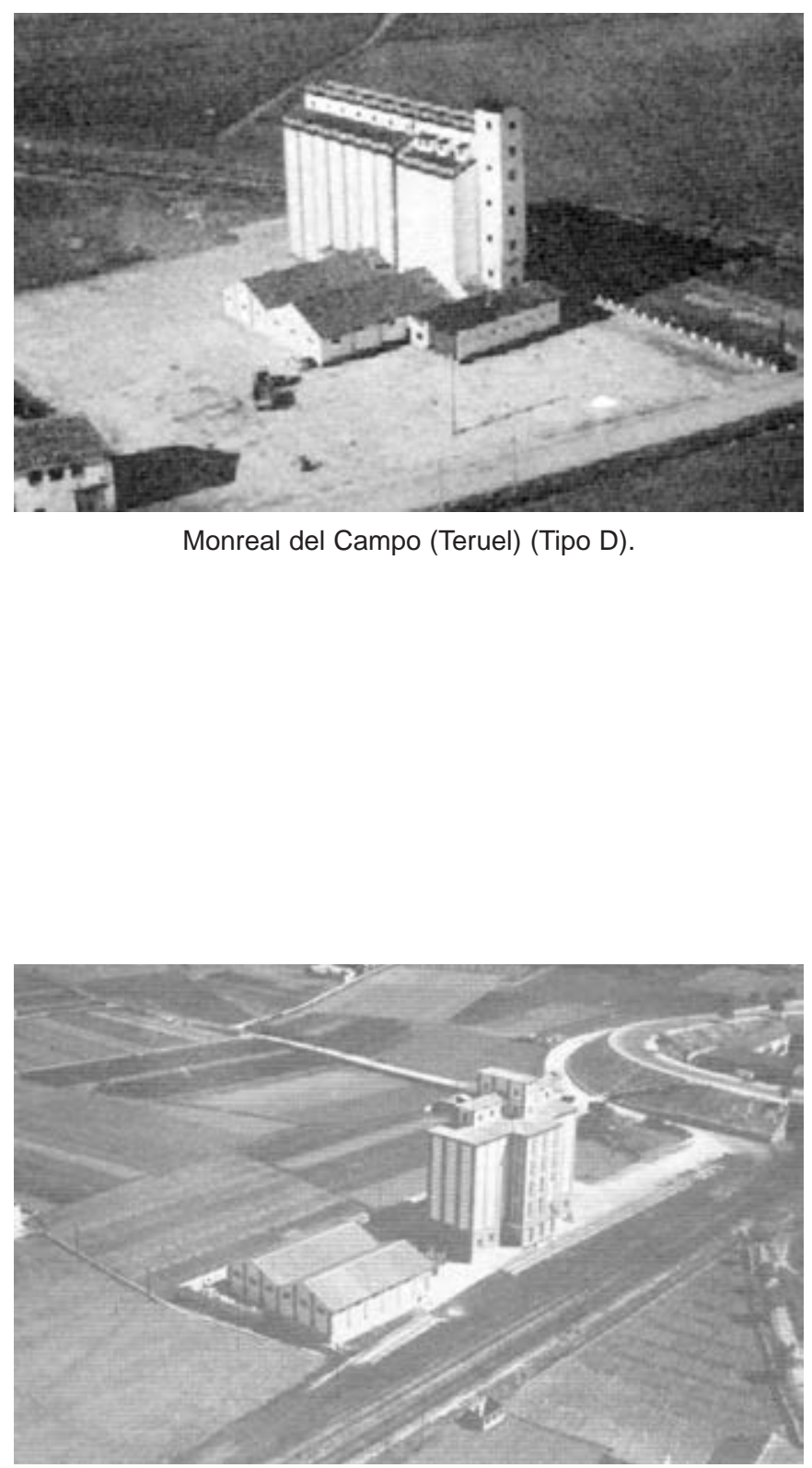

Silo de Zamora (Tipo F). 


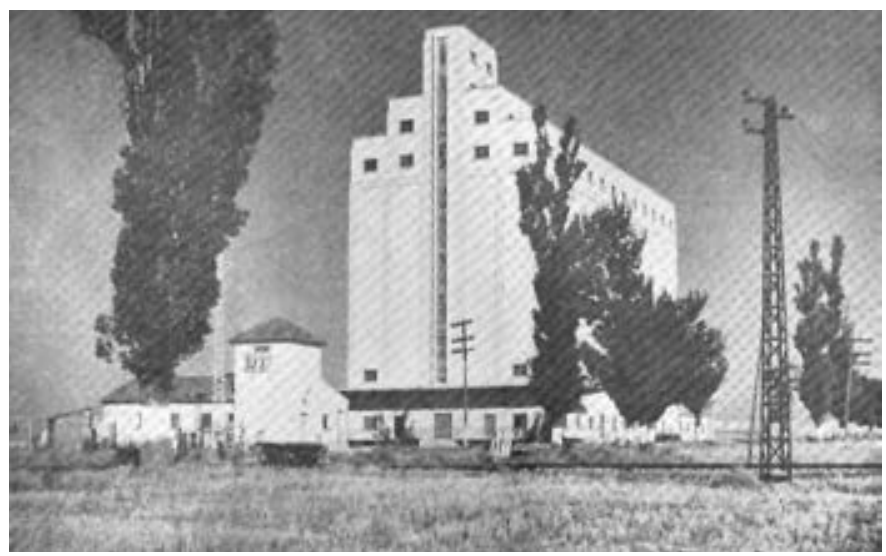

Silo de Medina de Rioseco (Valladolid).

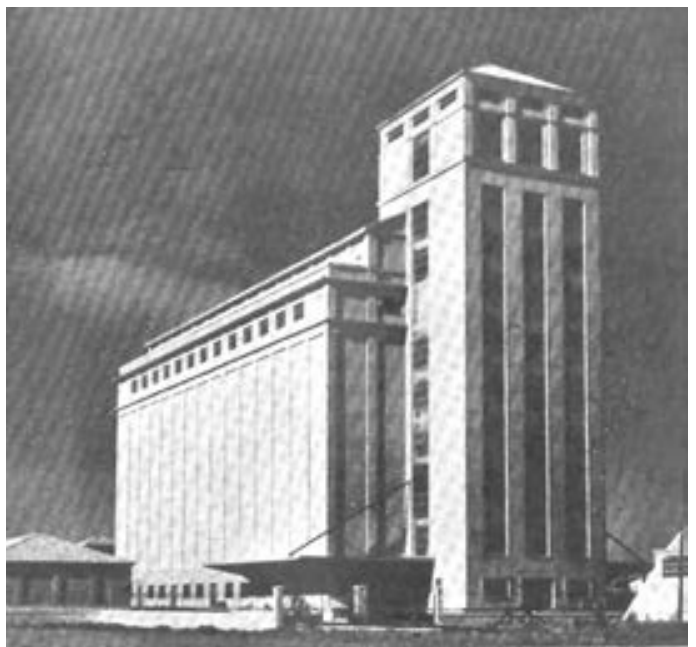

Silo de Burgos. 



\section{Indice}

Prólogo

LA RED NACIONAL DE SILOS Y GRANEROS (1930-2000) ........... 9

1. Introducción ..................................................................... 9

2. Las líneas básicas de la política cerealista en España entre

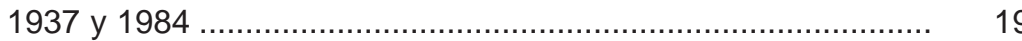

3. La construcción de la Red ..................................................... 31

4. Los costes y la financiación de la Red ...................................... 73

5. La liquidación y el desmantelamiento de la Red ....................... 86

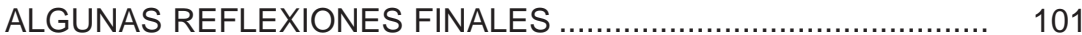

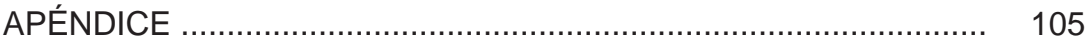

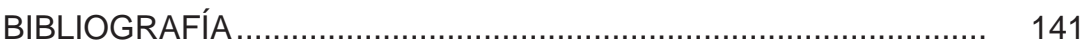

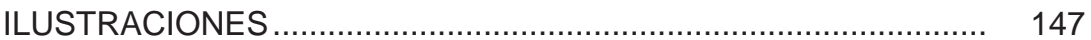



Este libro, número 5 de la colección Monografias de Historia Rural, se terminó de imprimir en los talleres de INO Reproducciones, S. A., de Zaragoza,

el 5 de diciembre de 2007<smiles>C1#CC=C1</smiles> 
Este libro es una historia de la Red Nacional de Silos y Graneros, un ambicioso proyecto gestado y desarrollado durante la dictadura franquista. La idea de contar con una red pública de silos surgió durante los años de la crisis triguera que se inició en 1932 y que afectó notablemente a la estabilidad del régimen republicano. Tras la parálisis que sufrió la economía española durante los años de la posguerra, a partir de los cincuenta se invirtieron cuantiosísimos recursos públicos en la construcción de la Red, que se extendió por todas las comarcas cerealistas. Su diseño, basado en concepciones autárquicas, se mostró totalmente inadecuado para afrontar las consecuencias de la integración de España en el Mercado Común Europeo. Las nuevas condiciones del mercado triguero tuvieron un efecto demoledor, nunca mejor dicho, sobre un sistema levantado con fundamentos aislacionistas.

"Ni un hogar sin lumbre, ni un español sin pan" fue el eslogan acuñado por el Caudillo que reflejaba, a la vez, las aspiraciones y las carencias de la España autárquica.
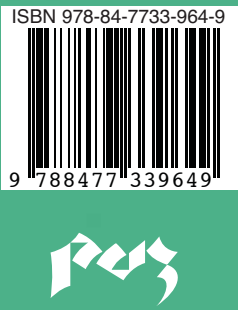

Prensas Universitarias de Zaragoza

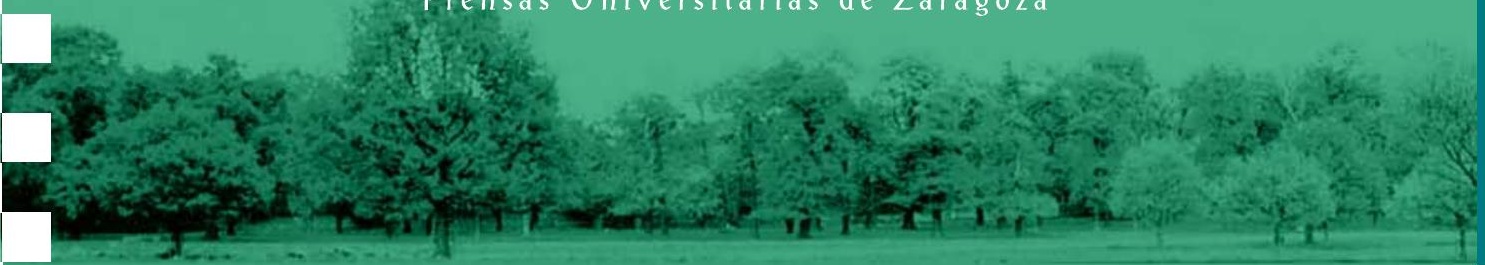

